lsisued by Sandia National Laboratories, operated for the United States Department of Energy by Sandia Corporation.

NOTICE: This report was prepared as an account of work sponsored by an ayency of the United States Government. Neither the United States Government nor any agency thereof, nor any of their employees, nor any of their contractors, subcontractors, or their employees, makes any warranty, express or implied, or assumes any legal liability or responsibility for the accuracy, (ompleteness, or usefulness of any information, apparatus, product, or process disclosed, or represents that its use would not infringe privately owned rights. Reference herein to any specific commercial product, process, or service by trade name, trademark, manufacturer, or otherwise, does not necessarily constitute or imply its endorsement, recommendation, or favoring by the United States Government, any agency thereof or any of their contractors or subcontractors. The views and opinions expressed herein do not necessarily state or reflect those of the United States Government, any agency thereof or any of their contractors.

Printed in the United States of America. This report has been reproduced directly from the best available copy.

Available to DOF and DOE contractors from

Office of Sicientific and Technical Information

P() Box 6:2

()ik Ridge. TN $378: 31$

Prices available from (615) 576-8401, FTS 626-8401

Available to the public from

National Technical Information Service

('S I)epartment of Commerce

igni Port Roval Rd

springfield, VA 22161

N'TIS' price codes

Printed copy: A06

Microfiche copy: A01 


\title{
PHOTOVOLTAIC CONCENTRATOR MODULE IMPROVEMENTS STUDY
}

\author{
S.L. Levy, K.A. Kerschen \\ Black \& Veatch \\ Kansas City, MO 64114 \\ Gus Hutchison \\ Solar Kinetics, Inc. \\ Dallas, TX 75220 \\ M.J. Nowlan \\ Spire Corporation \\ Bedford, MA 01730
}

Sandia Contract: 56-7211

\begin{abstract}
This report presents results of a project to design and fabricate an improved photovoltaic concentrator module. Using previous work as a baseline, this study conducted analyses and testing to select major module components and design features. The lens parquet and concentrator solar cell were selected from the highest performing, available components. A single $185 \mathrm{X}$ point-focus module was fabricated by the project team and tested at Sandia. Major module characteristics include a 6 by 4 compression-molded acrylic lens parquet $\left(0.737 \mathrm{~m}^{2}\right.$ area $)$, twentyfour 0.2 ohms-cm, FZ, p-Si solar cells $\left(1.56 \mathrm{~cm}^{2}\right.$ area) soldered to ceramic substrates and copper heat spreaders, and an aluminized steel housing with corrugated bottom. This project marked the first attempt to use prismatic covers on solar cells in a high-concentration, point-focus application. Cells with 15 percent metallization were obtained, but problems with the fabrication and placement of prismatic covers on these cells lead to the decision not to use covers in the prototype module. Cell assembly fabrication, module fabrication, and module optical design activities are presented here. Test results are also presented for bare cells, cell assemblies, and module. At operating conditions of 981 watts $/ \mathrm{m}^{2}$ DNI and an estimated cell temperature of $65^{\circ} \mathrm{C}$, the module demonstrated an efficiency of 13.9 percent prior to stressed environmental exposure.
\end{abstract}




\section{Acknowledgements}

The authors would like to thank several members of the Sandia PV staff, including Alex Maish, Clement Chiang, Beth Richards, Paul Basore, and Jack Cannon for their contributions to various activities of this project.

In addition, the efforts of Misch Lehrer and Karl $M^{\mathfrak{c}}$ Allister of E G \& G (on-site Sandia contractor) are greatly appreciated. They conducted many of the performance testing procedures for the cell assemblies and module.

We would also like to thank Charles B. Stillwell, who served as contract monitor for most of this project, for his valuable assistance and support. 
Contents

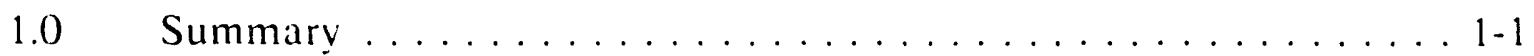

1.1 Module Characteristics . . . . . . . . . . . . . . 1-1

1.2 Evaluation Test Results . . . . . . . . . . . . . . 1-9

$2.0 \quad$ Introduction $\ldots \ldots \ldots \ldots \ldots \ldots \ldots \ldots \ldots \ldots \ldots \ldots \ldots \ldots \ldots .1$

2.1 Project Objectives . . . . . . . . . . . . . 2-1

2.2 Project Team and Responsibilities . . . . . . . . 2-2

2.3 Project Programmatic Issues . . . . . . . . . . 2-2

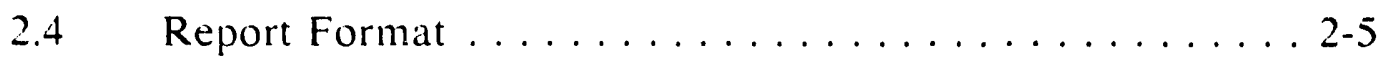

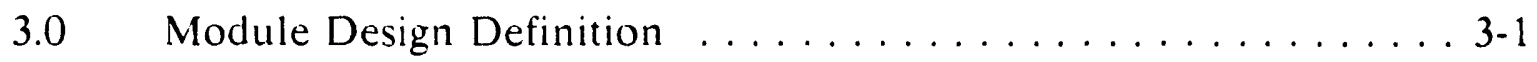

3.1 Component Selection . . . . . . . . . . . . . 3-1

3.2 Optical System Design and Analysis . . . . . . . . . 3-6

3.3 Module Structural Design and Analysis ......... 3-15

3.4 Module Electrical Design and Analysis .......... 3-23

4.0 Cell Assembly Fabrication and Testing . . . . . . . . . . 4-1

4.1 Component Procurement and Acceptance Testing .... . 4-1

4.2 Cell Assembly Procedures ............... . 4-14

4.3 Preliminary Cell Assembly Tests . . . . . . . . . . 4-22

4.4 Module Cell Assembly Tests . . . . . . . . . . . 4-28

5.0 Prototype Module Fabrication and Assembly . . . . . . . . . 5-1

5.1 Module Fabrication .................. 5-1

5.2 Module Assembly .................. 5-8

6.0 Module Testing ........................ 6-1

6.1 Initial Characterization . . . . . . . . . . . 6-1

6.2 Thermal Cycling ................. 6.6

6.3 Humidity-Freeze Cycling . . . . . . . . . . . 6-6

6.4 Final Characterization ...............6-10

7.0 References .......................... 7-1 


\section{Contents (Continued)}

Appendix A A Performance Molel for Nonuniformly llluminated Front-Gridled Concentrator Cells . . . . . . . . A-1

Appendix B Design, Fabrication, and Performance of Silicon Solar Cell Assemblies for Concentrator Modules . . . . . . B-1

\section{Tables}

Table 1-1

Black \& Veatch Prototype Module Component Summary . 1-3

Table 1-2 Black \& Veatch Prototype Module Design Characteristics Summary ................ 1-5

Table 1-3 Summary of Electrical Performance Measurements . . . . 1-10

Table 3-1 Cell Assembly Candidate Solder Alloys . . . . . . . . 3-26

Table 3-2 Cell Assembly Hot Spot Thermal Analysis ......... 3-31

Table 4-1 Summary of Test Specifications for Cell Assemblies and Receiver Sections . . . . . . . . . 4-26

Table 5-1 Module Depth Component Dimensional Characteristics . 5-4

\section{Figures}

Figure 1-1 Photograph: Black \& Veatch Module (Lens Parquet Removed) . . . . . . . . . . . . . . 1-2

Figure 1-2 Representative Module IV Cure .............. . 1-13

Figure 2-1 Project Team Organization .............. 2-3

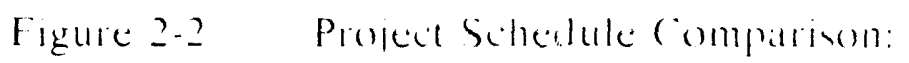

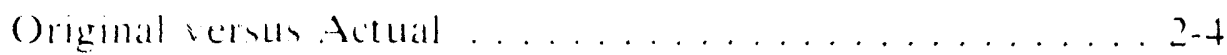

Figure 3-1 Fresnel Leris Facet Angle Profiles for the SBMIII and BNVB Lenses . . . . . . . . . . . . 3-5

Figure 3-2 PVOPTICS Performance Eotimates versus Lens Height for the SBMII and BNVB Lenses . . . . . . . 3-5

Figure 3-3 PVOPTICS Module Component Integration and Evaluation Flowchant ................ . . . . .

Figure $3-t$ PVOPTICS Menu Screen .............. 
Contents (Continued)

Figures (Continued)

Figure 3-5

Figure 3-6

Figure 3-7

Figure 3-8

Figure 3-9

Figure 3-10

Figure 3-11

Figure 3-12

Figure 3-13

Figure 4-1

Figure 4-2

Figure 4-3

Figure 4-4

Figure 4-5

Figure :-6

Figure 4-7

Figure 4-8

Figure $4-9$

Figure +10

Figure 4-11

Figure 4-12

Figure +13

Figure +14

Figure $4-15$
Secondary Optical Element Dimensional Specifications . 3-10 Relative Efficiency Change for

Metallization Increases .................. 3-14

Thermal Deformation Tests Setup .......... 3-18

Spring Clipped Edge Configuration . . . . . . . . 3-20

Module Air Breather Design Drawing . . . . . . . 3-22

Concentrator Cell Assembly Drawing . . . . . . . . . 3-25

Prototype Module Electrical Configuration . . . . . . . 3-28

Cell Assembly Thermal Load versus Shade Factor . . . . 3-30

Prototype Module Electrical Feedthrough

Design Drawing . . . . . . . . . . . . . 3-33

Photograph: Concentrator Cell Assembly ........ 4-2

UNSW Concentrator Cell Metallization Design

for Prismatic Cover . . . . . . . . . . . . . . . . 4-3

Line Chart Display: Bare Cell Flash Test

Voc and $V m p$ Data ................... 4-5

Line Chart Display: Bare Cell Flash Test

Isc and Imp Data . . . . . . . . . . . . . . 6

Line Chart Display: Bare Cell Flash Test

Fill Factor and Efficiency Data . . . . . . . . . . 4-7

Substrate Design Drawing $\ldots \ldots \ldots \ldots \ldots \ldots \ldots .4-8$

Front Tab Design Drawing ............... 4-10

Front Tab Modifications for

Prismatic Cover Placement ................. 4-11

Heat Spreader Design Drawing ............. 4-12

Line Chart Display: IX Flash Test Data for

Prism-Covered Cell Assemblies ............. . 4-1.5

Line Chart Display: 190X Flash Test Data for

Prism-Covered Cell Assemblies .............. 4-16

Cell Assembly Soldering Alignment Fixture . . . . . . t-18

Fabrication Flow Chart for Concentrator

Cell Assemblies . . . . . . . . . . . . . . . . . 4-20

Cell Assembly Evaluation Test Sequence . . . . . . . 4-24

Thermal Cycle for Cell Assemblies . . . . . . . . . . . . 4-29 
Contents (Continued)

Figures (Continued)

Figure 4-16 Humidity/Freeze Cycle for Cell Assemblies

Figure 4-17 Normalized IV and Power Curve Data Ranges for

Outdoor Tests of 32 Cell Assemblies ......... . 4-31

Figure 4-18 Line Chart Display: Cell Assembly Outdoor Test

Voc, Vmp, Isc, Imp Data . . . . . . . . . . . . 4-32

Figure 4-19 Line Chart Display: Cell Assembly Outdoor Test

Fill Factor and Efficiency Data . . . . . . . . . 4-33

Figure 4-20 Cell Assembly Power Output Comparison and

Module Cell Selection .............. 4-35

Figure 4-21 Cell Groupings for Module Substrings . . . . . . . . . . 4-37

Figure 4-22 Schematic of Module Cell Assembly Arrangement . . . . 4-39

Figure 5-1 Module Depth Diagram -- Genera! . . . . . . . . . . 5-2

Figure 5-2 Module Depth Diagram -- Details . . . . . . . . . . 5-3

Figure 5-3 Corrugated Housing Assembly Diagram. . . . . . . . . 5-6

Figure $5-4 \quad$ Parquet Truss Support Diagram . . . . . . . . . . . 5-7

Figure 5-5 Lens Parquet Machining Detail . . . . . . . . . . . 5-9

Figure 5-6 Module Assembly Drawing . . . . . . . . . . . . . 5-10

Figure 6-1 Module Evaluation Test Sequence . . . . . . . . . 6-2

Figure 6-2 Typical Pre-environment Module IV Curve . . . . . . . 6-3

Figure 6-3 Pre-environment Module Efficiency

versus Cell Temperature ...............6-5

Figure 6-4 Comparison of Measured versus Modeled Performance . . . 6-5

Figure 6-5 Thermal Cycle for Modules . . . . . . . . . . 6-7

Figure 6-6 Humidity/Freeze Cycle for Modules . . . . . . . . . . . 6-7

Figure 6-7 Photograph: Lens Parquet Bowing after

Humidity/Freeze Cycling .............. 6-8

Figure 6-8 Typical Post-environment Module IV Curve . . . . . . . . 6-9

Figure 6-9 Typical Post-environment Module IV Curve

Two-thirds of Module Active . . . . . . . . . . 6-11

Figure 6-10 Typical Post-environment Module IV Curve

One-third of Module Active . . . . . . . . . . . 6-11

Figure 6-11 Post-environment Module Efficiency versus

Calculated Cell Temperature ............. 6-12 


\subsection{SUMMARY}

The primary objective of this project was to design and fabricate an improved photonoltaic (PV) concentrator module while expanding the infrastructure for PV concentrator molules. A project goal was to fabricate four modules that operate at 20 percent efficiency. The project team consisted of Black \& Veatch, Spire Corporation, and Solar Kinetics, Inc. Spire was involved in the cell selection process and was the lead investigator for the cell assembly design and fabrication activities. Solar Kinetics was responsible for the module housing design and fabrication activities. Black \& Veatch provided the overall project management and performed systems analysis for the module's optical and electrical design.

The project has been slccessful with regard to the basic objectives of designing and fabricating an improved photovoltaic concentrator module, developing an understanding of acrylic lens parquet module behavior, and expanding the infiastructure of firms involved in concentrator module development and manufacturing. The project has been plagued with unavoidable schedule delays resulting first from the uncertain availability of module components and then from development of "module-ready" solar cells and from problems in fabrication and placement of prismatic covers on cells. The contract start date for this project was December 16, 1986. The original project schedule called for an approximate 18 -month project duration with a completion date in July 1988. Several delays were encountered, which slowed the project progress and greatly extended the project schedule. Among the issues that resulted in these delays were project scope changes, component procurement delays, unavalability of fabrication equipment, and inclement weather during the test evaluation.

This project marked the first attempt to use prismatic covers on solar cells in a high-eoncentration, point-focus application. Although problems with the fabrication and placement of the prismatic covers on the cells prevented their use in the prototype module, many design development issues were investigated to evaluate the potential module performance improvements for prismatically covered cells.

\subsection{Module Characteristics}

Figure $1-1$ is a photograph of the interior of the prototype module. For comparison, an isometric drawing of the module with cell assembly detail is provided ahove the photograph. Tahle $1-1$ provides a summary description of the 

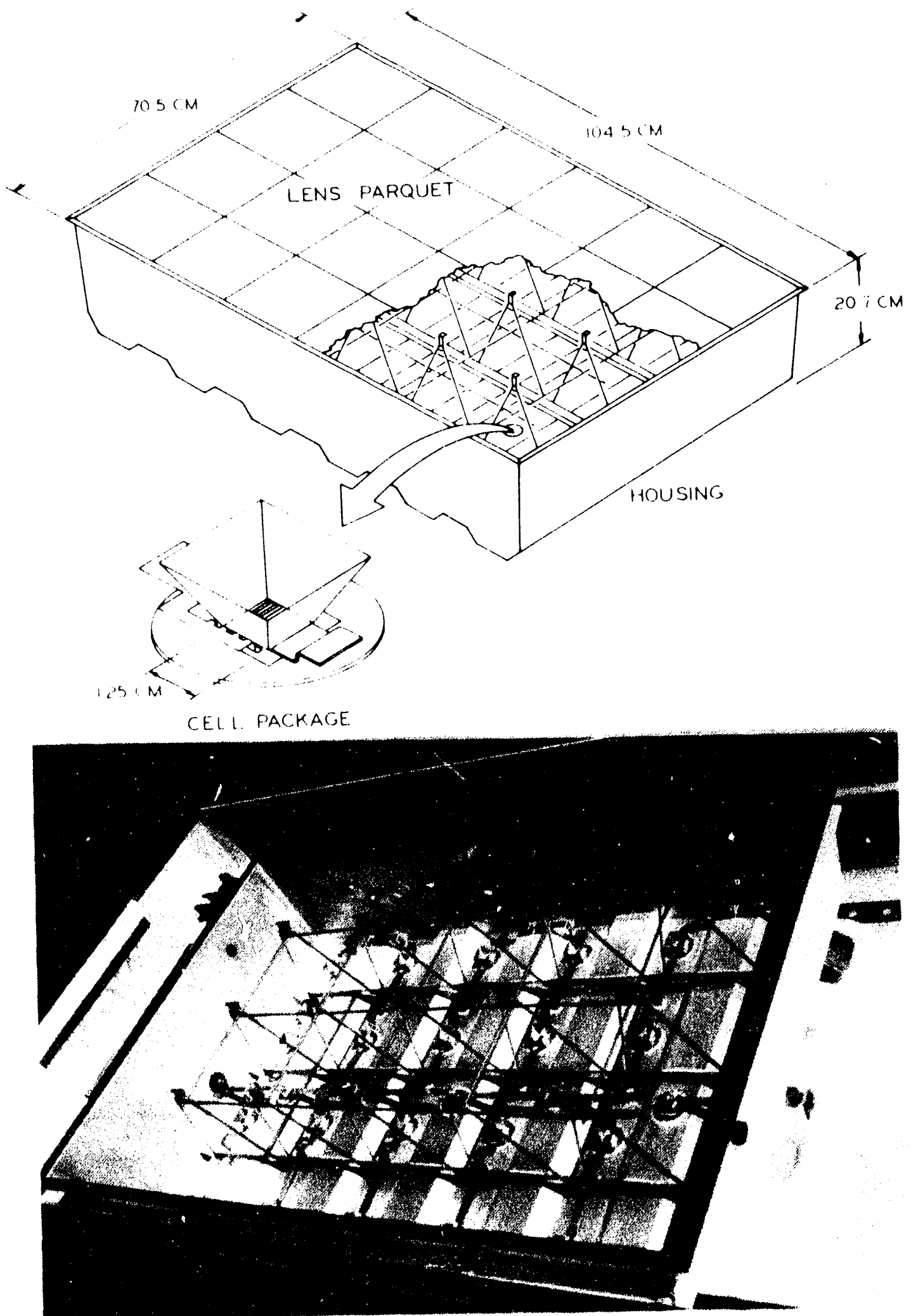

Photograph: B!ack \& Veatch Module (lens Parquet Removed) Figure $1-1$ 


\begin{tabular}{|c|c|c|c|c|c|c|c|}
\hline \multirow{5}{*}{ 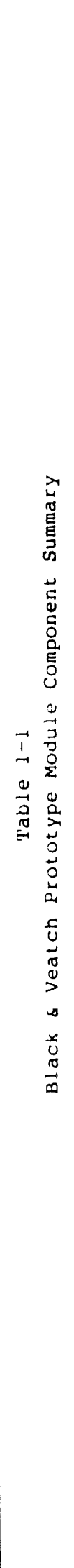 } & 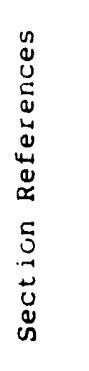 & \multicolumn{2}{|l|}{$\vec{n} \vec{n} \vec{n} \dot{n} \quad \ddot{n}$} & 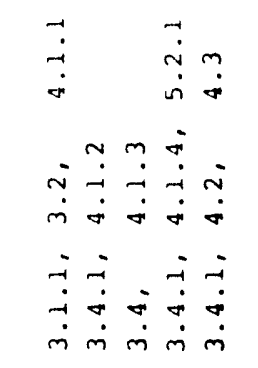 & 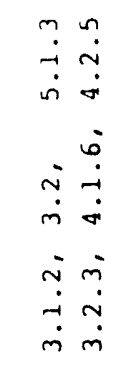 & 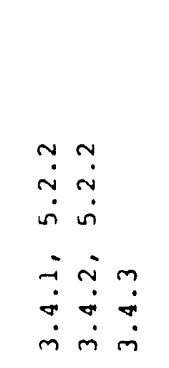 & 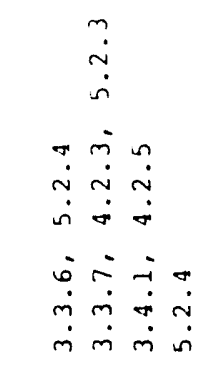 \\
\hline & $\begin{array}{l}\overrightarrow{0} \\
\overrightarrow{4} \\
0 \\
0 \\
2\end{array}$ & 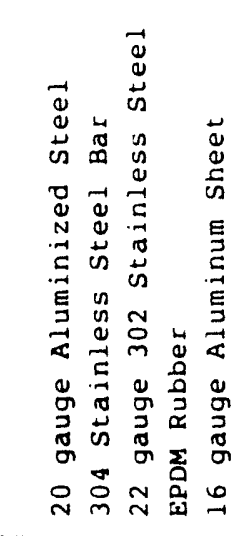 & 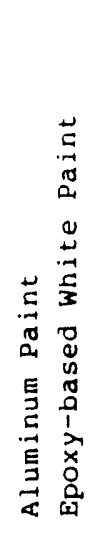 & 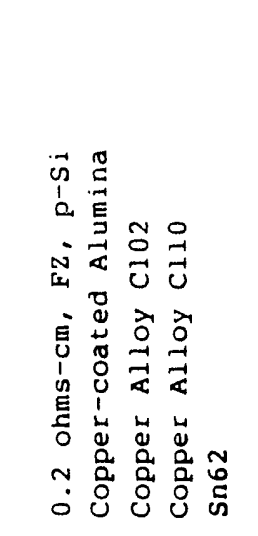 & 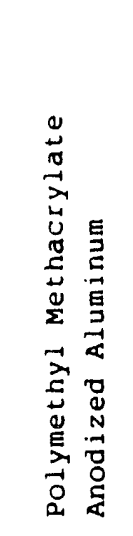 & 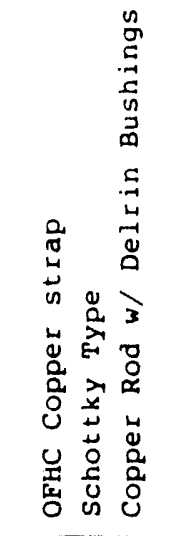 & 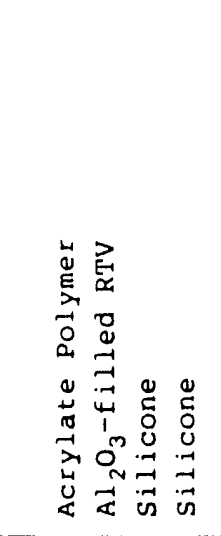 \\
\hline & 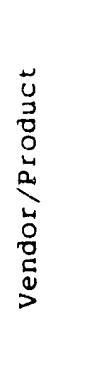 & 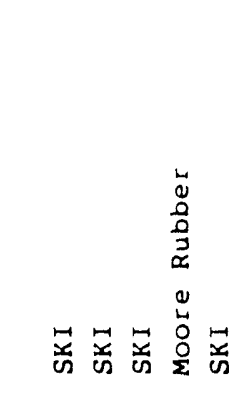 & $\mathfrak{z} \mathbf{z}$ & 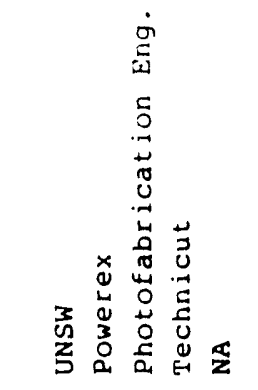 & 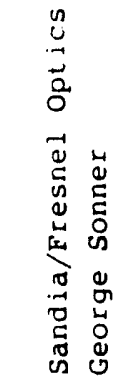 & 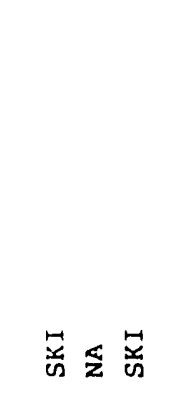 & 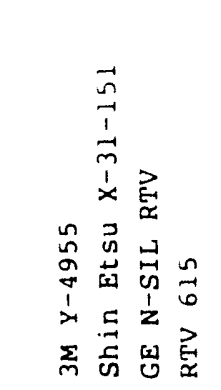 \\
\hline & 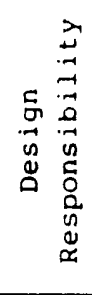 & 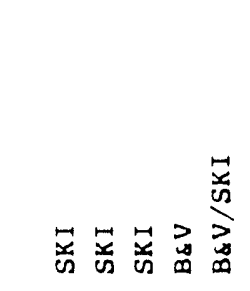 & 站嵒 & 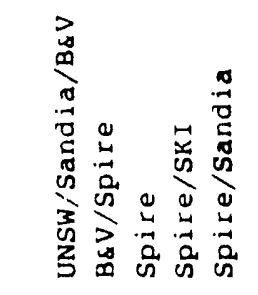 & 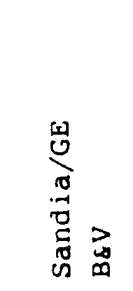 & 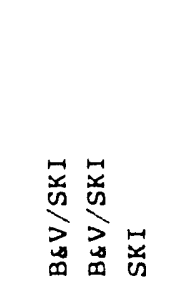 & 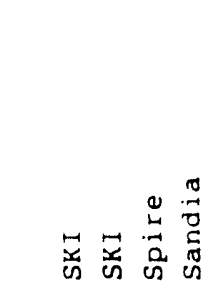 \\
\hline & 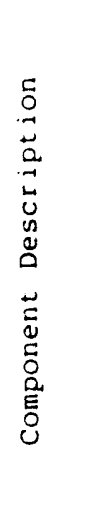 & 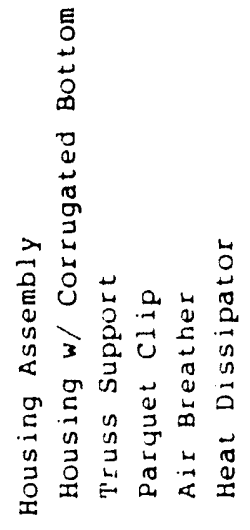 & 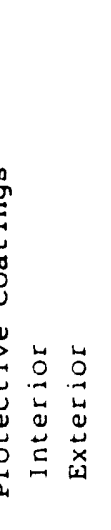 & 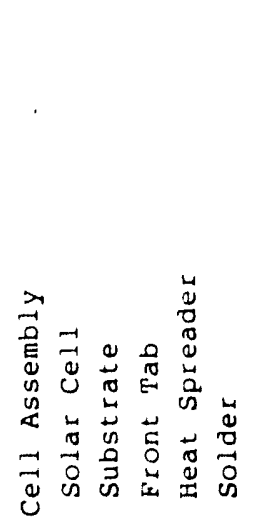 & 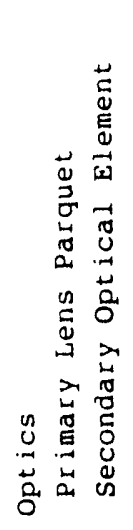 & 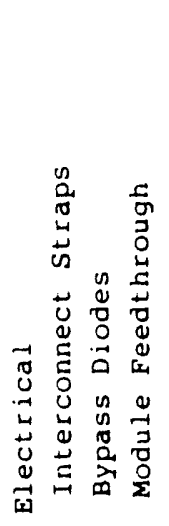 & 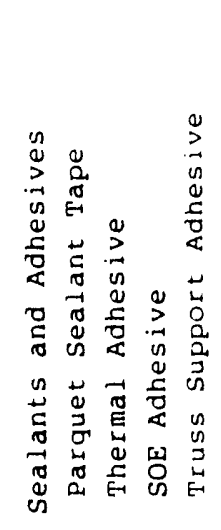 \\
\hline
\end{tabular}


module components, including report section references for additional component details. Table 1-2 summarizes the design features for the prototype module in four areas: optics, cell, module, and electrical. The following sections summarize the module design definition activities, the cell assembly activities. and the prototype module fabrication activities.

\subsubsection{Design Definition}

Module design activities were directed at three primary areas: (1) appraising current point-focus concentrator module technology, (2) assessing the impact of component technical merit and availability in meeting project objectives, and (3) analyzing key characteristics of the optical, structural, and electrical design. Solar cell and Fresnel lens component selections were made during the early stages of the project due to the strong impact that these components have on most aspects of module design. Component selection was based on technical merit as well as component availability. In addition, the project team conducted numerous design analyses and performed several component tests to establish the improved module design characteristics.

A preliminary screening of several cell fabricators was performed to assess the candidate vendors' product efficiency, production volume and technical and schedule risk. In the final analysis, nontechnical factors played the most important role in the cell vendor selection process. The University of New South Wales (UNSW) cell design was selected because the assurance of timely delivery was an overriding concern. The delivery of UNSW cells was considered low risk because of a cell development contract between UNSW and Sandia.

A preliminary screening of three compression-molded acrylic Fresnel lens designs applied two criteria: availability of tooling or a stock of parquets, and the design compatibility with the UNSW cell design. Parquets designed by General Electric (Sandia Baseline Module II [SBMII] lens developed under Sandia contract) and by Black \& Veatch (BNVB lens developed under Electric Power Research Institute [EPRI] contract) were selected for further consideration. In the final analysis, nontechnical factors once again played the most important roli in the selection process. EPRI declined to permit the use of the BNVB lens for this project. Fortunately, the SBMII parquets were available and needed only to be trimmed from 5 by 6 parquets to 4 by 6 parquets.

The optical system design objective was to integrate the current state of high concentration component development into a feasible module configuration. Optical design analyses utilized the capabilities of PVOPTICS, a computer 


\section{Table 1-2}

Black \& Veatch Module Design Characteristics Sumrary

\begin{tabular}{||l|l||}
\hline \hline DESIGN ELEMENT & CHARACTERISTIC \\
\hline OPTICS & \\
Lens Parquet & Compression Molded Acrylic \\
Arrangemint & 4 by 6 \\
Lens size & $17.0 \mathrm{~cm} \times 17.0 \mathrm{~cm} \times 0.318 \mathrm{~cm}$ \\
Parquet size & $104.5 \mathrm{~cm} \times 70.5 \mathrm{~cm} \times 0.318 \mathrm{~cm}$ \\
Facet width & $0.076 \mathrm{~cm}$ \\
Number of facets & 157 \\
Secondary Optical Element & Four-sided Reflector \\
Entrance aperture & $3.08 \mathrm{~cm} \times 3.08 \mathrm{~cm}$ \\
Exit aperture & $1.23 \mathrm{~cm} \times 1.23 \mathrm{~cm}$ \\
Height & $1.6 \mathrm{~cm}$ \\
& \\
CELL & Wafer Silicon \\
Die Size & $1.8 \mathrm{~cm} \times 1.8 \mathrm{~cm}$ \\
Active Cell Size & $1.25 \mathrm{~cm} \times 1.25 \mathrm{~cm}$ \\
Gridline Coverage & 15 percent \\
& \\
MCDULE & Aluminized Steel \\
Fiousing & Formed Sections w/ Corrugated Bottom \\
Geometric Concentration & $185 \times$ \\
Lens-to-Cell Spacing & $20.4 \mathrm{~cm}$ \\
ELECTRICAL & \\
Module & 3 Series Blocks \\
Block & 2 Parallel Strings \\
String & 4 Series Cells \\
Diode & 1 per 8 Cells \\
\hline
\end{tabular}


simulation code written by Black \& Veatch for use in the optical design of highconcentration modules. The results provided by PVOPTICS guided the selection of lens and cell components as well as many of the module design specifications, such as housing depth, cell metallization co erage, secondary optical element (SOE) design, and dimensional tolerance allowances. PVOPTICS provides the ability to simulate this complex interaction and to estimate the performance of single cell units comprising a primary lens, an SOE, and a photovoltaic cell.

The SOE concept selected for the prototype module is a four-sided reflective component fabricated of anodized aluminum in a cut-and-fold operation. Other design concepts, such as total internal reflective glass SOE's and imaging glass SOE's, were considered but were regarded as too costly to develop for this project.

The potential for improved module performance by using prismatically covered cells was investigated by the project team. In principle, prismatic covers reduce shadow losses by redirecting solar energy from the cell metallization to unmetallized areas, and lower $I^{2} R$ losses in the grid lines due to the higher allowable cell metallization coverage. An enhanced PVOPTICS performance model was developed to estimate the power output for nonuniform (as produced by the SBMII lens) illumination on prismatically covered cells with metallization coverages from 6 percent to 21 percent. Increasing the metallization coverage from 6 percent to 15 percent resulted in an estimated 15 percent performance improvement for the nonuniform illumination condition. On the basis of these analyses, Sandia and the project team decided to pursue the use of prismatic covers on the UNSW cells for the prototype module. A 15 percent metallization coverage was selected for cells in this application.

\subsubsection{Cell Assembly}

The cell assembly consists of a solar cell, its electrical terminations, a secondary optical element, and a cell mount, which includes a high-voltage insulator and a heat spreader. The cell assembly design utilizes a $0.51-\mathrm{mm}$ (0.()2()-inch) thick alumina substrate with direct-bonded copper metallization on both sides to provide the electrical isolation and thermal path between the cell and the copper heat spreader. A solder bond attaches the conventional hifacial contact solar cell to the top of the substrate and the heat spreader to the bottom of the substrate. Electrical contact to the cell back surface is made by the same copper layer that is bonded to the top of the alumina substrate. A copper tab was designed to be soldered to the cell's front contact that minimises I'R loss, 
maintains low stress on the cell metallization, and provides redundancy through the use of multiple parallel leads.

The cell assemblies were vacuum soldered in the SPI-LAMINATOR 240, a commercial product manufactured by Spire for lamincting flat-plate PV modules using sheet encapsulants. The assembly components were loaded into an alignment fixture and placed in the laminator for vacuum soldering. This equipment was chosen because there are similarities between cell encapsulation and eell solder bonding. Both processes require the void-free bonding of planar objects with solid, thick films that melt at elevated temperatures. In addition, the use of the laminator had two main advantages over conventional hot-plate soldering. First, it achieves full air removal prior to the solder melt to reduce both void size and occurrence. Second, the laminator temperature and pressure parameters are presct and computer-controlled, thereby allowing automated processing of each cell assembly. The use of the laminator on properly procured and prepared components offered the potential to reduce solder void content and, therefore, to improve solder bond quality.

\subsubsection{Prototype Module Fabrication}

The module structural design activities consisted of analyses and testing in three principal areas: housing strength, housing bottom buckling, and parquet deflection. Tests were performed to establish material response to expected operating conditions for thermally induced buckling of the housing bottom, and gasket material and thermal adhesive selection. In addition, designs were developed for the parquet-to-housing clip and the module air breather.

The prototype module housing is made of 20-gauge (0.036-inch) aluminized sheet steel with bottom corrugations. Both aluminum and steel were considered as candidates for the housing material. Aluminum exhibits good thermal characteristics and offers excellent corrosion resistance to the environment while steel offers substantially greater stiffiness per unit of cost and lower manufacturing costs. The selection of aluminized steel was based on its expected lower production cost than that for aluminum housings.

The housing was fabricated by welding formed sections of the corrugated primary pan and two secondary side members. The primary pan includes the lens mounting rims, ends, and bottom corrugation bends. Each side member includes the lens mounting rim, side, and ends to the corrugations across the bottom. All sheet metal members were fabricated using hydraulic, numerical control press brakes. The three formed sections were placed on a male vacuum chuck to hold 
the members during the tungsten inert gas welding process. The use of the vacuum chuck maintained quality dimensional control in the critical areas, namely the cell assembly mounting surfaces and the lens mounting rim, to within $0.30 \mathrm{~mm} 0.012 \mathrm{inch}$ ) as measured with a coordinate measuring machine.

The compression-molded acrylic SBMII lens parquets, provided by Sandia in the original 5-by-6 lens configuration, were trimmed and edged by Fresnel Optics Company to the 4-by-6 lens configuration needed for the prototype module. Three oblong guide slots were machined on the parquet rim for registration of the parquet with the housing. PEM studs were used as the alignment pins on the housing rim to keep the parquet position stable after assembly and prevent thermal ratchetting from shifting the position of the parquet on the housing during diurnal and seasonal iemperature and humidity changes.

The 24 cell assemblies selected for the module were individually positioned and bonded to the housing bottom. The cell positions were determined relative to the optical center of the housing as given by the locations of the parquet-tohousing registration pins. The assemblies were bonded with a layer of thermally conductive silicone adhesive. Alignment of the circular heat spreader of the cell assemblies with the rectangular housing was guided by two diametrically opposed semi-circular notches cut into the heat spreader perimeter. These notches were located opposite the two non-tabbed cell sides and provided a referenced orientation for each cell assembly. A cell-to-housing installation tool was fabricated to hold the cell assembly in position while providing a constant load to the assembly during the adhesive curing period.

The electrical configuration of the 24-cell module consists of three series blocks. Each series block contains two parallel strings of four cells each. A single bypass diode was placed in parallel with each series block. Diode stands were fabricated with cell assembly components (a copper heat spreader and an alumina suhstrate) and copper brackets. Cell interconnect straps are fabricated of 12.7 by $0.81-\mathrm{mm}(0.50$ by 0.032 -inch) oxygen free high-conductivity copper strap. Stress relief hends are placed into the straps. Two module feedthrough connectors penetrate the module ends and are purposely shifted from the module's longitudinal centerline so as to provide visual distinction of module polarity. This arrangement should be beneficial during field installation of production units by reducing ambiguity regarding module polarity.

An air breather design was prepared and fabricated for use in modules with 20-gauge steel housing. The air breathers are fabricated of EDPM rubber. Aluminum sheet-metal heat radiators, called heat dissipators, are bonded to the 
outside of the housing hottom at locations that coincide with the cell assemblies. The heat dissipators are fabricated into "plus sign" shapes from 16-gauge (0.063-inch) aluminum sheet. The four tabs were ben: to form a set of fins to increase the convective surface area. The thermal path added by the heat dissipators improves the modules' ability to disperse the thermal energy of each cell assembly.

\subsection{Evaluation Test Results}

Tests were conducted by Sandia for evaluation of the preliminary cell assemblies, the module cell assemblies, and the prototype module. The tests included electrical performance measurements, high-voltage isolation tests, nondestructive $x$-ray and ultrasound tests, and environmental exposure tests. Table 1-3 presents a summary of the electrical performance measurements for the bare cells, cell assemblies, and prototype module. The following sections summarize the cell assembly evaluation testing and the prototype module evaluation testing.

\subsubsection{Cell Assembly Evaluation Testing}

Sandia conducted a series of electrical and evaluation tests on five prismatically covered cell assemblies. Each cell assembly was required to pass these tests before authorization was given to proceed with the module fabrication activities. The test sequence include two environmental tests, thermal cycling and humidity/freeze cycling, to which the samples are subjected.

Baseline electrical tests were conducted at approximately $190 \mathrm{X}$ in Sandia's cell development laboratory flash tesier. In order to retain the best cell assemblies for use in the module, the cell assembly with the poorest electrical performance prior to SOE placement was chosen as the control unit and was not subjected to environmental tests. The control unit average efficiency was 19.8 percent with a maximum power output of 5.97 watts. The average efficiencies for the other four assemblies were $19.8,20.5,19.9$ and 20.5 percent with maximum power outputs of $6.17,6.25,6.25$, and 6.11 watts. Final electrical tests were conducted following hi-pot tests, $x$-ray and ultrasound imaging, and thermal shock cycling tests on the four non-control assemblies, and the additional humidity/freeze cycling tests on two of the four non-control assemblies. All cell assemblies exhibited essentially the same maximum-power efficiency as for the baseline characterization. 


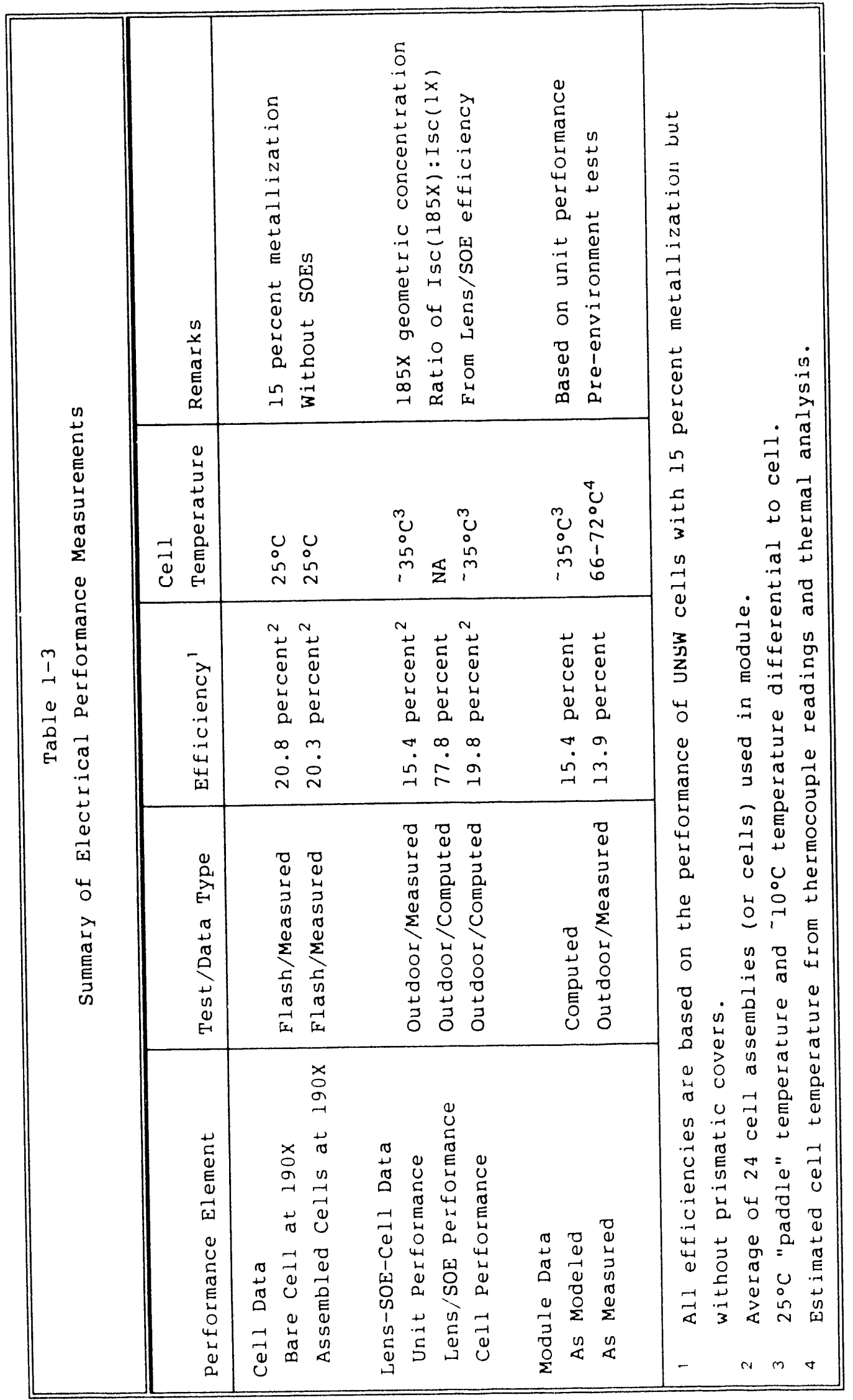


All the evaluation tests were successful with the exception of the failure of one of the assemblies to pass the high-voltage (2200-volt) isolation test alter humidity/freeze cycling and the presence of large void areas in the two solder bonds. The failed unit broke down at 1750 volts. After the unit was dried, it was retested and passed the 2200-volt requirement. Ultrasound images were taken prior to and after environmental testing to detect the presence of solder void areas. These images showed extensive voids in both solder bonds of the cell assemblies, although no significant differences in void area were observed alter environmental testing indicating that these tests caused no damage to the solder bonds. All cell assemblies show voids in excess of 10 percent in both solder bonds. The four noncontrol assemblies were also subjected to 60 cycles of temperature shock. Visual examination revealed no signs of degradation. The two assemblies that showed the most and the least voids as determined by the ultrasonic testing were returned to the cycle chamber to accumulate a total of 250 cycles. These assemblies showed no signs of degradation.

The cell assembly was given a conditional acceptance despite the high-voltage breakdown and the large voids because the failure was not catastrophic, the module will not be subjected to these high voltages in test operation, and the module is not scheduled for a production system. Future cell assembly design alternatives exist that may avert this high voltage breakdown and reduce the solder bond void percentage.

Spire made 32 cell assemblies to provide a pool of assemblies for selection and placement in the prototype module. These cell assemblies were not covered with prismatic covers due to problems encountered in the placement and honding of covers to the cells. These cell assemblies were tested outdoors by Sandia at the Photovoltaic Advanced Solar Test Facility. Sandia conducted outdoor lens/cell performance measurements on each cell assembly. These outdoor tests provided complete current-voltage (IV) curve data for each cell assembly at the measured test conditions. Each cell assembly was tested with a lens identical to the parquet lenses used in the prototype module at a lens-to-cell spacing of $2(14 \mathrm{~mm}$ (8.03 inches). The cell assemblies were fastened to a "paddle" for ease of placement within the test apparatus. Coolant flow through the paddle maintained an approximate $25^{\circ} \mathrm{C}\left(77^{\circ} \mathrm{F}\right)$ heat sprealer temperature. Normalized IV curve data for the 32 cell assemblies showed a range of Isc values from 7.21 amps to 7.91 amps, a range of peak power values from 4.20 watts to 4.66 watts, and a range of Voc values from 0.736 volts to $(0.780$ volts. 


\subsubsection{Module Evaluation Testing}

A single prototype module was delivered to Sandia for testing and evaluation. The module was tested by Sandia at the Photovoltaic Advanced Solar Test Facility. Because only one was available, the PV concentrator module evaluation test sequence consisted of an initial characterization of the module, temperature shock cycling, and humidity/freeze cycling.

The electrical characterization was made to establish a baseline prior to the environmental testing. Although the solar cells were designed for use with prismatic covers, the module cells did not have prismatic covers. Therefore, the module performance was expected to be about 15 percent lower than with covered cells. Representative module performance as given by current-voltage curve data indicate current, voltage, power, fill factor, and efficiency for the module at maximum power to be 12.9 amps. 7.26 volts, 93.8 watts. 78.5 percent. and 13.9 percent respectively. These readings were obtained at $981 \mathrm{~W} / \mathrm{m}^{2}$ direct normal insolation. Figure $1-2$ is a representative IV curve for this module.

The module was subjected to 120 cycles of thermal shock. A visual inspection after the exposure revealed no change in the module. After thermal cycling, the module was subjected to 10 cycles of the humidity/freeze cycle. After this exposure very pronounced bowing of the lens parquet was observed and there was a crack in the parquet. The module parquet truss support structure prevented the parquet from bowing into the module; therefore, it was bowed out. Measurements made of the individual lenses showed that those in the interior of the parquet had been stretched. The peripheral lenses showed no stretching on the outer edges where ihey are bonded and clamped to the housing. The crack originated at the alignment hole on the side of the parquet and extended approximately perpendicular to the edge into the parquet about 10 inches. It was adjacent to, hut not on, the intersection on the lenses. There was no other visual damage observed in the module resulting from the environmental tests.

An investigition into the callse of the lens bowing was conducted. A conclusion of this investigation is that the steel clamp used to hold the lens parquet in place is just too stiff. It exerts too much force on the parquet, thus, not allowing it to float, relative to the steel housing, as a result of differential expansion caused by changing temperature and humidity. Exacerbating the situation is the differential expansion of the inner and outer lens parquet surfaces which appears to result from the hygroscopic properties of acrylic. Moisture absorption into the outer parquet surface, and its attendant material expansion, may have contributed to the outward bow of the lens. 


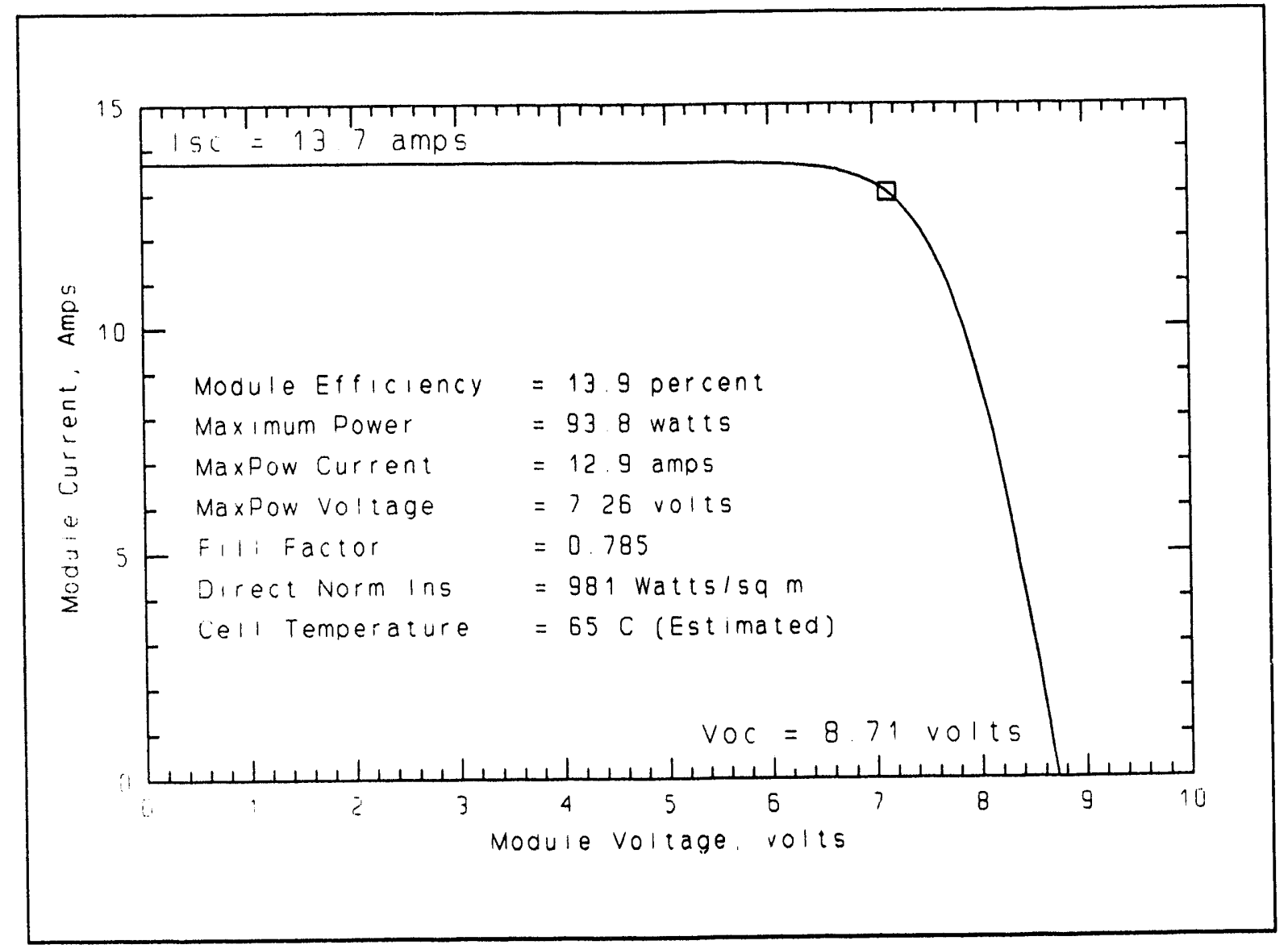

Representative Module IV Curve

Figure 1-2 
A new parquet was installed to continue the tests. The post-environmental electrical characterization showed about a $1+$ percent efficiency degradation compared to the specification allowable degradation of 8 percent. The module IV curves taken during the post-environment characterization show anomalous drops in the module current. These steps are the largest contributor to the lower module efficiency. The cause of these anomalies has not yet been identified; however Sandia will continue to investigate for the source. 


\subsection{INTRODUCTION}

This project, Photovoltaic Concentrator Module Improvements, was funded by the U.S. Department of Energy and administered by Sandia National Laboratories, Albuquerque NM, as Contract Number 56-7211. Project activities were initiated in December 1986 and were concluded in June 1991. The project has been successful with regard to the basic objectives of designing and fabricating an improved photovoltaic concentrator module, developing an understanding of acrylic lens parquet module behavior, and expanding the infrastructure of firms involved in concentrator module development and manufacturing. The project has been plagued with unavoidable schedule delays resulting first from the uncertain availability of components from the Electric Power Research Institute (EPRI) and then from development of "module-ready" solar cells and from problems in fabrication and placement of prismatic covers on cells. This section addresses these issues by describing the project objectives, the project team and responsibilities, the programmatic issues that resulted in schedule delays, and concludes with the report format.

\subsection{Project Objectives}

The basic objective of this project was to design and fabricate improved photovoltaic (PV) concentrator modules and enhance the infrastructure for PV concentrator modules. A project goal was to fabricate four modules that operate at 20 percent efficiency. An additional objesive was to develop realistic cost estimates for key components and for the assembled module at production rates of $5 \mathrm{MW}, 25 \mathrm{MW}$, and $100 \mathrm{MW}$ per year. To meet these objectives, the following technical tasks were established:

- Design Definition and Component Optimization

- Cell Assembly Fabrication and Testing

- Prototype Module Fabrication and Testing

- Manufacturing Cost Estimates

Black \& Veatch assembled a project team including two major manufacturing firms to accomplish these objectives. The Black \& Veatch team's approach to design development and fabrication of improved PV concentrator modules was to start with a baseline design. At the onset, the project design activities were directed at achieving an optimal design while retaining the essence of the baseline configuration. This approach was selected because it capitalized on previous work by allowing maximum use of already developed designs and components, 
it provided project emphasis on the cell assembly, and it offered the opportunity to achieve the project goals within tight budgetary requirements.

Due to several project programmatic issues as described in Section 2.3 below, the project objectives were modified to reflect a realistic balance of project goals with project funding, and to show the project team's commitment to providing hardware as evidence of its concerted effort. The project deliverables were reduced to the fabrication of one prototype module instead of the original four modules. Also, the requirement to provide a manufacturing cost estimate was eliminated. Still, completion of the project was accomplished with significant cost-sharing contributions by the project team.

\subsection{Project Team and Responsibilities}

The project team consisted of Black \& Veatch, Spire Corporation, and Solar Kinetics, Inc. Figure 2-1 displays the general areas of responsibility for each organization. Spire was involved in the cell selection process and was the ind investigator for the cell assembly design and fabrication activities. Solar Kinetics was responsible for the module housing design and fabrication activities. Black \& Veatch provided the overall project management and performed systems analysis for the module's optical and electrical design. Spire and Solar Kinetics provided relevant manufacturing experience, which complemented Black \& Veatch's design and systems experience.

\subsection{Project Programmatic Issues}

The contract start date for this project was December 16, 1986. The original project schedule called for an approximate 18 month project duration with a completion date in July 1988. Several delays were encountered, which slowed the project progress and greatly extended the project schedule. Among the issues that resulted in these delays were project scope changes, component procurement delays, equipment unavailability, and inclement weather. Figure 2-2 provides a time-line comparison of the original schedule to the actual schedule for this project.

Several changes in project scope were enacted during the early phases of the project to investigate design alternatives that showed merit for further consideration. For instance, module design parameters were developed in parallel for both the baseline $500 \mathrm{X}$ geometric concentration module and a $200 \mathrm{X}$ module 


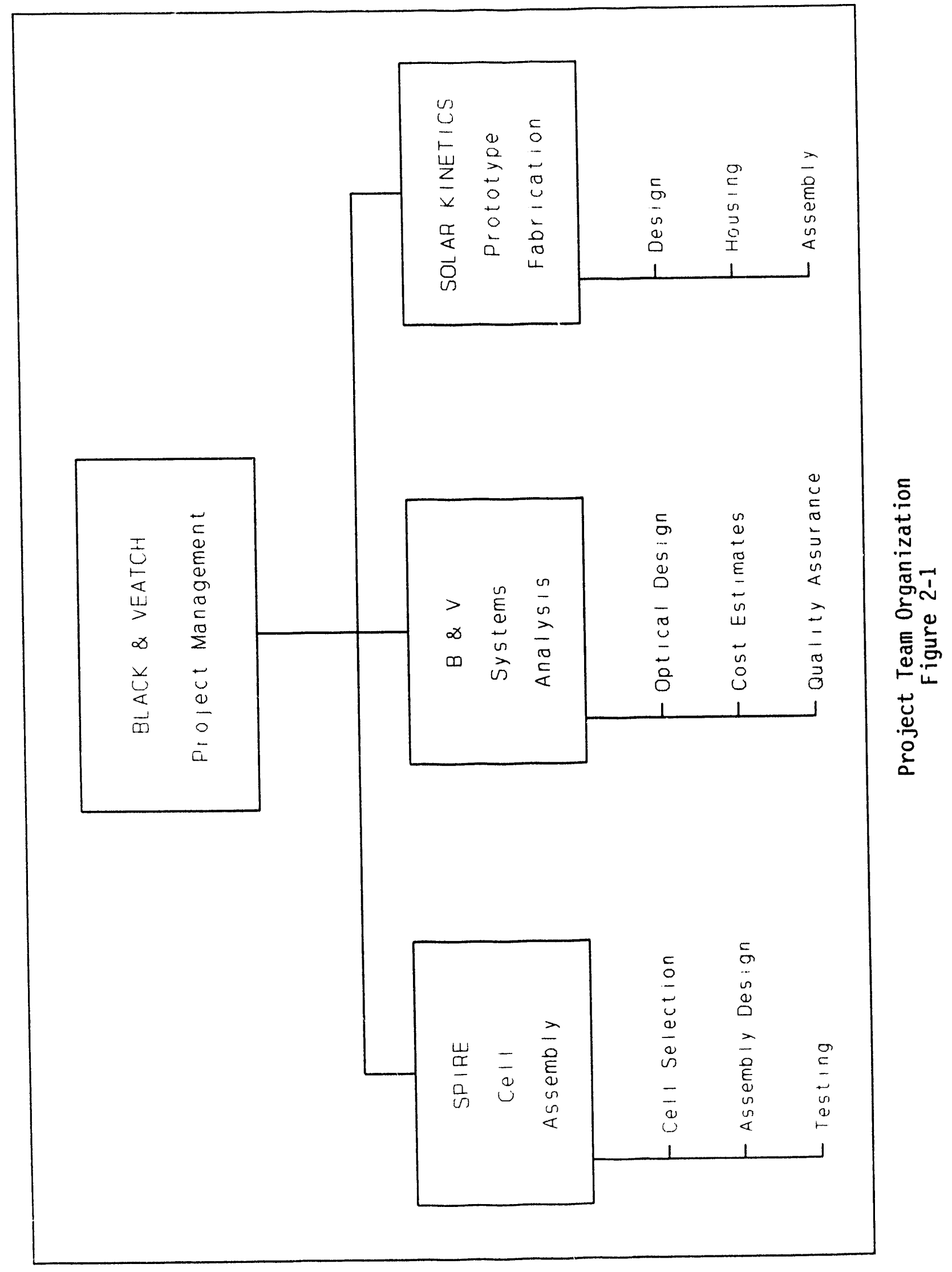




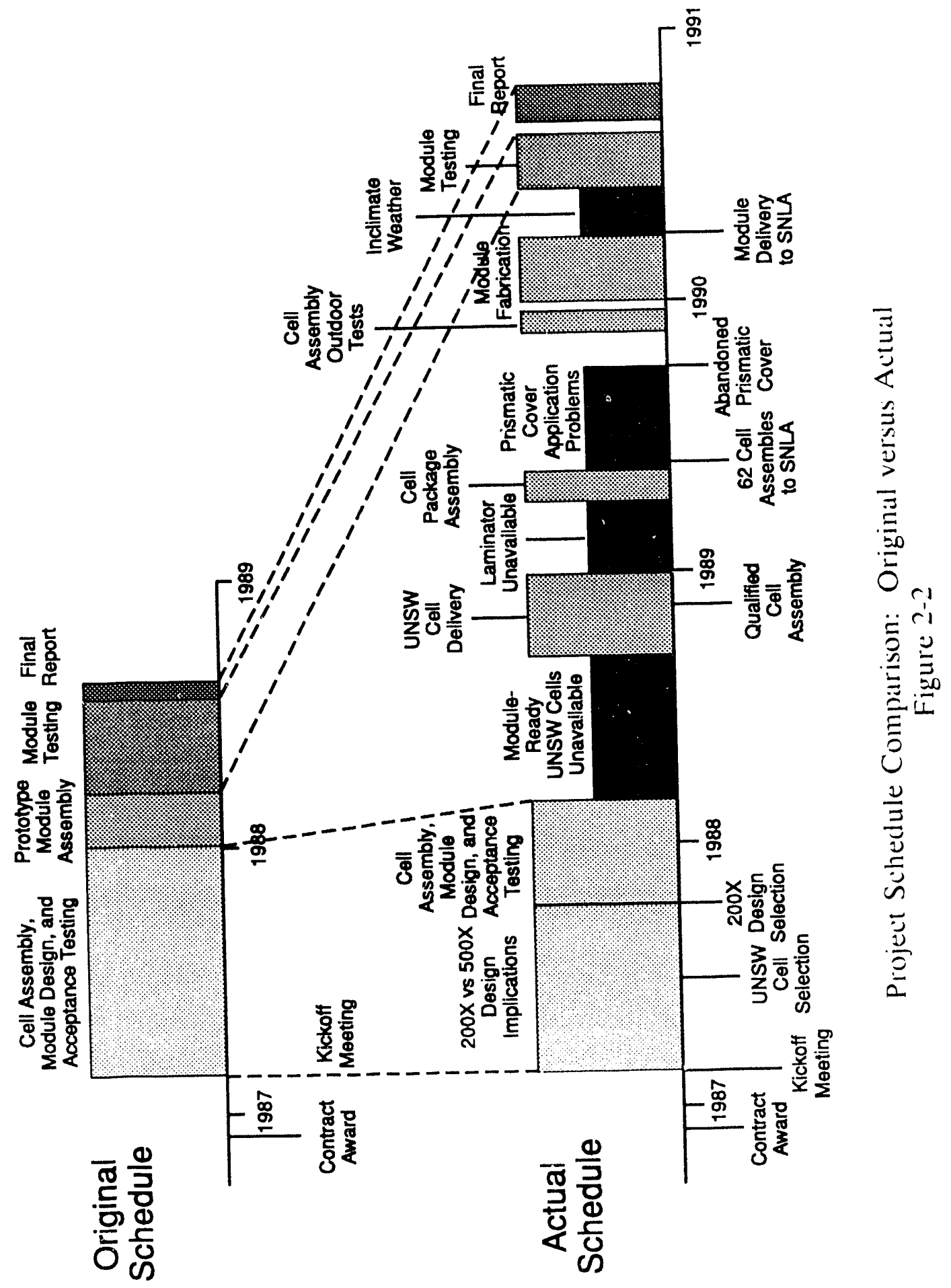


while the avalability of lens parquets and solar cells was being evaluated. This parallel development was taken as a precautionary measure to ensure the timely continuance of the project following the election of the lens and cell components and was supported with additional funds.

However, numerous activities of merit not within the original scope of work were performed by the project team although additional funding was not provided. In order to accommodate the project schedule, these activities were undertaken and often completed before authorization of additional funds could be assured. The following out-of-scope activities are listed with references to the appropriate report sections where summary descriptions are provided:

- Enhanced cell performance model, Section 3.2.4.

- Extensive analysis of prismatic cover design, Section 3.2.5.

- Structual analysis of housing design options, Section 3.3.1.

- Thermal testing of housing design options, Section 3.3.2.

- Parquet sizing requirements and acceptance tests, Section 5.1.3.

Completion of these out-of-scope activities was accomplished during the first 18 months of the project and did extend the project schedule. However, the one aspect of the project whose original duration was expanded the most was the prototype module assembly activities. Delays in obtaining module-ready solar cells, problems with the application of prismatic covers, and delays resulting from incidental factors such as inclement weather and fabricition equipment unavailability all contributed to lengthening the prototype module assembly activities by about 2 years.

This project marked the first attempt to use prismatic covers on solar cells in a high concentration, point focus application. Although problems with the fabrication and placement of the prismatic covers on the cells prevented their use in the prototype module, many design development issues were investigated to evaluate the potential module performance improvements for prismatically covered cells.

\subsection{Report Format}

This introduction is preceded by a summary section and followed by five other sections and two appendices. The first of the following sections deals with the design definition of the module. Other sections deal with cell assembly and prototype module fabrication activities and the testing that was conducted at each 
of these levels. The final section contains a list of references for all sections of the report. The appendices are reprints of two technical papers prepared by members of the project team.

\section{SECTIONS}

- Section 1.0 -. Summary.

- Section 2.0 -- Introduction.

- Section 3.0 -- Module Design Definition. Summarizes the component selection activities and the optical, structural, and electrical design and analysis activities.

- Section 4.0 -. Cell Assembly Fabrication and Testing. Summarizes the component procurement activities, cell assembly activities, and qualification and performance testing on the cell assemblies.

- Section 5.0 -- Prototype Module Fabrication and Assembly. Summarizes the fabrication and assembly activities for the prototype module.

- Section 6.0 -- Module Testing. Describes the results of module testing conducted by Sandia. Tests performed were a subset of the Block V tests as adapted to concentrator modules.

- Section 7.0 -. References.

\section{APPENDICES}

- Appendix A -- A Performance Model for Nonuniformly Illumina.ed Frontgridded Concentrator Cells.

- Appendix B -- Design, Fabrication, and Performance of Silicon Solar Cell Assemblies for Concentrator Modules. 


\subsection{MODULE DESIGN DEFINITION}

Module design activities for this project were directed at three primary areas: (1) appraising current point-focus concentrator module technology, (2) assessing the impact of component technical merit and availability in meeting project objectives, and (3) analyzing key characteristics of the optical. structural, and electrical design. The project team reviewed the Electric Power Research Institute (EPRI) High Concentration PV module design (500X geometric concentration) and the Sandia Baseline Module II design (154X geometric concentration) for attributes with the potential for improved performance or cost reduction. ${ }^{1.2}$ Solar cell and Fresnel lens component selections were made during the early stages of the project due to the strong impact that these components have on most aspects of module design. Component selection was based on technical merit as well as component availability. In addition, the project team conducted numerous design analyses and performed several component tests to establish the improved module design characteristics.

At the onset of this project. the project team and Sandia chose to conduct parallel design actirities for wo module configurations ats a risk-mitigating measure due to uncertainty of cell and lens availability. The two contigurations selected were 200X and 500X; referred to as geometric concentration and determined as the ratio of lens area and cell area. This section describes the component selection activities and the optical, structural, and electrical system analyses that define the improved prototype module design.

\subsection{COMPONENT SELECTION}

A strong design and performance interaction exists between the selection of cell and lens and the other design characteristics of the module. Module specifications such as housing depth, cell package requirements, electrical isolation and interconnection design, thermal characteristics, component alignment tolerances, and others are heavily influenced by the cell and lens design characteristics. In addition, a high level of design coordination is required to ensure that the cell and lens are well matched for optimum performance in the module. This section describes the cell and lens candidates and presents the design selection rationale for these components. 


\subsubsection{Cell Candidates}

Selection criteria were established at the outset of this project to guide the cell selection process. These criteria were intended to meet the program goals $o^{\prime}$. producing 20 percent efficient modules with a reliable design that could be transferred into a production environment. The five criteria for cell selection are listed below:

- High efficiency to achieve 20 percent module efficiency goal

- Compatibility with lens designs of existing parquet tooling

- High reliability

- Low cost in production volumes

- Timely delivery

Five concentrator cell fabricators were identified as potential candidates for a preliminary screening of concentrator cells: three cell designs had conventional bifacial contacts, and two cell designs had point-type contacts on the back surface. The three bifacial cell suppliers were the University of New South Wales (UNSW). Spire Corporation, and Applied Solar Energy Corporation. The two point-contact cell suppliers were Stanford University and Acrian. The status of

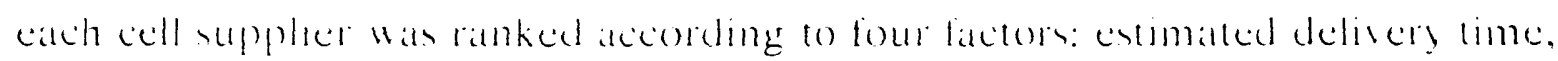
efficiency, production volume, and relative risk. Based primarily on the efficiency requirements to meet the program goals, this set of five suppliers was reduced to two, Acrian and UNSW.

Additional design analyses were performed to establish a pair of preliminary module configurations based on the Acrian and UNSW cell design specifications and performance estimates. The primary distinctions between these module configurations were geometric concentration and housing (lepth. The Acrian cell, with $64 \mathrm{~mm}^{2}\left(0.099 \mathrm{in}^{2}\right)$ active area, was designed for operation in the $400 \mathrm{X}$ to $500 \mathrm{X}$ geometric concentration range, whereas the UNSW cell, with $156 \mathrm{~mm}^{2}$ $\left(0.2+2 \mathrm{in}^{2}\right)$ active area, was designed for operation in the $100 \mathrm{X}$ to $200 \mathrm{X}$ range. ${ }^{3 .}$

The housing depth is principally determined by the lens design and the cell size. A preliminary analysis of housing depth was conducted for both cells using a lens design developed by Black \& Veatch, referred to as BNVB. Parquets of this lens design are currently being used in the EPRI High Concentration Photovoltaic Array installation at the PVUSA site in Davis, California. Performance estimates wh this lens design confirmed its compatihility with each cell design as evidenced by full. near-uniform illumination of the cell active area. This analysis indicated that the preferred housing depths were $280 \mathrm{~mm}$ (11.0 inches) and $260 \mathrm{~mm}$ (10.2 inches) for the Acrian cell and the UNSW cell, 
respectively. More information on lens design implications and lens selection is provided in Section 3.1.2.

In the final analysis, nontechnical factors played the most important role in the cell selection process. The UNSW cell design was selected because the assurance of timely delivery was an overriding concern. The delivery of UNSW cells was considered less risky than that of Acrian cells due to a cell development contract between UNSW and Sandia.

\subsubsection{Parquet Candidates}

Three Fresnel lens designs for which lens parquet tooling was available were identified as candidates for the improved module. All three parquet designs are point-focus-type lenses made of polymethyl methacrylate using compression molding technology. Two of the parquet designs were developed under Sandia contracts by General Electric and Intersol. The other parquet design was developed under EPRI contract by Black \& Veatch.

A preliminary screening of lens designs applied two criteria to each of the candidate designs: availability of tooling or a stock of parquets, and the design compatibility with the Acrian and UNSW cell designs. Combining the lems parquet candidate designs with information from the preliminary screcening of cell candidates, Section 3.1, resulted in the selection of the General Electric and the Black \& Veatch lens designs for further characterization.

An acrylic compression molded version of the General Electric parquet, referred to as the Sandia Baseline Module II (SBMII) parquet, comprises 30 individual lenses placed in a 5 by 6 arrangement. It was designed to provide $154 \mathrm{X}$ concentration at a lens height of $198 \mathrm{~mm}$ ( 7.80 inches). The lens size is $170 \mathrm{~mm} \times 170 \mathrm{~mm} \times 3.18 \mathrm{~mm}(6.67$ inches $\times 6.67$ inches $\times 0.125$ inch) square with 157 facets, a facet pitch of $0.76 \mathrm{~mm}(0.030 \mathrm{inch})$, and a 3 -degree draft angle.'

The Black \& Veatch-designed BNVB parquet comprises $2+$ individual lenses placed in $a+$ by 6 arrangement. It was designed to provide $500 x$ concentration at a lens height of $280 \mathrm{~mm}$ (11.0 inches). The lens size is $178 \mathrm{~mm} \times 178 \mathrm{~mm} \times$ $4.76 \mathrm{~mm}$ (7.0 inches $\mathrm{x} 7.0$ inches $\mathrm{x} 0.188 \mathrm{inch}$ ) square with 168 facets, a facet pitch of $0.76 \mathrm{~mm}\left(0.030 \mathrm{inch}\right.$ ), and a 1 -degree draft angle. ${ }^{1}$ Sandia measured the efficiency of the Black \& Veatch BNVB lens (with reflective secondary optical element) to be 86.4 percent, one of the highest optical efficiencies recorded.

As described in Section 3.1.1. the optimum module depth is primarily a function of lens design and cell design. Other influencing factors include secondary optical element design (SOE) and sensitivity to sun pointing errors 
(tracking errors). Understanding the complex interactions of these factors necessitates the use of a computer-aided design tool. Black \& Veatch has developed such a computer simulation tool for concentrating PV systems, called PVOPTICS. ${ }^{5}$ Module performance is estimated by PVOPTICS for a lens, SOE, cell combination at specified conditions. Section 3.2 describes the capabilities of PVOPTICS.

Several lens design distinctions are conveyed by a comparison of the facet angle profiles as displayed in Figure 3-1. The larger facet angles (higher refractive power) of the SBMII lens implies that the required housing (lepth for a module with the SBMII parquet would be less than for a module with the BNVB parquet. However, the higher refractive power increases the average Fresnel reflection losses at the facet surfaces to about 5.6 percent as compared to 4.7 percent with the BNVB lens. In addition, the 3-degree draft angle of the SBMII lens reduces the lens efficiency by about 1.5 percent below that of the 1 -degree draft angle BNVB lens. PVOPTICS analyses include the effects of the Fresnel reflection losses and draft angle losses in the estimates of unit performance.

Preliminary analyses with PVOPTICS were performed for combinations of the two lenserand the wo cells that passed the preliminary screening. By condlicting these analyses over a range of lens-to-cell spacings, the preferred housing depth was established for each lens-cell combination. As illustrated in Figure 3-2, relative performance indices, estimators of lens-cell performance, are shown for both lens designs in combination with the UNSW cell design. These analyses indicate that both lenses operate equally well with the UNSW cell design. However, the SBMII lens (denoted by the solid curve) operates most effectively at the lens-to-cell spacing of $204 \mathrm{~mm}$ (8.03 inches), while the BNVB lens (denoted by the dashed curve) operates most effectively at $260 \mathrm{~mm}$ (10.2 inches). Note that the lens height scale for the SBMII lens is shown at the top of the figure and has been shifted to coincide with the peak performance lens height of the BNVB lens in a $200 \mathrm{X}$ module (i.e., with the UNSW cell). Also shown as the dotted curve in Figure 3-2 is the performance of the BNVB lens with the Acrian cell. This combination has an optimum module depth of $280 \mathrm{~mm}$ (11.0 inches). These performance analyses indicate that either lens would produce acceptable results wiren operated with the selected UNSW cell, although the BNVB lens had a wider lens-to-cell spacing tolerance band. 


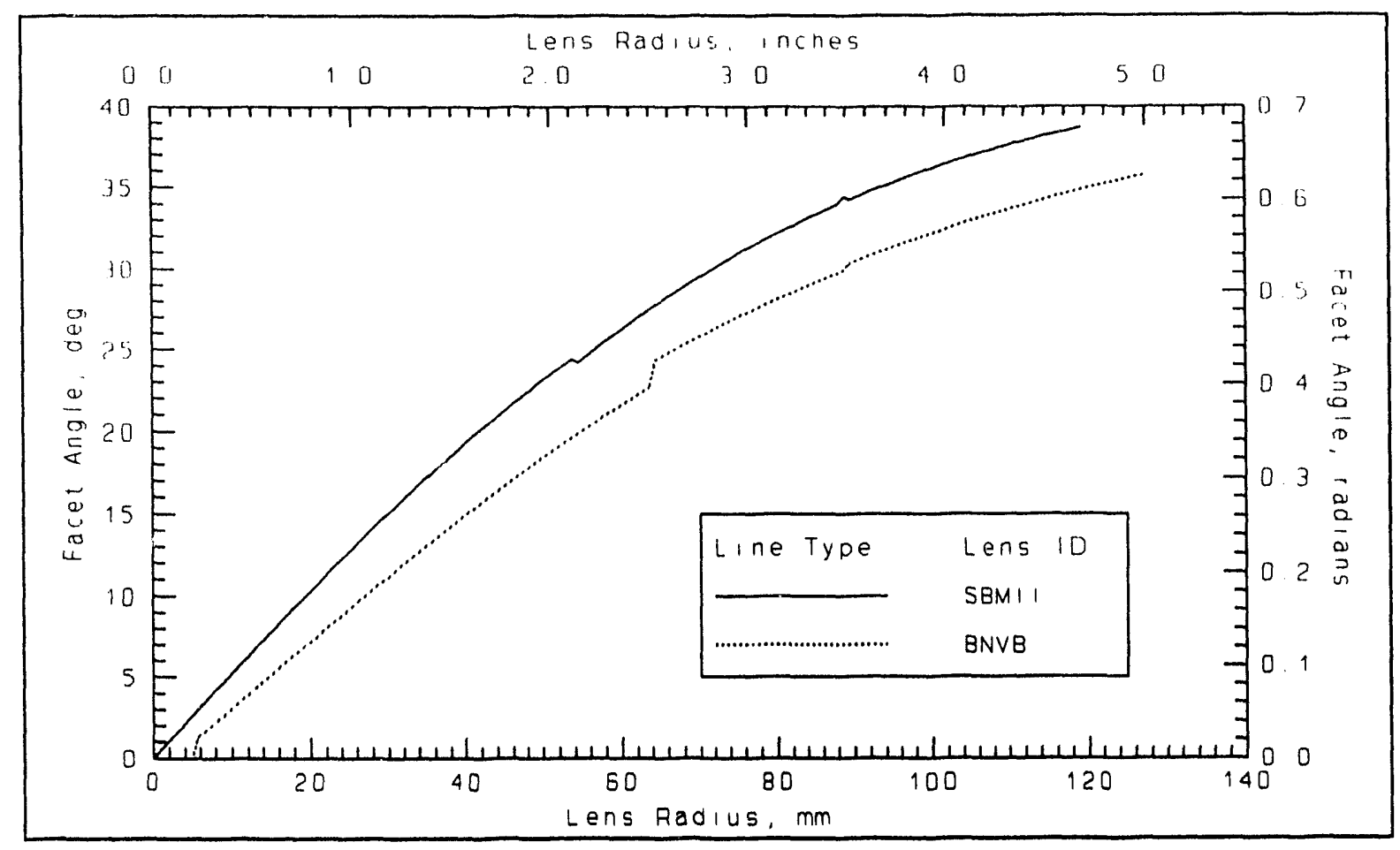

Fresnel Lens Facet Angle Profiles for the SBMII and BNVB Lenses Figure 3-1

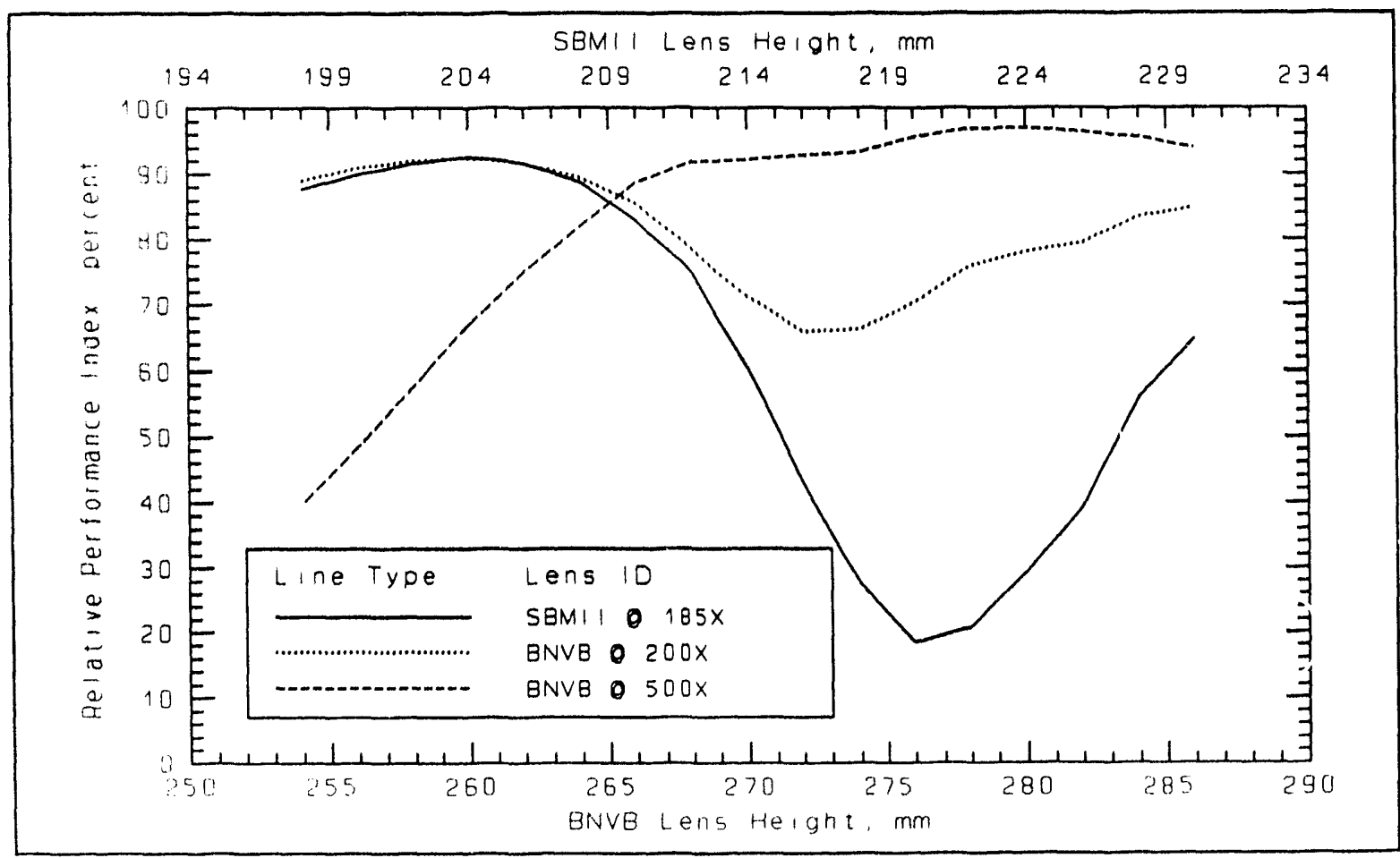

PVOPTICS Performance Estimates versus Lens Height for the SBMII and BNVB Lenses

Figure 3-2 
In the final analysis, nontechnical factors once again played the most important role in the selection process. FPRI, for which the BNVB lens was designed, declined to permit its use in the module. Fortunately, the SBMII parquets were available and needed only to be trimmed from 5 by 6 parquets to 4 by 6 parquets.

\subsection{OPTICAL SYSTEM DESIGN AND ANALYSIS}

The optical system design objective wals to integrate the current state of high concentration component development into a feasible module configuration. The lens and cell components selected for use in the prototype module are the SBMII lens ( $169 \mathrm{~mm} \times 169 \mathrm{~mm}[6.67$ inches $\times 6.67$ inches]) and the UNSW cell (12.5 mm $\times 12.5 \mathrm{~mm}[0.492$ inch $\times(0.492$ inch $])$. These component sizes produce a module with about $185 \mathrm{X}$ geometric concentration. The balance of the optical system design was driven by the characteristics of this lens-cell combination.

The optical design analyses utilized the capabilities of PVOPTICS, a computer simulation code written by Black \& Veatch for use in the optical design of highconcentration modules. The results provided hy PVOPTICS impacted many of

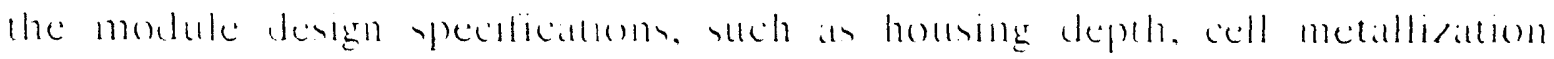
coverage. secondary optical element design, and dimensional tolerance allowances. Figure 3-3 illustrates the module component integration and evaluation features of PVOPTICS. This section describes PVOPTICS and the module specifications that resulted from the use of this model.

\subsubsection{Description of PVOPTICS}

The complex interaction of components in a point-focus photovoltaic concentrator module necessitates the use of computer-aided design and engineering techniques. PVOPTICS provides the ability to simulate this complex interaction and to estimate the performance of single cell units comprising a primary tens. at secondary optical element (SOE), and a photoroltaic cell. PVOPTICS uses geometric optics to trace the path of photons from the sun through the lens and ultimately to the cell. The performance calculations and power output estimates are based on Monte Carlo calculation techniques. The analysis routines use appropriate mathematical algorithms for sun and material spectral and optical properticen ats well as the cell's photovoltaic characteristics. The imput data are defined by direct entry and option selection from a menu screen, an example of which is shown in Figure 3-t. 


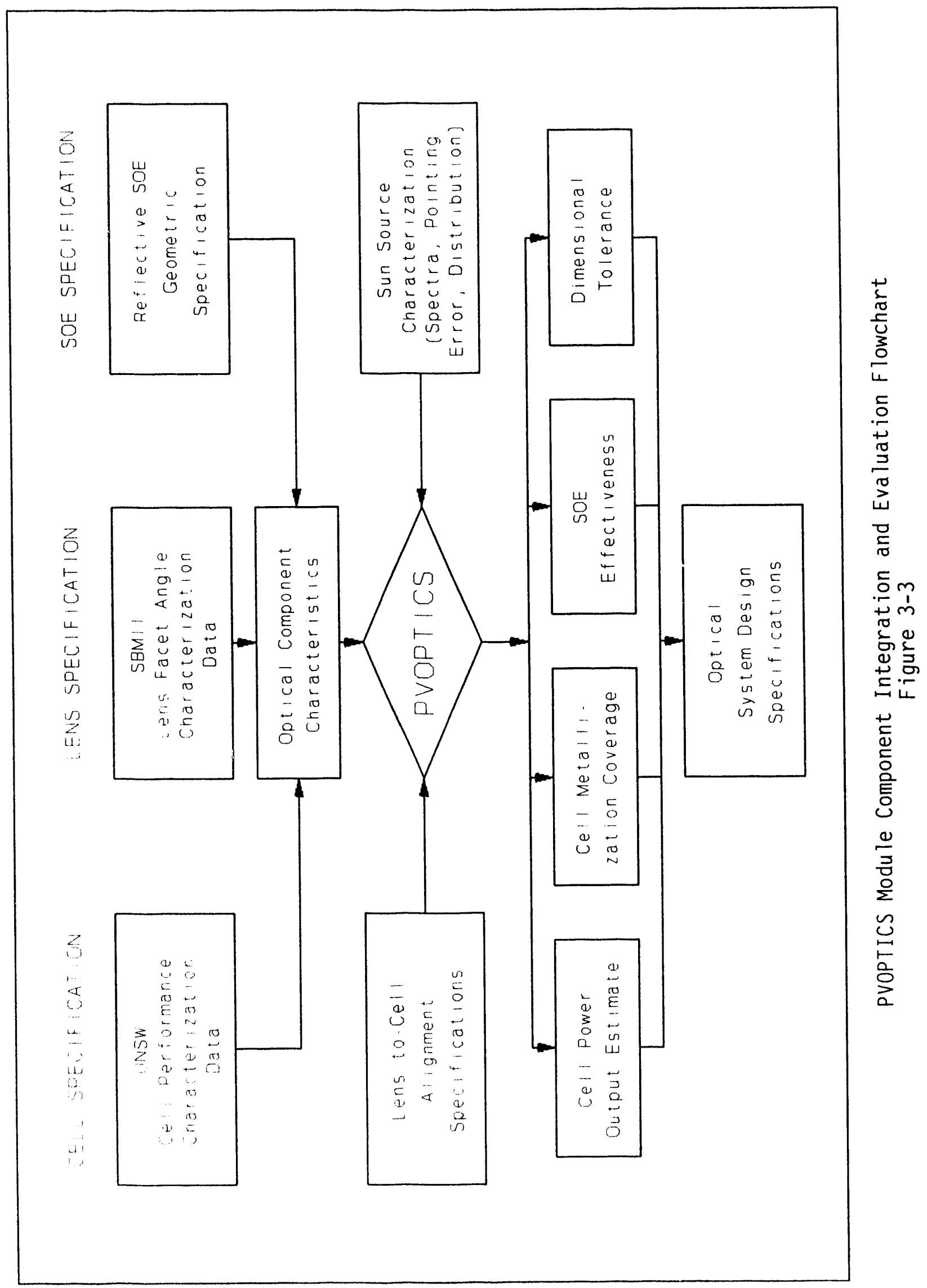


PV RA A T T A C E DATA D D P T I D N

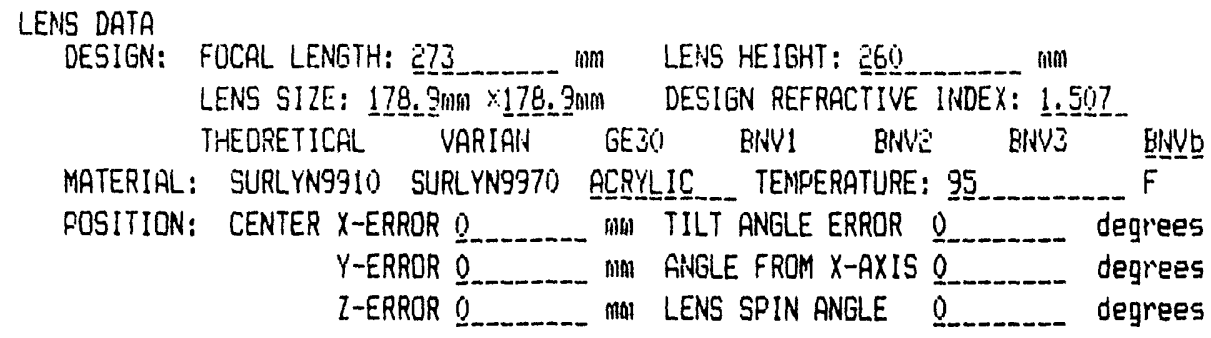

SOE/CELL DATA

SOE: ANGLE ENTRY 30...._..... deg/mim HEIGHT: $16 \ldots$

EXIT APERTURE: $12 \ldots \ldots \ldots$ RADIUS: 100000

CELL DESIGN: EPRI UNISW SDE MAT: Al AU Ag REFL:

SUN DATA

FOINTING ANGLE ERROR: $\underline{0}_{2} \underline{1}_{2} 5$ deg DISTRIBUTION: UNIFORM LIME-DARKENED ANGLE FROM X-AXIS: $\underline{Q}_{1} 4 \underline{E}_{2} E_{2}$ deg SFECTRUM: ASTM AIOL A1OH AISH AZOL R2OH

SYSTEM DATA

INUMBER OF RAYS: 1000 INSULATION: $0.8 \ldots \mathrm{kw} / \mathrm{m} * 2$ LENS EFFICIENCY: 0.85

CELL ELEMENTS: 100_ TEMPERATURE: $27 \quad 47 \quad 67 \quad 87 \quad 107 \quad 127 \quad \mathrm{C}$

RANDOM LINK: 12345ET7890 CAPTURE FROE: ON OFF EXPUNGE: ON OFF

OUTPUT DFTIONS

FRIIT: EVHENU CESEID RAYEATH ELUXDIST ELUXSTAT

STORE: PUDATA RAYFATH FLUXDIST FLUXSTAT CELLFTS LAMDA SUNFTS LENSFTS

DATE: $3 / 18 / 87$ TIME: 09:16 LIBId: C: WISGROUPS WSId: 4 PVOPTJRF

CASE COMMENTS:

Meru screen print with enhancements

PVOPTICS Menu Sireen

Figure 3-t 
PVOPTICS simulates the illumination pattern on a cell surface produced by a lens and reflective SOE for a specified alignment of components and orientation to the sun. A cell performance model estimates the power output that would result from the illumination pattern. Thus, PVOPTICS provides an estimate of expected cell power output for a specified solar power spectrum, sun spatial distribution, and module configuration. Typically, PVOPTICS performance estimates are stated as a "relative performance index." This measure conveys the same information as power output, but is normalized to the maximum possible power output associated with the geometric concentration, lens transmission, and uniform cell illumination characteristics.

Several new features were added to PVOPTICS to more accurately model the module components for this project. These features include the addition of two cell performance models for the UNSW cell, several spectral insolation models, and new SOE design tools.

\subsubsection{Lens-to-Cell Spacing Analysis}

As lescribed in the previous section. PVOPTICS analysis indicates that a

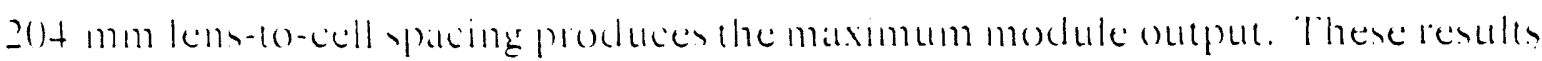
were obtained from relative performance comparisons of UNSW cells with prismatic covers under nonuniform illumination. Section 3.2 .4 provides a description of this cell model. Slight deviations from the design lens-to-cell spacing are estimated to have minimum impact on module performance. Devations of $\pm 1 \mathrm{~mm}$ result in a 0.4 -percent performance degradation: while deviations of $\pm 2 \mathrm{~mm}$ result in a 1.2 -percent performance degradation.

\subsubsection{Secondary Optical Element Design}

The secondary optical element (SOE) concept selected for the prototype module is a four-sided reflective component fabricated of anodized aluminum in a cut-and-fold operation. Other design concepts, such as total internal reflective glass SOE's and imaging glass SOE's were considered, but were regarded as too too costly to develop for this project. Figure 3-5 displays the final SOE dimensional specifications. The procedures for development of this specification are discussed below.

Three SOE design parameter's were evaluated with PVOPTICS: slope, height, and exit aperture. The slope is the angle between the cell normal and the inner surface of the SOE. The SOE height is measured from the cell plane perpendicular to the SOE entrance aperture. The exit aperture is measured 


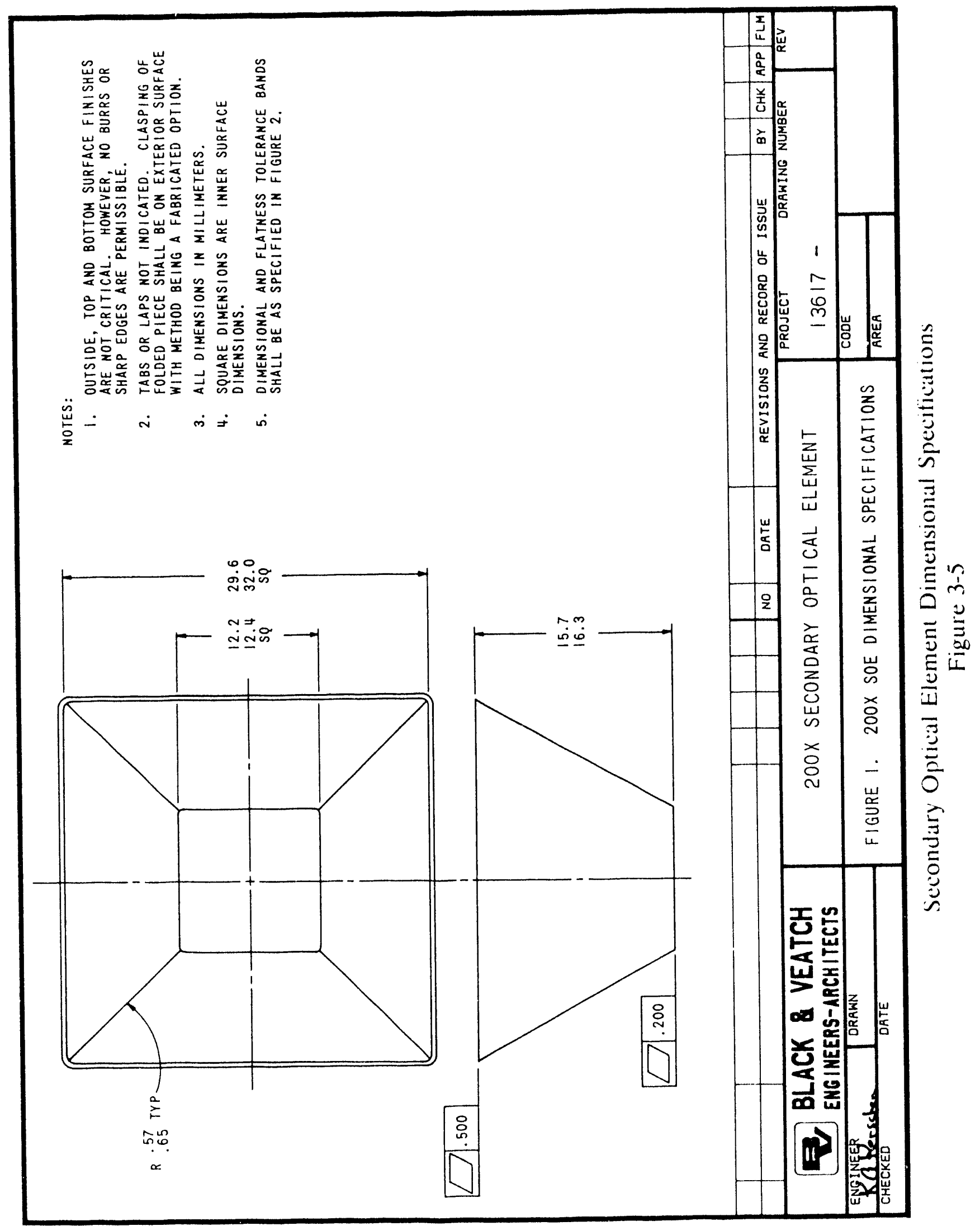


across the bottom plane of the SOE. Several considerations influence these design chanacteristics. The most important consideration pertains to the geometrical relationship between the lens, SOE, and cell. Additional considerations include the incidence angles of rays striking the SOE surface and reflecting to the cell surface as these angles influence the optical efficiencies of the SOE and the anti-reflection coating or the prismatic cover on the cell. For these (lesign activities, a constant 82 percent specular reflectance for the aluminum SOE has been assumed. Finally, other considerations of SOE design are the allowances for manufacturing and placement colerances of the SOE.

The SOE angle selection was hased on PVOPTICS performance estimates and SOE design interaction with the cell prismatic cover design. Performance estimates are relatively insensitive to variations in the SOE angle between the range of 24 to 36 degrees, though larger angles are favored as the sun pointing error increases. Prismatic cover design requirements are less stringent when reflected rays strike the cell cover at steep angles. This criterion favors the SOE's with smaller angles (steeper slope). The 30 (legree angle was selected to give better performance at larger pointing errors and for its compatibility with pismallic corces.

The criterion for determining the SOE height wats to rellect all rays toward the cell for sun pointing errors less than 0.75 legrees. The combination of module tracking errors and component alignment allowances are not expected to exceed this total. The $16-\mathrm{mm}$ (0.63-inch) SOE design height meets this condition.

SOE exit aperture dimensions were selected to allow for fabrication tolerances and placement errors of the SOE on the cell surface so as not to expose inactive cell area. The expected fabrication tolerances for the exit aperture is $\pm 0.1 \mathrm{~mm}$, and the expected placement tolerance is $\pm 0.2 \mathrm{~mm}$. A $12.3-\mathrm{mm}(0.48$-inch) SOE exit aperture was selected to meet an RMS error budget for tolerance and placement requirements.

\subsubsection{Cell Performance Models}

PVOPTICS capabilities include both a basic and an enhanced performance model for estimating the relative performance of solar cells under simulated operating conditions. The two models vary in complexity and application. Both models apply the solar cell spectral responsivity to the incident spectral irradiance to establish the "effective" spectal distribution as utilized by the cell. The features and distinctions of these two cell models are described below. 
The basic cell model considers the cell as a set of subcells operating independently and contributing individually to the total power output of the cell. The cell efficiency is modelled for the expected range of concentration levels. Geometric ray tracing establishes a point pattern on the cell surface indicating where each photon of the Monte Carlo simulation strikes the cell. This simulated illumination pattern (typically nonuniform in distribution) is divided into its subcell constituents and is translated into concentration levels. Then, table lookups establish efficiency values for each subcell. The model calculates the electrical power for the cell as the sum of the subcell powers, which are determined from the incident powers and the operating efficiencies. Performance estimates from this model are obtained quickly and are used mainly for comparative analyses.

The enhanced cell model uses the simulated illumination pattern along with cell model algorithms developed by Dr. Paul Basore at Sandia. Localized photogenerated current densities are calculated from the point pattern and are coupled with cell physical and electrical characteristics to determine the base, emitter, and grid losses. The enhanced model was developed to evaluate and relect the preterted metallization corcrage for a prismatically covered Livsw solar cell. Prismatic cover efficiency was assumed to be constant for all metallization coverages. A more detailed description and case analysis of the enhanced performance model is provided in Appendix $A$. The application of this performance model to optimize the cell metallization coverage is described in the following section.

\subsubsection{Prismatic Cover Considerations}

It is widely publicized that prismatic covers placed on the cells of linear-focus, low-concentration photovoltaic modules improve the module performance." However, prismatic covers have not been designed for, nor applied to, cells of high-concentration point-focus modules which generate larger current densities and require a finer gridline structure than do cells of low-concentration linearfocus modules. The project team investigated the potential for improved performance of the prototype module shouid prismatically covered cells be used.

In principle, prismatic covers provide two major performance benefits. The primary benefit is the elimination of shadow losses of the cell grid lines. In addition, lower I'R losses in the grid lines are anticipated due to the higher allowable cell metallization coverage. Concentrator cell researchers conservatively estimate that a 10 percent performance improvement could be 
attained with prismatically covered cells as compared to the performance of an uncovered 6-percent metallized cell.

Black \& Veatch developed an enhanced PVOPTICS performance model to estimate the cell power output for nonuniform illumination on cells with metallization coverages from 6 percent to 21 percent. Cell power output is estimated by calculating the series resistance in the base, emitter, and grid of the cell model. This model is described in Section 3.2.4. The model assumes that the prismatic cover performance is uniform over the entire cell surface and for all module tracking conditions. It does not include the refractive effect of a prismatic cover.

Figure 3-6 summarizes the results of the cell performance analysis for metallization coverages from 6 percent to 21 percent. These curves display an obvious "diminishing returns" characteristic. For example, increasirs the metallization coverage from 6 percent to 15 percent shows a cumulative efficiency improvement of about 15 percent for the nonuniform illumination condition. However, the additional benefit of increasing the metallization coverage from 15 percent to 17 percent is less than 0.8 percent.

In a separate effort. Entceln developed a new prismatic conce design for this applacition. Sardia and Black \& Veatch provided data to Entech on the expected distribution of incidence angles on the cell surface for this point-focus application. Entech's analysis showed that the new cover should completely illuminate the active area of a 15 percent metallized cell in this application.

On the basis of these analyses, Sand a and the project team decided to pursue the use of prismatic covers on the UNSW cells for the prototype module. A 15 percent metallization coverage was selected for cells in this application. Because no previous experience exists in the design or placement of prismatic covers on point-focus concentrator cells, any slight performance improvements for metallization coverages above 15 percent may be more than offset by the possible decreases in prismatic cover efficiencies that are more likely with more highly metallized cells.

These analyses guided the cell gridline specifications for the UNSW cell. The UNSW cell metallization design was defined as parallel grid lines of $19-\mu \mathrm{m}$ $(0.75$-mil) width on $127-\mu \mathrm{m}(5$-mil) centers. The grid line cross-sectional area for this design was detined as $125 \mathrm{\mu m}^{2}$, roughly equivalent to a hemispherical cross section. 


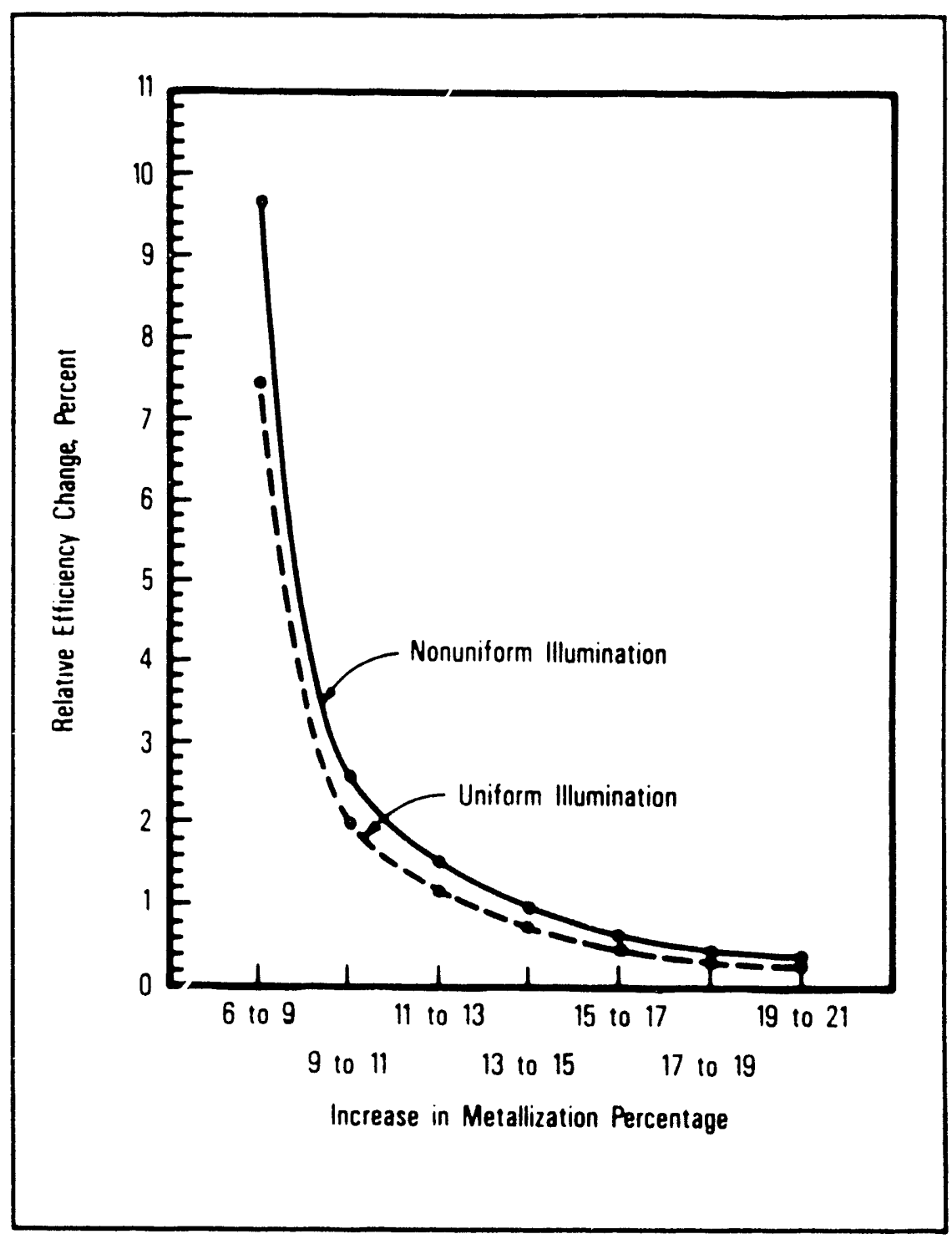

Relative Efficiency Change for Metallization Increases Figure 3-6 
Performance tests were conducted by Sandia on the "module-ready" cells as received from UNSW and during the assembly process. The results of these tests are presented in Section 4. The measured performance improvement of prismatically covered cell assemblies was significantly less than the anticipated 15 percent improvement. The average improvement for seven prismatically covered cells was about 10 percent, with a wide range of individual cell improvements from 6 percent to 15 percent.

\subsection{MODULE STRUCTURAL DESIGN AND ANALYSIS}

The module structural design objective was to verify the applicability of the baseline structural design for the $185 \mathrm{X}$ module by conducting analysis and testing. Analyses were performed in three principal areas: housing strength, housing bottom buckling, and parquet deflection. Tests were performed to establish material response to expected operating conditions for thermally induced buckling of the housing bottom, and gasket material and thermal adhesive selection. In addition, designs were developed for the parquet-to-housing clip and the module air breather. These activities are described in the following sections.

\subsubsection{Housing Strength Analysis}

Housing strength was evaluated for two configurations of a 24 -cell module. One module configuration was 2 cells wide by 12 cells long, the other was 4 cells wide by 6 cells long. The housing material was selected to be 20-gauge (0.036-inch) sheet steel. The analysis included two parquet support stringer options: sheet metal bulkheads and wire bar joists. The strength and deflections were calculated for the structural portion of the module. This portion included the housing, the internal support stringers (sheet metal or wire bar joists) and the acrylic lens parquet.

The analysis considered survival loads of $1200 \mathrm{~Pa}(25 \mathrm{psf})[42 \mathrm{~m} / \mathrm{s}(95 \mathrm{mph})$ winds|, and strength and operating loads of $100 \mathrm{Pit}(2 \mathrm{ps})[12 \mathrm{~m} / \mathrm{s}(27 \mathrm{mph})$ winds]. For survival loads, buckling analysis of the sheet steel was considered a primary failure mode candidate. In most of these analyses the bottom was considered as a flat sheet, that is without corrugations. Final analysis also considered a corrugated bottom. In addition to the wind loads, gravity loads of $500 \mathrm{~Pa}(10.5$ pst) for the 2 by 12 molule and 4.50 Pa (9.3 pal) for the 4 hy 6 module were also considered. Allowable shear and compressive stresses were calculated according to the American Iron \& Steel Institute's "Cold-Formed Steel Design Manual": 1977 and 1980 editions.? 
3.3.1.1 4 by 6 versus 2 by 12. The analysis indicates that both modules were capable of withstanding the survival loads. The lighter weight of the 4 by 6 module and the availability of a 4 by 6 lens parquet led to designating the 4 by 6 as the module of choice from strength and cost criteria.

The 4 by 6 modules were quite stiff, and deformation of the module due to bending and shear was calculated to be less than $0.05 \mathrm{~mm}(0.002$ inch) with a $(.1$ mrad rotation at its ends under survival loads. Thus the slight deformation under operating conditions would cause no performance degradation. The 2 by 12 module maximum deformation was $0.26 \mathrm{~mm}(0.010 \mathrm{inch})$ with a 0.4 -mrad rotation at its ends under survival conditions.

The analysis of the module's strength and deformation was with a torsional load on the module and a three-point support used between the module and the tracking array structure. Typically, the tracking array structure would provide the support for 100 or so modules. A three-point support isolates the module from torsional loads induced by array deformation, whereas a four-point module support couples the module deformation to the array deformation. The stress levels in the steel and acrylic were acceptably low for both the 2 by 12 - and the + hy (6)-module configuratlom.

3.3.1.2 Parquet Support Options. Bar joist stringer supports formed by $3.2-\mathrm{mm}$ (0.125-inch) steel wire were preferred over 20-gauge $(0.036$-inch) steel sheet because of a weight advantage, $0.45 \mathrm{~kg}(1 \mathrm{lb})$ compared to $2.3 \mathrm{~kg}(5 \mathrm{lbs})$. Analysis of bar joist strength showed that a single-wire bar joist would not buckle under the combined bending load and wind load transferred from the rather flexible acrylic parquet.

An analysis was made to estimate the effect of a corrugated bottom on module stiffness and deformation. This analysis indicated that the reduced long axis (longitudinal) module bending stiffness caused by corrugating the bottom would increase the load on the stringer supports so that the buckling load on the diagonal member of the bar joist would have a safety factor of 1.27 -a value considered too low. Use of 4.8 - $\mathrm{mm}(0.188$-inch) wire for the diagonal ruises the safety factor to an acceptable value, 6.4, with only minor increase in bar joist weight, from $0.45 \mathrm{~kg}$ (1 lb) to $0.59 \mathrm{~kg}(1.3 \mathrm{lbs})$.

Because of deformation of the acrylic parquet and stress levels at its support points. it was determined that the use of three stringers is preferted. The use of the $4.8-\mathrm{mm}$ diagonal wire for the bar joists provides stiffness that would keep deflection of a flat housing bottom at contact points with the bar joist below $0.12 \mathrm{~mm}$ ( 5 mils) under survival wind conditions. This analysis indicates that a 
flat bottomed housing would be acceptable. If three bar joists were used the small size wire would be acceptable for the bar joist diagonals.

\subsubsection{Housing Bottom Thermally Induced Buckling Analysis and Testing}

A concern of using a flat-bottomed housing was the possible oil can buckling deformation that could occur in the bottom between support points. If it occurred, this buckling would result in changes in the lens-to-cell spacing and degradation in the module performance. It would be induced by the higher temperature that exists at the center of each cell unit in the roughly $178-\mathrm{mm} x$ 178 - $\mathrm{mm}$ (7.0-inch $\times 7.0$-inch) area of the module with the cell at its center. The three bar joist trusses support the bottom at grid points on $178-\mathrm{mm}$ (7.0-inch) centers, but the thermal expansion along the center-line of each cell unit is greater than the thermal expansion along the boundary of each cell unit.

Because thin plate buckling analytical methods were very elaborate and not reliable, testing was conducted at Solar Kinetics to determine if thermally-induced buckling would occur. The bottom of the housing with its grid support by bar joists was simulated by a $585-\mathrm{mm}$ (23-inch) square steel sheet supported on 10-32 studs sel at 178-mm (7.)-inch) grid points. This shect simulated a 3 by 3 alltil. Electric heaters mounted in copper blocks were used to provide the thermal load and simulate the heat from the cell package and the heat spreader, respectively. Figure 3-7 displays the experimental setup. A coordinate measuring machine was used to measure the deformation; thermocouples were used to measure the sheet temperature.

Several tests were conducted with 18-gauge steel (0.048-inch) and 20-gauge steel (0.036-inch). Deformations were measured for flat plate and corrugated material simulating the housing bottom design options, with and without heat dissipitors attached to the outer surface. The advantages of using 20 -gauge steel over 18-gauge steel for the housing were a $5-\mathrm{kg}(11-\mathrm{lb})$ weight advantage, a 25-percent materials cost reduction, and lower weight to be carried by the array structure.

Initial tests made without heat dissipators showed rather high temperatures and deformation. Temperatures measured with heat dissipators in place indicated temperatures reached levels in concert with analysis done by B\&V in its EPRI project. Those calculated thermal levels were confirmed by experimental tests carried out at Pacific Gas \& Electric's solar test facility under the EPRI project.

SKI test results indicated that flat-bottomed 20 -gauge steel modules would be unacceptable due to vertical deformations of $1 \mathrm{~mm}(0.039 \mathrm{inch})$ with 30 watts 


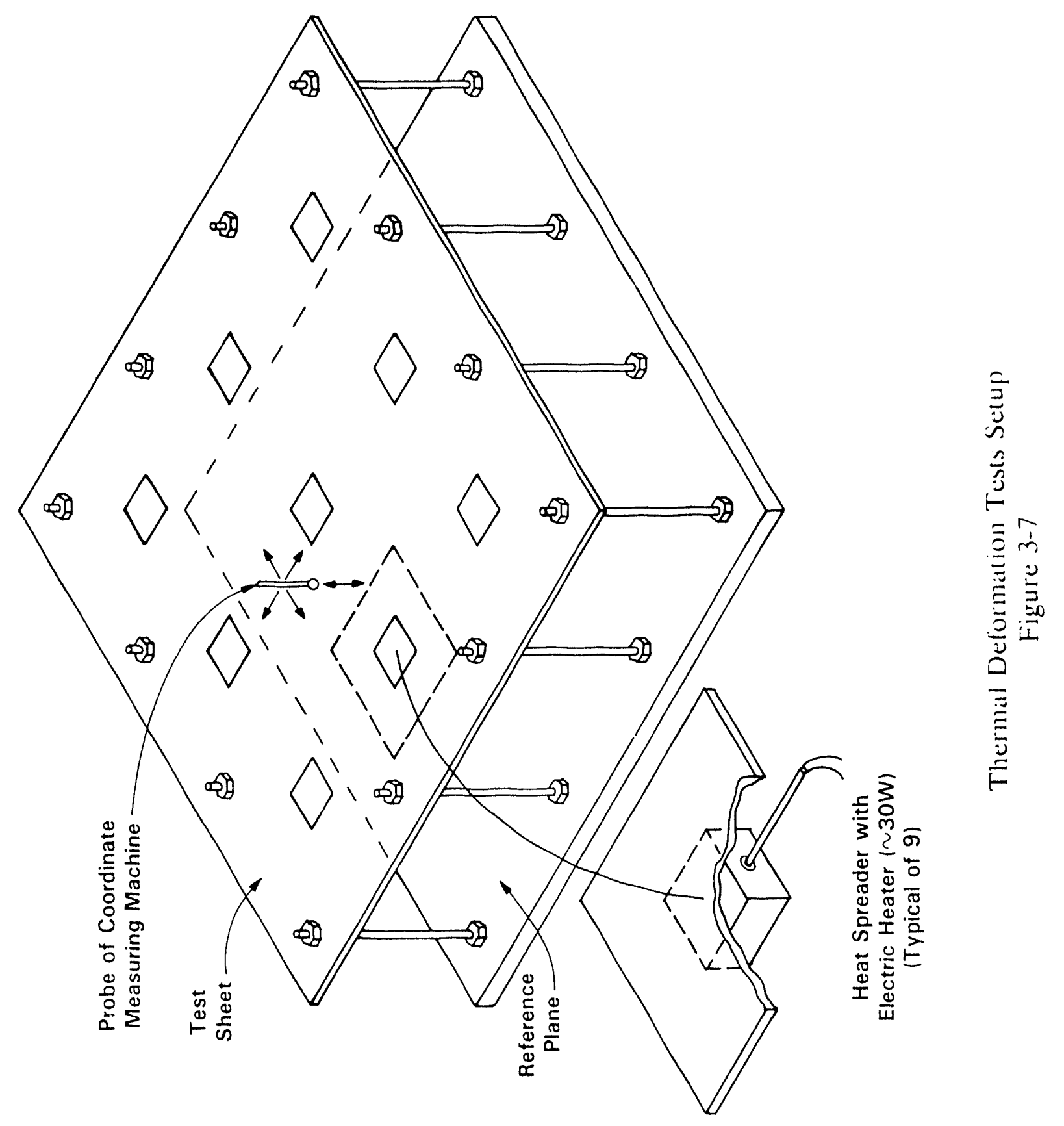


thermal input. The use of 18-gauge steel showed acceptable deformation levels of the order of $0.1 \mathrm{~mm}(0.003 \mathrm{inch})$. These experiments were also applied to the corrugated design 20-gauge steel. Vertical deformations of less than $0.25 \mathrm{~mm}$ (0.010 inch) were observed with 30 watts thermal input. The 20-gauge steel housing with corrugated bottom was selected for the module.

\subsubsection{Parquet Deflection Analysis}

A scoping analysis was conducted to establish the bounds of parquet surface dislocation due to wind loads. Module performance may be impaired due to lens cupping between parquet support points. Sandia has measured significantly different flux patterns for $3 \mathrm{M}$ fabricated lenses due to cupping or bowing of the lens.

A parquet distortion analysis was performed for candidate parquet support conditions for a range of thin $(1.5 \mathrm{~mm}$ [.063 inch]) to thick $(4.7 \mathrm{~mm}[0.188 \mathrm{inch}])$ parquet thickness. For these analyses the main measure of performance was the deflection of the lens center point. The load on the parquet was assumed to be uniform and caused by wind pressure. Under operating conditions of $12-\mathrm{m} / \mathrm{s}$

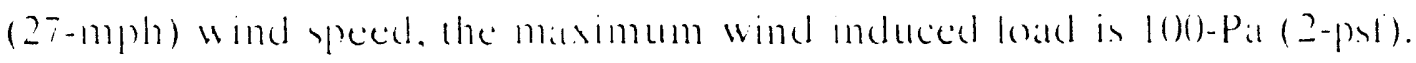

The support of the parquet edge at the housing rim is in reality an elastic surport depending on the housing. Two edge conditions were considered: cantilever (built in stiff edge) and simply supported (free to rotate at the edge). These two cases correspond to a lower bound on deflection (best case) and an upper hound on deflection (worst case), respectively. Simplified plate theory and finite element analyses were used in the calculations.

These calculations indicated that deflections of approximately $0.3 \mathrm{~mm}$ (0.012 inch) are expected for a $4.7-\mathrm{mm}(0.188$-inch) thick parquet with a single bar joist supporting the parquet on "points" every $178 \mathrm{~mm}$ ( 7 inches). The use of three such bar joists would reduce the deflection to $0.03 \mathrm{~mm}(0.001$ inch $)$ for the thick parquet. Deflections of approximately $0.2 \mathrm{~mm}(0.008$ inch) were calculated for the 2.4- $\mathrm{mm}$ (1).(1)9-inch) thick parquet with three bar joists supports.

\subsubsection{Parquet Clip Design}

The parquet spring clip provides compressive force to secure the parquet edge against the sealant and housing rim. The clips were designed and fabricated by Solar Kinetics from 22-gauge (0.030-inch) type 302 stainless steel sheet, 1/2 hard. Figure 3-8 displays the spring clipped elge configuration. 


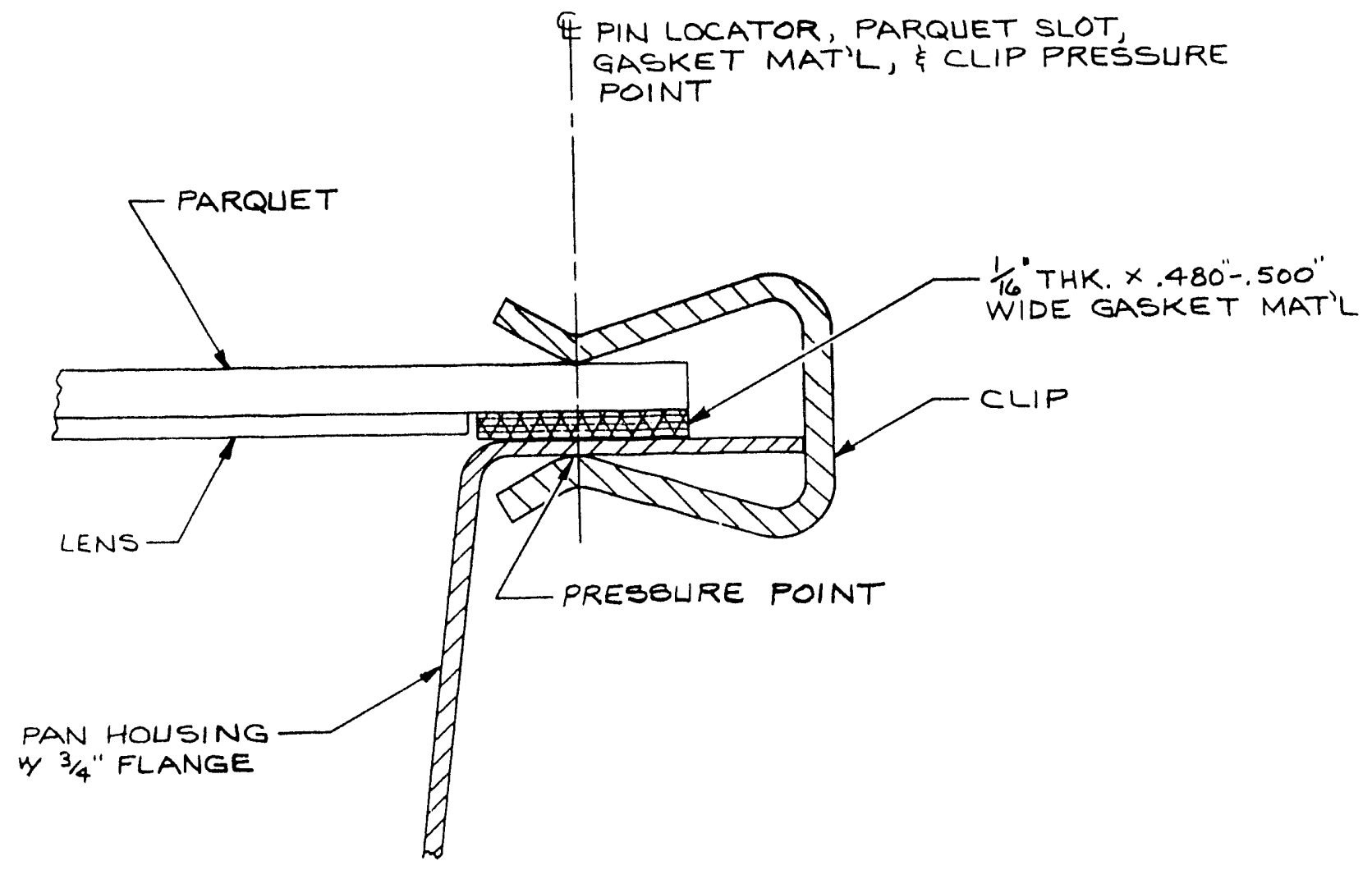

Spring Clipped Edge Configuration

Figure 3-8 


\subsubsection{Air Breather Design}

Black \& Veatch prepared an air breather design for use in modules with 20-gauge steel housing of $0.91-\mathrm{mm}(0.036$-inch) thickness. Figure 3-9 displays the design specifications for the air breather as provided in Black \& Veatch drawing 13617-SKM0001. This design was developed for use by the prototype module and the Alpha Solarco module. The air breathers are fabricated of EDPM rubber.

\subsubsection{Parquet Gasketing Material Selection and Tests}

Solar Kinetics conducted tests on gasket material products considered as parquet-to-housing sealant candidates. The objective of this testing activity wat to determine the compressive characteristics of the candidate gasket materials. Compressive yields were measured for loadings up to $100 \mathrm{psi}$. Sealants that exhibit a force-versus-compression curve with near-zero slope are necessary to maintain the preferred lens-to-cell separation.

Samples of five products were obtained for testing. Two products, $1.0-\mathrm{mm}$ (0.040-inch) thick $3 \mathrm{M} 1202 \mathrm{~T}$ and $1.6-\mathrm{mm}(0.063$-inch) thick 3M 1202T-NS, were made of butyl rubber. Two products, $3.0-\mathrm{mm}(0.12$-inch) thick $3 \mathrm{M} \mathrm{Y}-4959$ and

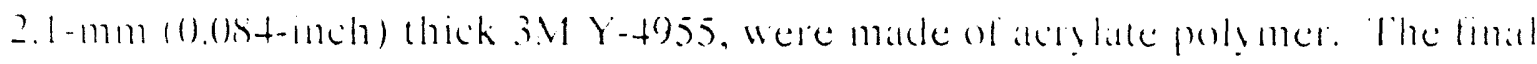
product. $0.91-\mathrm{mm}$ (0.036-inch) thick Unimica 150, was made of an undectared foam. The $3 \mathrm{M} 1202 \mathrm{~T}$ thick butyl rubber sealant was embedded with a loose woven fabric material, called scrim, that was reported to add dimensional stability by limiting the compressive action. Initial testing resulted in the selection of the three sealants for further evaluation: $3 \mathrm{M} Y-4955,3 \mathrm{M} 1202 \mathrm{~T}$, and $3 \mathrm{M} 1202 \mathrm{~T}-\mathrm{NS}$.

Additional testing was conducted on the 3M 1202T-NS for creep deformation and flow characteristics in the shear plane. These tests simulated the effects of long-term compression and differential thermal expansion of the mating surfaces. respectively. Both tests indicated unacceptable performance for this product. These tests were not performed on the $3 \mathrm{M}$ scrim sealant tape because $3 \mathrm{M}$ discontinued manufacturing the scrim sealant in $1.0-\mathrm{mm}$ (0.04()-inch) thickness. The $3 \mathrm{M} 1202 \mathrm{~T}$ tape was only available in $3.2-\mathrm{mm}(0.125$-inch) thickness which was considered too thick for use as the parquet-to-housing sealant.

The $3 \mathrm{M} \mathrm{Y}-4955$ sealant tape was selected for use as the parquet-to-housing sealant because of acceptable performance under compressive loads. 


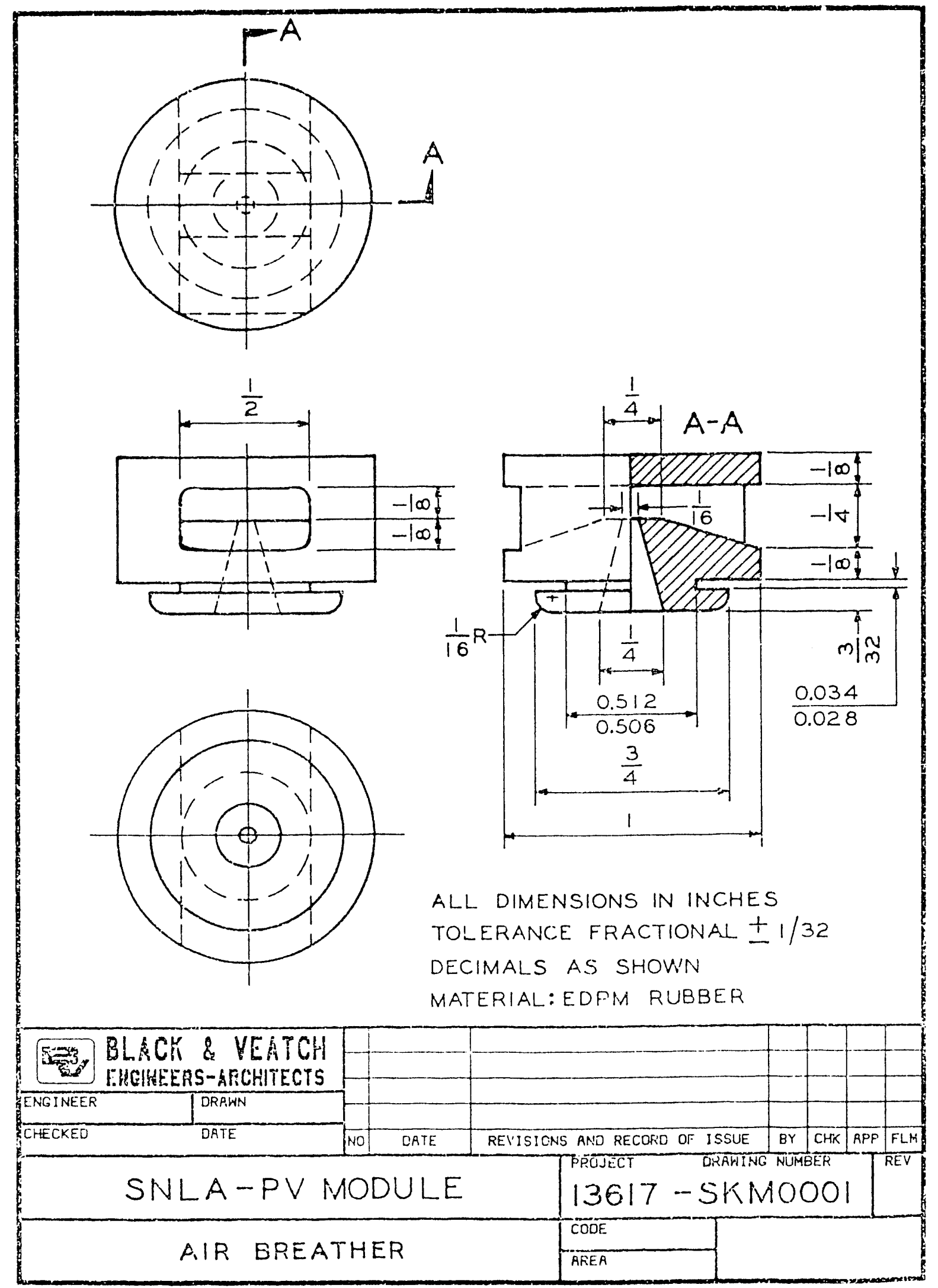

Module Air Breather Design Drawing

Figure 3-9 


\subsubsection{Thermal Adhesive Selection and Tests}

Solar Kinetics conducted a series of tests to select a thermal adhesive for bonding the cell assemblies to the housing bottom and the heat dissipators to the outside housing surface. Selection criteria included compatibility to aluminum and copper, high thermal conductivity, thin bonding properties, no post-cure outgassing, appropriate cure and service temperature, and low solar absorptivity. Epoxides, acrylics, and silicones were considered. In order to test the adhesives under conditions similar to actual service, the adhesive bonds hetween the copper heat spreader and the aluminized steel were subjected to a 30-watt thermal load.

Preliminary testing with square heat spreaders bonded by epoxy and acrylic adhesives resulted in bond failure or severe corrosion under less than 30 watts and only gravity load. Localized heating and differential expansion of the copper and steel resulted in concentrated stress on the corners of the copper heat spreaders. The heat spreader design was changed from square to round to eliminate corner stress concentrations, and epoxy and acrylic adhesives were abandoned in favor of the more flexible silicone adhesives.

Several silicone adhesives were tested under thermal loading and tensile loatding conditions. Non of the silicones exhibited sittifictory temperatture and bonding strength characteristics. Two candidates were selected for further examination: DOW 3140 (one part silicone with 50 percent aluminum oxide) and Shin Etsu X-31-751 (one part thermally conductive adhesive).

The Shin Etsu product was analyzed by Sandia to confirm the fill material and percent composition. These analyses indicated a 60 percent by weight fill of aluminum oxide. A desirable characteristic of this adhesive was the fine, uniform size of the fill particles. Particle sizes ranged from $2-5 \mu \mathrm{m}(0.08-0.20 \mathrm{mils})$. The Shin Etsu X-31-751 thermal adhesive was selected for use in the module because the small, uniform aluminum oxide particles should lead to easily controlled, minimal bond thicknesses.

\subsection{MODULE ELECTRICAL DESIGN AND ANALYSIS}

The prototype module electrical design was developed as an extension of the existing electrical designs for similar concentrator systems. The module electrical design emphasis was to develop improved fabrication procedures for the cell assembly while maintaining acceptable electrical and thermal pertormance. The final design was developed as the result of numerous fabrication procedures and testing to attain a module desgn that met the core qualification requirements established for photovoltaic concentrator cell assemblies and modules. ${ }^{\text {. }}$ 


\subsubsection{Cell Assembly Design and Analysis}

The cell assembly design selected for the prototype module was based on the cell assembly design developed by Black \& Veatch for the EPRI high concentration array project. The cell assembly consists of a solar cell, its electrical terminations, a secondary optical element, and a cell mount which includes a high-soltage insulator and a heat spreader. The assembly is then mounted as a unit in the module housing. Figure 3-10 is Spire's Drawing C164-0)(0)2 of the concentrator cell assembly.

3.4.1.1 Design Baseline. The cell assembly design baseline utilizes a $0.51-\mathrm{mm}$ (0.020-inch) thick alumina substrate with direct-bonded copper metallization on both sides to provide the electrical isolation and thermal path between the cell and the copper heat spreader. A solder bond attaches the back-side contact solar cell to the top of the substrate and the heat spreader to the bottom of the substrate. Electrical contact to the cell back surface is made by the same copper layer that is bonded to the top of the alumina substrate.

An alumina insulator was chosen over other substrate materials, such as beryllia and boron nitride, hecause of a balance in engineering and economic conviderations. Alumina providen the needed combination of electrical iesistant? and thermal conductivity at a relatively low cost.

The use of direct-bonded copper on alumina was chosen over thick film metallization as the substrate metallization because of the thicker copper layers attainable with direct-bonding. Thicker copper reduces the $I^{2} R$ losses in the back side cell connection. Another benefit to direct-bonding is the formation of chemical bonds (copper oxides) during the honding process, which results in it very high strength bond, about $68 \mathrm{MPa}(10,000 \mathrm{psi})$.

This baseline design was modified for the larger size and conventional bifacial electrical contact design of the UNSW cell. The larger substrate design must accommodate greater thermal stresses due to the differential thermal expansion between copper and alumina. A copper tab was designed to be soldered to the cell's front contact that minimizes $I^{2} R$ loss, maintains low stress on the cell metallization, and provides redundancy through the use of multiple parallel leads.

3.4.1.2 Solder Selection. The two major issues identified as potential problems for the cell/substrate and substrate/heat spreader solder joints were fatigue-induced failure and voids in the solder. Proper choice of solder alloy minimises the fatigue problem for a given joint geometry, while proper soldering process minimizes the presence of voids. 


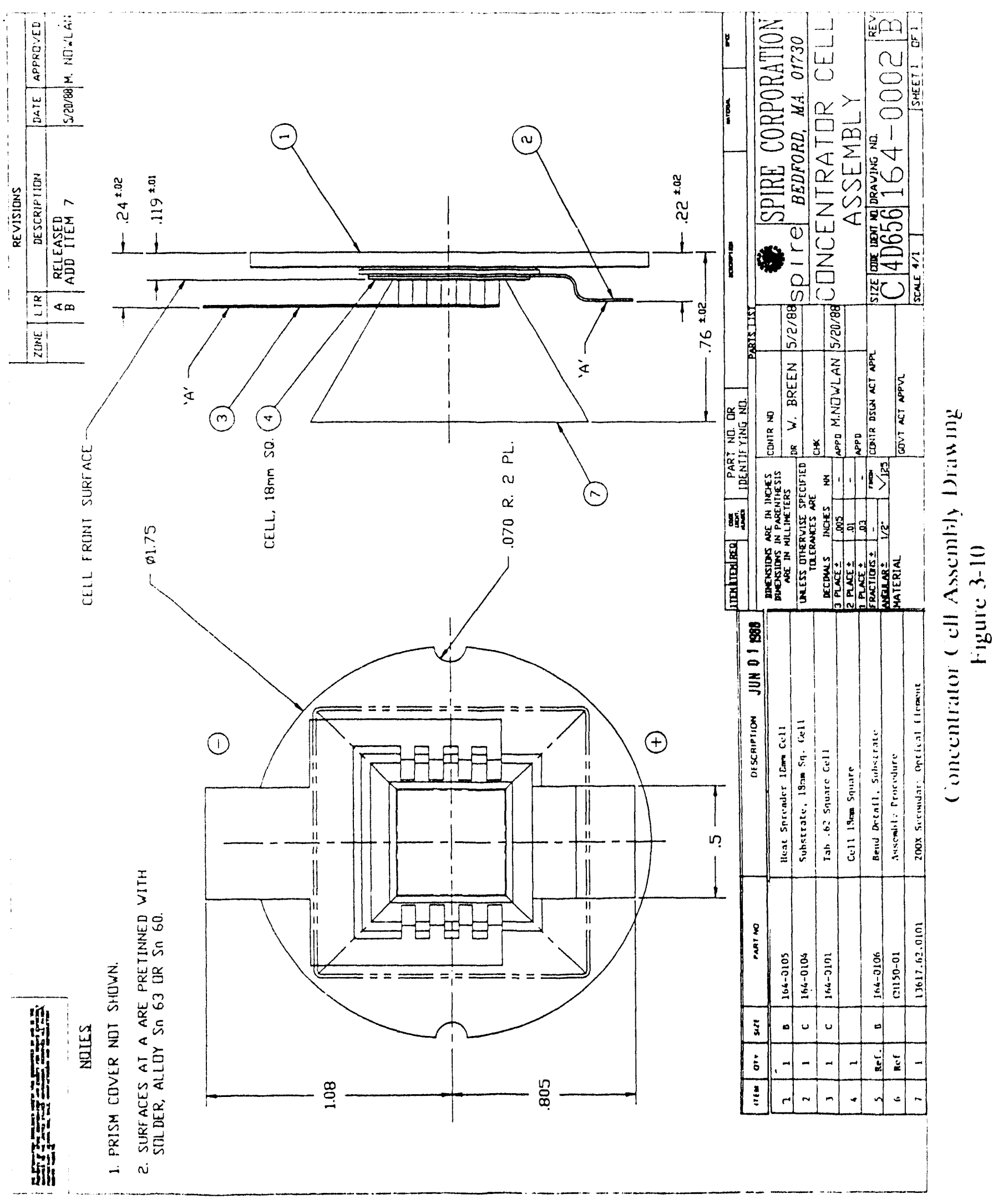


A pre-tinning approach was selected hecaluse of the large areas ineing soldered. Parts were precoated with solder either by electroplating or by hot timning in the presence of flux. Flux wan removed from all surfaces prior to joining the parts by solder reflow, thus avoiding flux inclusions.

A list of candidate solders is provided in Table 3-1. Alloy Sn62 is a standard electronics solder for use on silver contacts. The remaining alloys have been suggested by various sources for their improved fatigue resistance.

\begin{tabular}{|c|c|c|c|}
\hline \multicolumn{4}{|c|}{$\begin{array}{c}\text { Table 3-1 } \\
\text { Cell Assembly Candidate Solder Alloys }\end{array}$} \\
\hline Alloy & Composition & Solidus/Liquidus $\left({ }^{\circ} \mathrm{C}\right)$ & Status \\
\hline $\operatorname{Sn} 62$ & $62.5 \mathrm{Sn} / 36.1 \mathrm{~Pb} / 1 .+\mathrm{Ag}$ & 179 eutectic & Selected \\
\hline $\operatorname{Sn} 96$ & $96.5 \mathrm{Sn} / 3.5 \mathrm{Ag}$ & 221 eutectic & Selected \\
\hline Indalloy 151 & $5 \mathrm{Sn} / 92.5 \mathrm{~Pb} / 2.5 \mathrm{Ag}$ & $287 / 296$ & Selected \\
\hline Indialln! 7 & (1) 五 & $2(1) 18(1)$ & Rejected \\
\hline In(latlon 29) & $97 \ln 3.3 y$ & $1+.3$ culcetic & Rejected \\
\hline Indalloy 164 & $92.5 \mathrm{Ph} / 5 \mathrm{ln} / 2.5 \mathrm{Ag}$ & $30(0 / 310$ & Rejected \\
\hline
\end{tabular}

Alloys $\operatorname{Sn} 62, \operatorname{Sn} 96$ and Indalloy 151 were selected for preliminary evaluation. Sn62. with its atatively low melting point $\left(179^{\circ} \mathrm{C}^{\circ}\right.$ ) cutectic, provided a baseline alloy to compare with other solders. The results of thermal cycling of similar assemblies with this alloy at the University of Missouri indicate that solder joints with a low void fraction were possible.

Alloy $\mathrm{Sn} 96$ was recommended hy J. Devore at General Electric as haring superior fatigue resistance to Sn62. Testing (lone at General Electric showed that, in certain configurations, it was posshle to ohtain a filctor of 3 increase in solder bond life. Similar results were also reported by Bendix (Allied Signal).

Indalloy 151 was recommended for its fatigue resistance by $C$. Neugehauer at General Electric. Its use was also heing investigated by L. Beavis and C. Chiang at Sandia. It has a high liquidus $\left(296^{\circ} \mathrm{C}\right)$, which would make it useful for two-step soldering processes. The higher kemperatures pose a gleater risk to the eell and may cause rosin fluxes to char. A specially formulated flux was recommended by Indium Corporation: RMA-NC (rosin mildly activated-no char). 
Although indium is known for its ductility and good fatigue resistance, its high cost was prohibitive. Thus Indalloy 7 and Indalloy 290 were rejected as being too costly. Indalloy 164 was rejected because of its high liquidus $\left(310^{\circ} \mathrm{C}\right.$ ) and the high cost of indium, albeit an element of low percentage in this alloy.

Section 4.3 describes the solder bond test results for several cell assemblies fabricated with $\mathrm{Sn} 62$, Sn96, and Indalloy 151 solder.

3.4.1.3 SOE Adhesives. One-part silicone RTV adhesives were evaluated for use in attaching the secondary optical eiements to the cell assemblies. This adhesive type was selected because of its wide service temperature range $\left(-60^{\circ} \mathrm{C}\right.$ to $200^{\circ} \mathrm{C}$ ), its low durometer to accommodate materials with different thermal expansions such as silicon and aluminum, its resistance to flow or sag before curing, and its ease of use. The product choice was further restricted by the decision not to consider those RTV's that evolve corrosives while curing.

Two adhesive products were evaluated: Dow Corning 739 and General Electric N-SIL RTV 128. Both products are one-part translucent adhesives. Pull strength tests were conducted to compare the adhesive strength. The GE N-SIL adhesive was selected on the basis of adhesive strength.

\subsubsection{Electrical Configuration}

Thi: key considerations in the selection of the preferred interconnect topography for a PV module are cell current and voltage characteristics, and cell hot spot heating. Interrelated with these considerations and included in this analysis o: electrical configuration is the concept of fault-tolerant strategies, such as increasirg the numbers of series blocks and parallel strings per source circuit and the use of hypass diodes. Other considerations such as source circuit power losses and mirimizing energy costs are not directly integrated into this analysis. The issue of celi mismatch is addressed separately in Section 4.4.

3.4.2.1 Series/Parailel Arrangement. The module consists of 24 cells placed in a 4 hy 6 physical arrangement. Each cell produces a nominal (0.62 volts and 7.1 amps at $100 \mathrm{~mW} / \mathrm{cm}^{2}$ insolation with an SBMII lens and $35^{\circ} \mathrm{C}$ cell temperature. In summary, the selected electrical configuration for the 24-cell prototype modules is shown in Figure 3-11 and is defined as follows:

- Three series blocks per module.

- Tuo parallel strings per series block.

- Four series cells per string.

- One Schottky bypass diode per series block. 


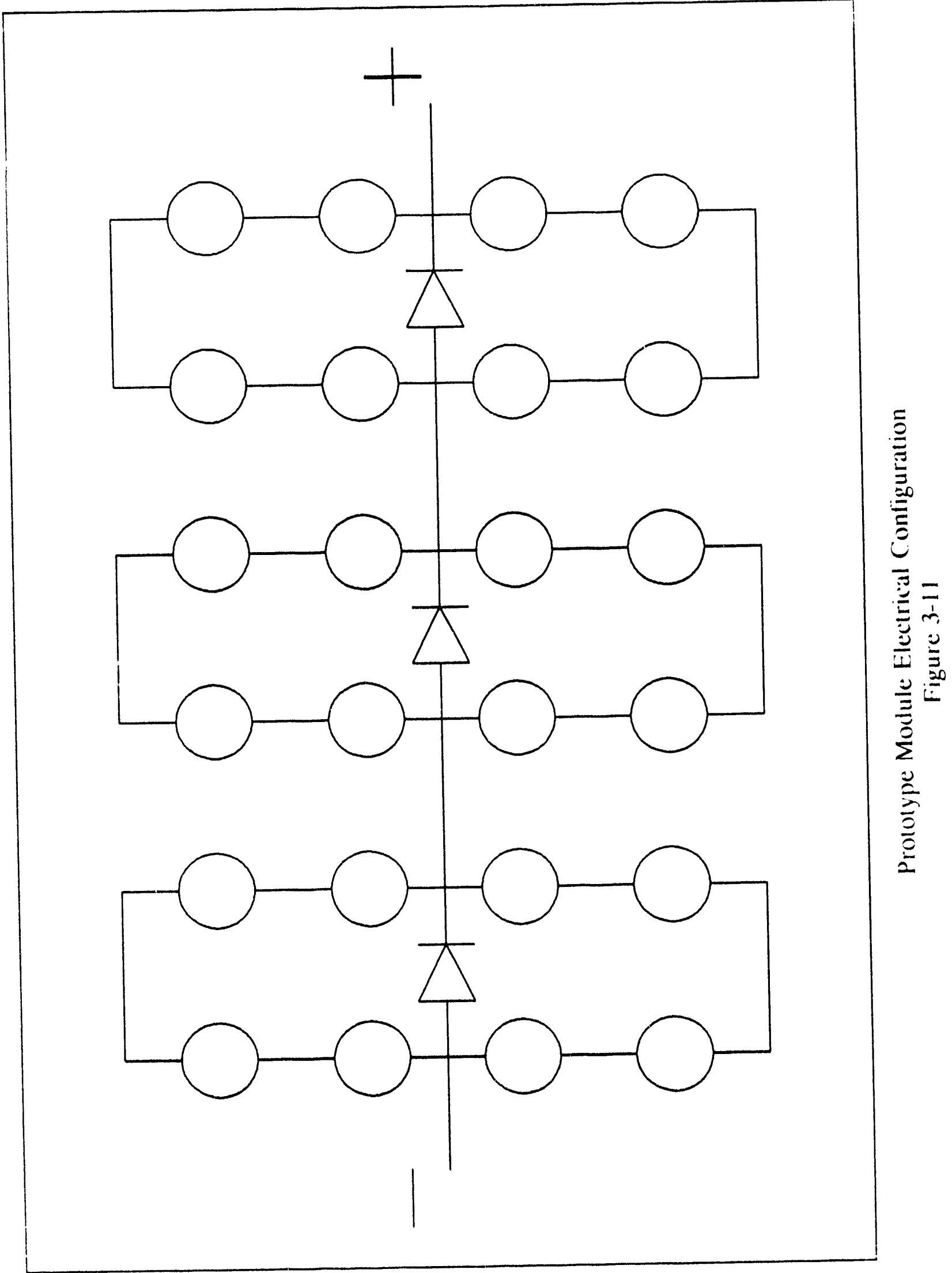


Two parallel strings result in a module nominal operating output of 7.45 volts and 14.3 amps. This arrangement was selected to provide alternate paths to carry the source circuit currents while maintaining a relatively low current level between modules to reduce $I^{2} R$ losses. In addition, a nominal 1000 volt source circuit voltage can be achieved on a single array (assuming series connection of approximately 100 modules). This source circuit voltage is consistent with the 3400-volt design target standoff capability for the cell assemblies.

The issue of cell hot-spot heating under partial illumination conditions was investigated for four combinations of series cell string length with both a pn junction diode and a Schottky diode. Hot-spot heating can occur when a cell is forced to operate in reverse bias due to partial shading or cell fracture. A main criterion for selecting the number of cells per series string was to ensure that the cell temperature was maintained at a safe level below that of the Sn62 solder melting point $\left(179^{\circ} \mathrm{C}\right.$ eutectic.) A two-part analysis procedure was applied to investigate the thermal implications of the series string length. Initially the thermal load was calculated for a partially illuminated cell, then the steady state cell temperature under worst case ambient conditions was estimated from a (hermal (rimyport model.

The four series-block configurations with bypass diocles analyzed were one diode per $12,8,6$, and 4 cells. Each configuration contained two parallel strings of cells paralleled by a bypass diode. Figure 3-12 displays the results of the thermal load analysis with a Schottky diode. The worst case thermal conditions occur at 10 percent shading of one cell in one parallel string. At 10 percent shading, there is a 23-watt decrease in thermal load as the number of cells per cliode decreases from 12 to 4. Diode type has a minor influence in the cell's thermal load under partial illumination. The pn junction diode case results indicate about a 3-watt increase in thermal load over that of the Schottky diode case in worst case shading conditions.

Cell temperature estimates were obtained by using the heat transport model (developed for the EPRI AP-3263 project.' This model is appropriate for the prototype module because the cell assembly and module geometry is very similar to the EPRI module characteristics. The heat spreader, heat dissipator, solder joints, and adhesive honds are nearly identical for both module designs. Table 3-2 shum the results of the worst case hot-spot thermal analysis at 10 percent shading of one cell in one string. The cell is forced to reject the electrical heat generatted due to reverse bias plus 100 percent of the incident solar energy. On a hot $(40)^{\circ} \mathrm{C}$ $\left[104^{\circ} \mathrm{F}\right.$ ! d day a comfortable margin of safety in cell temperature is provided by 

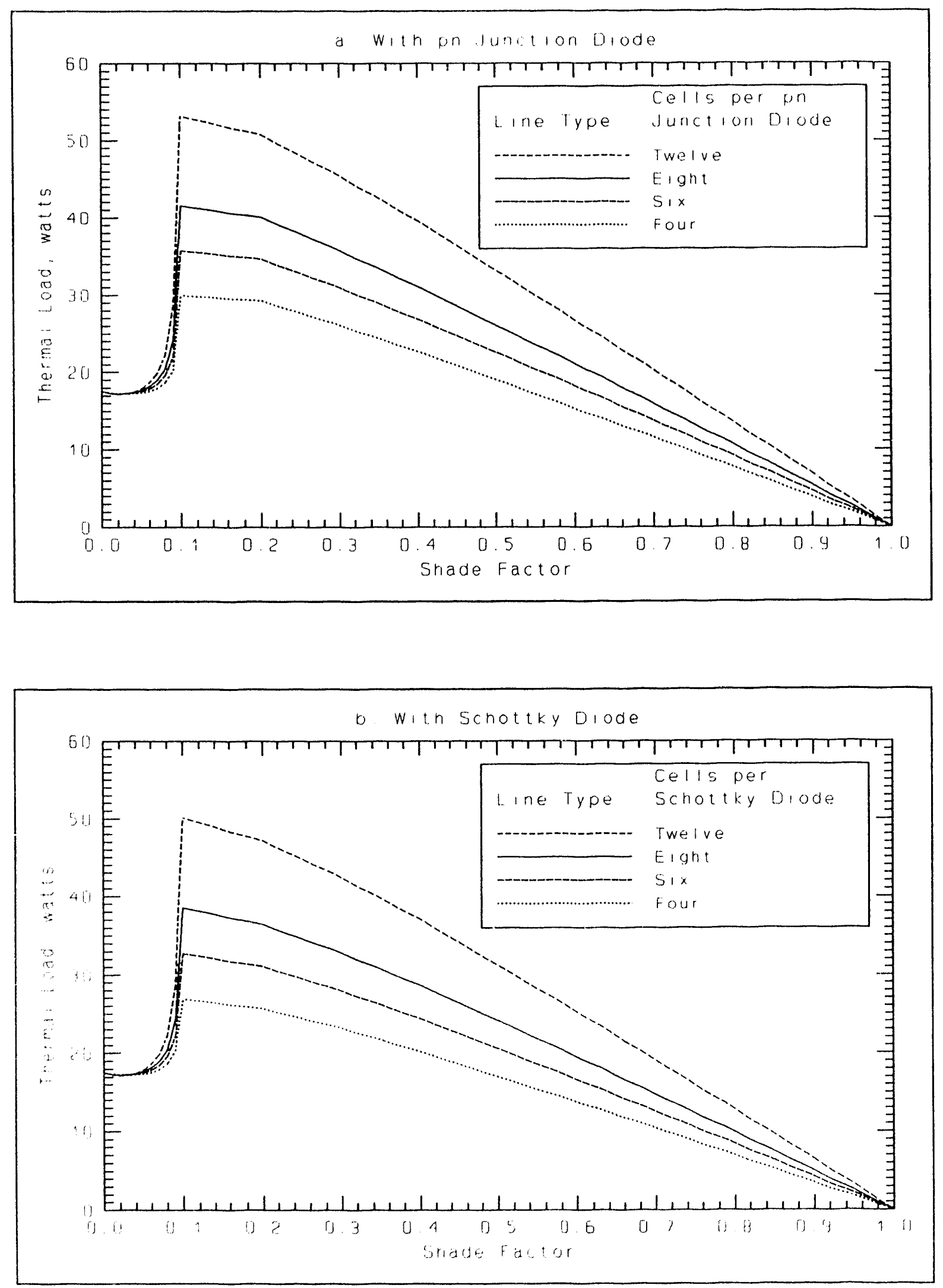

Cell Assembly Thermal Load versus Shade Factor Figure 3-12 


\begin{tabular}{|c|c|c|c|c|c|}
\hline \multicolumn{6}{|c|}{$\begin{array}{c}\text { Table 3-2 } \\
\text { Cell Assembly Hot Spot Thermal Analysis }\end{array}$} \\
\hline \multirow[b]{2}{*}{ Diode Type } & \multicolumn{5}{|c|}{ One Cell with 10 Percent Shading } \\
\hline & Series Cells & $\begin{array}{l}\text { Voltage } \\
(\text { Vde })\end{array}$ & $\begin{array}{l}\text { Current } \\
\text { (Amps) }\end{array}$ & $\begin{array}{c}\text { Heat } \\
\text { Rejection }\end{array}$ & $\begin{array}{l}\text { Hot Cell } \\
\Delta \mathrm{T}\left({ }^{\circ} \mathrm{C}\right)\end{array}$ \\
\hline pn & 12 & -3.8 & 8.5 & 53 & 101 \\
\hline pn & 8 & -2.4 & 8.5 & 42 & 80 \\
\hline pn & 6 & -1.7 & 8.5 & 36 & 69 \\
\hline pn & 4 & -1.0 & 8.5 & 30 & 57 \\
\hline Schottky & 12 & -3.4 & 8.5 & 50 & 96 \\
\hline Schottky & 8 & -2.1 & 8.5 & 39 & 75 \\
\hline Schottky & 6 & -1.4 & 8.5 & 33 & 63 \\
\hline Schottky & 4 & -0.7 & 8.5 & 27 & 52 \\
\hline \multicolumn{6}{|c|}{$\begin{array}{l}\text { Analysin Barse: } \\
\text { Two parallel strings of } n \text { cells per string, paralleled by a bypass } \\
\text { diode. } \\
\text { One cell in one string is } 10 \text { percent shaded } \\
\text {. } \triangle \mathrm{T} \text { is cell temperature minus ambient temperature } \\
\text {. Incident power: } 23.4 \mathrm{~W}=\left(950 \mathrm{~W} / \mathrm{m}^{2}\right)\left(0.029 \mathrm{~m}^{2}\right)((0.85)\end{array}$} \\
\hline
\end{tabular}

diode schemes with eight or fewer cells per series block. With eight cells per pn junction diode, the estimated shaded cell temperature will remain below 120$)^{\circ} \mathrm{C}$ : a $60^{\circ} \mathrm{C}$ safety margin below that of the Sn62 solder melting point. The Schottky diode, with its relatively low voltage drop. would provide an additional $5^{\circ} \mathrm{C}$ protection.

3.4.2.2 Bypass Diode Placement and Mounting. The main criterion for determining the diode placement was to minimize the length of copper strap required for interconnection. The key diode mounting considerations were the need to maintain electrical isolation and to provide a thermal path for diode heat rejection.

Two diode placement alternatives displayed were considered. The key difference between alternatives was the reduced strap length required of the diode interconnects that run parallel, instead of perpendicular, to the long dimension 
of the module. The $169-\mathrm{mm}$ (6.67-inch) cell separation results in an approximate $1020-\mathrm{mm}$ (40-inch) savings (neglecting stress relief bends) of interconnect strap length per module. A strap size of $12.5 \mathrm{~mm}$ by $0.76 \mathrm{~mm}$ ( 0.5 inch by $0.030 \mathrm{inch}$ ) yields a copper savings of $0.10 \mathrm{~kg}(0.23 \mathrm{lb})$ per module. This savings is substantial for production modules and was selected for use in the prototype.

The diode mounting scheme used in the prototype module was similar to the concept presented in the EPRI report. ${ }^{1}$ The mounting hardware consists of solder bonding of a round copper heat spreader, an alumina substrate, and an L-shaped copper bracket. The diode is mounted on the bracket.

\subsubsection{Electrical Feedthrough Design}

Solar Kinetics developed an electrical feedthrough design for the prototype module. Figure 3-13 is Solar Kinetic's Drawing 03-202 of the feedthrough design. This connector was designed for in-house production using a turned and partially threaded 25-mm (1-inch) diameter copper bar in combination with Delrin standoff bushings, o-ring seals, and hex nuts. The hub of the outer Delrin bushing extends about $7.9 \mathrm{~mm}(0.31 \mathrm{inch})$ through a $19-\mathrm{mm}(0.75$-inch) diameter penetration of the housing sule wall. Thin derign wan developed hecause no commercial product was readily available that met the criterion of (1) low cost, (2) ease of field installation, and (3) watertight operation. 


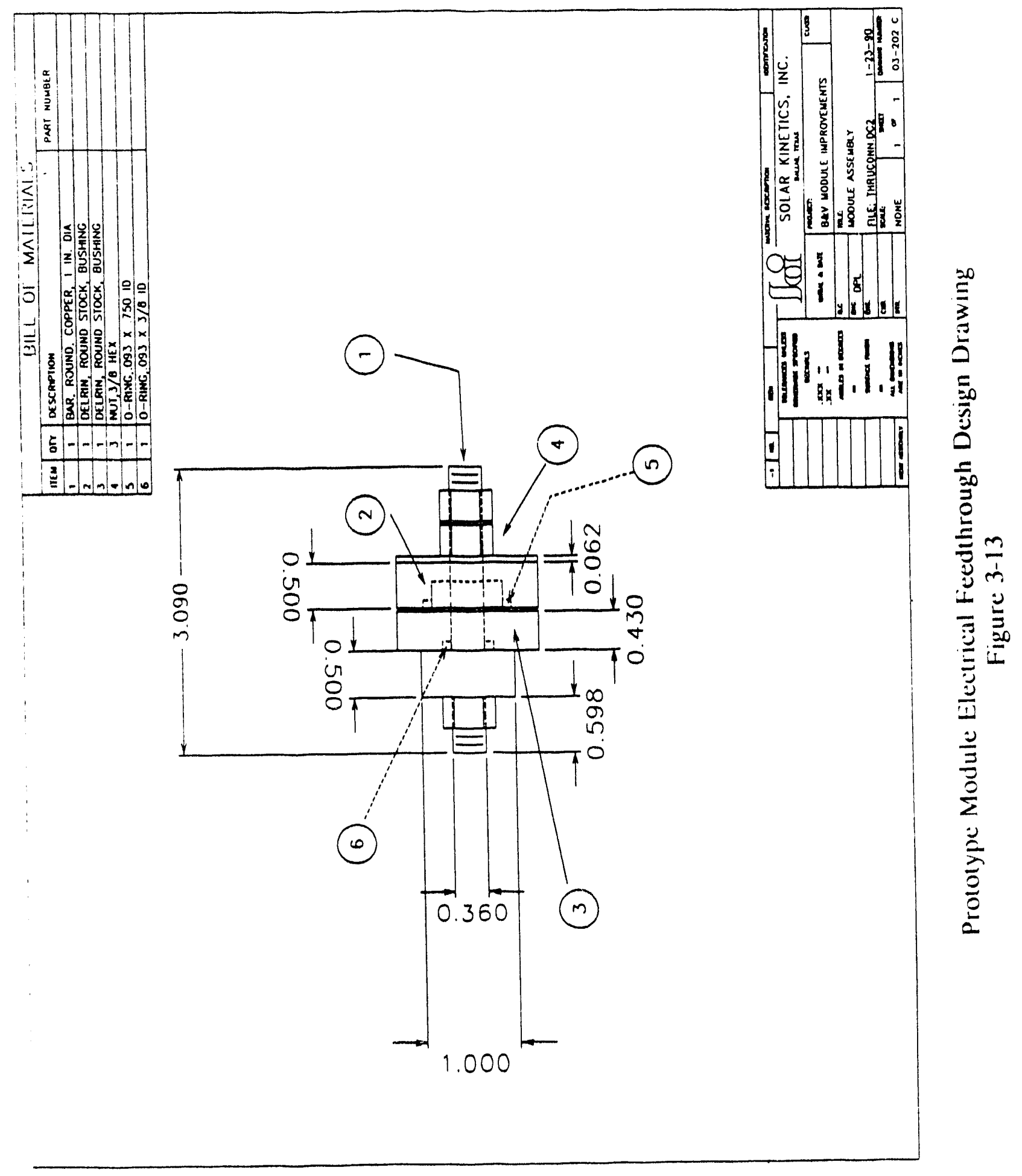




\subsection{CELL ASSEMBLY FABRICATION AND TESTING}

The cell assembly fabrication and testing activities were conducted by Spire, Sandia, and Entech. Spire was responsible for the procurement of most components of the cell assembly, although Sandia procured the cells and the prismatic covers. Spire also performed all the cell assembly fabrication activities, except for the prismatic cover placement activities performed by Entech and Sandia. Sandia performed the cell assembly evaluation tests and the performance testing for the module cell assemblies. Figure $t-1$ displays a cell assembly.

\subsection{COMPONENT PROCUREMENT AND ACCEPTANCE TESTING}

The cell assembly consists of five components: solar cell, voltage isolation substrate, heat spreader, front tab, and secondary optical element. Although the cell was designed for use with a prismatic cover, this component was not a part of the prototype module due to difficulty in the molding and placement of the prismatic covers. This section describes the procurement and acceptance testing for each of these components.

\subsubsection{Solar Cells}

The cell specified for the prototype module has been designed and fabricated by the Solar Photovoltaic Laboratory headed by Dr. Martin Green at the University of New South Wales (UNSW). ${ }^{+}$These cells were procured by Sandia under separate contract with UNSW.

These devices are passivated emitter solar cells made from 0.2 ohms-cm, float-zone, p-Si wafers of $280 \mu \mathrm{m}$ thickness. The cell active area is $12.5 \mathrm{~mm} \mathrm{x}$ $12.5 \mathrm{~mm}(0.49$ inch $\times 0.49$ inch $)$ with a total area of $18 \mathrm{~mm} \times 18 \mathrm{~mm}(0.71$ inch $x 0.71$ inch). The bus width is $2.75 \mathrm{~mm}(0.11$ inch) which includes a $2.25-\mathrm{mm}$ (0.089-inch) metallization band and a $0.5-\mathrm{mm}(0.02$-inch) unmetallized border around the perimeter.

The cell metallization pattern is designed for use with prismatic covers and as sucin extends parallel to the bus bar. The metallization covers 15 percent of the active cell area; with grid line widths of $19 \mu \mathrm{m}$ on $127-\mu \mathrm{m}$ centers. The grid line cross-sectional area is approximately $125 \mathrm{\mu m}^{2}$. Figure 4-2 presents a plan view of the cell metallization design.

Performance tests were conducted by Sandia on all cells as received from UNSW. The cells were tested in a flash tester under unconcentrated illumination (1X) and concentrated illumination (125X and 190X). Cell temperature was 


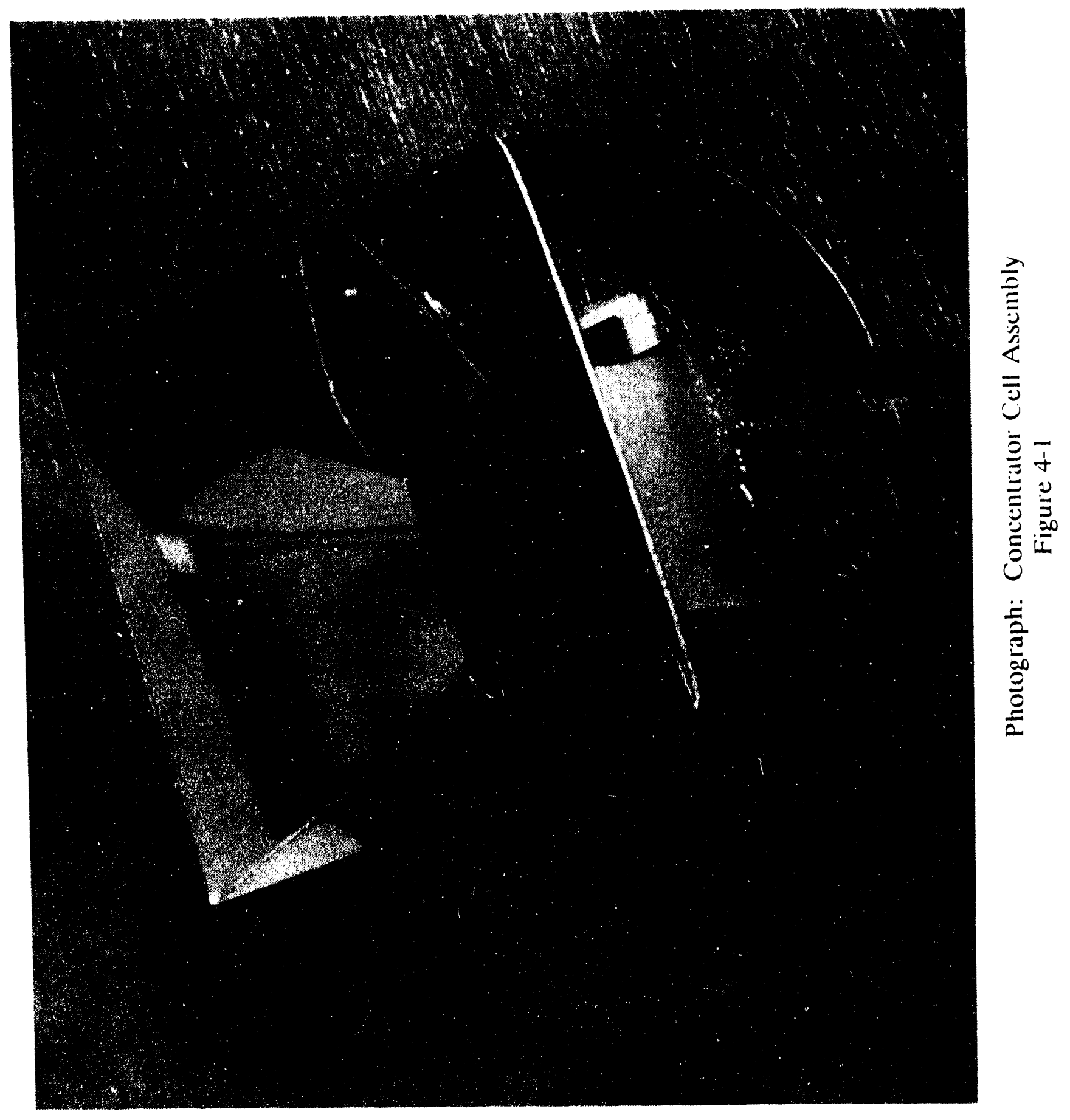




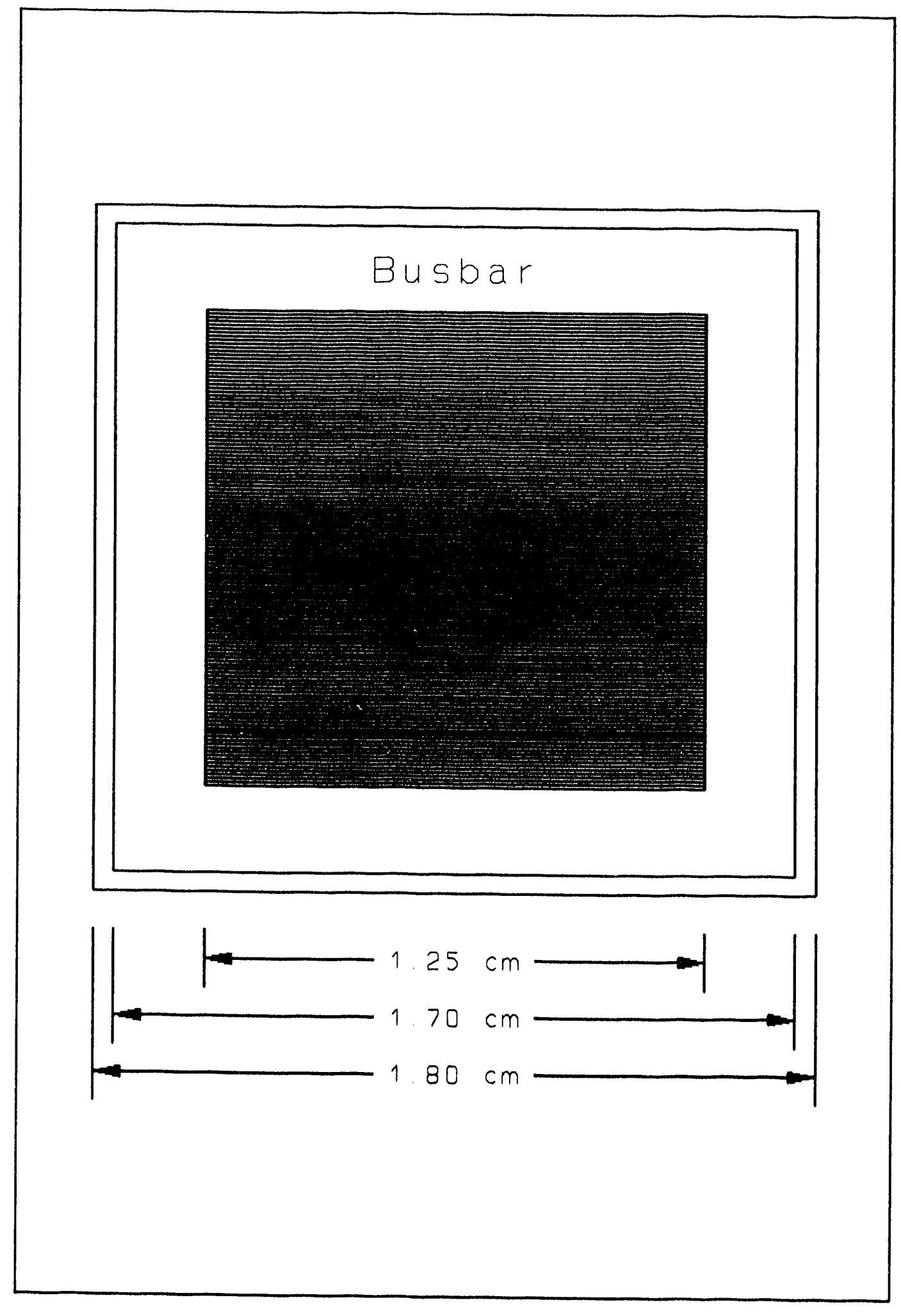

UNSW Concentrator Cell Metallization Design for Prismatic Cover Figure 4-2 
maintained near $25^{\circ} \mathrm{C}$. Test results for the $2+$ cells of the prototype module, identified by UNSW cell number, are displayed in Figures t-3, 4-t, and t-5. Data were taken on most cells at 1X, 125X. and 190X for open circuit and maximum power voltage (Voc and Vmp), short circuit and maximum power current (lsc and Imp). fill factor (FF), and cell efficiency. (Cell efficiencies averaged 17.3 percent at $1 \mathrm{X} .21 .0$ percent at $125 \mathrm{X}$, and 20.8 percent at $190 \mathrm{X}$.

\subsubsection{Substrates}

The subutrate specified for the 2()()X bificial cell evolved from the substrate design for the EPRI high-concentration array project developed by Black \& Veatch for the point-contact cell. The design consists of direct-bonded copper on alumina, which provides voltage isolation, bottom polarity electrical contact, and surface contact with the heat spreacler. Figure t-6 is Spire Drawing No. 164-0104 of the substrate for the $18-\mathrm{mm}(0.71$-inch $)$ cell. The thicknesses of the alumina and the direct-bonded copper are $0.51 \mathrm{~mm}$ and $0.25 \mathrm{~mm}(0.020$ inch and 0.010 inch), respectively. The surfaces of the soft-annealed alloy-110 copper are electroplated with solderable nickel or solderable electroless nickel. This surface finish preserves the solderability of the copper during assembly to the heat spreader and solar cell.

Concern over the difference in thermal expansion coefficients of copper verus alumina resulted in a reduction in the width of the top tab to $12.5 \mathrm{~mm}$ (0.5 inch so als to reduce distortion upon cooling from the bonding temperature. Also, an S-shaped bend was included to allow for strain relief during diurnal thermal cycling.

Quotations for supplying direct-bonded copper on alumina substrates designed for the UNSW cells were received from three vendors: Artwire/Doduco, Marubeni America, and Powerex. Powerex was selected to supply the substrates primarily because its price per substrate at low quantities was the least of the three potential vendors.

Initial deliveries of substrates from Powerex exhibited shallow dome-shaped regions or bumps where the copper appeared to be inadequately bonded to the alumina. This phenomenon is referred to as "pillowing." A high percentage of the substrates exhibited bumps ranging from $0.032-\mathrm{mm}$ to $0.2 .3-\mathrm{mm}$ (0.00)15-inch to 0.009-inch) high and were returned to Powerex. Bumps with heights of this magnitude could possibly interfere with the solder bonding process, which involves the use of $0.13-\mathrm{mm}(0.005$-inch) thick solder preforms. 

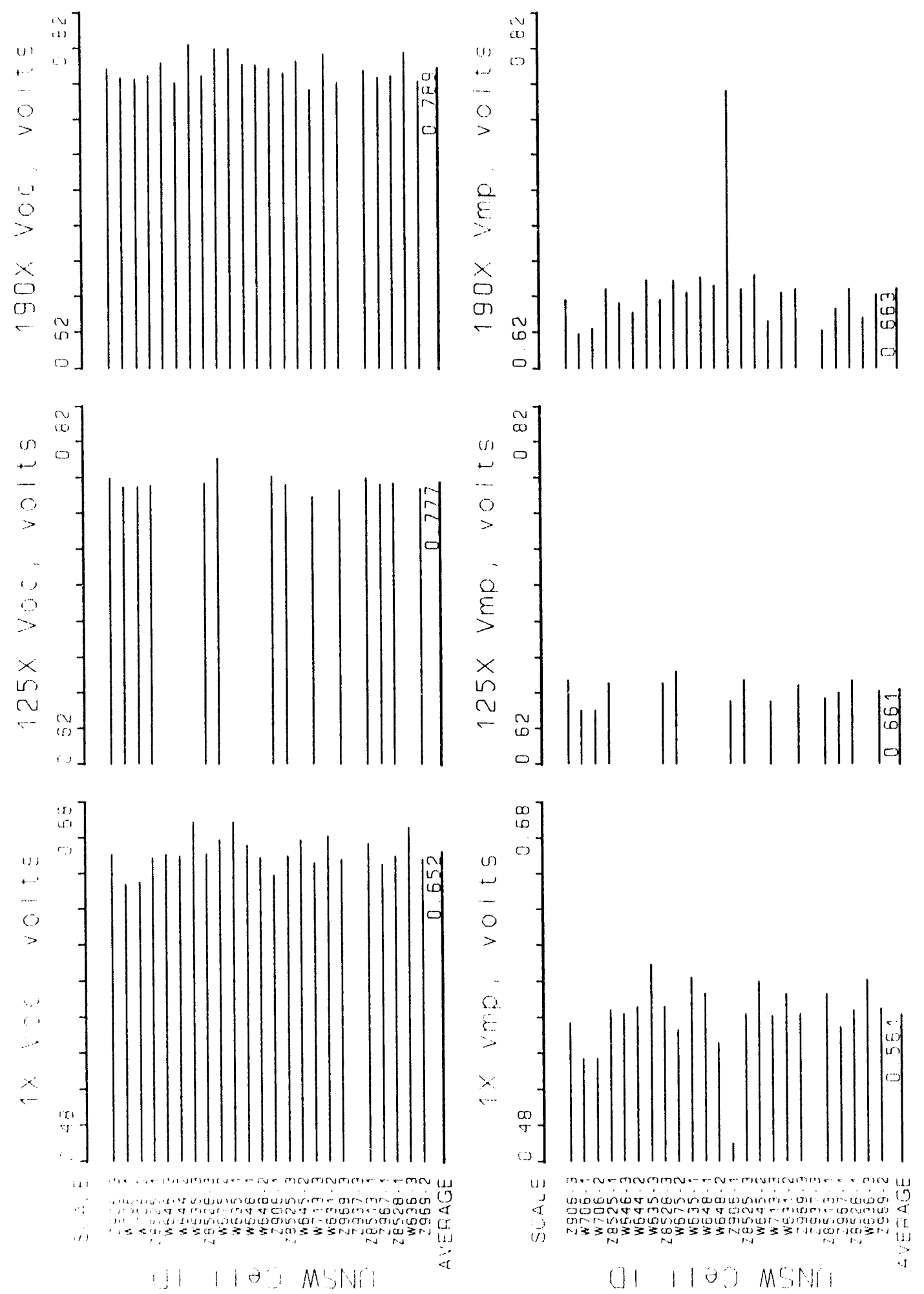

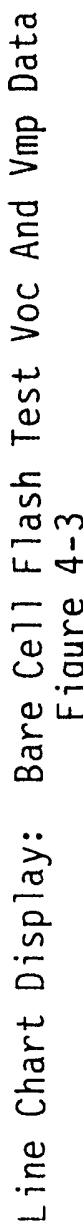




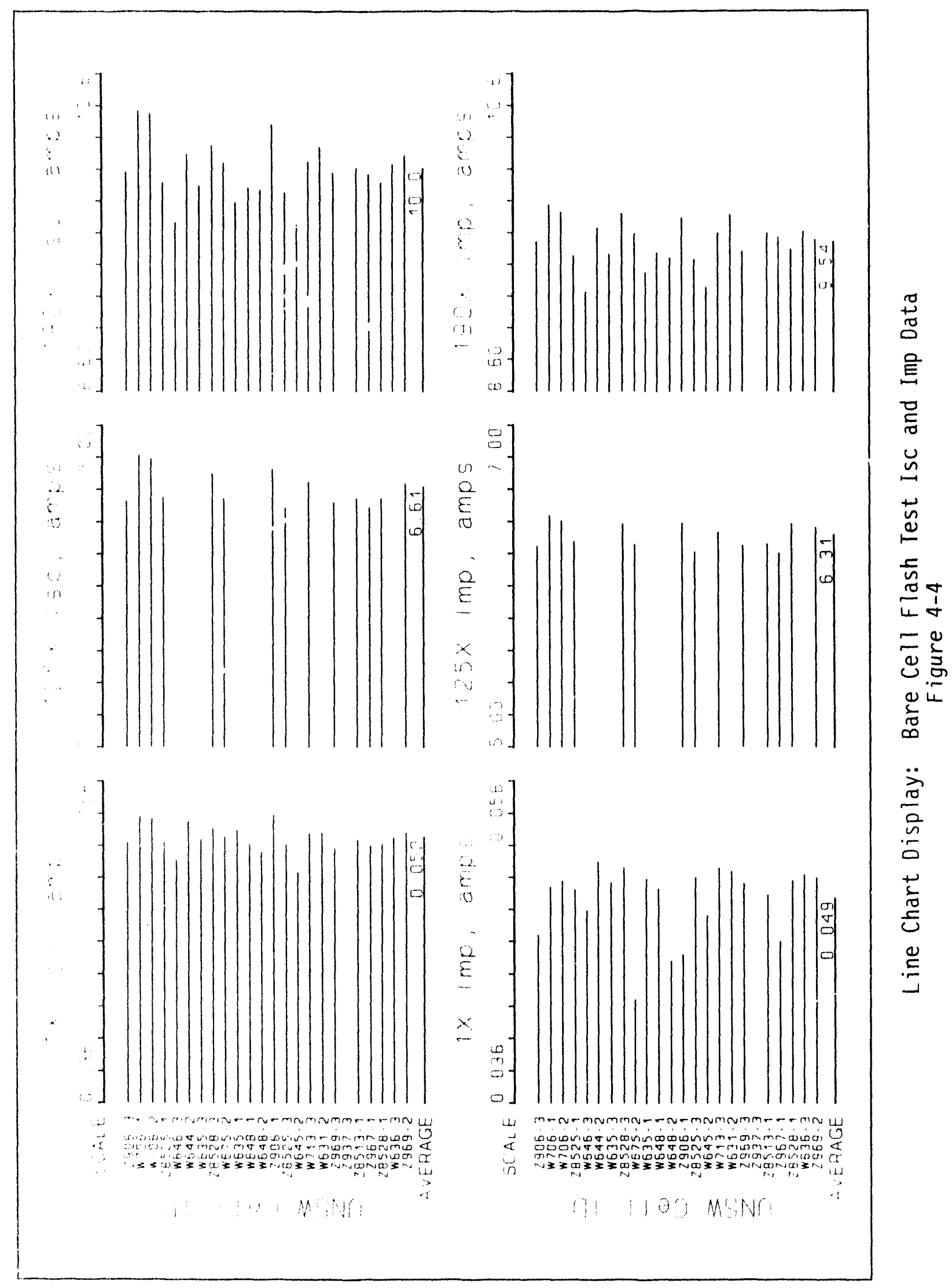




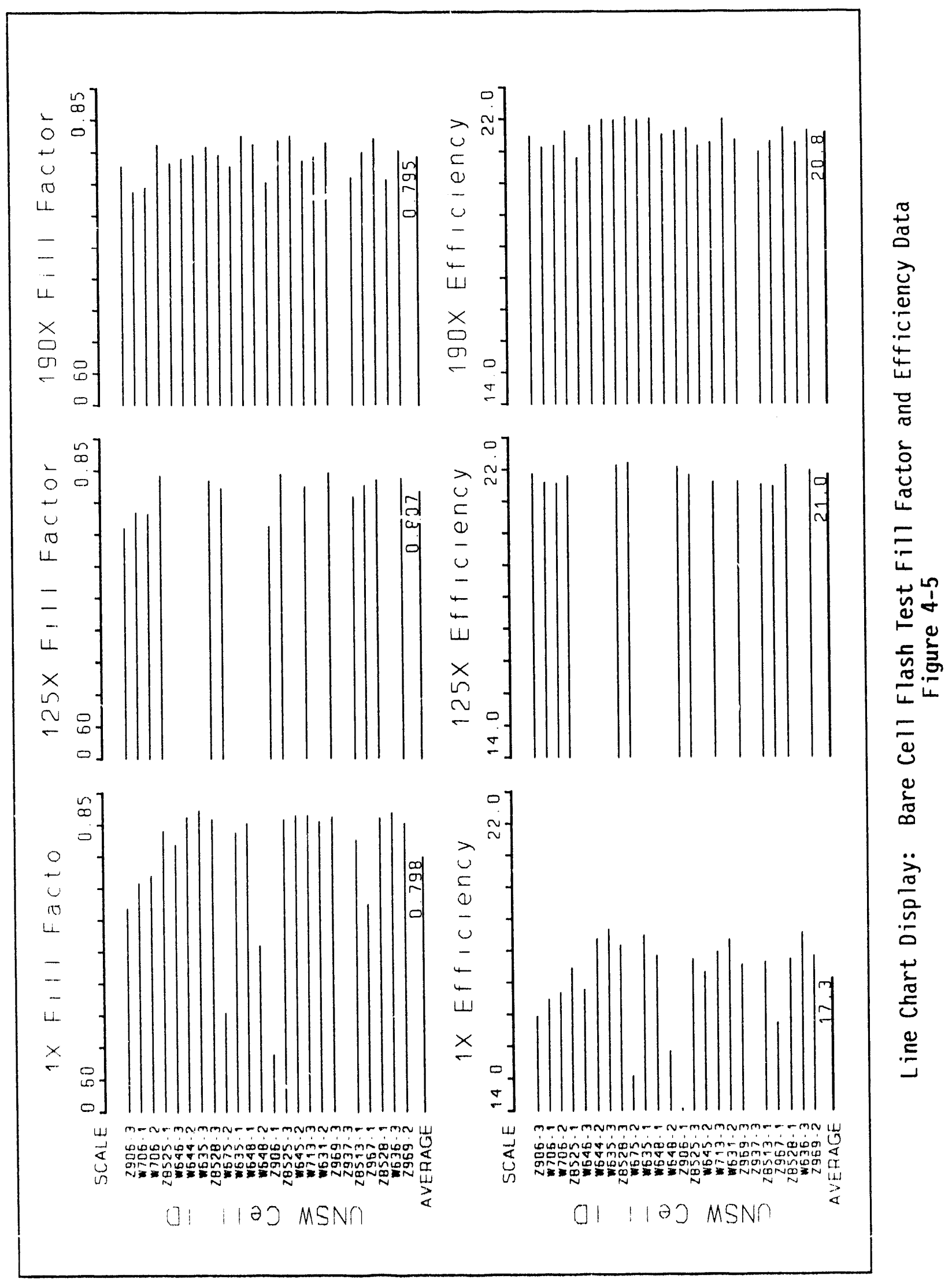




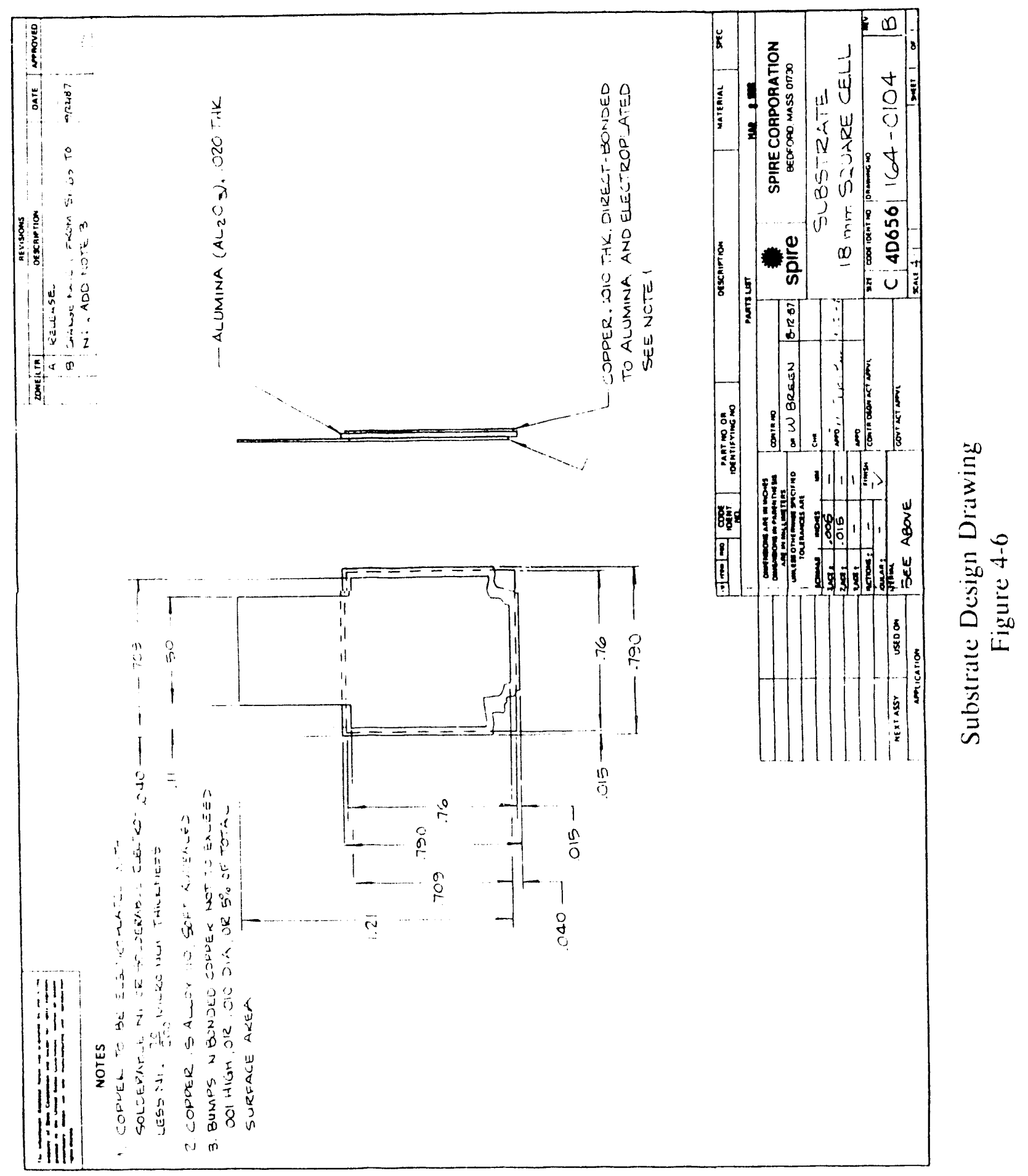


Two possible causes for the bumps on the substrates were identified: inadequate cleaning procedures for both the copper and alumina, or copper recrystallization during cooling in the direct bonding process. Two sectioned substrates were examined under microscope by Spire. One of the substrates showed a gap between the copper and alumina under the bump. The gap measured $0.039-\mathrm{mm}(0.0015$-inch $)$ high and $2.10-\mathrm{mm}(0.083$-inch $)$ wide. The second substrate showed no gap at the bump but displayed a $0.08 \mathrm{~mm}(0.003 \mathrm{inch})$ variation in copper thickness.

Subsequent deliveries showed a marked reduction in the presence and height of these pillowed regions, with bumps heights less than $0.05 \mathrm{~mm}(0.002$ inch) on the majority of the substrates.

\subsubsection{Front Tabs}

Front tabs were fabricated by chemical milling by Photofabrication Engineering Inc. of Milford, MA. Figure 4-7 is Spire Drawing C164-0101, which provides the component specifications for the front tabs. These tabs were solder electroplated by Plating for Electronics, Waltham, MA, with a $60 / 40(\mathrm{Sn} / \mathrm{Pb})$ solder alloy to a thickness range of $2.5 \mu \mathrm{m}$ to $7.6 \mu \mathrm{m}(0.1 \mathrm{mil}$ to $0.3 \mathrm{mil})$.

The front tab design was developed prior to the decision to consider prismatic covers. It $u$ as necessary to modify the front tabs as received from the vendor to facilitate the placement of prismatic covers. Figur. 4-8 shows the modifications to the front tabs. Each front tab was trimmed to remove eight of the sixteen small tabs to facilitate the placement of prismatic covers. After trimming, S-shaped stress-relief bends were formed in the eight small tabs using the tab bending fixture. After bending, the narrow connecting bus on the side opposite the large tab was trimmed.

\subsubsection{Copper Heat Spreaders}

The round sopper heat spreaders were fahricated by Technicut of Carrollon. TX. Figure 4-9 is Spire Drawing B164-0105 which provides the component specifications for the heat spreaders that were fabricated from copper alloy $\mathrm{C} 110$ (electrolytic tough pitch), soft annealed, 1.6- $\mathrm{mm} x+4-\mathrm{mm}$ diameter (.06)-inch $\mathrm{x}$ 1.75-inch). Each heat spreader was solder dipped in Sn6.3 solder $(63 \mathrm{Sn} .37 \mathrm{~Pb}$, 


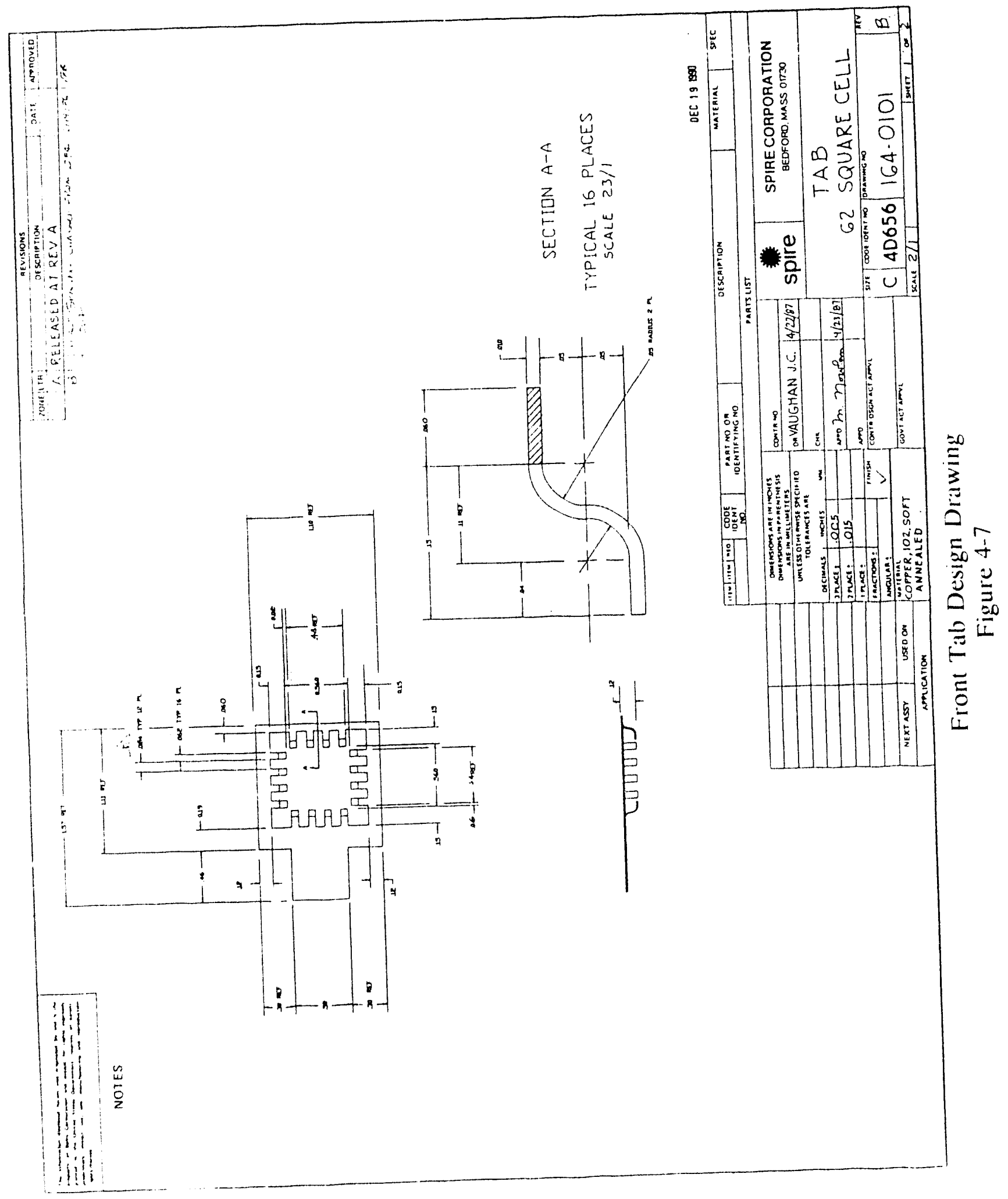




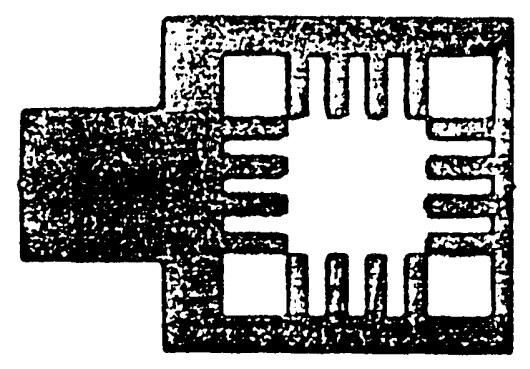

A. AS RECEIVED

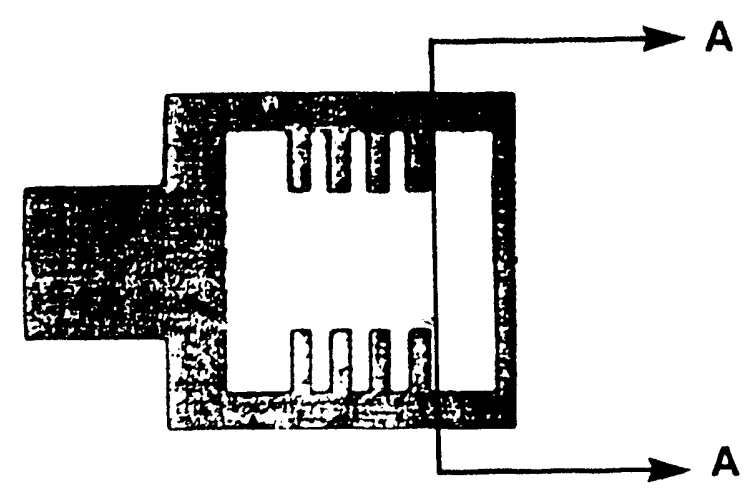

B. MODIFIED PRIOR TO BENDING NOTE: Section A-A removed after bending

Front Tab Modifications for Prinmatic Cover Placement Figure +-8 


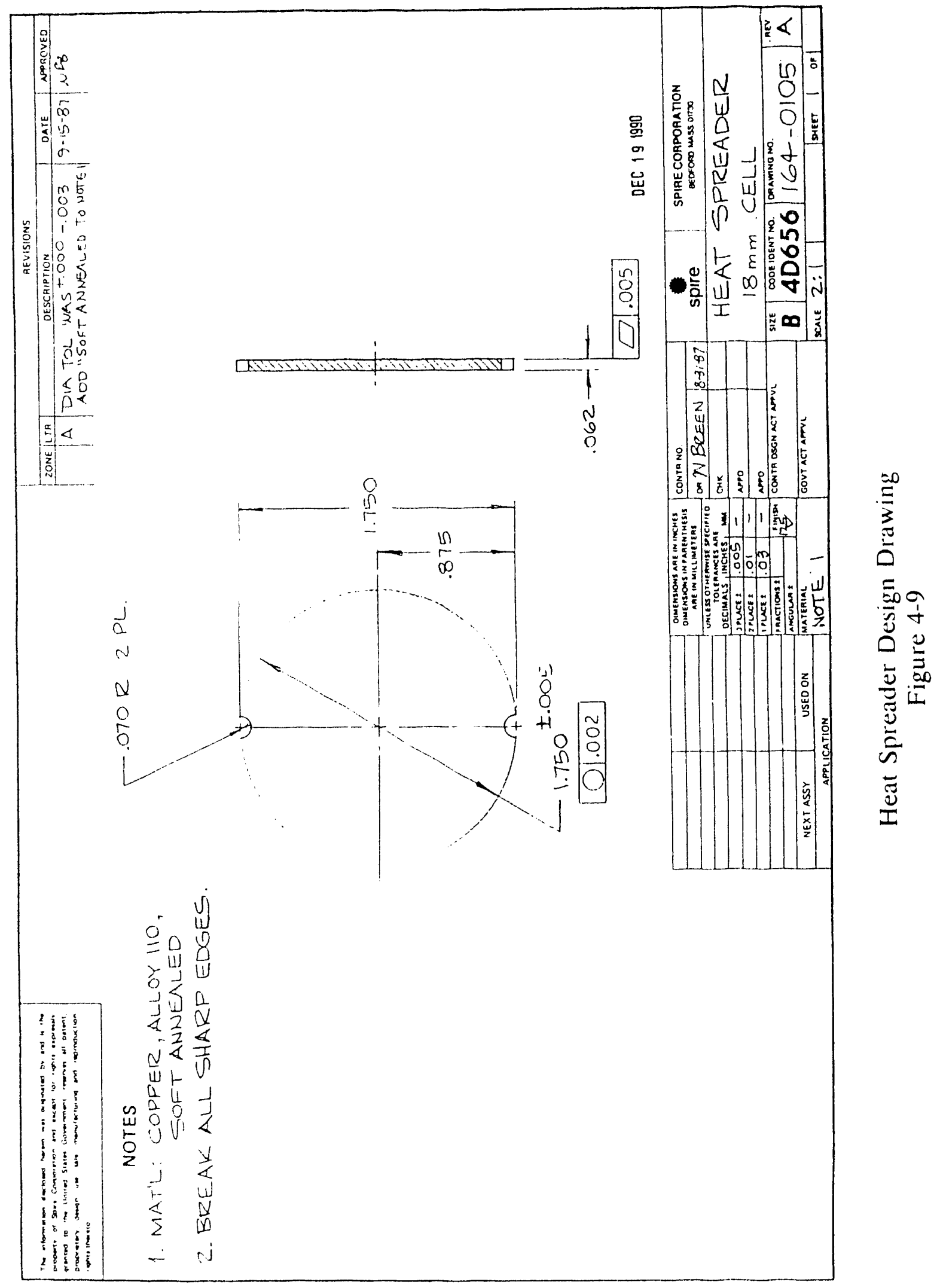


$183^{\circ} \mathrm{C}$ eutectic), the standard electronics soldering alloy, using Spire's automatic dipping machine. This tinning provides the following desirable feallures:

- An extremely solderable surface for honding to the substrate.

- A surface more resistant to corrosion in the atmosphere.

- A much better match to aluminized or galvanized steel than copper in terms of reducing galvanic corrosion.

- A less active chemical surface for RTV bonding.

Alter flux residue removal, the back side of the heat spreaders were rubbed on a tlat ahrasive surface to remove asperities in the solder surface. This also provided for more reproducible heat transfer during the vacuum soldering process, a thinner, more consistent adhesive bond line between the spreader and the module housing, and a rough surface for stronger adhesive honding.

The heat spreaders were fabricated with a conventional punch and die. Laser machining and abrasive jet machining of the heat spreaders were also investigated. These techniques achieve tighter cutting tolerance than die cutting, $\pm 0.13 \mathrm{~mm}$ versus $\pm 1.6 \mathrm{~mm}( \pm 0.005$ inch versus \pm 0.062 inch), which was preferable for alignment purposes. Laser machining of 1.6- $\mathrm{mm}$ (0.062-inch) copper was deemed impractical because copper's high conductivity dictates a very slow cut, leaving a rough edge that requires deburring. Abrasive-jet machining was available for about the same cost as conventional die cutting.

\subsubsection{Prismatic Covers}

The prismatic cover design for this application uses a patented process developed by Entech." Heretofore, prismatic covers have heen used primarily in linear-focus PV concentrator systems to reduce the shadow losses resulting from incident light being reflected from the cell top surface metallization. The consideration of prismatic covers in the prototype module was one of the first attempts to incorporate the covers in point-focus Fresnel lens concentrator systems. The prismatic coners were designed by Entech to reclirect the solar energy that normally strike the metallization on to the unmetallised portion of the cell. An approximate 15-percent performance improvement was expected for covered cells as compared to bare cells. Section 3.2 descrihes the evaluation process for selecting the preferred cell metallization fraction. The covers were procured under separate contract with Sandia.

Performance tests were conducted by Sandia on seven prism-covered cell assemblies. The cell assemblies were fabricated by Spire; the prismallic covers were molded and placed on each assembly by Entech. The results of the flash 
tests are shown in comparative line chatr form in Figures $4-10$ and +-11 . Datat were taken at $1 \mathrm{X}$ and $190 \mathrm{X}$ concentrations for Voc, lsc. Vmp. Imp. fill factor, and efficiency. Al 190x. the covered cells averaged 22.3-percent conversion efficiency compared to 20.2-percent for the hare cells. for an average improvement of 10 percent. Individual cell performance varied widely. with a minimum improvement of ahout foperent and a maximum improvement of about 15 percent.

Visual inspection of the covered assemblies identified that the covers were Hal!, indicating variations in adhesive thicklless. The waviness was seen as nonuniform reflection from the top surface of the prismatic covers. It was also seen as nonuniform changes in gridline obscuration as the angle of view was varied. In addition. the covers exhibited mall whitish regions within which no change in reflectivity was observed as the angle of view was varied. These regions were probahle areas where the cover was not honded to the cell. These cover bonding imperfections are the probable caluse of the observed variations in cell performance improvement described above.

\subsubsection{Secondary Optical Elements}

The secondary optical element design was developed by Black \& Veatch and the components were fabricated by George Sonner of Walton, NY. The SOE's were made from $0.31-\mathrm{mm}$ ((0.0)12-inch) thick anodized aluminum stock. Fabrication was accomplished with a cut-and-fold operation; the folded parts were lasten together by folding and crimping a sleeve and tab at a comer.

All S()F:" Here visually inspected and selectively meanured to ensure adherence to those aspects of the specification deemed most critical, such as surface quality and exit aperture size, flatness and squareness. Although product quality varied and some products were returned, it was possible to make minor alfustments to the SOE's that were out-of-spec so as to achieve the scpuareness and flatnes crilertid.

\subsection{CELL ASSEMBLY PROCEDURES}

Spire developed a set of cell assembly procedures for the prototype module cell ansemblies. These procedures were developed and refined during the peliminary qualification and testing of the cell assemoly and represent the quality control program of the cell assembly process.

The cell assemblies were racuum soldered in the SPI-LAMINATOR 24(), a commerial product manufactured by Spire for laminating flat-plate PV modules 


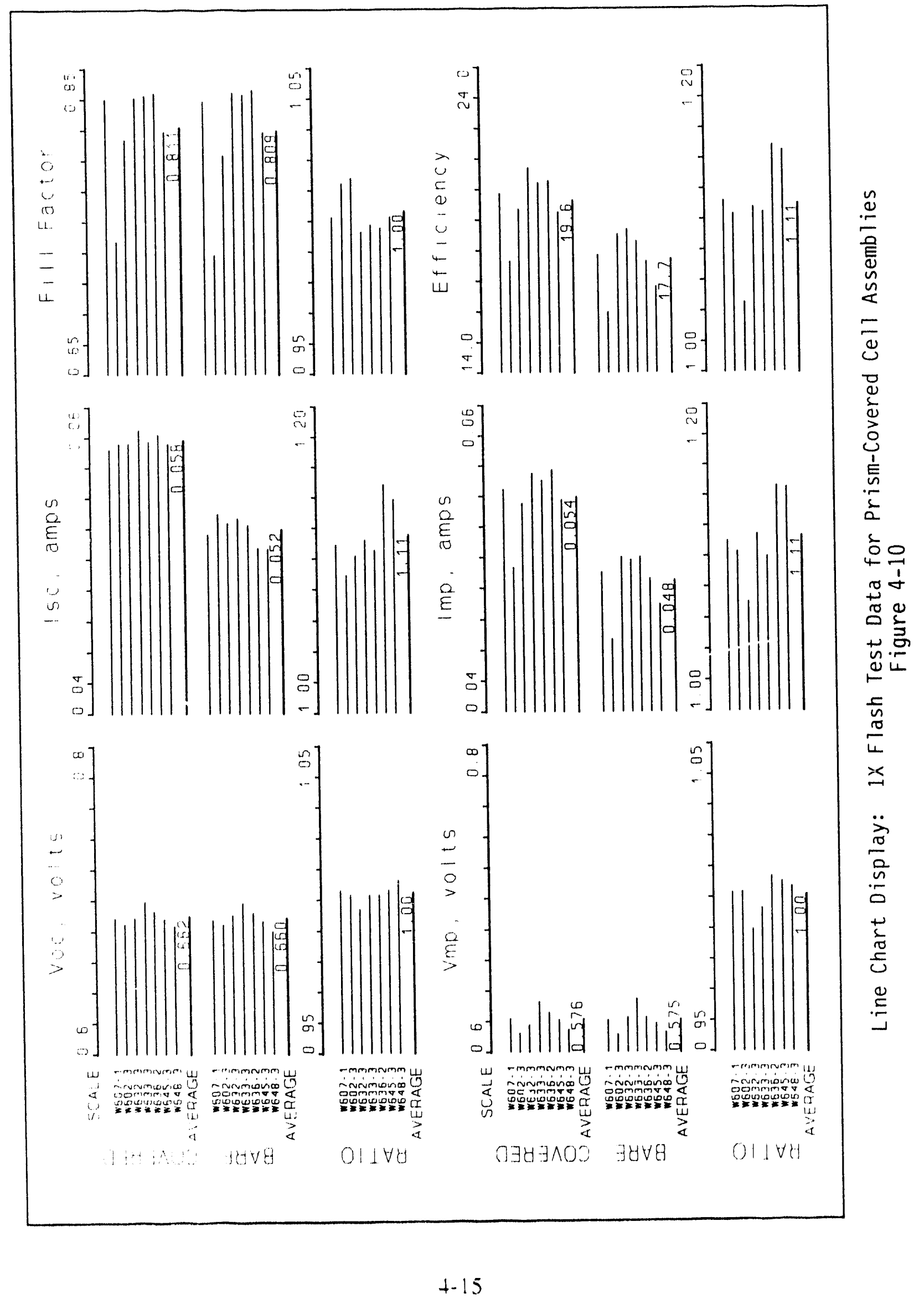




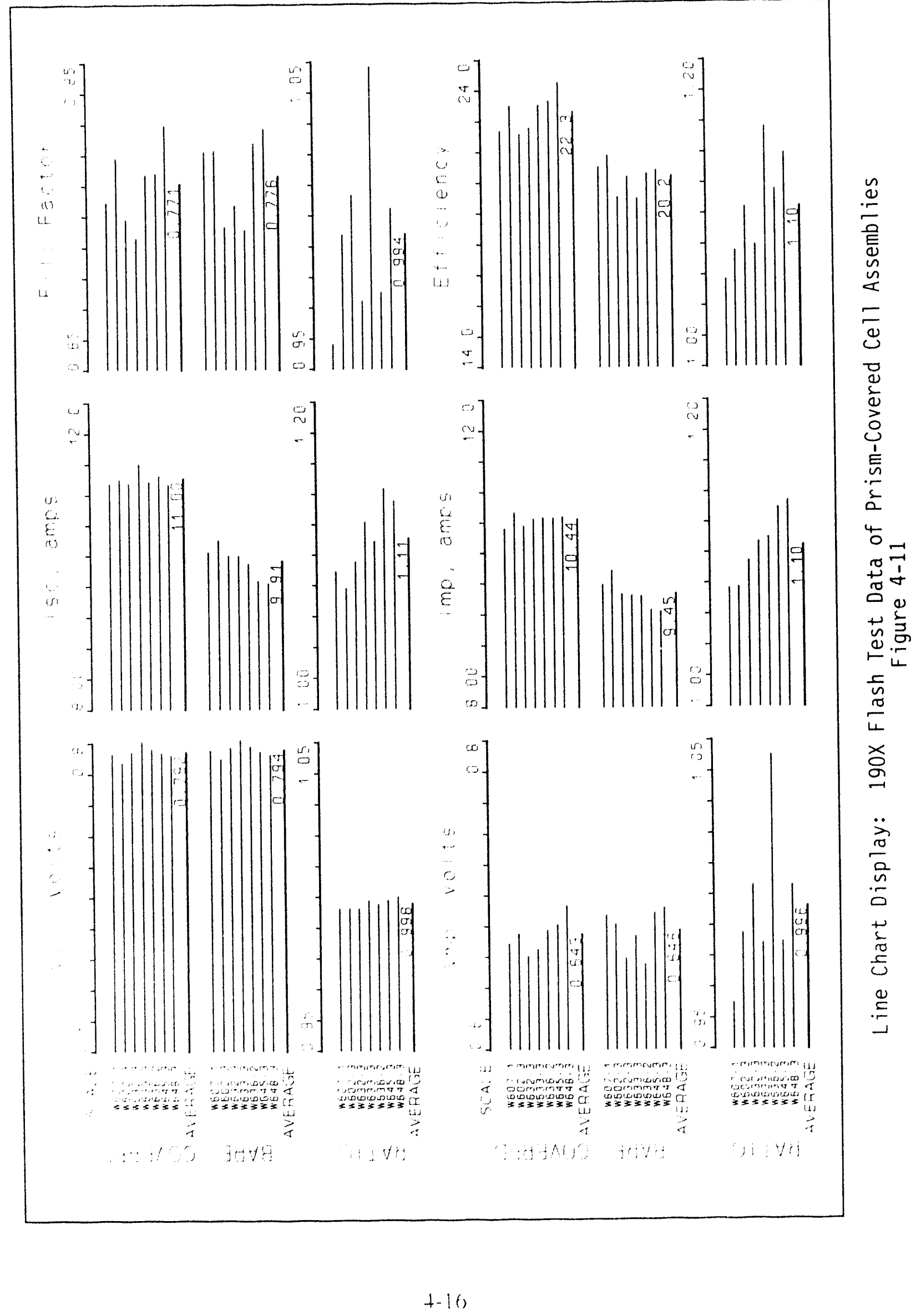


using sheet encapsulants. The assembly components were loaded into an alignment fixture and placed in the laminator for vacuum soldering. This equipment was chosen hecause there are similaritics between cell encapsulation and cell solder bonding. Both processes require the void-free bonding of planar objects with solid, thick films that melt at elevated temperatures. In addition, the use of the laminator had two main advantages over conventional hot-plate soldering. First, it achieves full air removal prior to the solder melt to reduce both void size and occurrence. Second, the laminator temperature and pressure parameters are preset and computer-controlled, thereby allowing automated processing of each cell assembly. The use of the laminator on properly procured and prepared components offered the potential to reduce solder void content and, therefore, improve solder bond quality. Additional information on cell assembly fabrication is presented in Appendix B, a reprint of a technical paper prepared by Spire.

This section describes the aligning and bending fixtures, the laminator equipment modifications for this soldering procedure, the cell assembly fabrication steps, and prismatic cover placement and SOE attachment procedures.

\subsubsection{Cell Assembly Aligning and Bending Fixtures}

Spire designed and fabricated several precision, multilevel alignment and bending fixtures for fahricating the cell assemblies for the prototype module. A solder alignment fixture was developed that holds the cell assembly components in alignment during the vacuum soldering process. Bending fixtures were developed to place stress relief bends in the substrate bottom tab and the front tab fingers.

Figure 4-12 displays the solder alignment fixture. The fixture has an aluminum base with a milled pocket to hold a solder-dipped heat spreader, and four press-fit stainless steel pins. The pins are used to align two aluminum plates that sit on top of the base and spreader. These top plates align the substrate in the proper location with respect to the heat spreader. Additional fixturing positions the solar cell on top of the substrate and locates the front tab on the solar cell.

A bending fixture was developed for making two $1.3-\mathrm{mm}$ (0.05-inch) radius bends in the $0.25-\mathrm{mm}(0.010$-inch) thick copper substrate bottom tabs. The bends provide stress relief for the interconnections between cells in the module, as the module undergoes cyclical thermomechanical stresses in the field. The fixture produces bend radii between $1.0 \mathrm{~mm}$ and $1.3 \mathrm{~mm}(0.04 \mathrm{inch}$ and 0.0 .5 inch). 


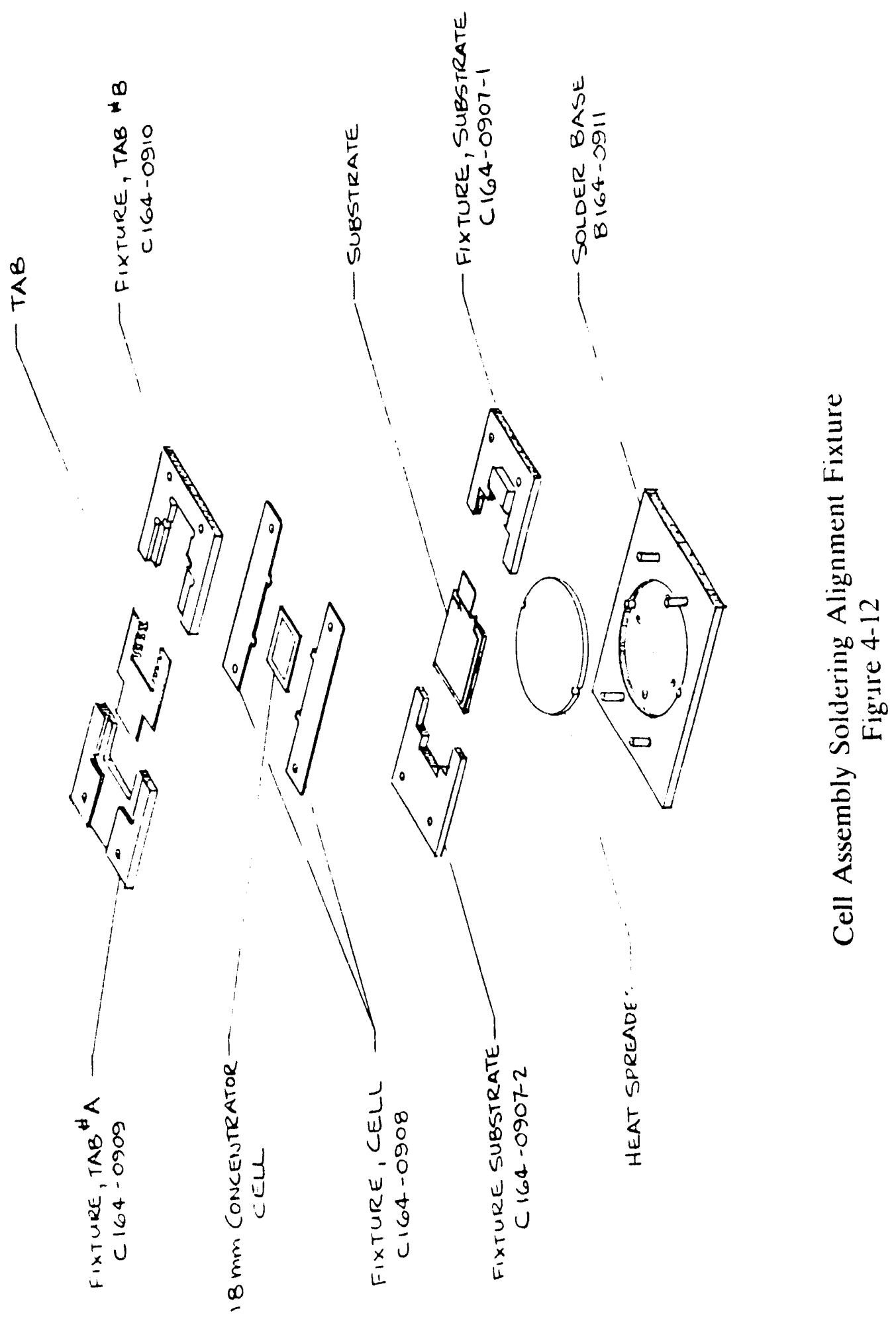


A three piece bending fixture was fabricated for putting in stress-relief hends in the sixteen small tabs on the front tab. The fixture comprises a hase and an anvil for aligning the tab and forming double radius bends and a guide plate for clamping the tab on the base and aligning the anvil. Front-contact pull-strength measurements revealed that a marked increase in pull strength was observed when solder joints terminated inside the outer edge of the cell contact band. The tab bending fixture was redesigned to shift the contact location of the tabs closer to the cell center.

\subsubsection{Vacuum Laminator Equipment Modification}

A SPI-LAMINATOR 240 was modified to operate at the higher temperatures required for the cell assembly soldering process. Higher temperature insulators and covers were installed, and the hardware and software high temperature limits were reset from $180^{\circ} \mathrm{C}$ to $260^{\circ} \mathrm{C}$.

A station for solder dipping heat spreaders has been installed in the Spire module development laboratory. The dipping station was originally built for solder dipping solar cells. The station performs automatic dipping of parts into a solder pot, eliminating the variations in solder thickness and quality that can result from hand dipping. The station includes a programmable dipping arm that can execute a single or a louble dip. Each dip has two separate and adjustable down speeds, two separate and adjustable up speeds and an adjustable dwell time in the solder. The solder temperature is also adjustable. A simple fixture was designed and built for holding the heat spreaders.

\subsubsection{Cell Assembly Fabrication}

The cell assembly fabrication process was developed by Spire and involves a multistep process. Figure 4-13 displays a fabrication flow chart that depicts the steps leading to vacuum soldering of the assembly and post-soldering activities. Spire prepared a set of technical specifications to describe the fabrication procedure. The specification numbers and titles are listed below:

CM100-02 Solder Dipping of Bare Copper Heat Spreader

CM120-03 Pretinning, $18 \mathrm{~mm}$ Cell Substrate

CM130-01 Pretinning, $18 \mathrm{~mm} \mathrm{Cell}$

CM1+0-01 Front Tab Preparation

CM150-02 Vacuum Soldering

CM160-01 Silicone Insulation Application

CM170-01 SOE Attachment 


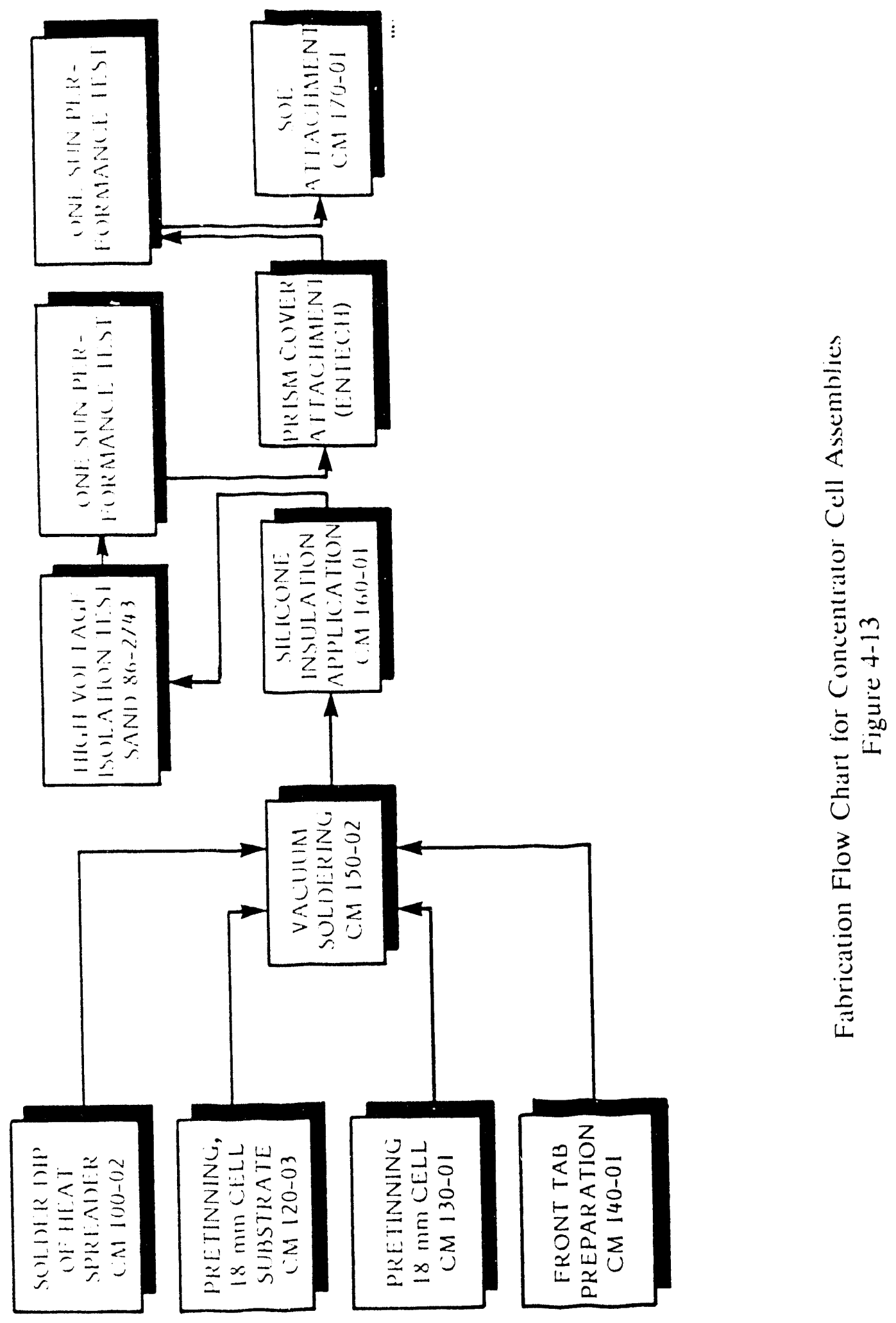


After the completion of preparatory activities, the alignment fixture is loaled with parts and placed in the laminator's vacuum chamber. The air is evacuated and the parts are heated until the solder melts. A light mechanical pressure (0.02 to 0.03 atmosphere) is applied inside the vacuum chamber with a pneumatic diaphragm to ensure that all of the components are in phyical contact. The diaphragm allows the pressure to be applied without disturbing the vacuum. Pressure and vacuum are maintained as the components are cooled until the solder freezes.

\subsubsection{Prismatic Cover Placement}

Prismatic cover placement was initially planned to be performed by Entech. The molding and placement processes are batch operations and would require modification if intended for a production environment. A moderately high personnel skill level is required to produce "calibrated" covers of the proper thickness and size to align with the grid lines. In additio:1, the adhesive's thickness and uniformity are critical, and the alignment of each cover is guided with the aid of a microscope.

After initial attempts at cover placement by Entech resulted in unacceptably low yields and lower cell efficiencies than expected. Sindia personnel developed alternative molding and placement processes aimed at increasing product yield and product quality. Although the results obtained by the Sandia team showed an improvement in both areas, transfer of these techniques to Entech petsonnel did not achieve the desired results. Therefore, the decision was made to not use the prismatic covers on cell assemblies for the prototype module. This decision was based on the extremely low yield of covered cell assemblies with acceptab! performance as delivered by Entech.

Others have experienced difficulties in prismatic cover placement and have measured lower than expected performance $f$ om covered cell assemblies. Silver and Patel at Solarex report that certain covering losses, such as local misalignments and delaminations, may he avoidable in the future. howerer the current process might be difficult to control in production."

\subsubsection{SOE Attachment}

The SOE attachment to the cell assembly was performed by Spire. The SOE is the finat component to be altatined to the ceil asseming. Generai Eiecric N-SIL. 128 silicone RTV was uned as the adhesive to bond the SOE to the front tabs. Bonding the SOF to the front tah was preferred to bonding along the 
cell SOE boundary so as to eliminate the possibility that ad hesive would encroach on the cell active areat.

\subsection{PRELIMINARY CELL ASSEMBLY TESTS}

Several preliminary cel! assembly tests were performed by the project team. The majority of these tests were conducted by Sandia and Spire. These experiments included soldering and ultrasound imaging of cell subassemblies, pull testing of cell contacts, and qualification testing of fabricated cell assemblies.

\subsubsection{Cell Subassembly Solder Bond Tests}

Spire prepared nine subassemblies using solder preforms of $\mathrm{Sn62}, \mathrm{Sn} 96$, and Indalloy $15 i$ for solder bond evaluation. The subassemblies consisted of pretinned copper rat spreaders, substrates and preforms. The subassemblies with Sn96 and Sn62 preforms were vacuum soldered without flux in the SPI-LAMINATOR 240. The subassemblies with Indalloy 151 preforms were vacuum soldered without flux in an electrostatic bonder due to the high liquidus temperature. Solder hond thicknesses ranged from $(0.028 \mathrm{~mm}$ to $0.071 \mathrm{~mm}$ $(0.0011$ inch 100.0028 inch) for the subassemblies processed in the laminator, while bond thicknesses ranged from $0.071 \mathrm{~mm}$ to $0.17 \mathrm{~mm}(0.0028$ inch to 0.0067 inch) for the subassemblies processed in the bonder. X-ray testing of the subassemblies detected minimal voids for the Sn62 and Sn96 samples, estimated at less than 5 percent of the total area. Void area for Inctalloy 151 was estimated to range from 5 to 20 percent.

Sandia also prepared six subassemblies using components provided by Spire. Sandia used the same solder alloy preforms but soldered with flux on a hotplate. Solder bond thicknesses ranged from $0.02 \mathrm{~mm}$ to $0.043 \mathrm{~mm}(0.0008$ inch to 0.0017 inch).

Ultrasound imaging tests were performed on all the subassemblies after fabrication and after exposure to 251 and 748 thermal cycles. Ultrasound imaging identifies solder delamination and poor surface wetting, discontinuities left undetected by x-ray imaging. The ultrasound imagirg results showed that Sn62 solder produced the best solder bonds. Also, the use of flux seemed to improve the subassemblies ability to withstand the thermal cycling.

Basec on the examination of these subasscmblies. Sn62 was selected for the protolype module ceil assembites due tó its siperior portormance over Sing and Indalloy 151 in thermal cycling tests, and the improved wetting of the solder due to the presence of flux. The flux selected was Multicore Xersin 2112, a 
noncorrosive flux with a low solids content. The large areas of the cell assembly solder bonds and the possibility l'at some flux residues would become trapped in the bond were considerations in this selection.

\subsubsection{Cell Contact Pull Tests}

Cell contact pull tests were conducted to ensure adequate strength of the cell front contacts. Destructive pull tests were performed on the soldered fingers of the front contact of cells with poor electrical performance. To tacilitate this test, the eight fingers of each of the two front tabs were separated by shearing the copper bus, thus resulting in 16 independent pull tests. Fingers were pulled at a 45-degree angle from the surface of the cell

Initial tests by Spire revealed that the front contacts peeled from the underlying oxide layer at low forces of less than 160 grams $(0.36 \mathrm{lb})$. Sandia and UNSW also performed pull-strength measurements on cell front tabs and experienced similar results. Further investigation by UNSW revealed that soldered front tab pull strength was markedly increased when the solder joints teiminate inside the edge of the cells' contact band, rather than extending t" the cell edge. Therefore, in order to improve tab pull strength and increase module reliability. the tab bending fixture was redesigned to bring the stress relief bends closer to the center of the cell. Section 4.2.1 provides a more detailed description of the bending fixture.

Further pull-strength testing was conducted on front tabs as shaped by the redesigned bending fixture and resulted in coisistently high force values exceeding 5700 grams $(12.5 \mathrm{lbs})$. These high pull-strength values are a positive indication that the solder joints and contacts should withstand the rigors of terrestrial operation.

\subsubsection{Cell Assembly Evaluation Tests}

Sandia conducted a series of evaluation tests on five prismatically covered cell assemblies." The evaluation tests were defined in the statement of work for this contract: these tests are now the basis of the SAND86-2743 document entitled Qualification Tests for Photovoltaic Concentrator Cell Assemblies and Modules. ${ }^{*}$ Each cell assembly was required to pass these tests before authorization was given to proceed with the module fabrication activities. The test sequence used for evaluating the cell assemblies is shown in Figure 4-14, and the corresponding test 


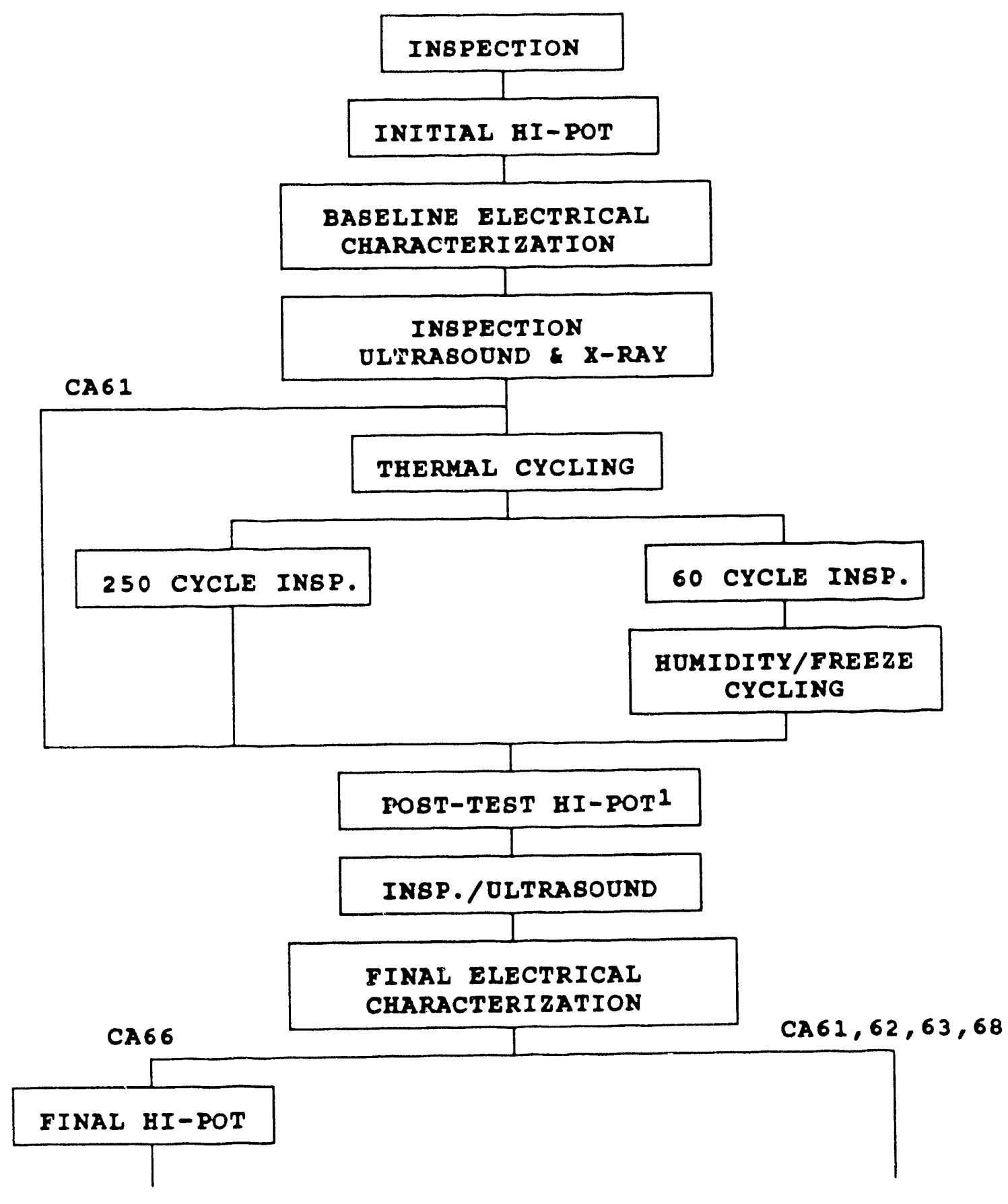

1 Within 1 hour for humidity/freeze units

Cell Assembly Evaluation Test Sequence

Figure 4-14 
specifications are shown in Table 4-1. The test sequence includes two environmental tests, thermal cycling and humidity/freeze cycling, to which the samples are subjected.

All the evaluation tests were successful with the exception of the failure of one of the assemblies to pass the high voltage isolation test after humidityifreeze cycling and the presence of large void areas in the two solder honds. The failed unit broke down at 1750 volts but was required to survive 2200 volts. Alter the unit was dried, it was retested and passed the 2200-volt requirement. All cell assemblies show voids in excess of 10 percent in both solder bonds. This was not a rejection criterion for this contract, although it is rejection criterion given in the qualification test requirements. The cell assembly was given a conditional acceptance despite this breakdown and the large voids because the failure was not catastrophic, and the module is not scheduled for a production system.

A summary of the evaluation test report prepared by Sandia is provided below for the results of the visual inspection, voltage isolation tests, electrical characterization, thermal cycling and humidity freeze cycling tests, and the $x$-ray and ultrasound testing of the solder bonds.

4.3.3.1 Visual Inspection. The initial visual inspection andicated that the cell assemblies "generally looked good," except with respect to the prismatic cover positioning. Slight misalignment of the prismatic covers with the cell grid metallization around the cell edges was noticed on most cell assemblies. Also, the tops of the covers were not flat.

4.3.3.2 Voltage Isolation Tests. All cell assemblies passed the initial 2200-volt hi-pot test. No leakage current was detected during the one minute voltage duration. The voltage level for this test was the default value in reference 8 , since no system voltage requirements are defined for these cell assemblies.

Within one-half hour after being removed from the humidity freeze chamber, two cell assemblies were subjected to a post-test hi-pot test. Although one cell assembly passed the hi-pot test, the other assembly failed at 1750 volts when the leakage current exceeded 50 Hamps. At the same time the other three cell assemblies, two of which had been subjected to 250 temperature slock cycles, were also subjected to the hi-poc test and each passed the 2200-volt hi-pot with no observed leakage. A second attempt by the failed cell assembly resulted in a breakdown at 2100 volts. This assembly was placed in a sealed bag with a desiccant for 3 days and when again subjected to the hi-pot test, achieved 2200 -volt isolation with no observed leakage current. 


\begin{tabular}{|c|c|c|c|c|c|c|c|c|}
\hline 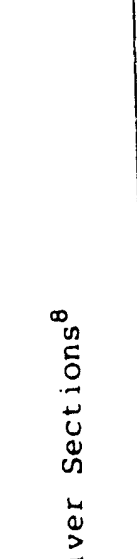 & 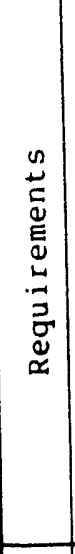 & 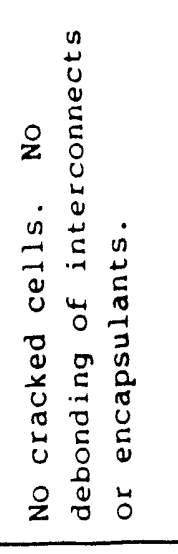 & 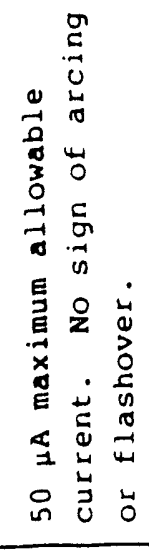 & & 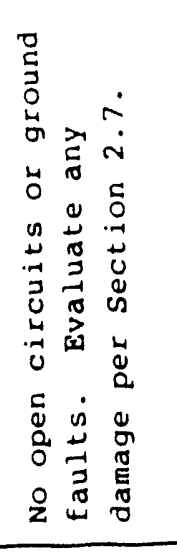 & 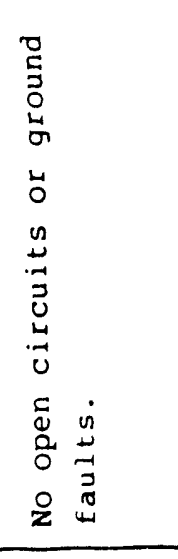 & 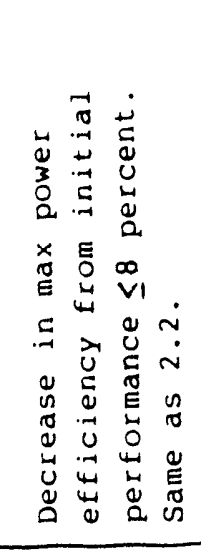 & 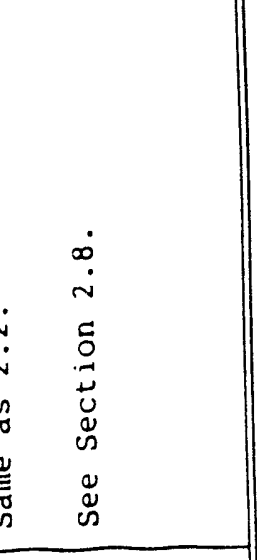 \\
\hline 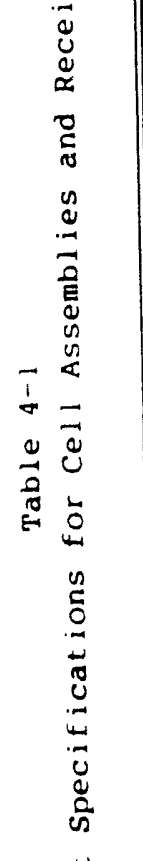 & 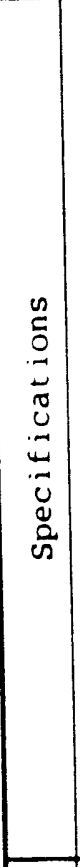 & 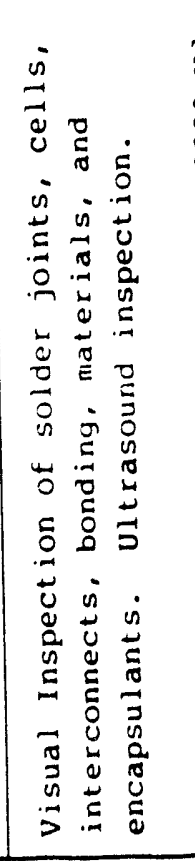 & 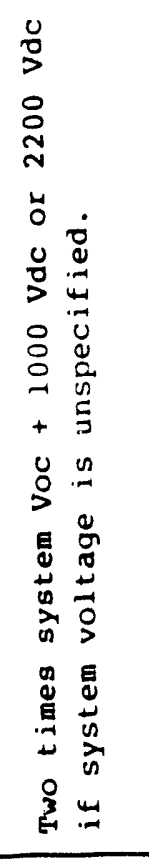 & 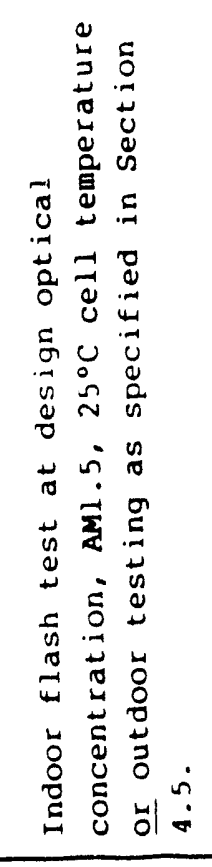 & 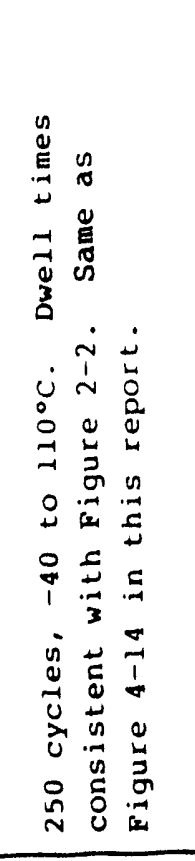 & 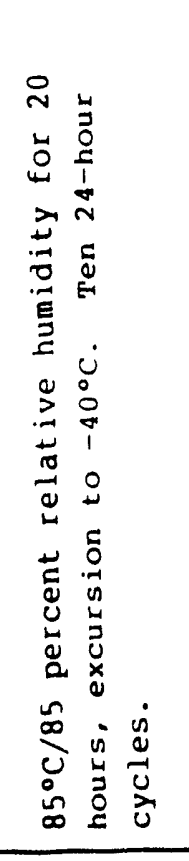 & 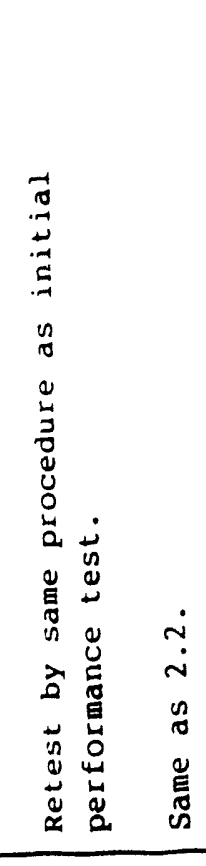 & 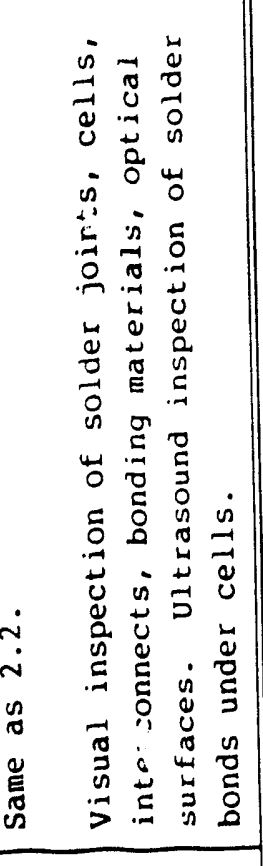 \\
\hline 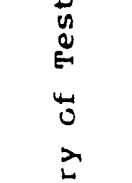 & 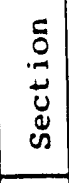 & $\vec{i}$ & $\underset{\sim}{\sim}$ & $\stackrel{m}{i}$ & $\dot{i}$ & $\stackrel{n}{i}$ & $\stackrel{\stackrel{i}{i}}{ }$ & 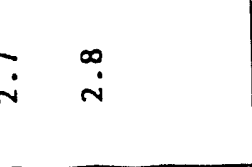 \\
\hline$\vec{\omega}$ & 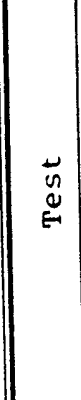 & 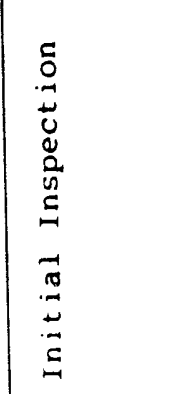 & 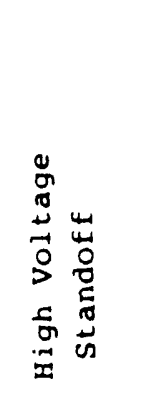 & 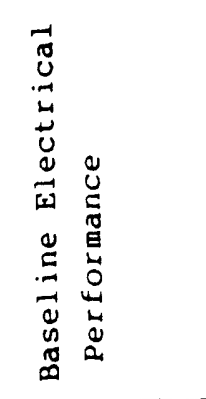 & 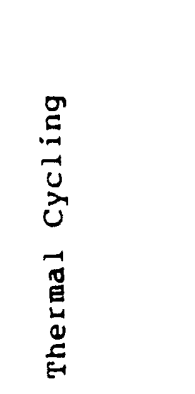 & 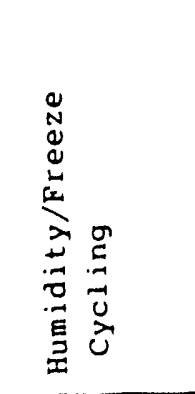 & 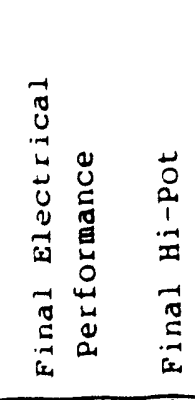 & 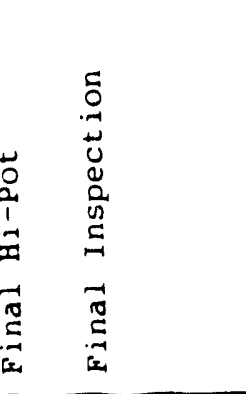 \\
\hline
\end{tabular}


The breakdown was suspected to have occurred at the edge of the ceramic between the cell bottom contact and the heat spreader. At this interface the insulation path is only about $0.51 \mathrm{~mm}(0.020$ inch). Spire had also observed voltage breakdown along this path and had cleaned and encapsulated the area with RTV.

Because in operation the single prototype module would not be subjected to these high voltages, and because redesigning the substrate was not feasible, the decision was made to thoroughly clean and encapsulate the substrate edge with void-free RTV to prevent the reoccurrence of this voltage breakdown. Future substrate design alternatives exist that may avert this high voltage breakdown. An increase in the size of the alumina wafer would provide a longer surface path length between the cell bottom contact and the heat spreader. Also, a bend in the cell bottom contact away from the alumina wafer would increase the distance to the heat spreader.

4.3.3.3 Electrical Characterization. The baseline electrical tests were conducted at approximately $190 \mathrm{X}$ in Sandia's cell development laboratory flash tester. The cell assembly with the poorest electrical performance prior to SOE placement was chosen as the control unit and was not subjected to the environmental tests. The flash tester fixture was positioned so that this assembly with SOE produced the same 9.98 -amp short-circuit current at $25^{\circ} \mathrm{C}$ cell temperature that was previously obtained at $190 \mathrm{X}$ for this unit without SOE. All cell assemblies were tested with the flash tester fixture at this position. The control unit average efficiency was 19.8 percent with a maximum power output of 5.97 watts. The average efficiencies for the other four assemblies were 19.8, $20.5,19.9$ and 20.5 percent with maxim: m pewer outputs of $6.17,6.25,6.25$, and 6.11 watts.

The final electrical tests were conducted following hi-pot tests, $x$-ray and ultrasound imaging, and thermal shock cycling tests on the four non-control assemblies, and the additional humidity/freeze cycling tests on two of the four non-control assemblies. All cell assemblies exhibited essentially the same maximum-power efficiency as for the baseline characterization. The control unit's efficiency showed about a 1-percent degradation, as did three of the four noncontrol assemblies. The fourth assembly showed a 3-percent improvement. These slight performance variations are within the realm of expected measurement error. 


\subsubsection{Thermal Shock and Humidity/Freeze Cycling Tests. The four}

noncontrol assemblies were subjected to 60 cycles of cemperature shock as prescribed in Figure +-15 . Visual examination revealed no signs of degradation. The two assemblies that showed the most and the least voids as determined by the ultrasonic testing were returned to the cycle chamber to accumulate a total of 250 cycles. These assemblies showed no apparent signs of degradation.

The other two of the assemblies were subjected to 10 cycles in the humidity/freeze chamber with environmental settings as prescribed in Figure 4-16. Visual observations after the assemblies were removed from the chamber revealed no degradation.

4.3.3.5 X-ray and Ultrasound Testing of Solder Bonds. X-ray and ultrasound testing was performed on the cell assemblies to discern the solder bond void area and void location. The $x$-ray images were taken prior to environmental testing at two $x$-ray incident angles from the cell perpendicular to establish a stereo image that allowed determination of the interface in which the voids were located. All images show voids with total area greater than 10 percent of the cell area.

The ultrasound images were taken prior to and after environmental testing. These images showed extensive voids in both solder bonds of the cell assemblies, although no significart differences in void area were observed after environmental testing indicating inat these tests caused no damage to the solder bonds.

The acceptance criterion for solder void area was not defined in the qualification requirements defined at the onset of this project. Because no deterioration in bond quality was observed following environmental testing, the cell assembly solder bonds were deemed acceptable. Although the bond strength may be adequate, the large number and size of these voids may result in in increase in the cell's normal operating temperature and thus lower the cell effictericy. This condition was recognized as being possibly critical for large-scale implementation. however the soldering procedure was qualified for use in the fabrication of cell assemblies for the prototype module.

\subsection{MODULE CELL ASSEMBLY TESTS}

Spire made 32 cell assemblies to provide a pool of assemblies for selection and placement in the prototype module. These cell assemblies wert not covered with prismatic covers. After being fabricated, these cell assemblies were tested outdoors by Sandia at the Photovoltaic Advanced Solar Test Facility. The results of these tests reported in the following sections nere used to establish the grouping of cells for placement in the module. 


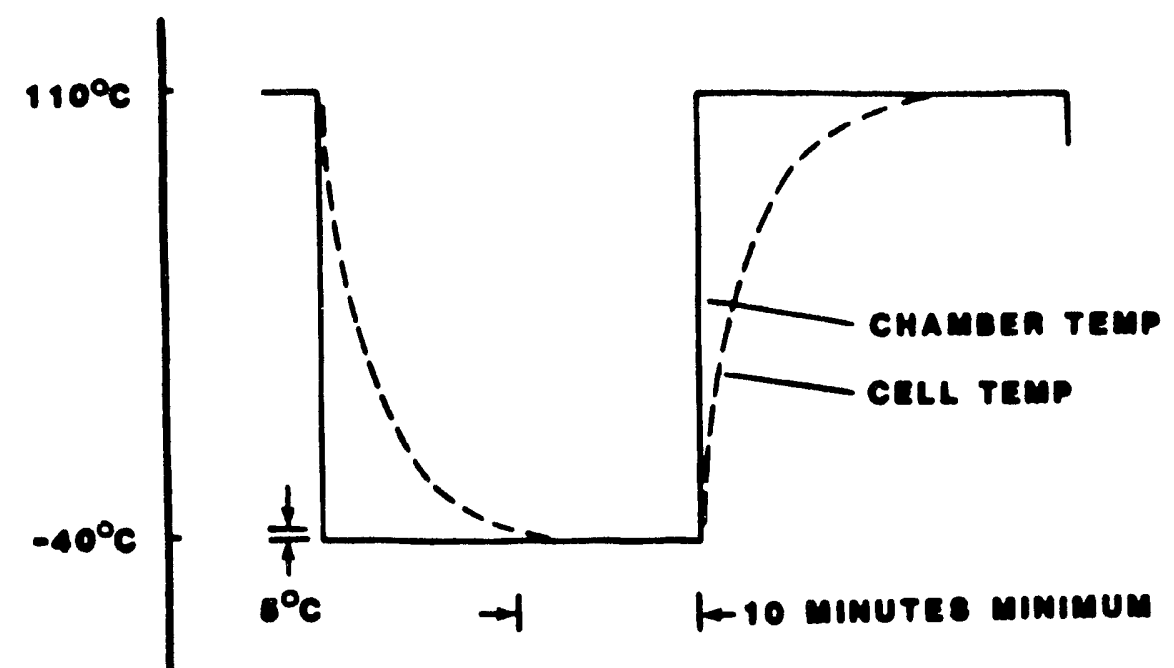

TOtal crele tIME -

Thermal Cycle for Cell Assemblies

rigure +-1.5

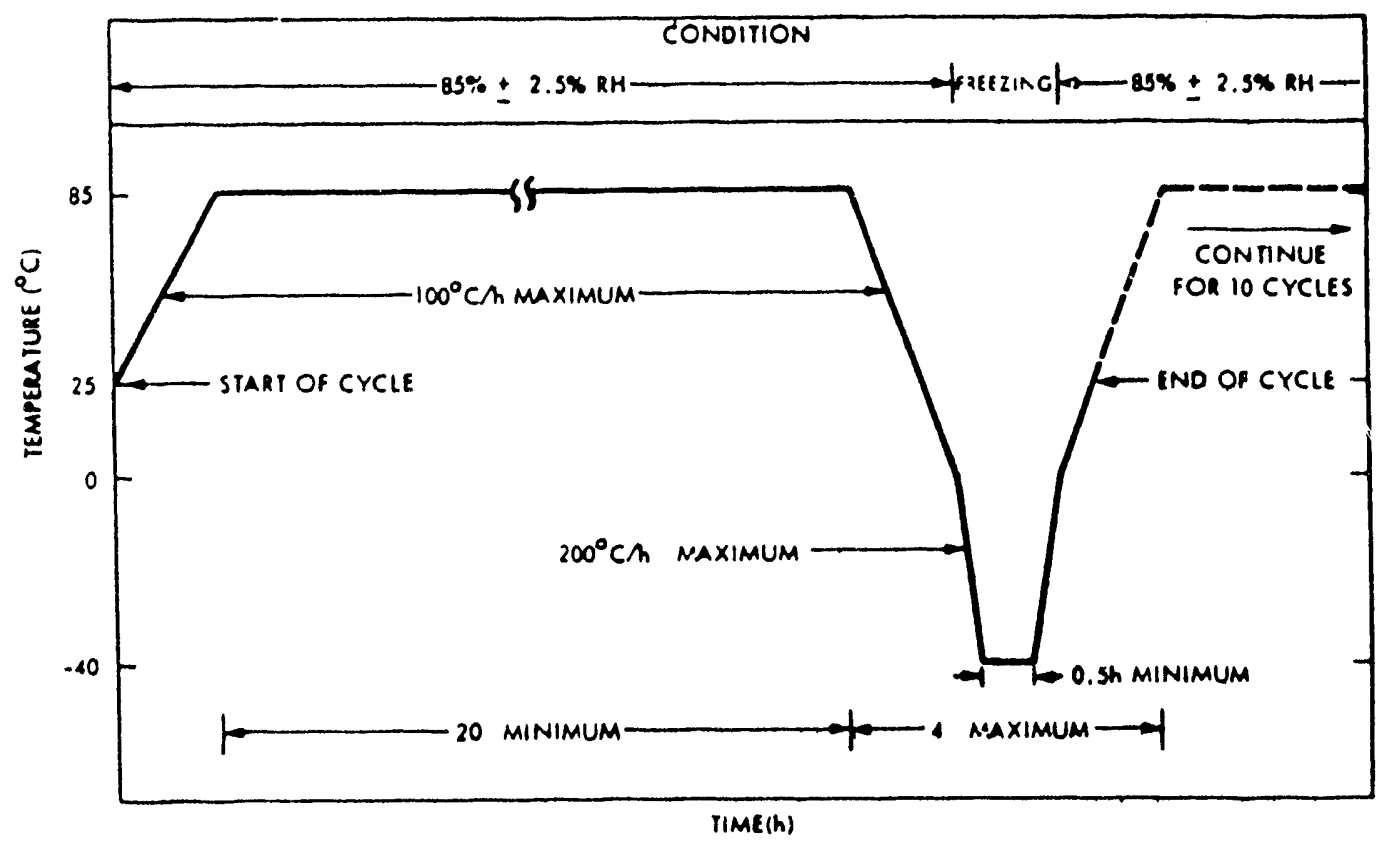

Humidity/Freeze Cycle for Cell Assemblies

Figure 4-16 


\subsubsection{Outdoor Performance Tests}

Sandia conducted outdoor lens/cell performance measurements on 32 cell assemblies. The assemblies consisted of a solar cell, a reflective secondary, a direct-bonded copper-on-alumina substrate, and a copper heat spreader. These outdoor tests provided complete current-voltage (IV) curve data for each cell assembly at the measured test conditions. These test conditions include direct normal insolation, ambient temperature, wind speed and direction, and cell assembly temperatures (as measured by thermocouples).

Each cell assembly was tested with a lens identical to the parquet lenses used in the prototype module. The lens-to-cell spacing was maintained at $204 \mathrm{~mm}$ ( 8.03 inches) for all tests. The cell assemblies were fastened to a "paddle" for ease of placement within the test apparatus. Coolant flow through the paddle maintained an approximate $25^{\circ} \mathrm{C}\left(77^{\circ} \mathrm{F}\right)$ heat spreader temperature. The temperature differential between the cell and heat spreader was estimated to be 10 to $15^{\circ} \mathrm{C}$, based on a thermal analysis of a similar cell assembly. The direct normal insolation (DNI) data were measured with a normal incident pyrheliometer and a standard cell. A thermocouple was embedded in the paddle beneath the cell assembly to measure the paddle temperature.

Figure +-17 displays the variation in normalized IV curve data as depicted by minimum and maximum values for both current and power over a voltage range from 0 to 0.78 volts for the 32 cell assemblies. The current values are normalized to $100 \mathrm{~mW} \mathrm{~cm}^{2}$ DNI as given by the standard cell insolation readings. The Isc values vary from 7.21 amps to 7.91 amps, the peak power values ranged from 4.20 watts to 4.66 watts, and the Voc values vary from 0.736 volts to 0.780 vults.

Pertormance comparisons of the 32 cell assemblies are provided in Figures 4-18 and 4-19 in ine chart form for key performance parameters. The following list summarizes the average values for the 32 cell assemblies at a normalized DNI of $100 \mathrm{~mW} / \mathrm{cm}^{2}$ and with an estimated cell temperature of 35 to $40^{\circ} \mathrm{C}$.

$\begin{array}{ll}\text { Short Circuit Current, } & \text { Isc }=7.53 \text { amps } \\ \text { Open Circuit Voltage, } & \text { Voc }=0.758 \text { volts } \\ \text { Maximum Power Current. } & \text { Imp }=7.13 \text { amps } \\ \text { Maximum Power Voltage, } & \text { Vmp }=0.621 \text { volts } \\ \text { Fill Factor, } & \mathrm{FF}=77.7 \text { percent } \\ \text { Total Efficiency, } & \mathrm{Eff}_{2}=15.3 \text { percent } \\ \text { Optical Efficiency, } & \mathrm{Eff}_{n}=77.6 \text { percent } \\ \text { Cell Efficiency, } & \text { Eff }_{\mathrm{c}}=19.7 \text { percent }\end{array}$




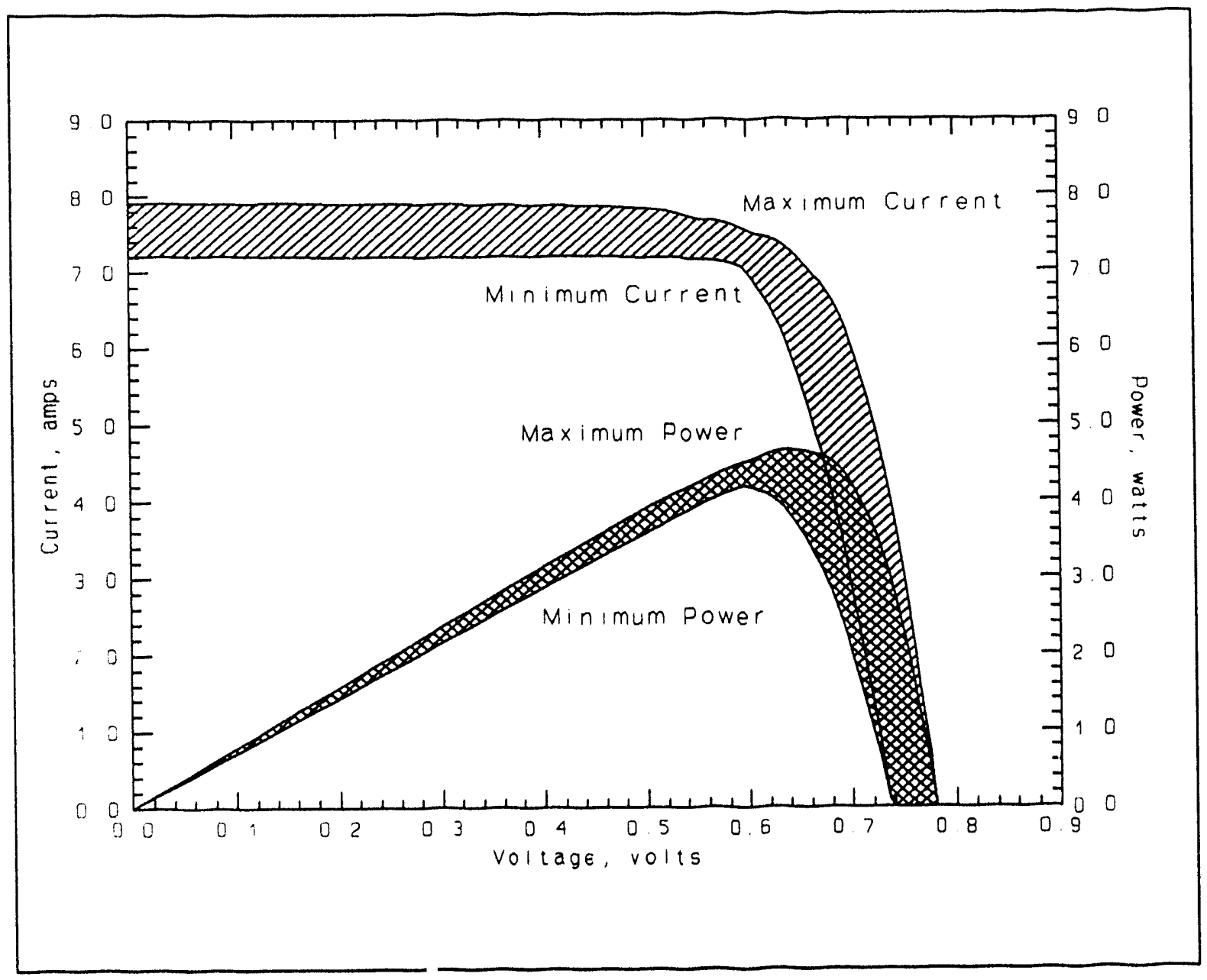

Normalized IV and Power Curve Data Ranges for Outdoor Tests of 32 Cell Assemblies

Figure 4-17 


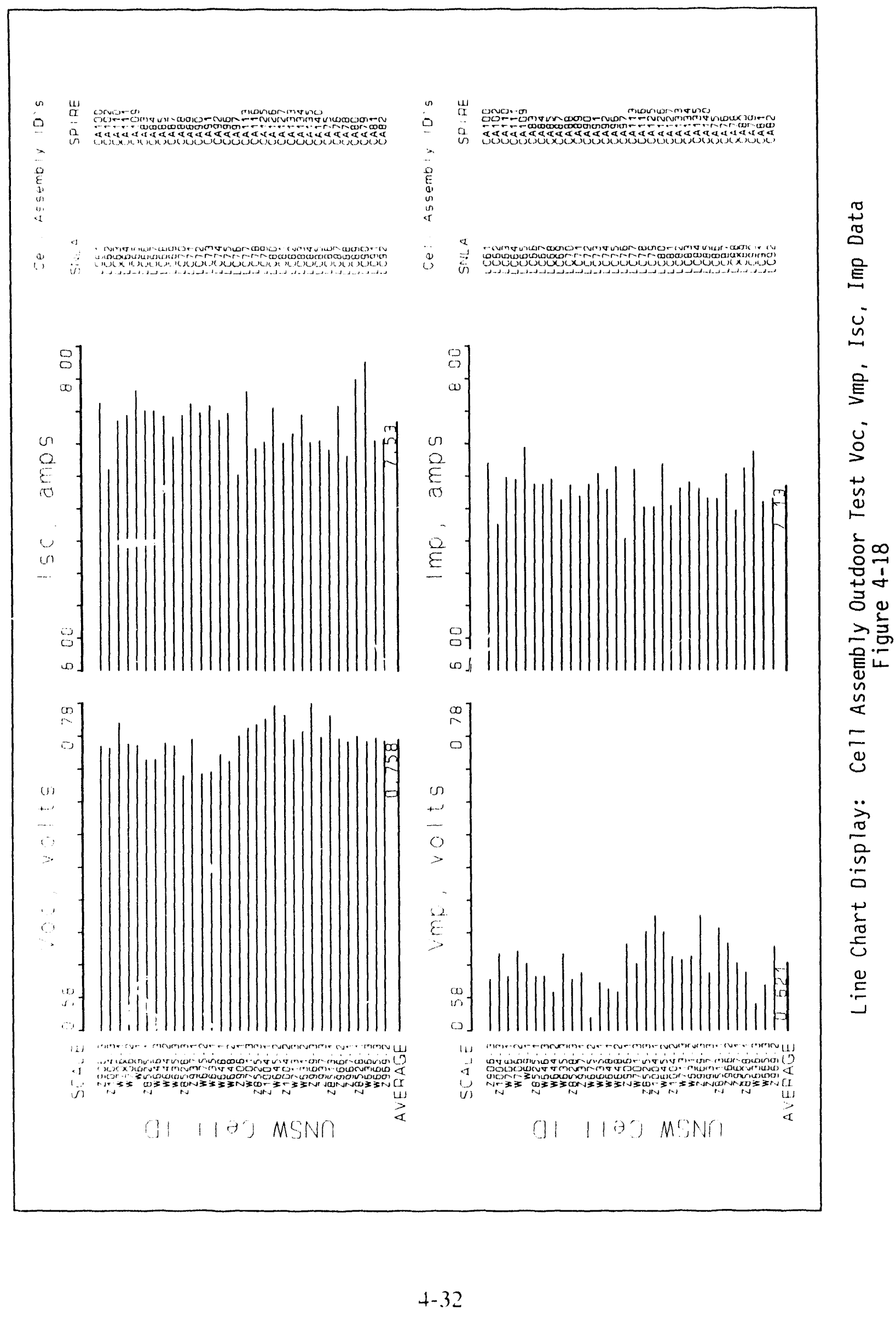




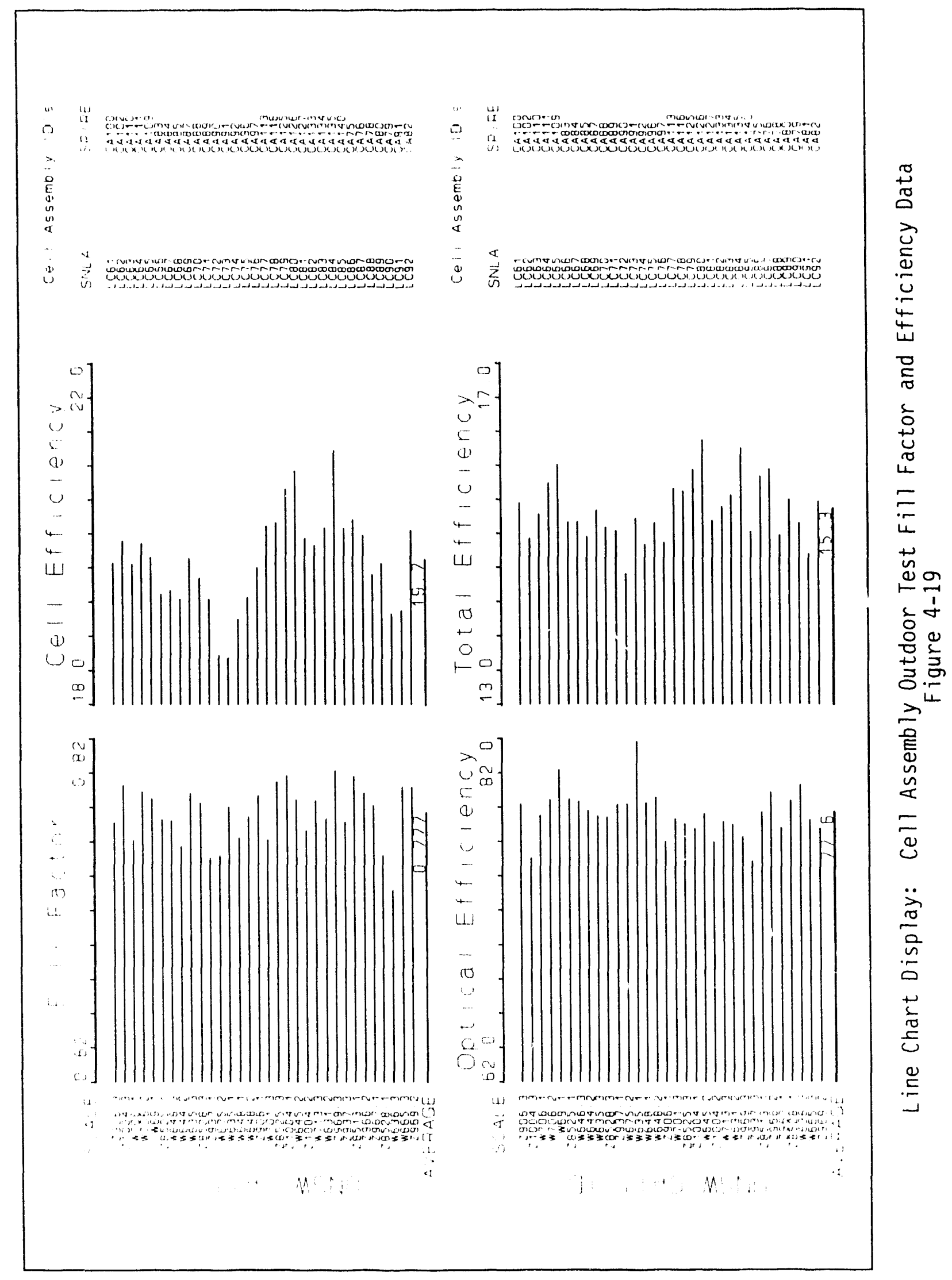


The geometric concentration of the lens-cell combination is $185 \mathrm{X}$, as determined by the ratio of lens area $\left(289 \mathrm{~cm}^{2}\right)$ to cell area $\left(1.56 \mathrm{~cm}^{2}\right)$. The measured concentration averages about $1++X$, as determined by the ratio of the normalized, outdoor Isc values of the lens-cell combination to the one-sun, indoor lsc values of the flash-tested cell assemblies. Therefore. the average optical efficiency of the primary lens and reflective secondary element is about 77.6 percent, as given by the ratio of measured concentration to the geometric concentration. This optical efficiency (primary lens and SOE) value is used to compute the cell efficiency by dividing the total efficiency by the optical efficiency.

\subsubsection{Cell Assembly Grouping Activities}

A procedure was developed to select, sort, and arrange cell assemblies in the prototype module according to measured performance parameters. This procedure provides a reasonable and systematic approach that reduces the uncertainty in estimating the collective performance of cells in a module caused by variations in individual cell performance. This procedure uses the outdoor performance measurements of 32 cell assemblies as the database for estimating the performance of the 24 -cell prototype module. The basic elements of this procedure are listed below and are lescribed in this section:

- Performance normalization and cell selection

- Substring sorting and grouping

- Module performance estimates

- Module cell assembly arrangement

4.4.2.1 Performance Normalization and Cell Selection. The IV curve data were normalized to $100 \mathrm{~mW} / \mathrm{cm}^{2}$ insolation so that selection of the best performing cells could be made on a common basis. The standard cell insolation level was chosen for this normalization because standard cells were used to establish intensity levels for the indoor flash test conducted on these cell assemblies. Variations in performance due to spectral content, wind speed, and slight fluctuations in tracker alignment and heat-spreader temperature were considered second-order effects that would have minimal impact on this comparative procedure.

Figure 4-20 compares the peak power values of the 32 cell assemblies in line chart form. The $2+$ cell assemblies selected are listed by cell assembly identification numbers in the center of the figure. The selected cell assemblies are. with few exceptions, the highest pouer producers. Exceptions to this 


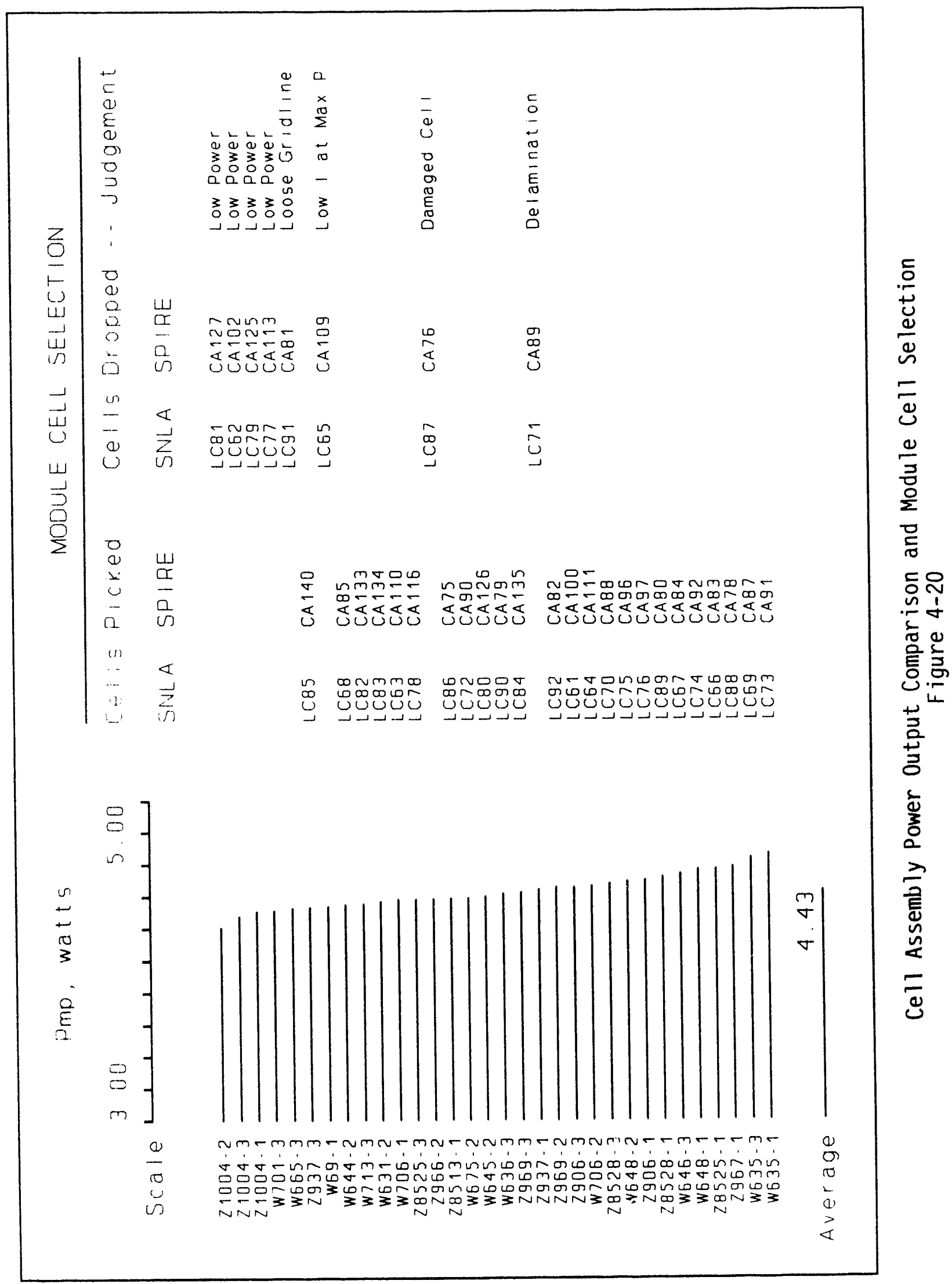


criterion include eliminating those cells damaged after outdoor measurements and eliminating those cells with low current at the peak power point. The cell assemblies dropped from consideration for the use in the module are listed on the right of the figure.

4.4.2.2 Substring Sorting and Grouping. The prototype module electrical configuration comprises 3 series blocks. Each series block consists of two parallel strings of four series cells each. Determination of this module electrical configuration is described in Section 3.4.2. The 2t cells selected for the module were sorted and grouped according to the following scheme.

To determine the six four-cell substring groupings, the cells were sorted by voltage at common current levels and grouped by matching summed four-cell voltages. Because the cells of a substring must carry the same current level, voltage and power relationships were estimated for all cells at several current levels. Voltage and power levels were interpolated from the normalized IV curve data for each cell. Current levels of 7.02, 7.10, 7.18, and 7.26 were chosen from a review of the peak power currents. Under normal operating conditions, the substring current levels are expected to be near the peak power current of individual cells. Figure +-21 illustrates the voltages for the 24 cell assemblies and the grouping of these cells into four-cell substrings.

The e six substrings were grouped into three sets of two substrings; each set comprising a series block. Within a series block the substrings operate at the same substring voltage but can carry differing amounts of current; however, the total current carried by each series block must be the same. The substrings that compose the three series blocks were chosen by matching substring voltages, although this voltage matching was essentially inconsequential, as the six substring voltage estimates varied by less than 1 percent.

4.4.2.3 Module Performance Estimates. Module performance estimates were obtained for the cell assembly arrangement by using a module performance simulation model developed by Black \& Veatch. The performance simulation model uses an iterative approach to balance the voltage and current constraints of the module electrical configuration.

The module's three series blocks are designated $A, B$, and $C$. The two substrings that compose each series block are designated 1 and 2. An initial estimate of the Al operating current, $I_{\lambda 1}$, provides the starting point for the performance simulation. Module output estimates, in watts, are determined from the following set of procedures. 


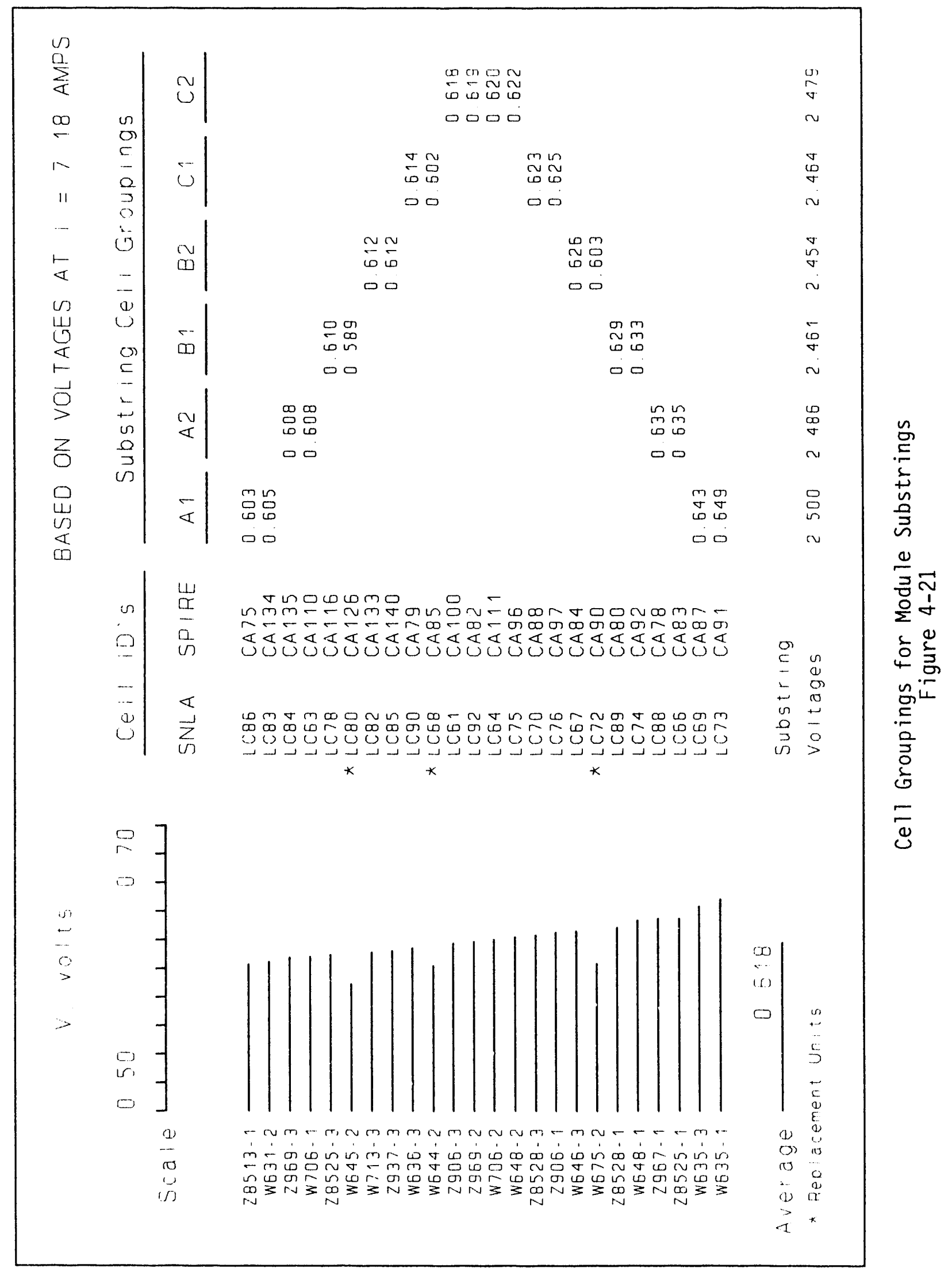


Step 1. Choose an operating current, $I_{A 1}$, near the Pmp current level for substring 1 of series block $A$.

Step 2. Determine the voltage, $V_{A 1}$, generated in substring $A l$ at current $I_{A}$.

Step 3. Force substring 2, series block $A$ to operate at $I_{A_{2}}=I_{A 1}$.

Step 4. Determine the voltage, $V_{A_{2}}$, generated in substring $A 2$ at current $I_{A 2}$.

Step 5. If $V_{A_{2}}=V_{A_{1}}$, then go to Step 6. If $V_{A_{2}}<V_{A_{1}}$, then decrease $I_{A_{2}}$. If $V_{A_{2}}>V_{A_{1}}$, then increase $I_{A_{2}}$. Go to Step 4 .

Step 6. Series block $A$ voltage is $V_{A}=V_{A_{1}}=V_{A_{2}}$.

Step 7. Series block $A$ current is $I_{A}=I_{A 1}+I_{A 2}$. Also, total module current is $I_{A}$.

Step 8. Continue for series block B and then series block C.

Step 9. Assume that series block B substrings carry equal current, $\mathrm{I}_{\mathrm{B} 1}=\mathrm{I}_{\mathrm{B} 2}=0.5 * \mathrm{I}_{\mathrm{A}}$.

Step 10. Go to Step 2.

Step 11. Module voltage is $\mathrm{V}=\mathrm{V}_{\mathrm{A}}+\mathrm{V}_{\mathrm{B}}+\mathrm{V}_{\mathrm{C}}$.

Step 12. Module power is

$$
P=\left[V_{A}{ }^{*}\left(I_{A 1}+I_{A 2}\right)\right]+\left[V_{B} *\left(I_{B 1}+I_{B 2}\right)\right]+\left[V_{C} *\left(I_{C l}+I_{C^{2}}\right)\right]
$$

Based on this simulation model, a module output estimate of 107 watts was obtained for a $100 \mathrm{~mW} / \mathrm{cm}^{2}$ direct normal insolation level and $25^{\circ} \mathrm{C}$ paddle temperature (imputed $35^{\circ} \mathrm{C}$ to $40^{\circ} \mathrm{C}$ cell temperature). Adjusting to account for the estimated $68^{\circ} \mathrm{C}$ cell operating temperature results in a derate of about 15 percent, which gives a derated module output estimate of 91 watts. For comparison, the measured module output, normalized to $100 \mathrm{~mW} / \mathrm{cm}^{2}$ and taken during initial module electrical characterization, was 88.9 watts. Section 6.1 provides a more thorough discussion on the interpretation of the measured module performance.

4.4.2.4 Module Cell Assembly Arrangement. Figure 4-22 displays a schematic of the cell assembly arrangement and the estimated voltage, current, and power relationships of the module as determined by the simulation model. The power output estimate is 99.7 percent of the summed individual peak power level of each cell. This high merit value indicates a high consistency in cell assembly performance, which is attributable to a high degree of quality control throughout the cell fabrication process and the cell assembly fabrication process. 


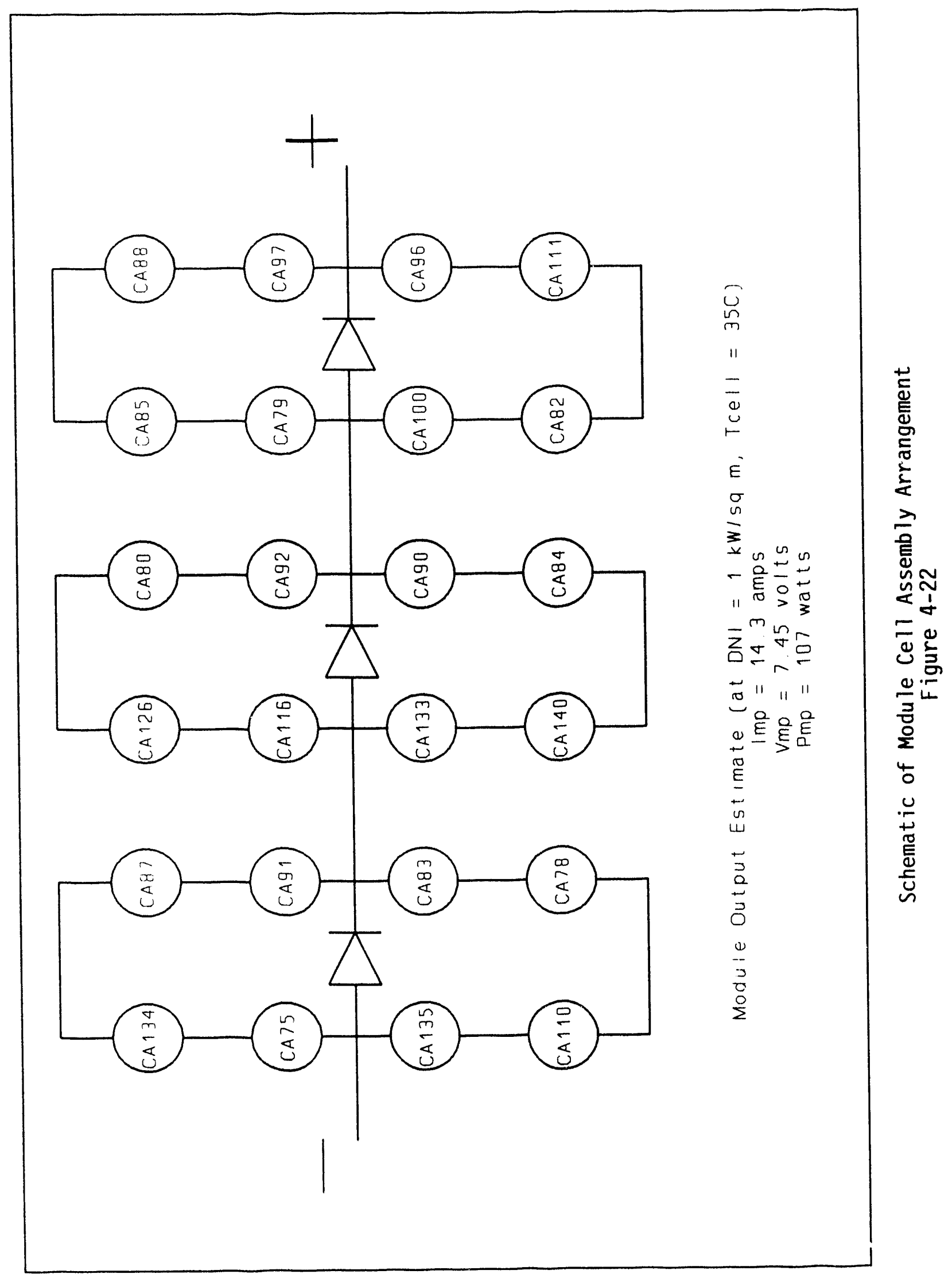




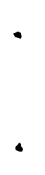




\subsection{PROTOTYPE MODULE FABRICATION AND ASSEMBLY}

The prototype module fabrication and assembly activities were conducted by Solar Kinetics and Black \& Veatch. Solar Kinetics' activities included the procurement and fabrication of the prototype housing, cell interconnect straps, module feedthrough, and bypass diode mounts, the assembly of all module components into a working unit, and the preliminary testing of the prototype module. Black \& Veatch performed an analysis of dimensional tolerances that functioned as a quality control document during the fabrication process. This section describes the various aspects of the fabrication and assembly process of the prototype module.

\subsection{MODULE FABRICATION}

Numerous preparatory activities were required before the prototype module components were ready for assembly. These preparatory activities included dimensional tolerance estimations, housing fabrication, and parquet sizing; they are described in the following paragraphs.

\subsubsection{Dimensional Tolerances}

A cumulative and root-mean-square (RMS) error budget for the module depth was estimated from dimensional data obtained from component fabrication and testing efforts. The module depth is defined as the distance from the powerplane of the lens to the top plane of the cell. Cell assembly experiments, housing deformation measurements, parquet measurements, and adhesive thickness analysis contributed to a greater understanding of the expected uncertainty in module lens-to-cell spacing.

Figure $5-1$ is an elevational view of the module that defines the key dimensions for determining the module depth. Figure 5-2 provides detailed drawings of the parquet edge and the cell package. All dimension descriptions, symbol clefinitions, design dimensions and uncertainties are provided in Table 5-1. The cumulative estimated uncertainty due to component thickness/depth variations is $204 \pm 1.45 \mathrm{~mm}$ (8.03 \pm 0.057 inches). The RMS value is $204 \pm 0.59 \mathrm{~mm} \quad(8.03 \pm 0.023$ inches $)$. Comparison of these estimated uncertainties with the performance estimates stated in Section 3.2.2 indicates that less than a one-percent performance degradation would be expected for these lens-to-cell spacing variations. 


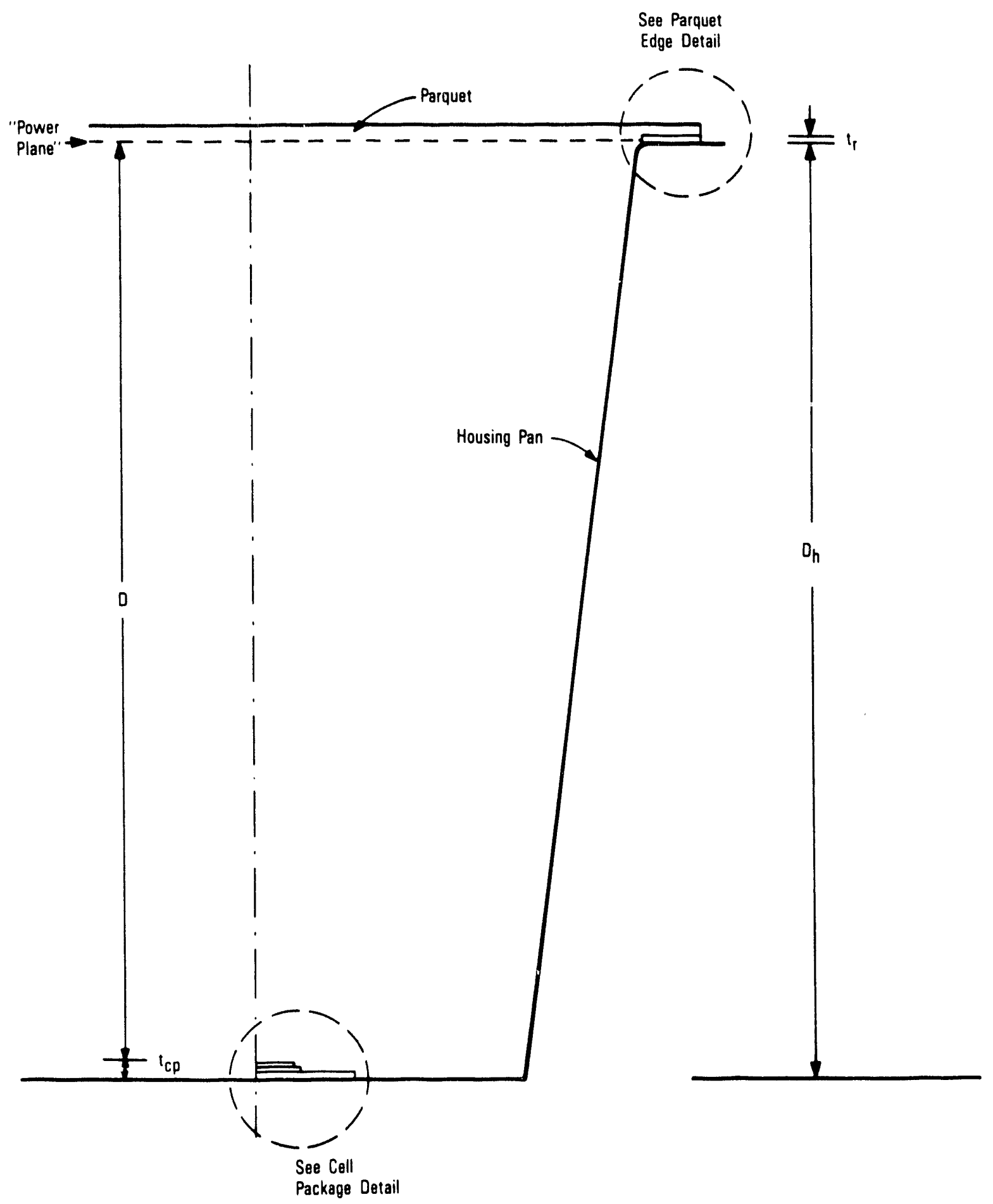

Module Depth Diagram -- General

Figure 5-1 
Parquet Edge Detail

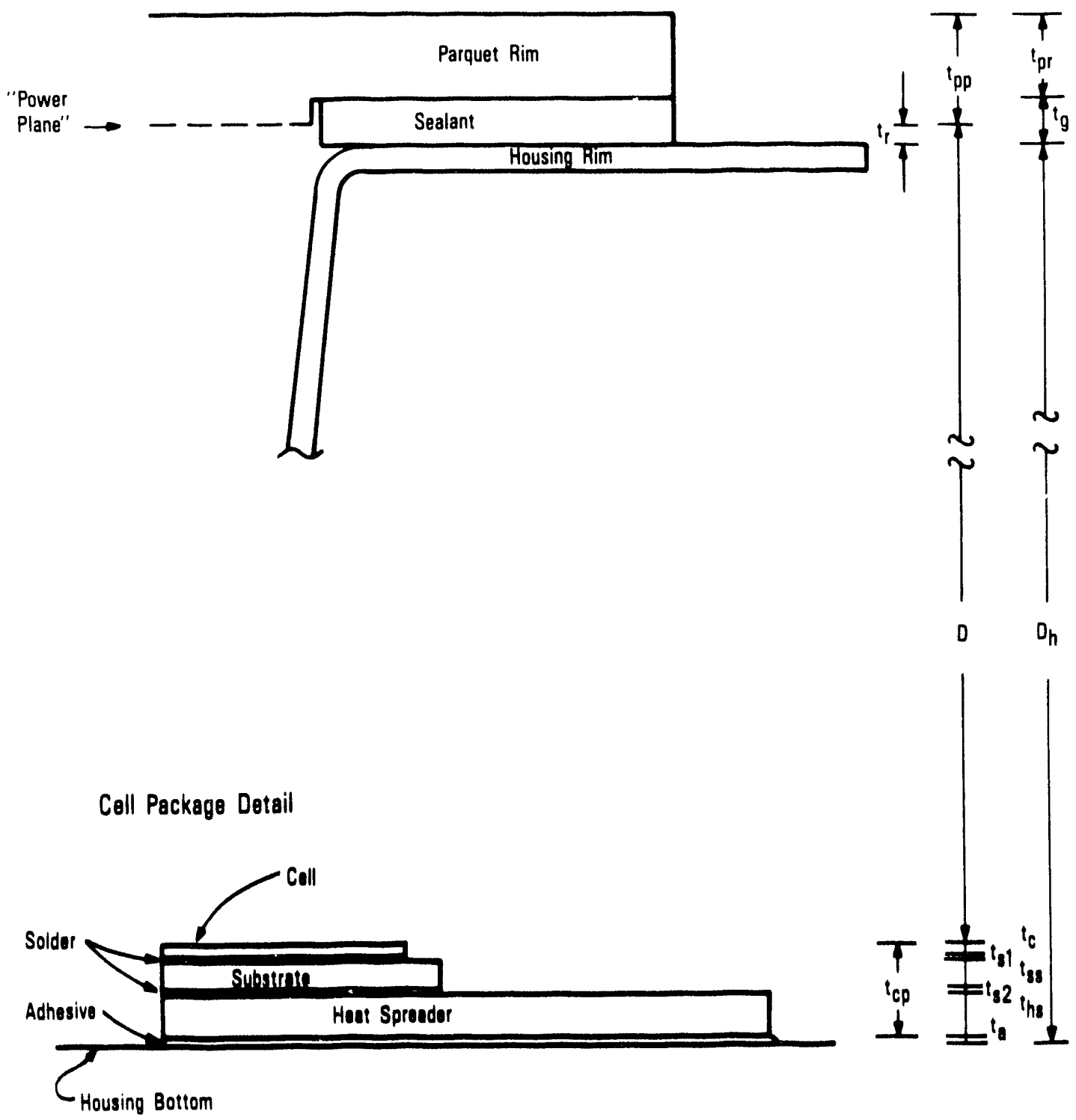

Module Depth Diagram -- Details

Figure 5-2 


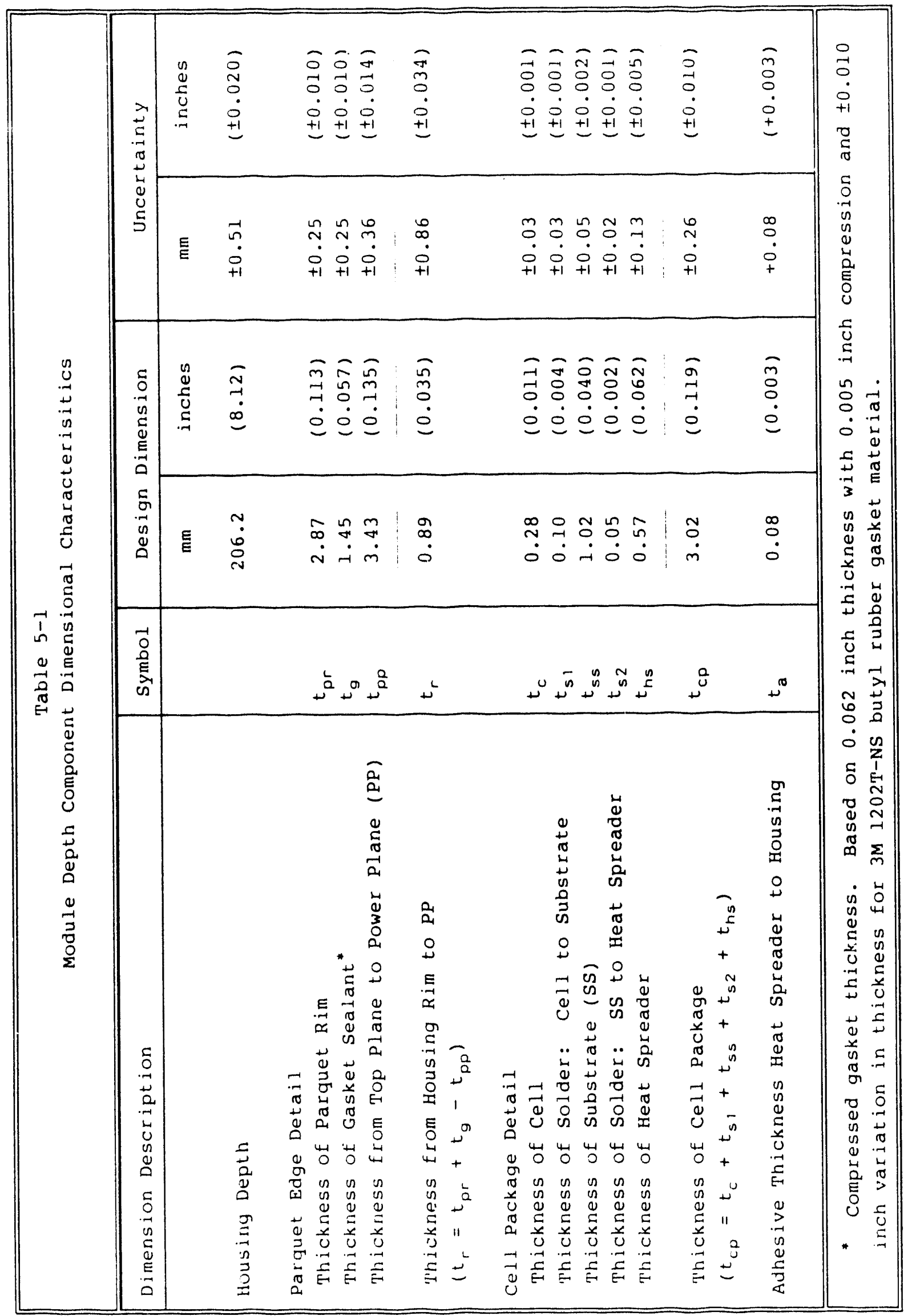




\subsubsection{Housing Fabrication}

The prototype module housing material is 20-gauge (0.036-inch) aluminized sheet steel. Previous work on high concentration PV module design by Black \& Veatch for EPRI considered hoth aluminum and steel as candidates for the housing material." Aluminum exhibits good thermal characteristics and offers excellent corrosion resistance to the environment. Steel offers substantially greater stiffness per unit of cost and lower manufacturing costs. The selection of aluminized steel was based on its expected lower production cost than that for aluminum housings.

The housing was fabricated by welding formed sections of the corrugated primary pan and two secondary side members. The corrugated housing assembly is shown in Figure 5-3. The primary pan includes the lens mounting rims, ends, and bottom corrugation bends. Each side member includes the lens mounting rim, side, and ends to the corrugations across the bottom. All sheet metal members were fabricated using hydraulic, numerical control press brakes capable of 0.5 -degree accuracy and $0.13-\mathrm{mm}(0.005$-inch) bend placement.

The three formed sections were placed on a male vacuum chuck to hold the members during the tungsten inert gas welding process. The use of the vacuum chuck maintained quality dimensional control in the critical areas, namely the cell assembly mounting surfaces and the lens mounting rim. After being welded, the housing assembly was measured with a coordinate measuring machine. The results indicate that the lens mounting rim was flat within $0.30 \pm 0.15 \mathrm{~mm}$ $(0.012 \pm 0.006$ inch $)$. Also, the cell mounting plane was measured to be within $\pm 0.28 \mathrm{~mm}$ ( \pm 0.011 inch) of the theoretical plane. The combined error of the lens mounting rim and the cell mounting plane was within the $\pm 0.59 \mathrm{~mm}$ ( \pm 0.023 inch) RMS error budget.

Parquet truss support members were fabricated as shown in Figure 5-4. The primary truss bars and secondary cross bracing were fabricuted from 4.76- $\mathrm{mm}$ (0.188-inch) diameter 304 stainless steel bars. The pan foot brackets welded to the corrugated housing bottom were fabricated from 18-gauge (0.0478-inch) 304 stainless steel sheet. The parquet support and leveling brackets were fabricated from 24-gauge (0.039-inch) 304 stainless steel sheet. Structural analyses of this parquet support design and other design options were performed and are reported in Section 3.3. 


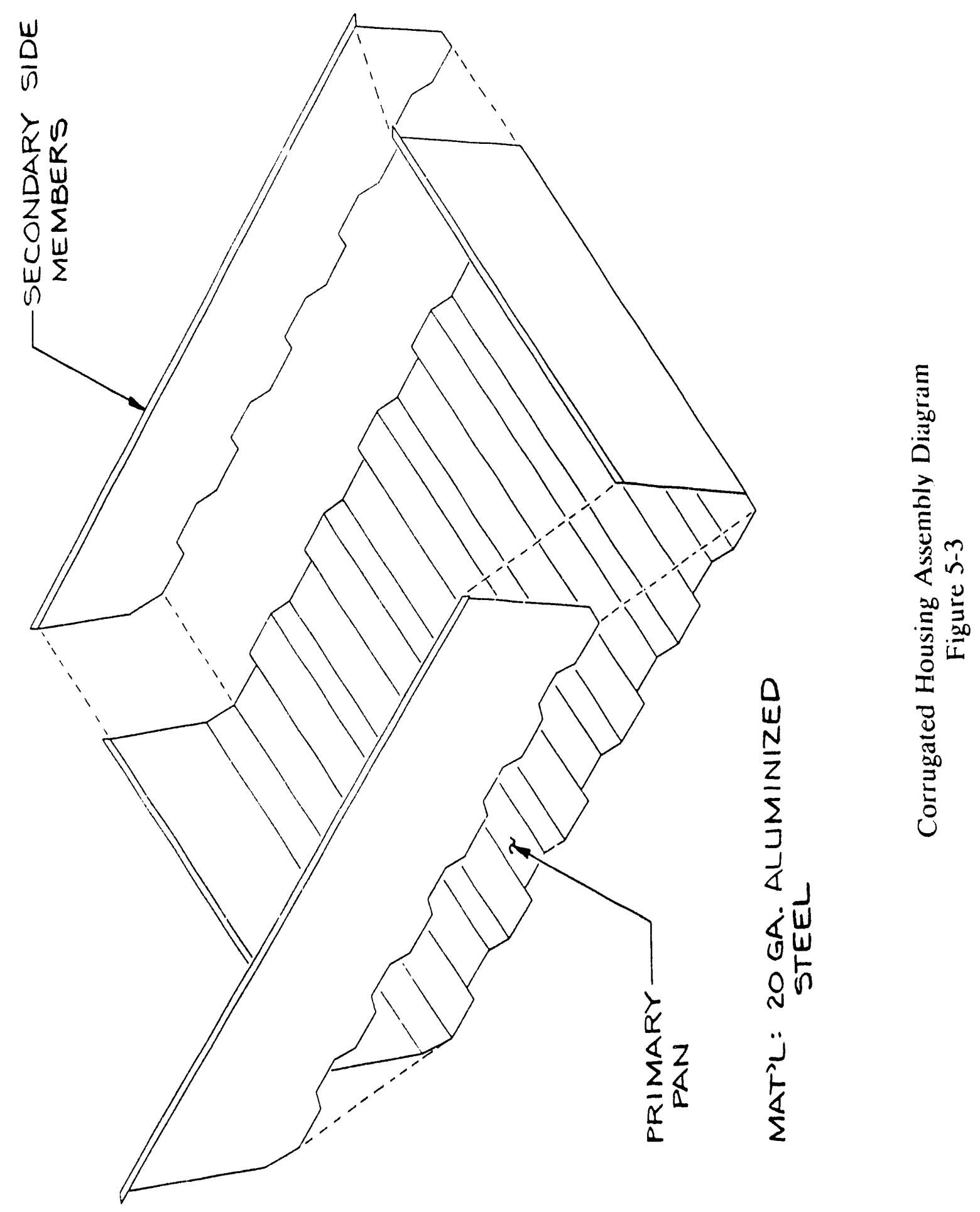




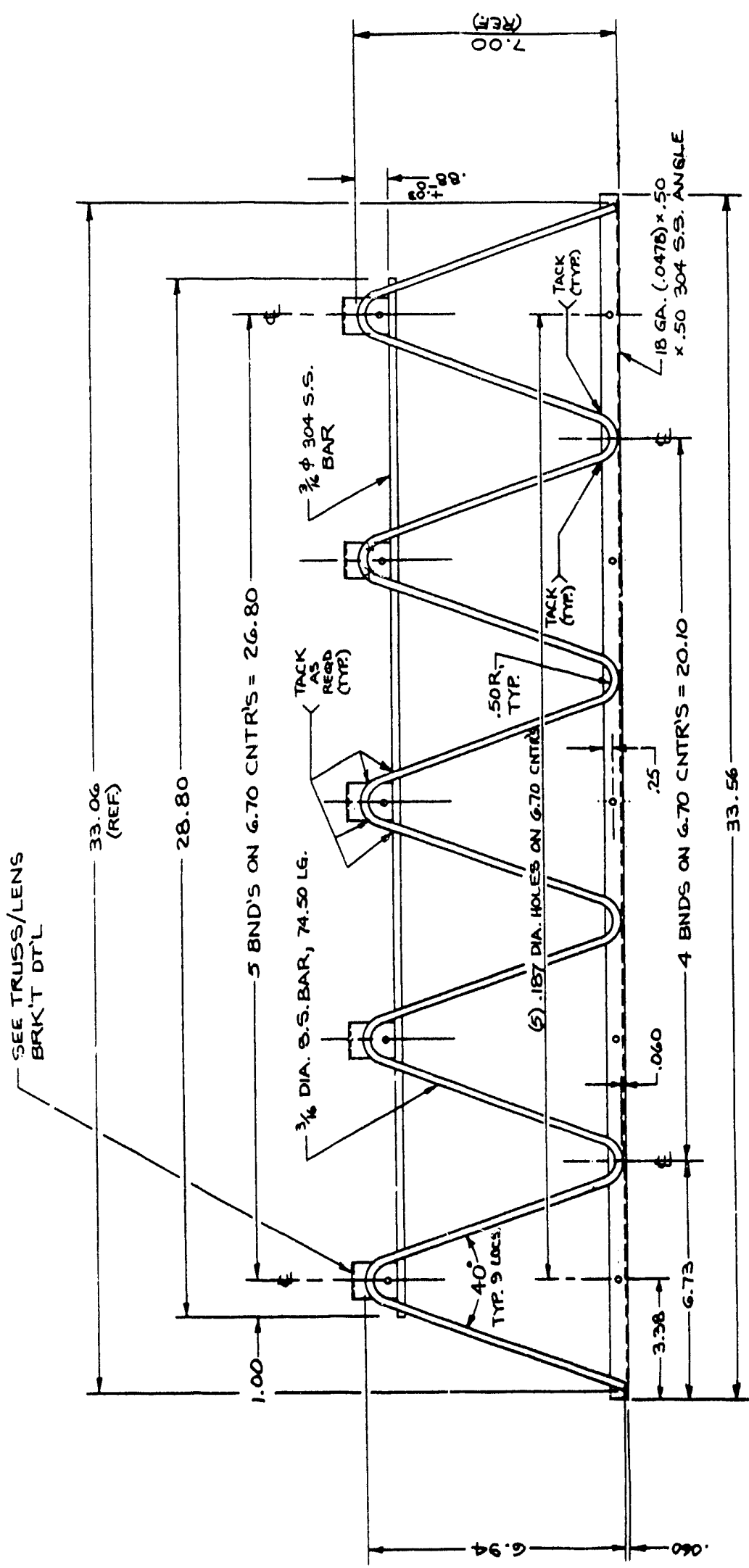

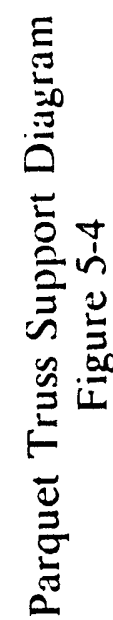


Support brackets were spot welded onto the long sides of the housing for mounting of the module onto the Unistrut of the tracking structure at Sandia. The brackets were fabricated from 16-gauge (0.063-inch) 1018 steel and were positioned $7.6 \mathrm{~cm}$ ( 30 inches) below the housing rim.

The interior and exterior housing surfaces were painted after all welding activities were complete. The interior surfaces were painted with an aluminum paint, and the exterior surfaces were painted with an epoxy-based white paint. Curing required elevated temperatures and was accomplished over a three-day period using heat lamps and thermocouple control.

\subsubsection{Parquet Sizing}

The lens parquet used in the prototype module was designed by General Electric and compression molded by Fresnel Optics. Several parquets were provided by Sandia in the original 5-by-6 lens configuration. Four of these parquets were trimmed and edged by Fresnel Optics Company to the 4-by-6 lens configuration needed for the prototype modules. Figure 5-5 is Solar Kinetic's Drawing 00-603B, which displays the trimmed parquet specifications.

Three oblong guide slots were machined on the parquet rim for registration of the parquet with the housing. The long dimension of each slot is perpendicular to the parquet edge, with one slot located at the center of one side and one slot located at the center of each end. The slots centered on the short dimensions align the parquet laterally, whereas the slot centered on the long dimension aligns the parquet center with the top of the housing center point. PEM studs were used as the alignment pins on the housing rim to keep the parquet position stable after assembly and prevent thermal ratchetting from shifting the position of the parquet on the housing during diurnal and seasonal temperature and humidity changes.

Selected measurements were made on the four trimmed parquets received from Fresnel Optics. Measurements of parquet edge thickness and parquet alignment slot location and size were in good agreement with the parquet specifications. The average edge thickness was approximately $2.85 \pm 0.15 \mathrm{~mm}$ $(0.112 \pm 0.006$ inch $)$. The specified thickness was $2.87 \mathrm{~mm}(0.113 \mathrm{inch})$.

\subsection{MODULE ASSEMBLY}

The module assembly activities performed by Solar Kinetics included cell assembly placement, electrical interconnection, heat dissipator attachment, and parquet attachment. A drawing of the assembled components is presented in Figure 5-6. The assembly activities are described as follows. 


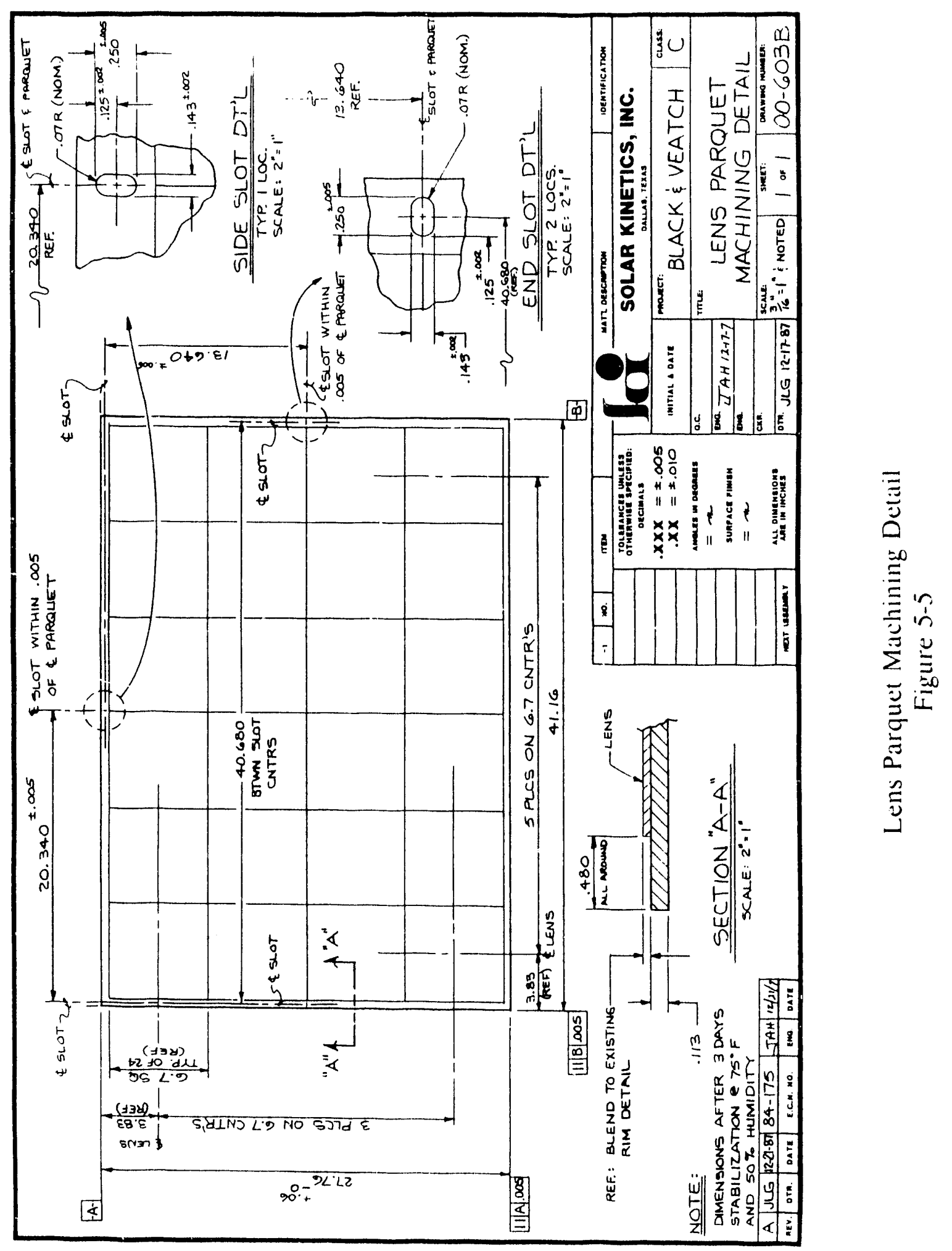



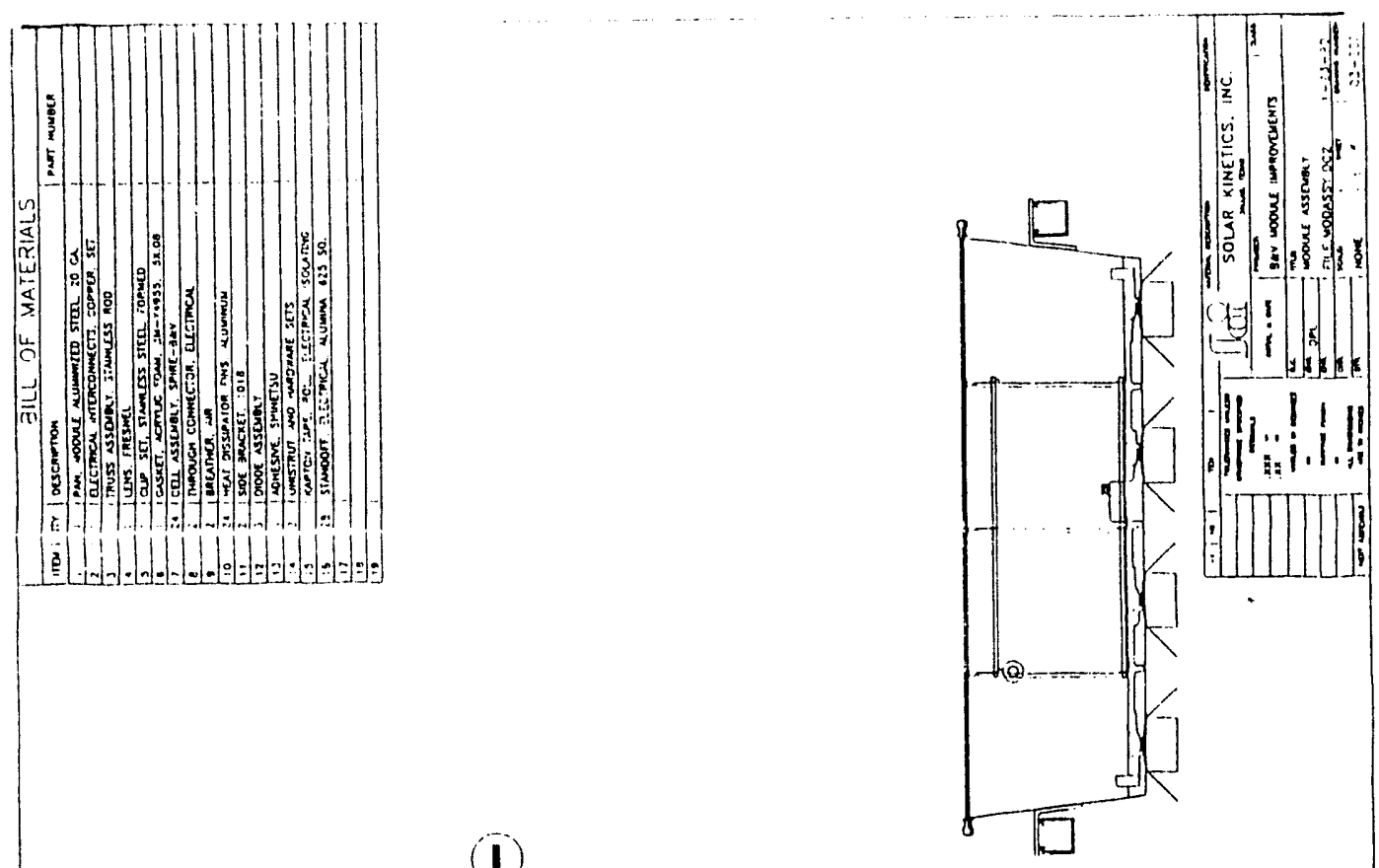

(i)

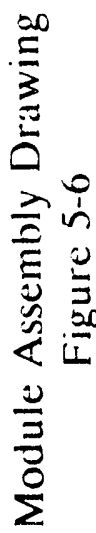
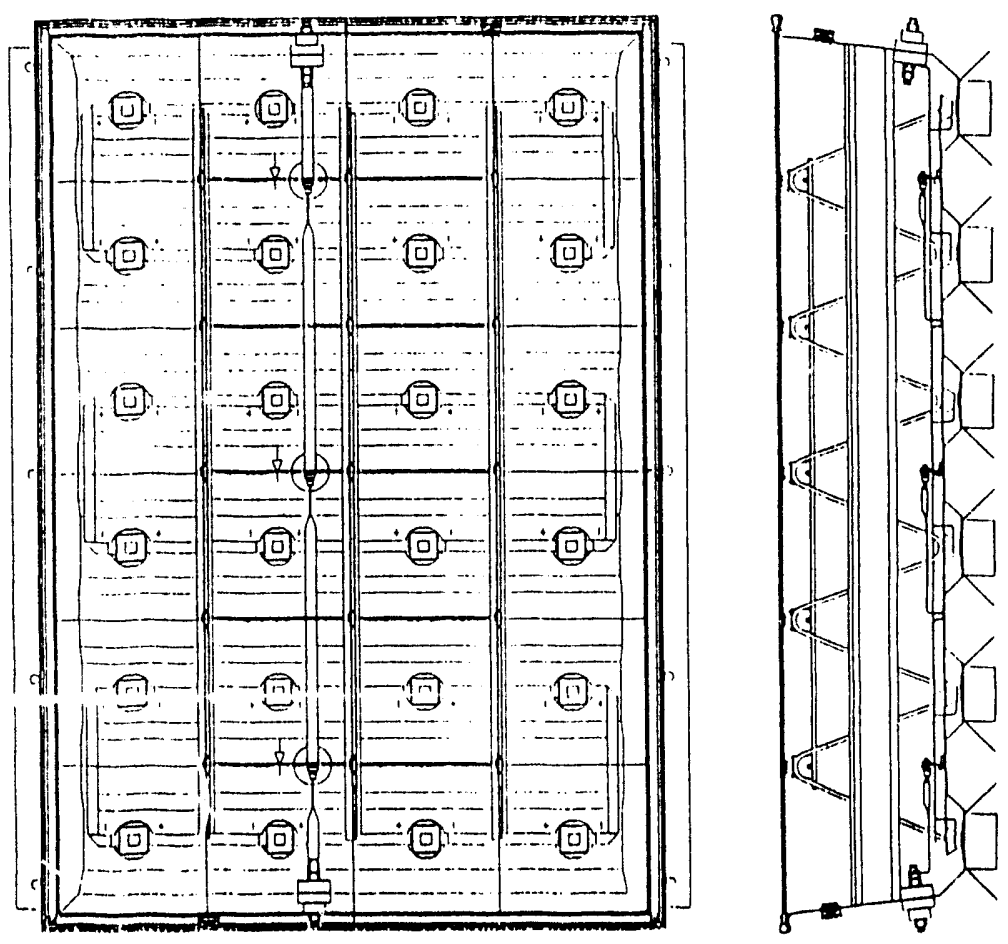

( 


\subsubsection{Cell Assembly Placement}

The 24 cell assemblies selected for the module were individually positioned and bonded to the housing bottom. The cell positions were determined relative to the optical center of the housing as given by the locations of the parquet-tohousing registration pins. The assemblies were bonded with a $0.076-\mathrm{mm}(0.003-$ inch) thick layer of thermally conductive silicone adhesive. The cell assembly positioning and bonding activities are described below.

Each cell assembly comprises a square cell package soldered to a round heat spreader. The cell package consists of the solar cell, the substrate, the front tab, and the secondary optical element. Alignment of the cell assemblies with the rectangular housing was assisted by two diametrically opposed semi-circular notches cut into the heat spreader perimeter. These notches were located opposite the two non-tabbed cell sides and provide a referenced orientation for each cell assembly.

A cell-to-housing installation tool was fabricated to hold the cell assembly in position while providing a constant load to the assembly during the adhesive curing period. This fixture includes a simple channel bridge and small Bimba brand air cylinder. A measured quantity of adhesive was placed on the heat spreader bottom surface. A compressive load was applied for a period of one hour. Excess adhesive, which exuded from under the heat spreader, was removed with a sharp plastic piece so as to not break the aluminum coating on the steel.

The selected adhesive, Shin Etsu X-31-751, is a filled silicone adhesive. It was chosen over other candidate silicone thermal adhesives because of two attributes that should improve the thermal characteristics of the bond: high percentage of fill material, and small, uniform particle sizes. The Shin Etsu adhesive is filled to 60 percent by weight with aluminum oxide particles. In addition, the aluminum oxide particles are fine and uniform in size. Particle sizes range from 2 to $5 \mu \mathrm{m}$ ( 0.08 to $0.20 \mathrm{mil})$. The small, uniform particles should lead to minimal, well-controlled bond thicknesses.

\subsubsection{Electrical Interconnection}

Module electrical interconnection entailed several activities: fabrication and placement of bypass diode stands and module feedthrough connectors, fabrication of copper strap interconnects, and attachment of interconnects to the cell contacts, bypass diodes, and feedthrough connectors. These activities are described below.

As described in Section 3.4.2, the electrical configuration of the 24-cell module consists of three series blocks. Each series block contains two parallel 
strings of four cells each. A single bypass diode was placed in parallel with each series block. Diode stands were fabricated from the excess inventory of cell assembly components and copper brackets. Each stand contains a copper heat spreader, an alumina substrate, and a ccpper mounting bracket. Sn63 solder was used to bond the substrate to the heat spreader and the bracket to the substrate. Shin Etsu X-31-751 adhesive was used to bond the diode stands to the housing bottom.

Two module feedthrough connectors were fabricated according to the design described in Section 3.4.3. The point of penetration of both feedthrough connectors was purposely shifted from the module's longitudinal centerline so as to provide visual distinction of module polarity. This arrangement should be beneficial during field installation of production units by reducing ambiguity regarding moduie polarity. Also, placing the polarities at opposite ends of the module reduces the cable length required to series-connect modules of an array.

The interconnect straps were fabricated of 12.7 by $0.81-\mathrm{mm}(0.50$ by 0.032 inch) oxygen free high conductivity copper. Stress relief bends with $3.18-\mathrm{mm}$ $(0.125$-inch) bend radii were placed into the straps.

The strap ends were cleaned and then prepared for soldering to the cell contacts with a three step dipping procedure: flux dip, Sn63 solder dip, and flux cleaner dip. This procedure eliminates the need to use flux during soldering, and thereby avoids cleaning flux residue from within the module assembly. Each interconnect strap was overlapped with the cell assembly tabs by about $4.0 \mathrm{~mm}$ ( 0.16 inch) and soldered with a heavy duty soldering iron. All cell interconnect and diode interconnect straps were electrically isolated from the housing with a layering of KAPTON tape, alumina squares, and KAPTON tape at all support points.

\subsubsection{Heat Dissipator Attachment}

Aluminum sheet-metal heat radiators, called heat dissipators, were formed and bonded to the outside of the housing bottom at locations that coincide with the cell assemblies. The heat dissipators were fabricated into "plus sign" shapes from 16 gauge ( 0.063 inch) aluminum sheet. The four tabs were bent to form a set of fins to increase the convective surface area. The contact surface area of each heat dissipator is approximately $40.3 \mathrm{~cm}^{2}\left(6.25 \mathrm{in}^{2}\right)$. The dissipators were bonded with a $0.076-\mathrm{mm}(0.003$-inch) layer of Shin Etsu X-31-751 filled silicone adhesive. 
The thermal path added by the heat dissipators improves the modules' ability to disperse the thermal energy of each cell assembly. Cell assembly temperature measurements were conducted by Pacific Gas \& Electric for modules of similar design with and without heat dissipators. These tests indicate that the use of heat dissipators reduces cell operating temperature by about 10 to $15^{\circ} \mathrm{C}$. Temperature measurements obtained during the housing bottom thermally induced buckling tests indicated a significant reduction in temperature when dissipators were bonded to the housing. Section 3.3 describes the test procedures.

\subsubsection{Parquet Attachment}

The final assembly task for the prototype module was the placement of the parquet on the housing. To facilitate access to the cell assemblies during initial module testing, the adhesive release liners were not removed from the 3M Y-4955 sealant tape. In addition, application of bonding compound on the truss leveling brackets was delayed until the module was ready for environmental testing. 
$5-14$ 


\subsection{MODULE TESTING}

A single prototype module was delivered to Sandia for testing and evaluation. The module was tested by Sandia at the Photovoltaic Advanced Solar Test Facility. Because only one was available, the PV concentrator module evaluation test sequence (described as qualification test sequence in SAND86-2743 ${ }^{8}$ ) normally used was modified as in Figure 6-1. The major elements of the evaluation test sequence are below:

- Initial characterization of the module.

- Temperature shock cycling test.

- Humidity/freeze cycling test.

- Water spray \& hail impact.

- Final characterization of the module.

- Extended outdoor performance test.

The following sections describe the module testing activities conducted by Sandia and reported in Reference 11.

\subsection{Initial Characterization}

The initial characterization of the module consisted of a visual inspection and an outdoor performance test sequence. The performance tests included electrical characterization and measurements of thermal performance.

\subsubsection{Visual Inspection}

Workmanship in module assembly was very good. The visual inspection revealed no anomalies in module fabrication. The module exterior looked very good, and when the lens parquet was removed the cell assemblies and interconnects looked good.

\subsubsection{Electrical Characterization}

The electrical characterization was made to establish a baseline prior to the environmental testing. Although the solar cells were designed for use with prismatic covers, the module cells did not have prismatic covers. Therefore, the module performance was expected to be about 15 percent lower than with covered cells. A typical current-voltage (IV) is shown in Figure 6-2. Representative current, voltage, power, fill factor, and efficiency for the module at maximum power are $12.5 \mathrm{amps}, 7.0$ volts, 87.7 watts, 77.0 percent, and 12.9 percent respectively. These readings were obtained at $986 \mathrm{~W} / \mathrm{m}^{2}$ direct 

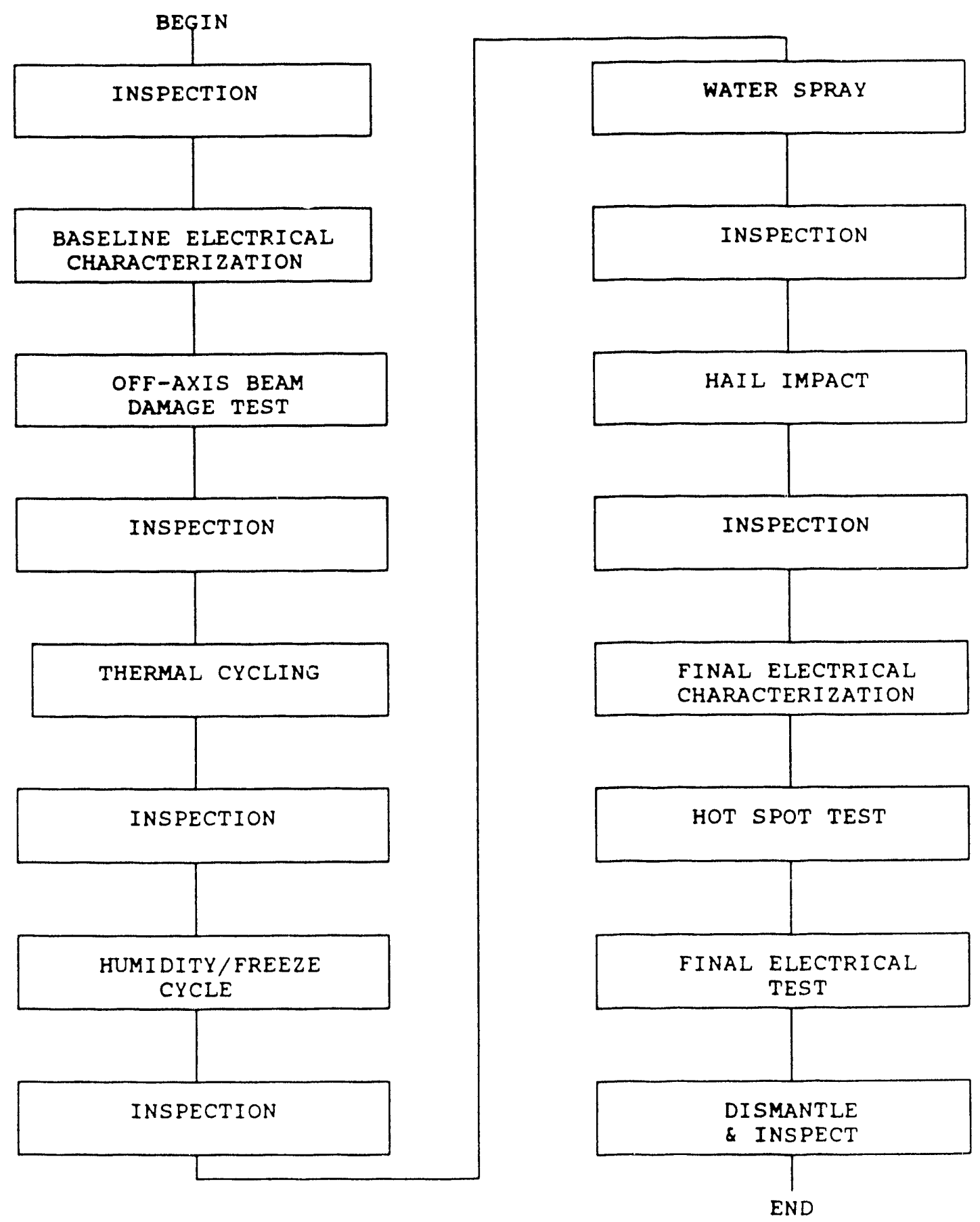

Module Evaluation Test Sequence

Figure 6-1 


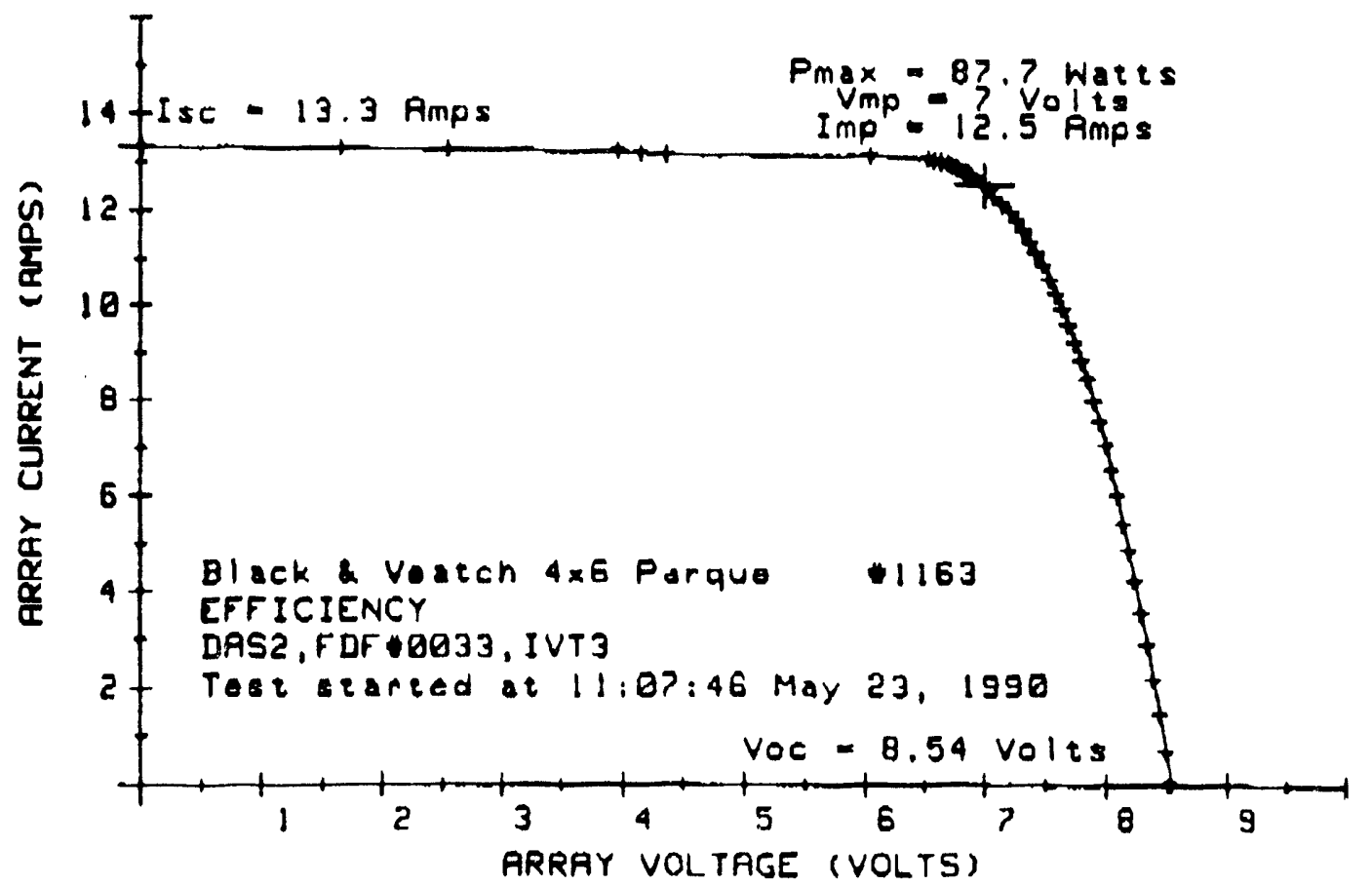

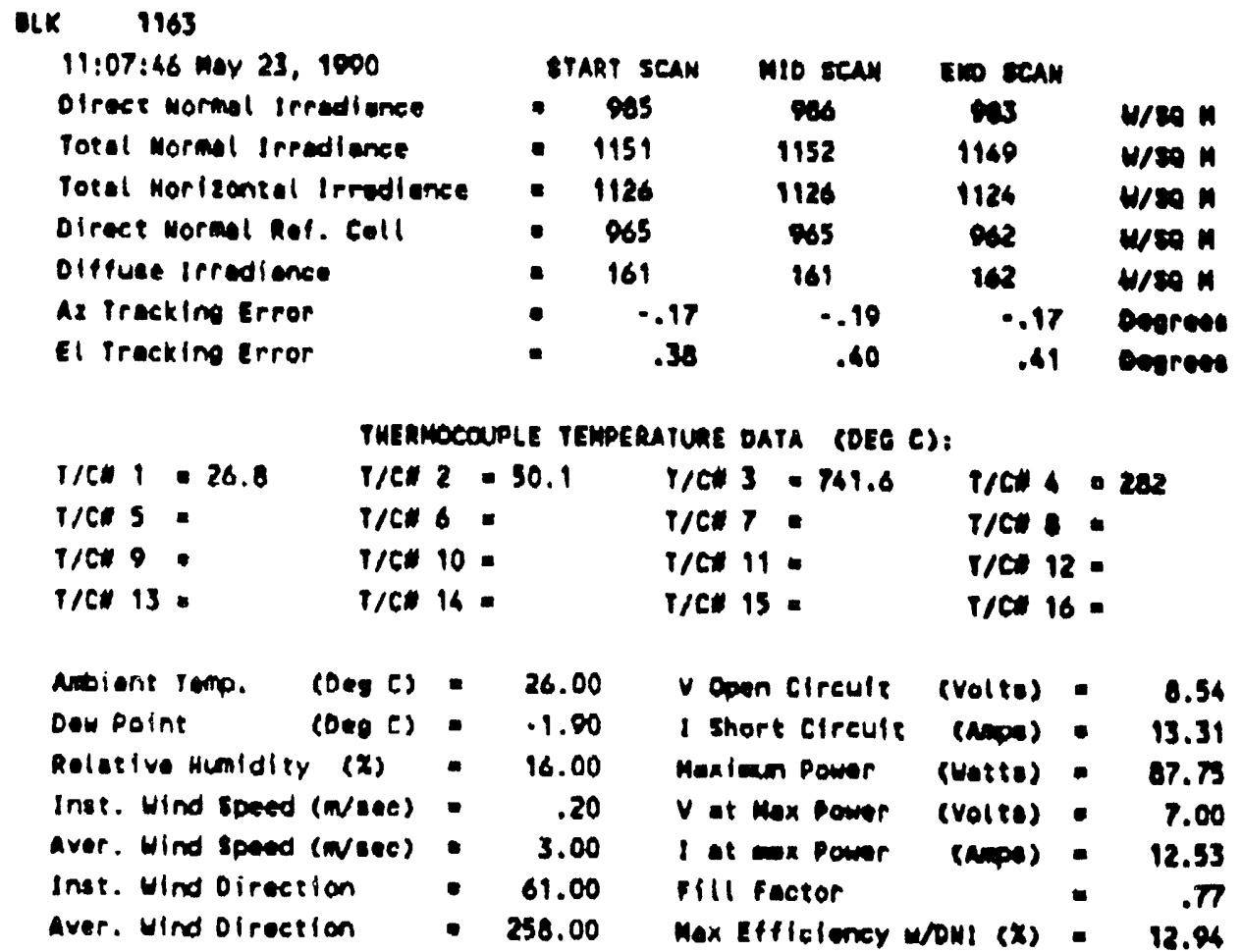

Typical Pre-environment Module IV Curve

Figure 6-2 
normal insolation as given by a normal incidence pryheliometer. Module efficiency ranged from 12.5 to 14.5 percent over the approximate 3 week testing period; this range is attributed to variations in ambient temperature (hence cell temperature) and spectral irradiance.

Off-track performance of the module was also measured. Figure 6-3 displays a comparison of normalized module performance, as measured by peak watts output, to normalized PVOPTICS estimates for module tracking errors to 1 degree.

\subsubsection{Thermi! Tharacteristics}

Cell temperature could not be measured directly; however estimates can be obtained from two analytical approaches. One approach combines the measured heat dissipator temperature with the estimated temperature differential between the heat dissipator and the cell. Thermocouples were placed inside the module on heat spreaders and outside on heat dissipators. For an ambient temperature range from 26 to $28^{\circ} \mathrm{C}$, a direct normal insolation range from 900 to $920 \mathrm{~W} / \mathrm{m}^{2}$, and a wind speed range from 2.5 to $3.5 \mathrm{~m} / \mathrm{s}$, the measured heat spreacler

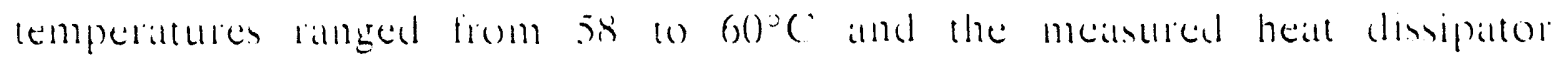
temperatures ranged from $551057^{\circ} \mathrm{C}$. These measurements are consistent with an analysis of module thermal characteristics conducted by Black \& Veatch for EPRI'. This thermal analysis also estimated a temperature differential range of 11 to $15^{\circ} \mathrm{C}$ between heat dissipator and cell. Combining measured dissipator temperatures with estimated differentials yields cell temperature estimates of 66 to $72{ }^{\circ} \mathrm{C}$.

The other approach is to apply a cell temperature versus $V O C$ and Isc relationship as measured by Sandia for single UNSW cells to the average single cell $\mathrm{Voc}$ and Isc values obtained from the module tests. Using these values and cell characterization data obtained from laboratory measured prismatically covered cells, the cell temperature could be approximated from the equation:

$$
\text { Tcell }=\frac{\text { Voc }-1.238}{0.0000623 * \ln (\text { Isc }) \cdot 0.00166}-273.16
$$

This approach provides a comparable cell temperature range of 65 to $75^{\circ} \mathrm{C}$ for ambient conditions similar to those stated above. This equation is not the 


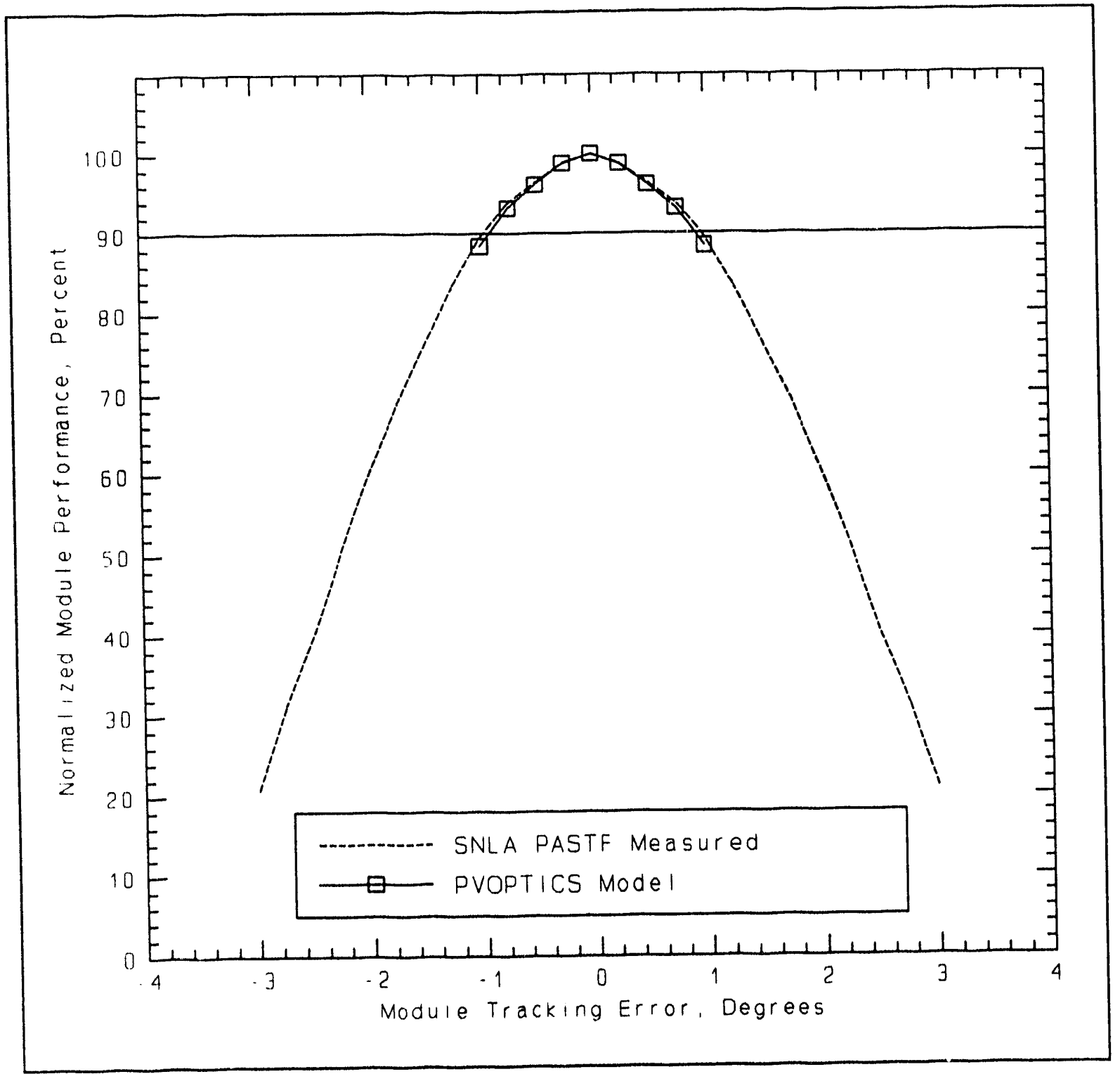

Comparison of Measured versus Modeled Performance

Figure 6-3 
exact one to use for this nodule; however, it is good for before and after module performance comparisons. Using temperatures calculated from this equation, a plot of module efficiency as a function of calculated cell temperature was made as shown in Figure 6-4. Since the data were taken over several days, linear curve fits were made for the two extreme days, May 8 and May 25, 1990.

\subsection{Thermal Cycling}

The module was subjected to 120 cycles of thermal shock as described in Figure 6-5. A visual inspection after the exposure revealed no change in the module.

\subsection{Humidity/Freeze Cycling}

After thermal cycling, the module was subjected to 10 cycles of the humidity/freeze cycle as defined by Figure 6-6. After this exposure very pronounced bowing of the lens parquet was observed as displayed in Figure 6-7, and there was a crack in the parquet. The module parquet truss support structure prevented the parquet from bowing into the module; therefore, it was bowed out. Measurements made of the individual lenses showed that those in the interior of the module had been stretched. The peripheral lenses showed no stretching on the outer edges where they are bonded and clamped to the box. The crack originated at the alignment hole on the side of the parquet and extended approximately perpendicular to the edge into the parquet about 10 inches. It was adjacent to, but not on, the intersection of the lenses. There was no other visual damage observed in the module resulting from the environmental tests.

An investigation into the cause of the lens bowing was conclucted. A conclusion of this investigation is that the steel clamp used to hold the lens parquet in place is just too stiff. It exerts too much force on the parquet, thus, not allowing it to float, relative to the steel housing, as a result of differential expansion caused by changing temperature and humidity. Exacerbating the situation is the differential expansion of the inner and outer lens parquet surfaces which appears to result from the hygroscopic properties of acrylic. Moisture absorption into the outer parquet surface, and its attendant material expansion, may have contributed to the outward bow of the lens. Because the lens parquet was cracked, the planned hail test and rain tests could not be performed. 
BLK900508Z

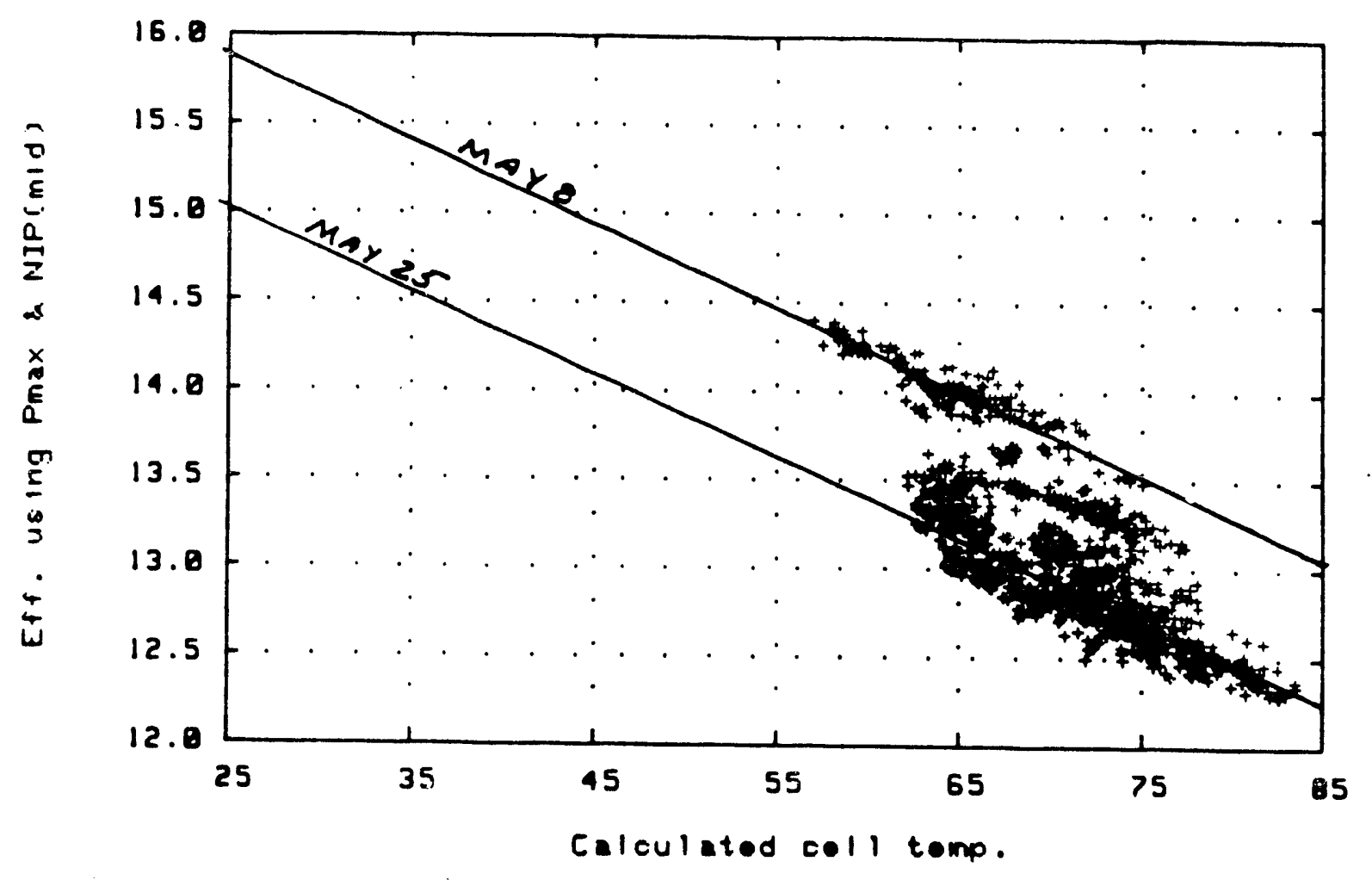

Pre-environment Module Efficiency versus Cell Temperature Figure 6-4 


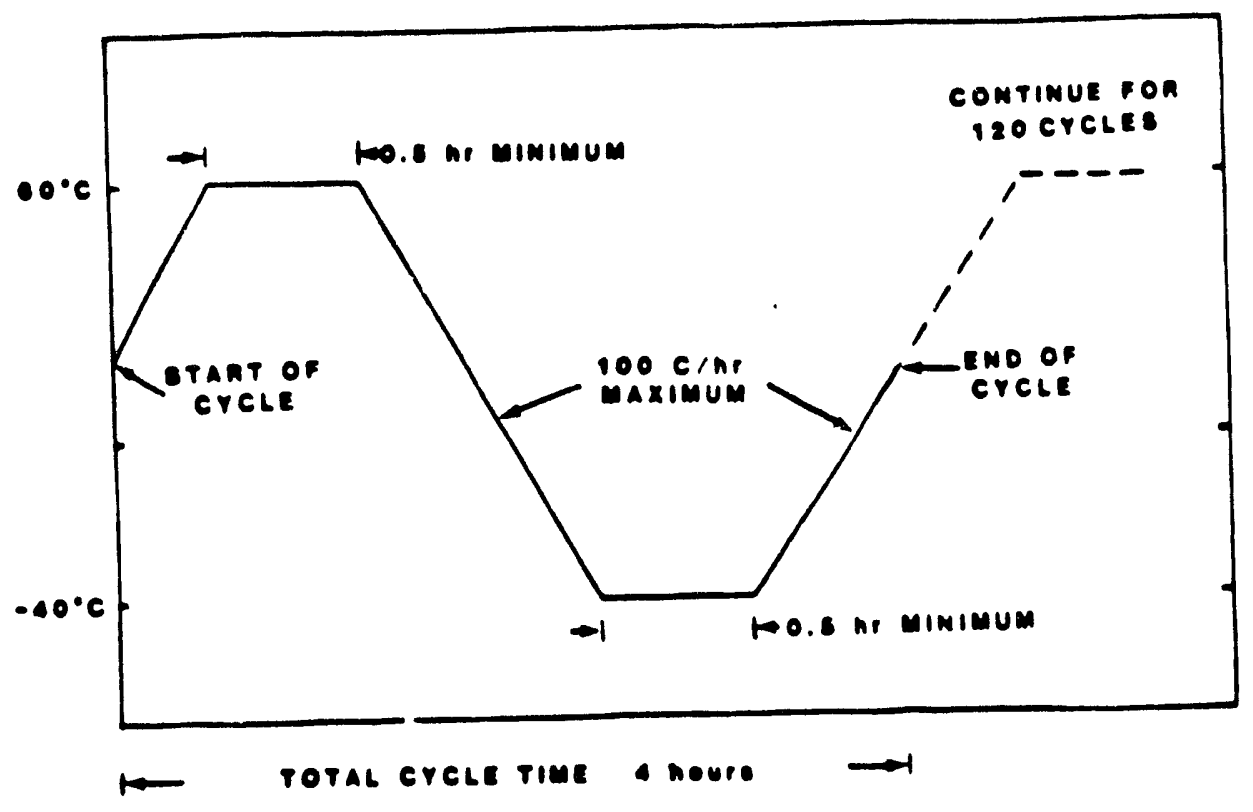

Thermal Cjele hor Molules Figure 6-5

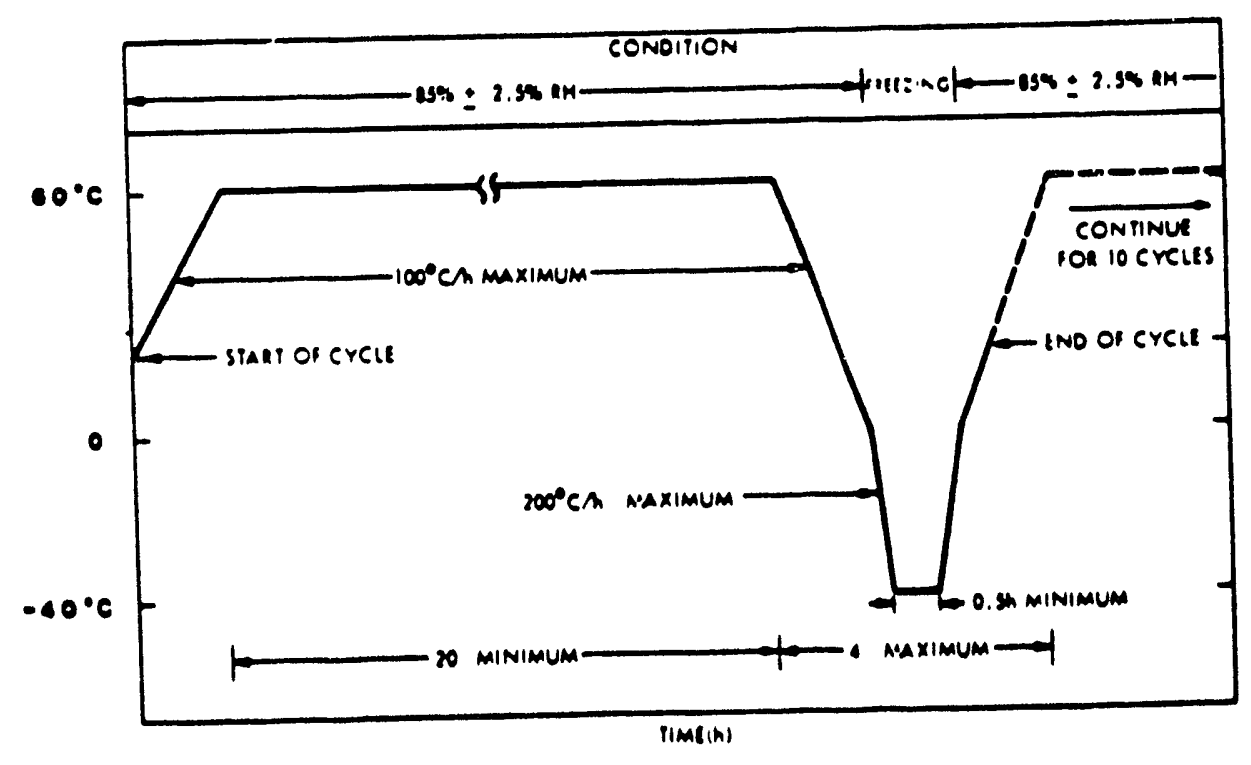

Humidity/Freeze Cycle for Modules

Figure 6-6 


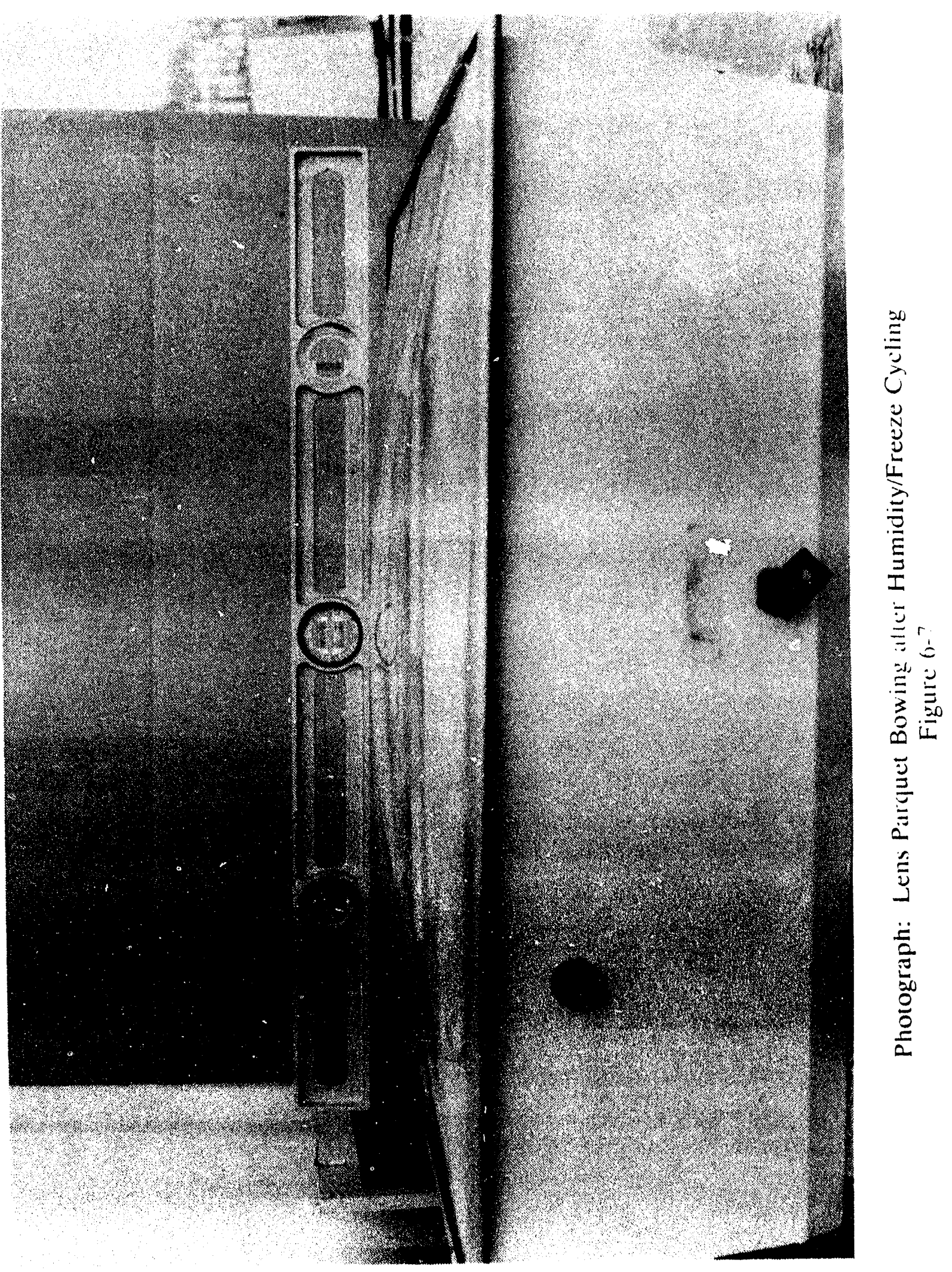




\subsection{Final Characterization}

The lens parquet bowing was so bad that it precluded any final electrical characterization because the lens images would not impinge on the cell assembly secondaries. In an attempt to gather as much information on the remainder $o^{-}$the module components, a new lens parquet was installed. The final electrical characterization was performed on this refurbished module. The IV curves obtained from the module were abnormal with two distinct current steps of about 0.3 amp at about 1.7 and 4.5 volts as illustrated in Figure 6-8. The curve shape first suggested a bad bypass diode or a leakage path. The diodes were removed and tested against new diodes. No bad ones were evident, thus they were reinstalled. While the bypass diodes were out, a 500-volt hi-pot test was made on the module and the diode mounting pads. No leakage was observed. Next one and then two of the parallel groups of cell were shorted and IV curves were made in an attempt to isolate the anomaly to a single group. When only one group was shorted (two groups active), one current step was observed. All three two-group configurations performed very similar as illustrated in Figure 6-9; however, some variation in Isc was observed. For the three single groups no anomalies were observed as illustrated in Figure 6-10. The cause of the anomalies has not yet been determined; however, Sandia will continue their investigation with consultation with Black \& Veatch.

The full electrical characterization was performed on the refurbished module. Results of this characterization, as shown by the module efficiency as a function of calculated cell temperature, is shown in Figure 6-11. Comparing efficiency on this figure with that of Figure 6-4, obtained during the initial characterization, shows a drop in module efficiency of between 9 and 14 percent. This compares to the qualification specification (Reference 8 ) allowance of 8 percent. Most of this degradation can be attributed to the current step anomalies described above.

During the process of investigating the anomalous IV curve characteristic, electrical performance became very erratic. Inspection of the module interconnects revealed that one of the cell assembly interconnects had come loose from the cell assembly top contact. This indicated a bad solder bond. It was resoldered and the characterization was completed. 


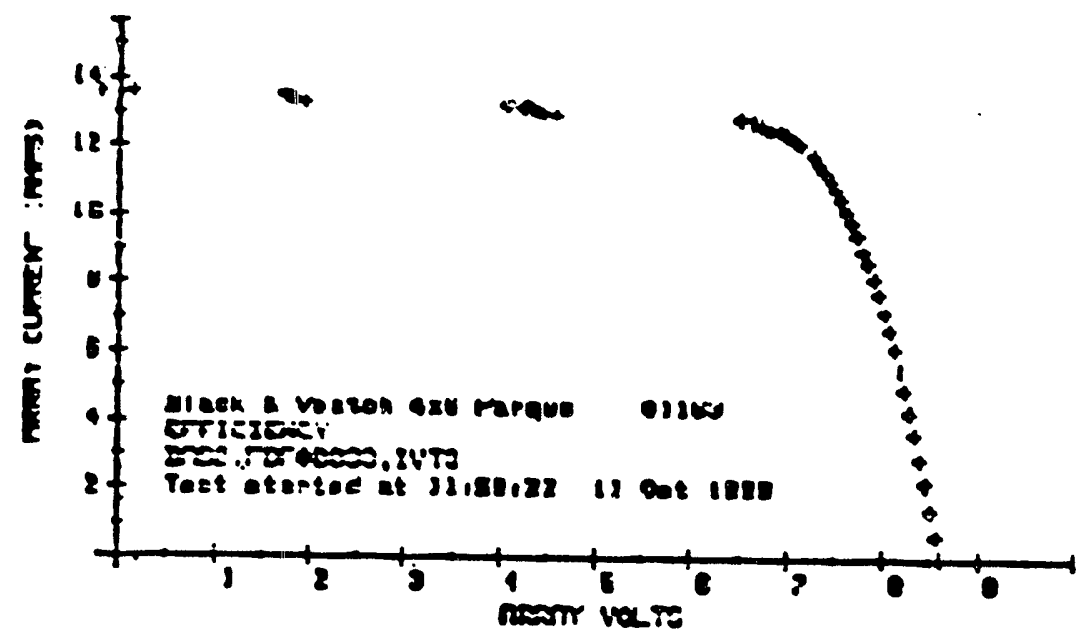

\section{BLY. IIE3}

$11: 59: 01 \quad 11$ Oe\& 1890

Dires Narnel Irpedines

Tola! Marrel Irredlence

Totel Herlzontel Irradiense

Direst Merral Ref. Cald

Odffuee Irraddence

Az Trestidng Error

El Tresking Errer

\begin{tabular}{|c|c|c|c|}
\hline $\begin{array}{c}\text { ETAPT ECAN } \\
=\quad 1011 \\
=\quad 1129 \\
=\quad 830 \\
=\quad 1012 \\
=\quad 19 \\
=\quad-1.32 \\
=\quad-.78\end{array}$ & $\begin{array}{l}\text { MID SCAN } \\
1019 \\
1129 \\
839 \\
1089 \\
19 \\
-1.31 \\
-.71\end{array}$ & $\begin{array}{c}\text { ENO SCAN } \\
1049 \\
1129 \\
231 \\
1012 \\
49 \\
-1.31 \\
-.75\end{array}$ & 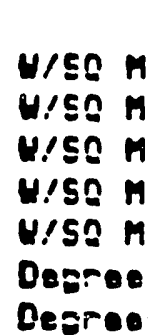 \\
\hline
\end{tabular}

\section{THEPMOCOUPLE TEMPERATIURE DATA (DEE C):}

$$
\text { T/CE } 2-189.5 \text { T/CE } 3-29.3 \text { T/CR } 1-275.1 .
$$

\begin{tabular}{|c|c|c|c|c|}
\hline 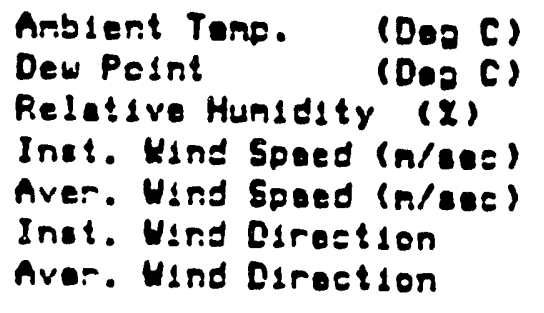 & 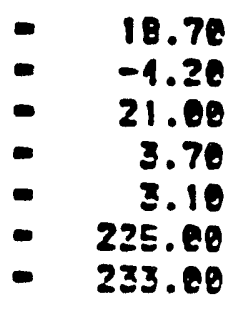 & $\begin{array}{l}\text { U Open Cdreudt } \\
\text { I Shert Cireudt } \\
\text { Mardnun Power } \\
U \text { of Mex Power } \\
\text { l at nax Power } \\
\text { Fldl Factor } \\
\text { Max Effdedency }\end{array}$ & $\begin{array}{l}\text { (Uoliz) } \\
\text { (Anse) } \\
\text { (Wet:E) } \\
\text { (Volte) } \\
\text { (AnDE) } \\
\text { IONI (I) }\end{array}$ & $\begin{array}{rr}= & 0.11 \\
- & 13.55 \\
= & 8 E .85 \\
- & 7.07 \\
= & 12.29 \\
= & .71 \\
-\quad 12.12\end{array}$ \\
\hline
\end{tabular}




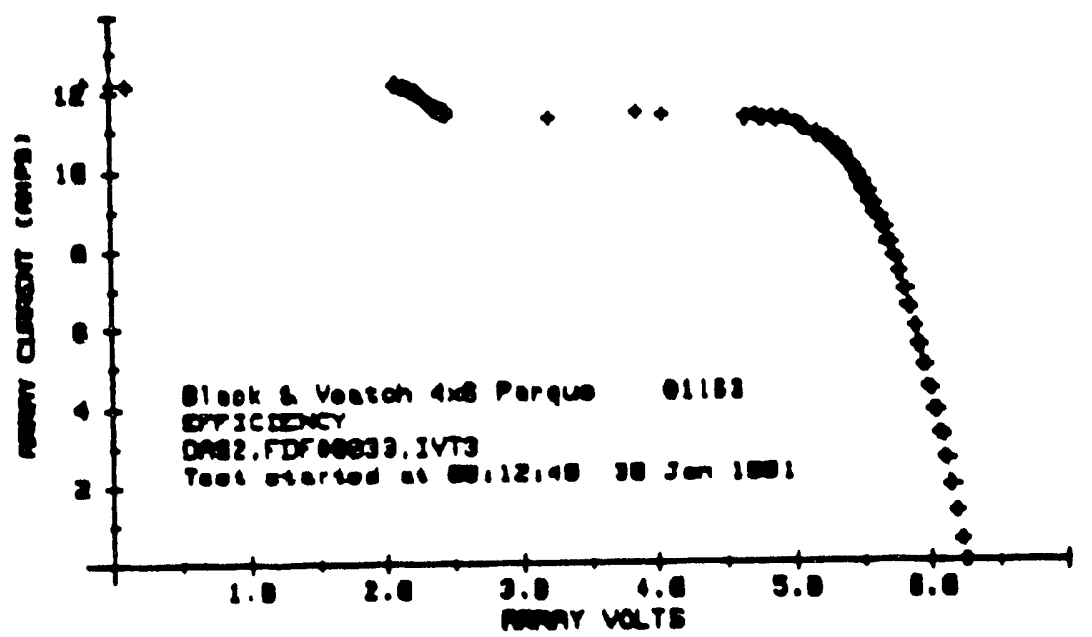

Typical Post-environment IV Curve

rwo-thuch ol Noluk dotio

Figule (6-)

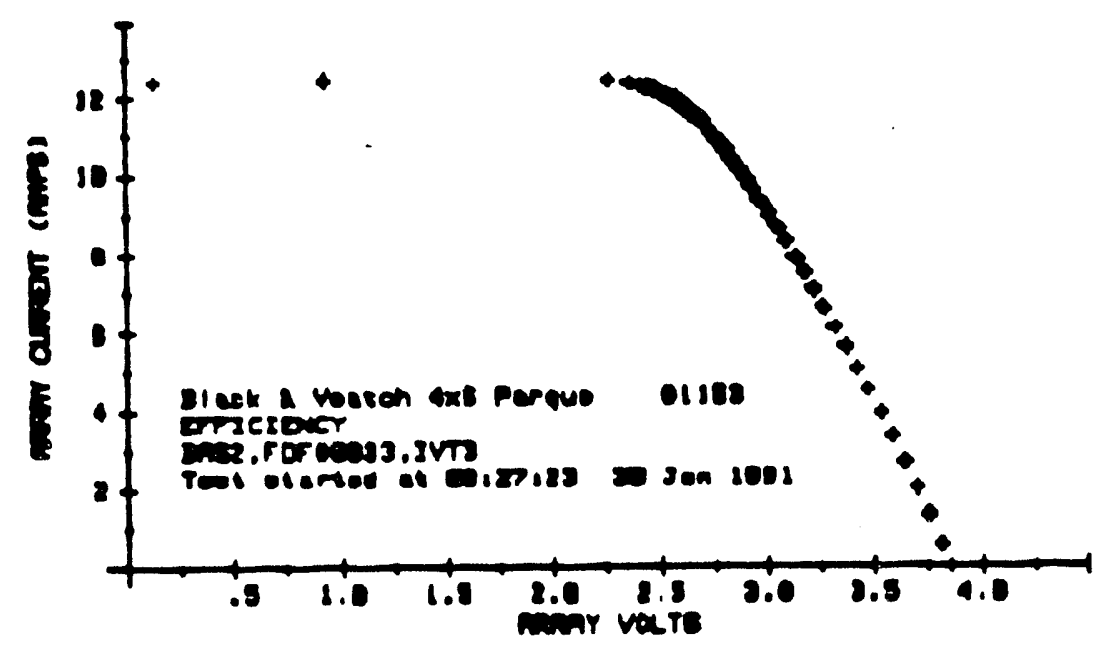

Typical Post-environment IV Curve

One-third of Module Active

Figure 6-10 


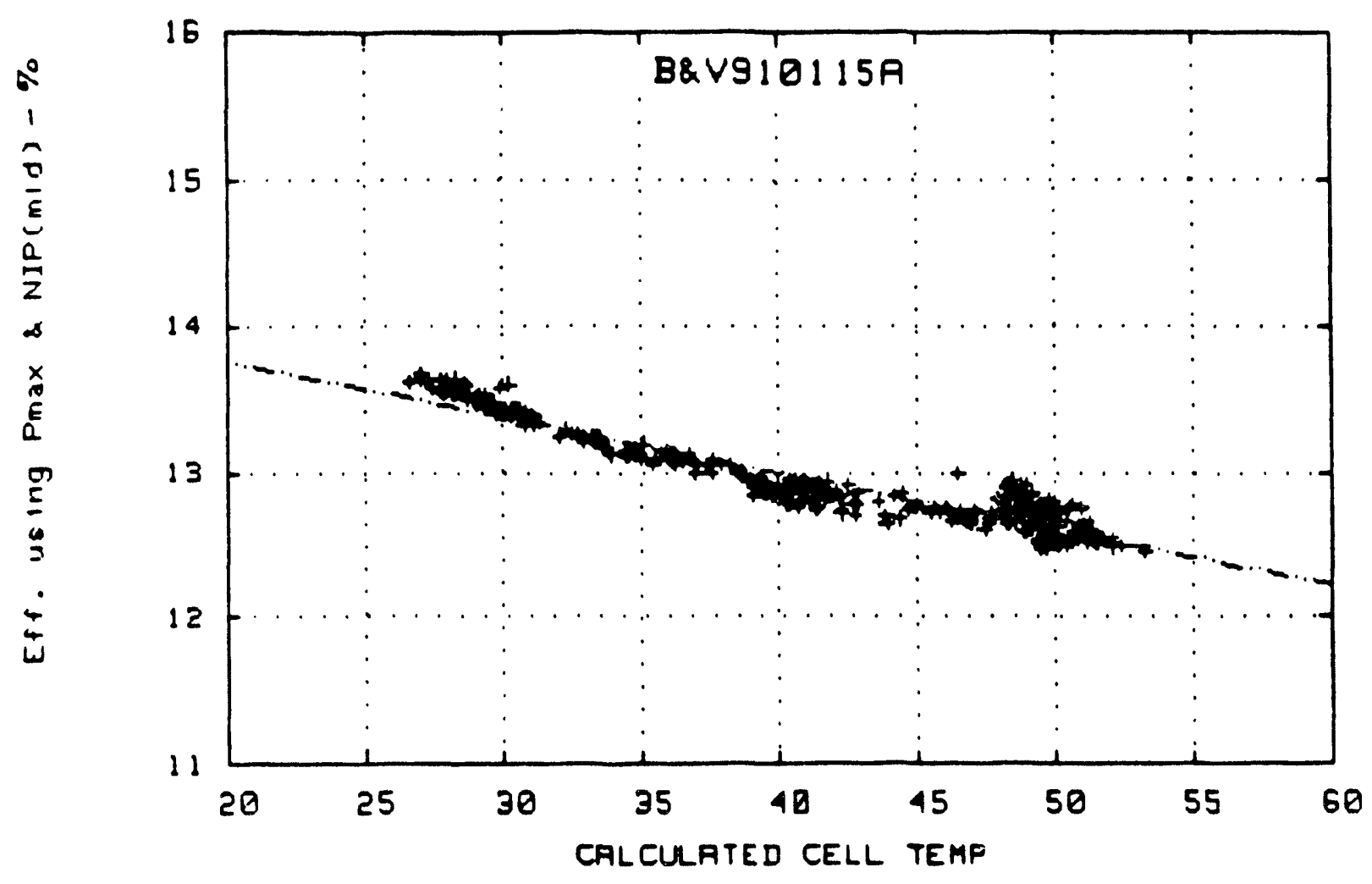

Post-environment Module Efficiency versus Calculated Cell Temperature Figure 6-11 


\subsection{REFERENCES}

1. S. L. Levy, High Concentration Photovoltaic Array Design. Final Report, EPRI AP-3263, December 1984.

2. R. C. Hodge, A Design and Development of Laminated Fresnel Lenses for Point Focus Photovoltaic Systems - Phase 2, Final Report, SAND82-7187. Albuquerque: Sandia National Laboratories, December 1982. Work performed by General Electric Company.

3. Richman and McNaughton, Recent Advancements in EPRI High Concentration Photovoltaics, Topical Report, EPRI RP1415-9, September 1991.

4. M. A. Green, et al. High-Efficiency Silicon Concentrator Solar Cell Research, SAND89-7041. Albuquerque: Sandia National Laboratories, December 1989. Work performed by the University of New South Wales, Australia.

5. K. A. Kerschen and S. L. Levy, "Determination of Photovoltaic Concentrator Optical Design Specifications Using Performance Modeling." Presented by Black \& Veatch at $19^{\text {th }}$ IEEE Photovoltaic Specialist Conference. May 4-8, 1987.

6. M. J. O’Neill, "Photovoltaic Cell Cover for Use with a Primary Optical Concentrator in a Solar Energy Collector." U.S. Patent 4711972 . Entech, Inc., DFW Airport, TX. December 8, 1987.

7. "Cold-formed Steel Design Manual," American Iron and Steel Institute.

8. R. S. Barlow and E. H. Richards, Qualification Tests for Photovoltaic Concentrator Cell Assemblies and Modules, SAND86-2743. Albuquerque: Sandia National Laboratories. January 1988. 
9. J. R. Silver and B. Patel, High-Efficiency Silicon Solar Cells for Use with a Prismatic Cover at 160 Suns, SAND90-7030. Albuquerque: Sandia National Laboratories, August 1990. Work performed by Solarex Corporation.

10. C. B. Stillwell to Dr. Sheldon Levy, "Cell Assembly Qualification Test Report, Black \& Veatch (Spire) Cell Assemblies, Contract 56-7211." Albuquerque: Sandia National Laboratories, December 21, 1988. Letter.

11. S. L. Levy and L. E. Stoddard, High-Concentration Photovoltaic Module Design, Final Report, EPRI AP-4752, August 1986.

12. C. B. Stillwell, Evaluation Test Report, Black \& Veatch Concentrator Module, Sandia Contract 56-7211. Albuquerque: Sandia National Laboratories, February 1991. 


\section{APPENDIX A}

A Performance Model for Nonuniformly Illuminated Front-Gridded Concentrator Cells 


\title{
A PERFORMANCE MODEL FOR NONUNIFORMLY ILLUMINATED FRONT-GRIDDED CONCENTRATOR CELLS*
}

\author{
Kevin A. Kerschen \\ Black \& Veatch, Engineers-Architects \\ Paul A. Basore \\ Sandia National Laboratories
}

\section{INTRODUCTION}

Black \& Veatch is leading a team in the design and fabrication of an improved concentrator module for Sandia National Laboratories, Albuquerque, New Mexico. A primary objective of this effort is to exceed 20 percent module efficiency, the highest to date. The cell selected for use in this module is the front-gridded silicon cell from M. A. Green at the University of New South Wales.' The module optical design has been evaluated with the point focus concentrator performance modeling code, PVOPTICS, developed by Black \& veatch.?

This improved concentrator module is one of the first point focus concentrator modules to use prismatically covered cells. Prismatic covers are a proven concept for reducing grid-line obscuration in linear focus concentrator modules. However, there is no previous experience in the design or performance of prismatic covers for point focus concentrator modules. This paper describes an approach for estimating the performance and optimization of a concentrator cell as a function of its metallization.

The module's prismatic cover design and performance characteristics are being developed by ENTECH, Inc. ${ }^{3}$ Factors that affect the optical efficiency of prismatic covers include grid-line width, module tracking condition, and cover alignment to the cell grid lines. Preliminary analysis from ENTECH indicates that prismatic cover efficiencies in point focus applications will remain reasonably constant and maintain an efficiency exceeding 95 percent for a range of metallization coverages from 6 to 15 percent. For this module performance analysis, a constant 95 percent optical efficiency of the prismatic cover is applied for all conditions. Therefore, the optimum metallization coverage is driven by the cell's ability to accommodate the nonuniform illumination on its surface.

This model bases the performance estimates of nonuniformly illuminated cell on standard test data of a uniformly illuminated reference cell. The reference cell test data used in this analysis were measured by Sandia, Albuquerque. Sandia's cell performance measurements are conducted when a cell is exposed to short pulses of uniform illumination. This model determines the nonuniform flux profile of concentrator module optics and estimates the modeled cell's response to this flux profile. This makes it possible to explore the performance of lens-cell combinations using cells of various sizes and metallization coverage, with or without a prismatic optical cover, under various primary and secondary components.

The discussion of this cell performance model addresses the following topics:

- PVOPTICS Summary.

- Cell Performance Model Description.

- Case Definition.

- Case Analysis and Results.

- Conclusion.

\section{PVOPTICS SUMMARY}

PVOPTICS is a performance modeling code that guides the optical design specifications of point focus Fresnel PV concentrator modules. PVOPTICS uses geometric optics to trace the path of photons from the sun, through the lens, and ultimately onto the cell where performance estimating routines are used to estimate power output. These performance estimating routines account for the sun shape, spectral, optical, and cell characteristics.

*The work reported here was conducted under contract to Sandid National Laboratories, with funding from the U.S. DOE Photovoltaic Energy Technology Division. 
Previous modeling with PVOPTICS analyzed the performance of point contact cells. ${ }^{4}$ These cells collect all current at the back surface of the cell; no front-surface metallization is required. The point contact cell performance routines assume that the cell comprises numerous subcell elements operating in parallel. Each ray that impacts within the boundaries of a subcell element represents discrete photons that contribute to the "suns" concentration of that subcell element. The performance of each subcell is independently calculated and summed to obtain the full cell performance.

These features provide the base requirements for performance modeling of front-gridded cells. The spatial distribution of discrete ray impacts on the cell surface, along with each ray's wavelength and optical efficien$c y$, is the point of departure for the new cell performance model. Figure 1 provides a block diagram that identifies the key conceptual elements of the PVOPTICS code, including the new features for front-gridded cells.

\section{CELL PERFORMANCE MODEL DESCRIPTION}

An improved calculation of cell power output requires not only an estimate of the cell's short-circuit current $\left(\mathrm{I}_{\mathrm{sc}}\right)$, but also an approach to determining the cell's open-circuit voltage $\left(\mathrm{V}_{\mathrm{oc}}\right)$ and an accurate estimate of the fill factor (FF) for the cell under nonuniform illumination. The following procedures have been developed for this cell performance model:

- Estimation of cell's $\mathrm{I}_{\mathrm{sc}}$.

- Conversion of discrete ray distribution into photocurrent density.

- Determination of cell's $V_{\text {oc }}$.

- Determination of current flow direction in grid lines.

- Estimation of cell's effective series resistance.

- Estimation of cell's fill factor.

The power output estimation for cells under nonuniform illumination begins with the calculation of the short-circuit current. In PVOPTICS a total of N rays are traced. Each ray emanates from the sun, is incident on the lens, and corresponds to an equal number of photons with energy greater than the band gap of the cell. For an ideal lens and cell, each ray would generate the same photocurrent in the cell. However, the actual photocurrent generated by each ray must

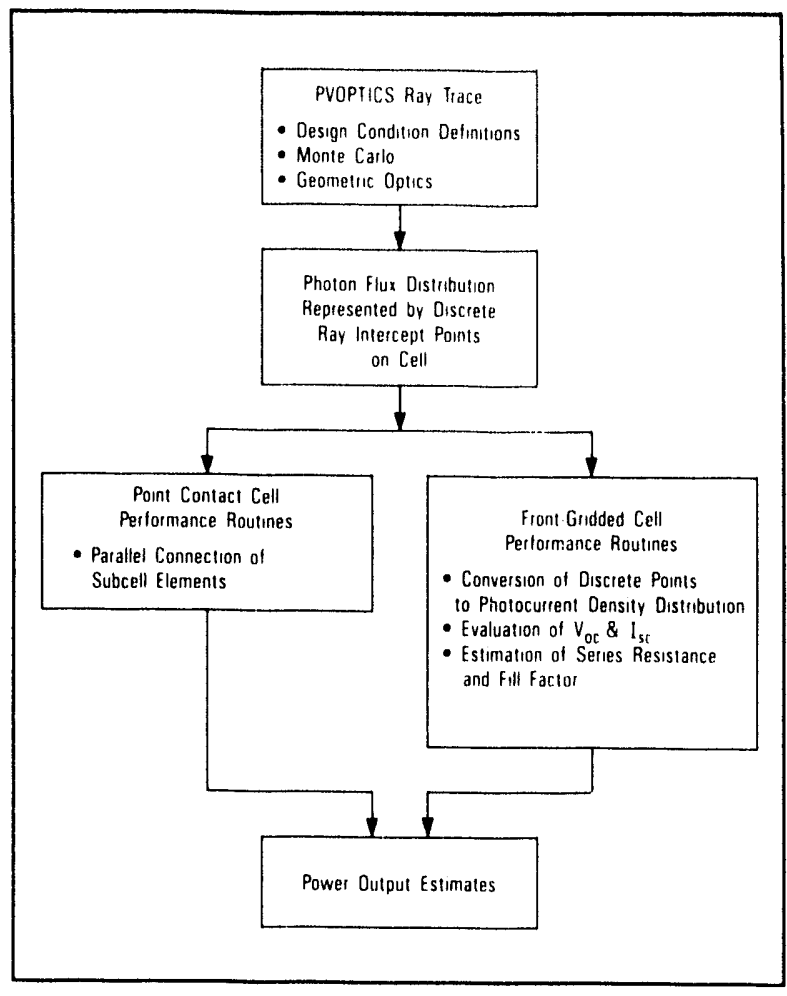

Figure 1

Performance Model Block Diagram

account for the optical losses in the primary and secondary concentrators, optical losses due to either the prismatic cover or grid-line obscuration, and the internal quantum efficiency of the cell.

The Monte Carlo methods of PVOPTICS provide a ray intercept point $\left(x_{n}, y_{n}\right)$ and a discrete photocurrent $\left(I_{n}\right)$ for each point. Because PVOPTICS treats each ray as an individual current source, the sum of all current sources yields the $I_{s c}$ of the full cell. Discrete current sources can provide an estimate of the photocurrent density by one of the following means. A large number of traced rays (possibly $N>100,000$ ), treated as discrete sources, produces a smooth photocurrent distribution due to the small current contribution of each ray. But this approach requires a powerful computer and protracted CPU use. Alternatively, each discrete current source can be viewed as extending over a given region of the cell. This distributed approach significantly reduces the number of traced rays (typically $N=1,000$ ) required to produce a reasonably smooth photocurrent distribution. Additionally, a less powerful (and less expensive) microcomputer can be used. 
Figure 2 presents a one-dimensional simplification of these two alternatives. Both representations contribute equal current to the total photocurrent of the full cell. However, the distributed source approach produces a cumulative smoothing effect on the cell's localized current level which ameliorates the spiked nature of a finite number of discrete current sources.

The distribution applied with this procedure is a twodimensional Gaussian distribution centered at the point of impact,

$$
Q_{n}(r)=\left(I_{n} / 2 \pi r_{o}^{2}\right) \exp \left(-r^{2} / 2 r_{o}^{2}\right)
$$

where $r_{0}$ is the distribution radius (standard deviation), and $r$ is the distance from the point of impact. The selection of the distribution radius is a compromise between the desire to maintain resolution (small $r_{0}$ ) and the need for smooth profiles (large $r_{0}$ ). This procedure selects $r_{0}$ based on the cell area and the number of traced rays as follows:

$$
\mathrm{Nr}_{\mathrm{o}}^{2}-\text { Area of Cell }
$$

The total photogenerated current density at any point on the cell $(x, y)$ is then given by

$$
Q(x, y)=\sum_{n=1}^{N} Q_{n}\left(r_{n}\right)
$$

where

$$
r_{n}=\left[\left(x-x_{n}\right)^{2}+\left(y-y_{n}\right)^{2}\right]^{1 / 2}
$$

The influence of the distribution radius on the contour of the modeled cell's photocurrent density is very apparent, as shown in Figure 3. Figure 3a displays the impact locations of 1,000 rays that represent the flux profile for a 0.75-degree $\mu=$-r'liel off-track condition. A parallel off-track condition shifts the flux parallel to the grid lines and toward the cell edge. Figure $3 b$ through Figure $3 \mathrm{~d}$ display the photocurrent density for three values of the distribution radius: $r_{0}=0.395 \mathrm{~mm}$ (base), $r_{0}=1.19$ (base $\times 3$ ), and $r_{0}=0.132$ (base +3 ), respectively. Though the contours are quite different in

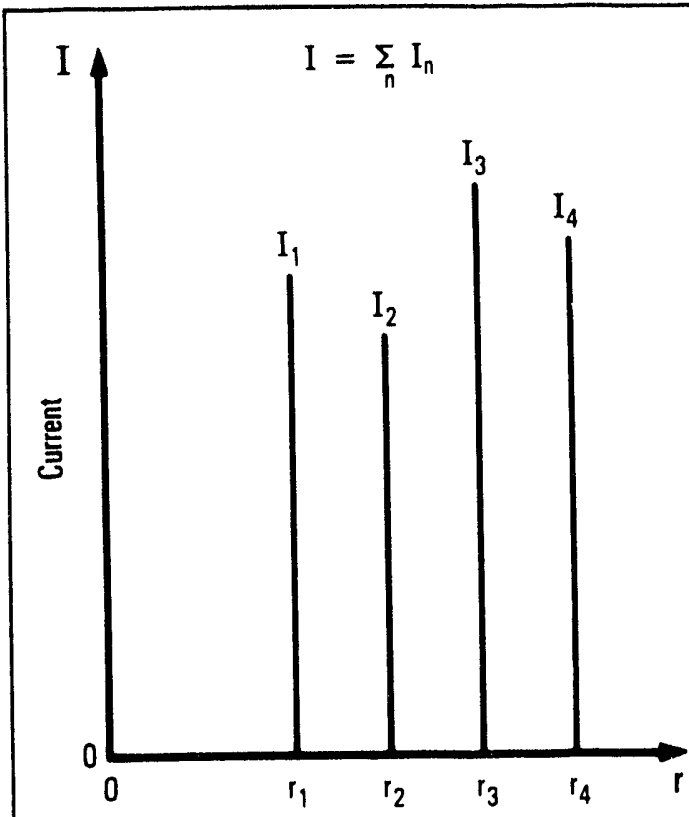

(A) DISCRETE CURRENT SOURCES

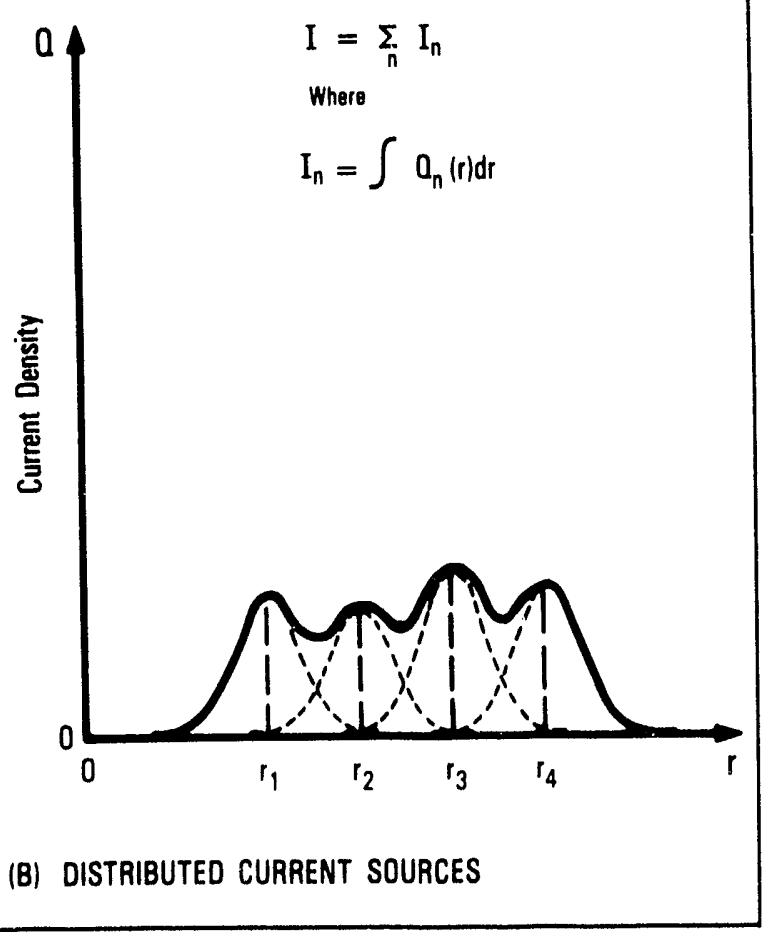

Figure 2

Photocurrent Source Concepts 


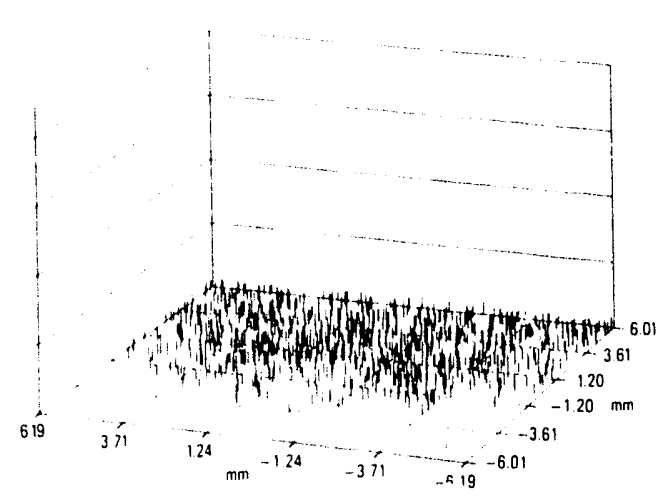

(A) IMPACT LOCATIONS OF 1000 RATS

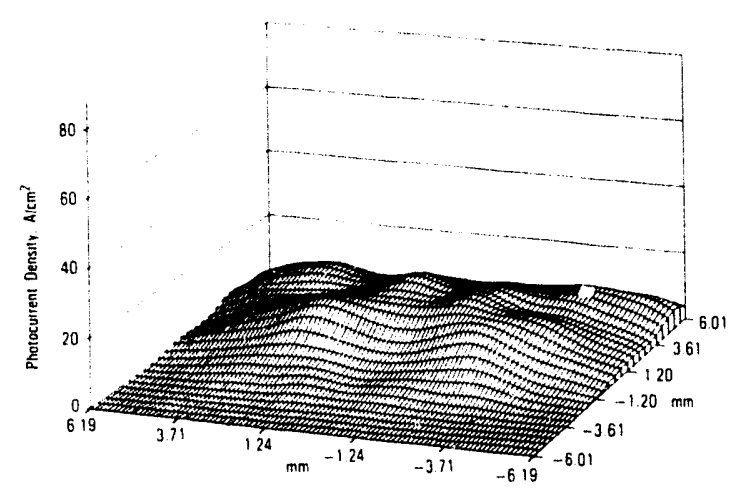

CI DISTRIBUTION RADIUS - $119 \mathrm{~mm}$ IBASE $=3$

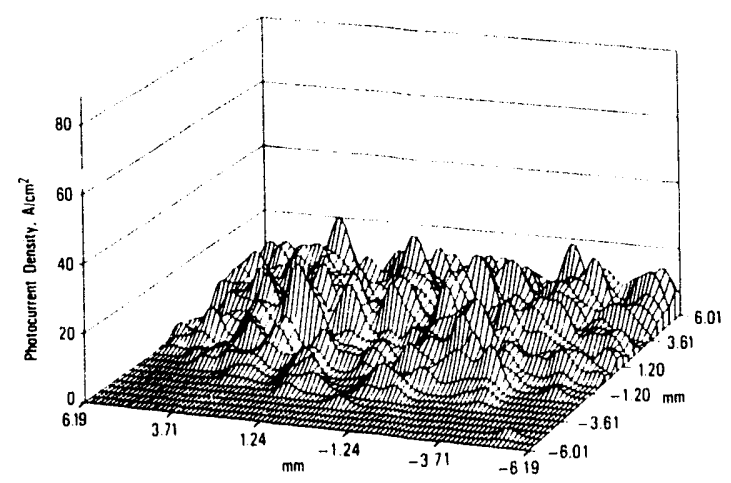

(B) DISTRIBUTION RADIUS $-0.395 \mathrm{~mm}$ (BASE)

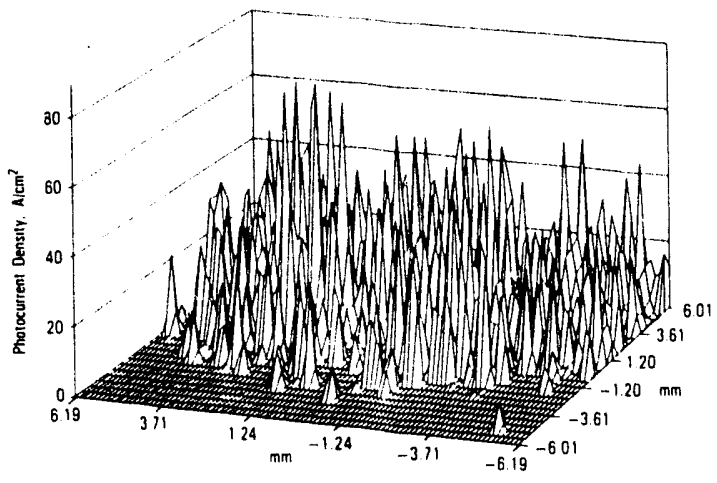

10. DISTRIBUTION RADIUS - $0.132 \mathrm{~mm} \mathrm{IBASE}+31$

Figure 3

Monte Carlo Ray Impact Locations and Photocurrent Jensities For 0.75-Degree Parallel Off-track Conditions

appearance, the total currents are equal in all cases. The base value was selected because it retains the local features of the distribution while it moderates the capricous nature of the contours produced by the narrow, or singular, current sources.

Several modeled cell paramicers are estimated from the computation of the cell's photocurrent density. The surface of the modeled cell is first divided into a large number of equal-area elements. The total photocurrent in each element on the cell surface is found by taking $Q$ at the element's midpoint and multiplying by the area of the element. The modeled cell's short-circuit current can be found by summing the currerit from all elements. Dividing the cell's short-circuit current by the celi's area gives the cell's short-circuit current density. Dividing the modeled cell's short-circuit current density by the reference cell's measured one-sun, short-circuit current density gives the average illumination intensity on the modeled cell in "suns." This assumes that the cell's short-circuit current increases linearly with increasing concentration.

Another important cell parameter is the cell's open-circuit voltage. For high-performance cells, a reasonable first-order awproach is to assume that the oren-circuit voltage of the modeled cell under nonuniform illumination is equal to the value measured for the reference cell under uniform illumination at the same number of "suns." 
The third important cell parameter is the fill factor. The fill factor in the modeled cell differs from that of the reference cell at the same number of "suns" because of different losses in the metal grid. These differences result from the nonuniform illumination profile and different grid design. The fill factor differences are manifested by changes in the series resistance of the modeled cell. A cell's series resistance consists of contributions from the base, the emitter, and the metal grid. Therefore, an appropriate approach for designing high-performance metallization is to first calculate the power dissipation due to each resistance component (base, emitter, and grid) under short-circuit current conditions. The total effective series resistance is then the total power dissipation divided by the square of the short-circuit current. ${ }^{5}$ For parallel grid lines that have no interconnection except at the bus bars, the power dissipation associated with each grid line is essentially independent of the others. The procedure described below calculates the three power dissipation components for a single grid line, from bus to bus; to get the total power dissipation, the process must be repeated for all grid lines on the cell, summing all contr. utions.

The grid lines are defined as having a wic'th (w); a center-to-center spacing to adjacent lines (s); a length (L); and a termination by bus bars on both ends. Each grid line is divided into $M$ segments, each associated with a cell area equal to ( $s \cup M$ ). The minimum number of segments required depends entirely on the nonuniformity of the illumination.

The emitter power loss for the single grid line is giver, by

$$
P_{e}=(1 / 12) Q_{e}(s-w) s(s L / M) \sum_{m=1}^{M} Q_{m}{ }^{2}
$$

where $Q_{m}$ is the photogenerated current density calculated at the midpoint of the m'th segment and $e_{e}$ is the emitter sheet resistance in ohms/square.

For low-resistivity cells at typical concentrations, the base of the cell is in low-level injection, so that the base power loss for a single grid line is given by

$$
P_{b}=e_{b} t_{b}(s L / M) \sum_{m=1}^{M} Q_{m}^{2}
$$

where $e_{b}$ is the base resistivity in ohm $\cdot \mathrm{cm}$, and $a_{b}$, is the base thickness.
The power loss in the grid-line metal requires the determination of the point along the grid line where the current splits and flows one direction or the other. This point represents the point of maximum voltage along the grid line. This approach divides the $M$ segments into two groups. The current in segments 1 through $m_{0}$ flows one direction, whereas the current in segments $m_{0}+1$ throu ?h $M$ flows the other direction. This "continental divide" for the current can be determined by initially setting $m_{0}=1$ and incrementing $m_{0}$ until the left-hand side of the following expression equals or just exceeds the right-hand side:

$\sum_{j=1}^{m}\left[\sum_{m=j+1}^{m_{0}} Q_{m}+(1 / 2) Q_{j}\right]=\sum_{j=m_{0}+1}^{M}\left[\sum_{m=m_{0}+1}^{M} Q_{m}+(1 / 2) Q_{j}\right]$

The total current flowing into each segment along the grid from all "upstream" segments is required. Different expressions are needed for the two flow directions.

$I_{j}= \begin{cases}(s L / M) \sum_{m=j+1}^{m_{0}} Q_{m} & ; j<m_{0} \\ (s L / M) \sum_{m=m_{o}+1}^{j-1} Q_{m} & ; j<m_{o}+1\end{cases}$

$I_{j}=0$ for segments $m_{0}$ and $m_{0}+1$. These expressions generate the current flows in front-gridded cells that start at the points of maximum voltage along the grid lines and increase monotonically toward the bus bars. Figure 4 presents the grid-line current distribution for the on-track condition and for selected off-track conditions. Figure 4a exemplifies the modeled grid-line current distribution for the on-track condition. The impact of off-track orientation on grid line current flow is apparent by comparing Figure $4 \mathrm{~b}$ to Figures $4 \mathrm{c}$ and $4 \mathrm{~d}$. Each case represents the current flow for 0.75-degree off-track conditions. However, Figure $4 \mathrm{~b}$ displays the parallel condition that causes a shift in the flux parallel to the grid lines. In this instance each grid line carries a similar current. In contrast, Figures $4 \mathrm{c}$ and $4 \mathrm{~d}$ display the diagonal and perpendicular off-track orientation, respectively. Here the flux shifts cause increased current flow in the highly illuminated cell regions and very little current flow in the lesser illuminated cell regions. The impact on cell performance caused by the flux shifts is addressed in this paper. 


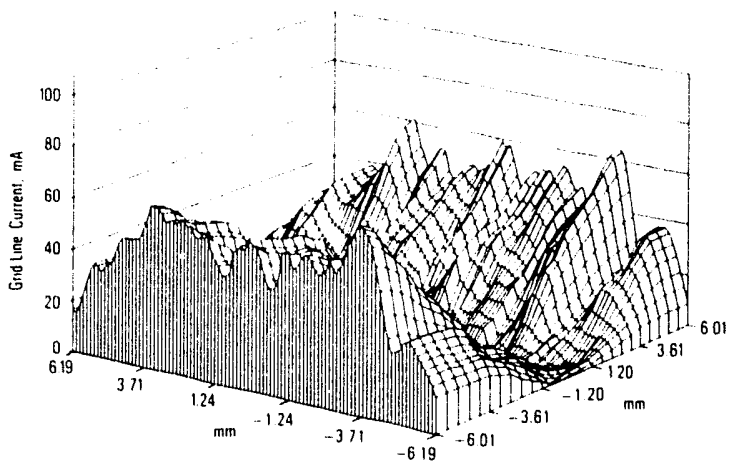

(A) ON TRACK CONDITIONS

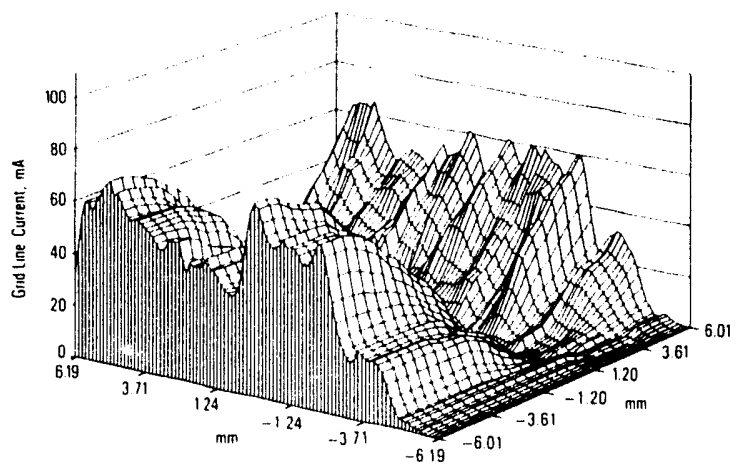

(C) 075 OEGREE DIAGONAI OFF.TRACK CONOMIONS

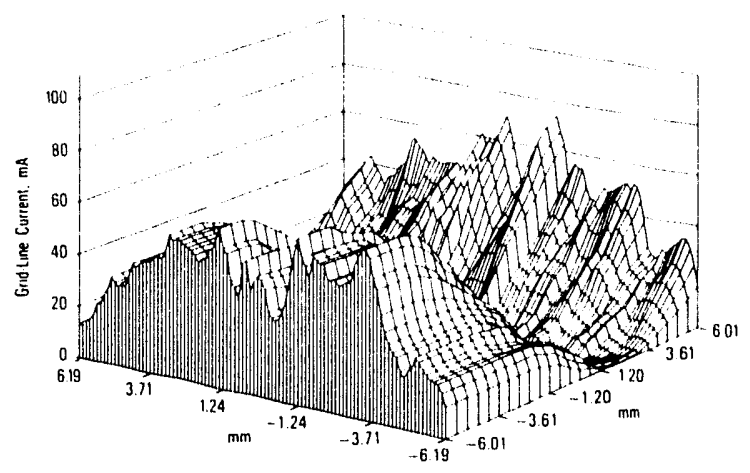

(B) 0.75 degreE. PARALLEL OFF.TRACK CONOITIONS

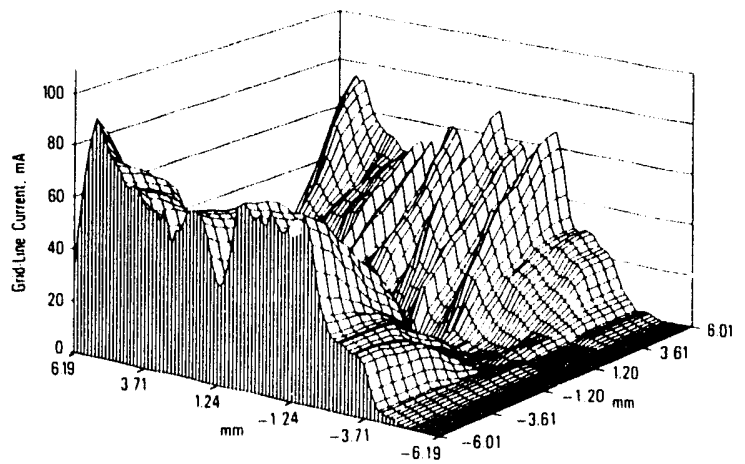

(0) 075 DEgREE, PERPENOICULAR OFF.tRaCK CONDITIONS

Figure 4

Representative Displays of Grid-line Current Distributions

The power dissipated in the grid-line metal is then given by

$P_{g}=\left(1 / M o g w^{2}\right) \sum_{m=1}^{M}\left[I_{m}{ }^{2}+I_{m} Q_{m}(s L / M)+(1 / 3) Q_{m}{ }^{2}(s L / M)^{2}\right]$

where $\sigma_{\mathrm{g}}$ is the conductivity of the grid metal (Siemens/cm) and " $a$ " is the effective aspect ratio, defined as the cross-sectional area of a single grid line divided by the square of its width.

The three power dissipations $\left(P_{e}, P_{b}, P_{B}\right)$ are summed over all grid lines and divided by the square of the cell's short-circuit current to get the effective series resistance.
The adjustment to the fill factor requires knowledge of the effective series resistance of both the modeled cell and the reference cell. It may be necessary to perform the resistance analysis just described on the reference cell in order to obtain a value for its series resistance. The fill factor of the modeled cell is then obtained by adding the following correction factor to the fill factor measured for the reference cell at the same number of "suns."

$$
\Delta F F=\frac{\left(I_{m p} R_{s}\right)_{\text {modeled }}-\left(I_{m p} R_{s}\right)_{\text {reference }}}{V_{O C}}
$$

where $I_{m p}$ is the current at the maximum power point for each of the cells. Within the accuracy of 
this approach, $I_{m p}$ can be approximated as 95 percent of $\mathrm{I}_{\mathrm{sc}}$ for each cell. It should be noted that in accordance with the procedure just described, $V_{\text {oc }}$ will necessarily be the same for both cells.

In summary, the short-circuit current is calculated to determine the number of "suns" on the cell. From this, the expected value of $V_{O C}$ can be obtained using experimental data from a representative reference cell. Finally, the effective series resistance is calculated and used to predict a shift in the fill factor from what was measured experimentally under uniform illumination. The modeled cell's power output is then calculated as the product of its $I_{S_{C}}, V_{O C}$, and FF.

\section{CASE DEFINITION}

The application of this model to a specific concentrator module design requires the selection of the reference cell and the definition of key module components. The reference cell selection is crucial to the viability of the analysis because its measured performance characteristics provide the basis for the modeled cell performance. Defining the key module components requires an in-depth understanding of the module's optical system and the concentrator cell to be modeled.

The reference cell selected for this analysis is a low resistivity, silicon concentrator cell from UNSW, designated as Z292-1 and tested by Sandia, Albuquerque. This reference cell has been chosen because its fabrication technology is similar to, and its performance is representative of, the larger cell to be modeled for this concentrator module. Table 1 summarizes the performance of this 6 percent metallized reference cell measured under uniform illumination. The cell's efficiency measured at 151 suns concentration is 23 percent. The effective series resistance of this cell is assumed to be 0.023 ohms.

The reference cell's design characteristics are similar to those ervisioned for operation in this module. Table 2 provides the key modeled cell parameters such as dimensions and cell properties. The grid lines are parallel to one another and run the length of the cell. This grid-line orientation was chosen to simplify the design and placement of the prismatic cover. The selection of a grid-line spacing of $0.125 \mathrm{~mm}$ establishes 100

\begin{tabular}{|c|c|c|c|c|}
\hline \multicolumn{5}{|c|}{$\begin{array}{c}\text { Table } 1 \\
\text { Reference Cell Performance } \\
\text { Measurements }\end{array}$} \\
\hline \multicolumn{2}{|c|}{ Cell Identification: } & \multicolumn{3}{|c|}{ UNSW Z292-1 } \\
\hline \multicolumn{2}{|l|}{ Cell Area: } & \multicolumn{3}{|c|}{$0.785 \mathrm{~cm}^{2}$} \\
\hline \multicolumn{2}{|l|}{ One-Sun $I_{s c}$} & \multicolumn{3}{|c|}{$29.5 \mathrm{~mA}$} \\
\hline \multicolumn{2}{|l|}{ One-Sun I $\mathrm{SC}$ : } & \multicolumn{3}{|c|}{$37.6 \mathrm{mAlcm}^{2}$} \\
\hline \multicolumn{2}{|c|}{ Cell Temperature: } & \multicolumn{3}{|l|}{$28 \mathrm{C}$} \\
\hline \multicolumn{2}{|c|}{ Measurement Date: } & \multicolumn{3}{|c|}{$\begin{array}{l}\text { January } 28,1987 \\
\text { 4:03 p.m. }\end{array}$} \\
\hline \multicolumn{2}{|l|}{ Measured by: } & \multicolumn{3}{|c|}{ Sandia, Albuquerque } \\
\hline $\begin{array}{l}\text { Solar } \\
\text { Concentration }\end{array}$ & Efficiency & $\underline{v}_{\text {oc }}$ & $\underline{\mathbf{I}_{\text {sC }}}$ & $\begin{array}{l}\text { Fill } \\
\text { Factor }\end{array}$ \\
\hline suns & percent & volts & amps & \\
\hline 2.2 & 20.9 & 0.670 & 0.064 & 0.828 \\
\hline 4.3 & 21.4 & 0.686 & 0.126 & 0.829 \\
\hline 10.8 & 22.2 & 0.712 & 0.320 & 0.830 \\
\hline 21.5 & 22.9 & 0.728 & 0.635 & 0.835 \\
\hline 43.6 & 23.2 & 0.744 & 1.29 & 0.828 \\
\hline 81.4 & 23.3 & 0.760 & 2.41 & 0.816 \\
\hline 105 & 23.3 & 0.764 & 3.11 & 0.810 \\
\hline 151. & 23.0 & 0.771 & 4.46 & 0.793 \\
\hline 209. & 22.5 & 0.776 & 6.19 & 0.769 \\
\hline 300 & 21.5 & 0.783 & 8.86 & 0.731 \\
\hline 403. & 20.4 & 0.786 & 11.9 & 0.690 \\
\hline 506. & 19.2 & 0.789 & 14.9 & 0.648 \\
\hline
\end{tabular}

grid lines on the $12.5-\mathrm{mm}$ by $12.5-\mathrm{mm}$ cell surface. The range of grid-line widths represents metallization coverages from 6 percent to 21 percent.

The other key components of the analysis are the optical elements of the module. The characteristics of these three elements, the primary concentrator, the secondary concentrator, and the prismatic cover, are summarized in Table 3. The module geometric concentration (lens area + cell area) is 185 . The 86.1 percent lens efficiency for the on-track condition is considered the base lens efficiency. In general, each off-track condition has a negative impact on the overall optical efficiency of the module, which is the combined efficiency of the lens, the secondary optical element (SOE), and the prismatic cover. For each 
off-track condition, the model determines the additional optical losses due to increased Fresnel reflection losses at the facetted lens surface and to increased front surface reflection losses on the SOE surfaces. The 95 percent efficiency of the prismatic cover is assumed constant for all tracking conditions and metallization coverages.

\begin{tabular}{|c|c|c|c|}
\hline \multicolumn{4}{|c|}{$\begin{array}{c}\text { Table } 2 \\
\text { Modeled Cell Design Characteristics }\end{array}$} \\
\hline Parameter & Symbol & Value & Units \\
\hline \multicolumn{4}{|l|}{ Cell Dimensions } \\
\hline Area & A & 1.56 & $\mathrm{~cm}^{2}$ \\
\hline \multicolumn{4}{|l|}{ Grid-line } \\
\hline Spacing & 5 & 125 & $\mu \mathrm{m}$ \\
\hline \multicolumn{4}{|l|}{ Grid-line } \\
\hline Width & w & $7.5 \cdot 26.3$ & $\mu \mathrm{m}$ \\
\hline Aspect Ratio & a & 0.35 & - \\
\hline \multicolumn{4}{|l|}{ Grid-line } \\
\hline Segments & $M$ & 26 & - \\
\hline \multicolumn{4}{|l|}{ Cell Properties } \\
\hline \multicolumn{4}{|l|}{ Emitter Sheet } \\
\hline \multicolumn{4}{|l|}{ Base } \\
\hline Resistivity & $e_{b}$ & 0.2 & ohm-em \\
\hline $\begin{array}{l}\text { Base Thickness } \\
\text { Grid Metal }\end{array}$ & $t_{b}$ & 280 & $\mu m$ \\
\hline Conductivity & ${ }^{\circ} 8$ & $5 \times 10^{5}$ & Siemens $/ \mathrm{cm}$ \\
\hline
\end{tabular}

\begin{tabular}{|c|c|}
\hline \multicolumn{2}{|c|}{$\begin{array}{l}\text { Table } 3 \\
\text { Modeled Optical System } \\
\text { Characteristics Summary }\end{array}$} \\
\hline Optical Element & Design Summary \\
\hline \multicolumn{2}{|c|}{ Primary Concentrator } \\
\hline Description & Point Focus Fresnel Lans \\
\hline Material & Acrlic. \\
\hline Efficlency ${ }^{2}$ & 86.1 percent \\
\hline \multicolumn{2}{|c|}{ Secondary Concentrator } \\
\hline Description & Four-sided Reflector \\
\hline Materlal & Anodized Aluminum \\
\hline Reflectivity & 82 percent \\
\hline \multicolumn{2}{|l|}{ Prismatic Cover } \\
\hline Description & ENTECH, Inc., Proprietary \\
\hline Material & Silicone \\
\hline Efficiency ${ }^{c}$ & 95 percent \\
\hline \multicolumn{2}{|c|}{$\begin{array}{l}\text { "Cistimated efficiency total includes } 4 \text { percent first surface } \\
\text { Fresnel loss, } 1 \text { percent absorption loss, } 4 \text { percent draft and } \\
\text { facet definition losses, and } 5 A \text { percent second surface } \\
\text { fresnel loss. } \\
\text { b Assumed constant for all wavelengths and Incidence angles. } \\
\text { Esstimated efficlency. Assumed constant for all conditions. }\end{array}$} \\
\hline
\end{tabular}

\section{CASE ANALYSIS AND RESULTS}

Application of this general cell performance model to the characteristics of a specific concentrator module design is a multistep process. The results of this process can be best illustrated by a stairstep display shown in Figure 5. Figure 5a presents the stairstep efficiencies for on-track conditions. Similar stairsteps are provided in Figures 5b, 5c, and $5 d$ for representative, parallel offtrack conditions. Each stairstep displays a step efficiency, a cumulative efficiency, and a step power based on an incident direct normal insolation level of $0.1 \mathrm{~W} / \mathrm{cm}^{2}$. This insolation level illuminates the cell with an average of 150 "suns" during the on-track condition. Each step represents a key procedure performed by the model and described as follows for the 6 percent metallized case.

Initially, the solar power incident on the lens surface is calculated. This value is decreased by the optical system efficiency, which includes the constant 95 percent prismatic cover efficiency. The module geometric concentration ratio and the optical efficiency determine the equivalent "suns" of uniform concentration. For this level of "suns," the efficiency of the 6 percent metallized reference cell is calculated from measured data. The modeled cell's performance differs because of the benefit of a prismatic cover and the penalty of a reduced fill factor. Finally, the performance is derated for the effects of nonuniform illumination.

This same conceptualization can be applied to other metallization coverages as well. For eac'i tracking condition, the first three steps of the procedure are identical to the 6 percent metallization case. However, with the application of the prismatic cover, the performance is substantially boosted as a result of decreases in the series resistance of the more highly metallized modeled cell.

With an understanding of the procedural basis for this analysis, the continuing emphasis will present those performance parameters that most indicate the influence that metallization coverage and nonuniform illumination have on module performance. Those parameters are the solar-to-electric efficiencies of the modeled cell with uniform illumination and with nonuniform illumination. 


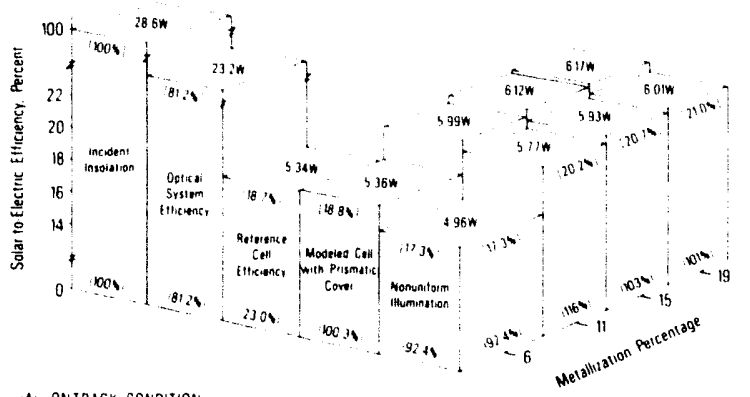

(A) ONTRACK CONDIIION

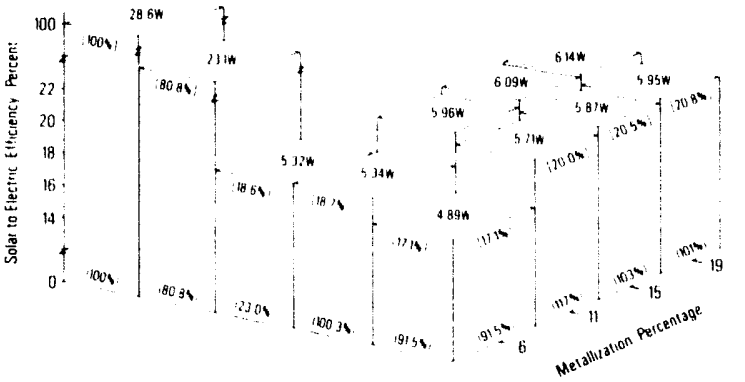

(B) 025 degref parallel of track condition

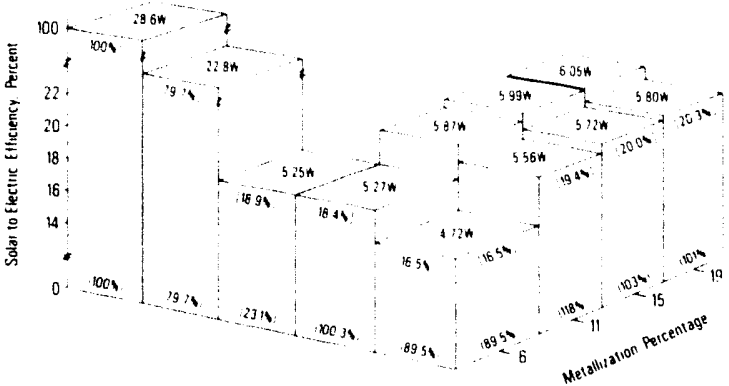

(C) O.5O degree parallel OFF track CONDITION

1. Step Eftictencr

$\therefore$ - Cumulative Elficiener

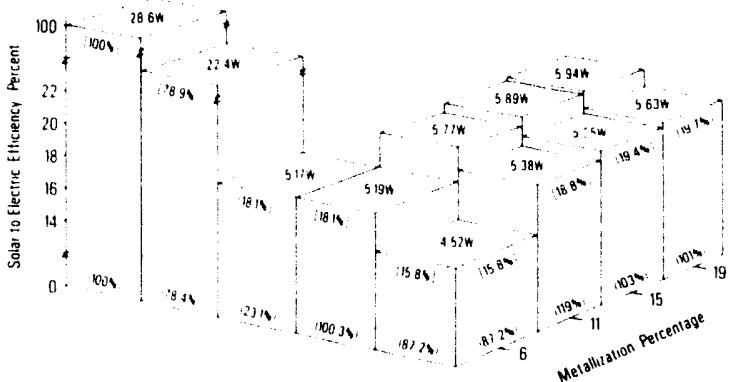

(D) 075 degree parallel off thack CONOITION

Figure 5

Efficiency Stairsteps for Representative Metallization and Tracking Conditions

Figure $6 a$ and Figure $6 b$ are histograms of solar-toelectric efficiencies that display the beneficial impact of increased metallization and the adverse impact of increased off-track conditions. An indication of the performance impact of nonuniform illumination can be obtained by comparing the efficiency of uniform illumination cases with the efficiencies of analagous nonuniform illumination cases. For instance, comparison of on-track efficiencies indicates a range of performance deratings from 8.0 percent $(1-17.3 \div 18.8)$ with 6 percent metallization to 2.3 percent $(1-21.1 \div 21.6)$ with 21 percent metallization. Also, at a one-degree off-track condition, the performance deratings increase to a range of 14.3 percent with 6 percent metallization to 6.5 percent with 21 percent metallization. Clearly, nonuniform illumination performance degradation is buffered by increases in metallization coverage.

The selection of the preferred metallization coverage requires a closer imestigation of the relative performance improvements brought on by metallization increases. Figure 7 presents the relative solar to electric efficiency change for each incremental increase in metallization from 6 percent to 21 percent. The base 23.0 percent efficiency of the reference cell at 150 "suns" is used for this relative comparison. These curves display an obvious "diminishing returns" characteristic. For example, increasing the metallization coverage from 6 percent to 15 percent shows a 


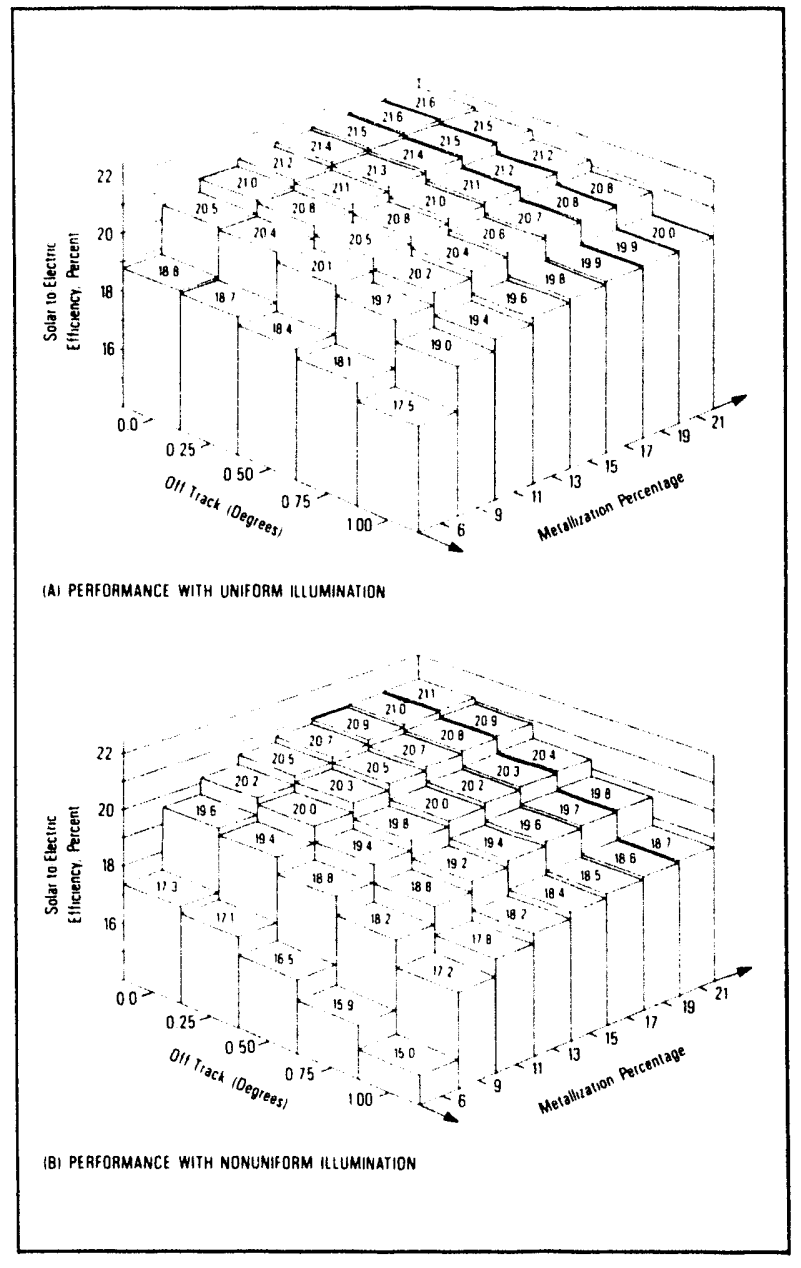

Figure 6

Efficiency Histogram for

Candidate Metallizations and

Parallel Off-track Conditions

cumulative efficiency improvement that exceeds 14 percent for the nonunifor 7 illumination condition. However, the additional benefit of increasing metallization coverage from 15 percent to 17 percent is less than 0.8 percent, with reduced incremental benefit for even higher metallization coverages.

An additional noteworthy feature of this display is that the relative efficiency change is insensitive to off-track conditions. Hence, the single curve for each illumination profile is representative of all tracking conditions.

On the basis of the analysis of this module's expected performance and in consideration of the fact that

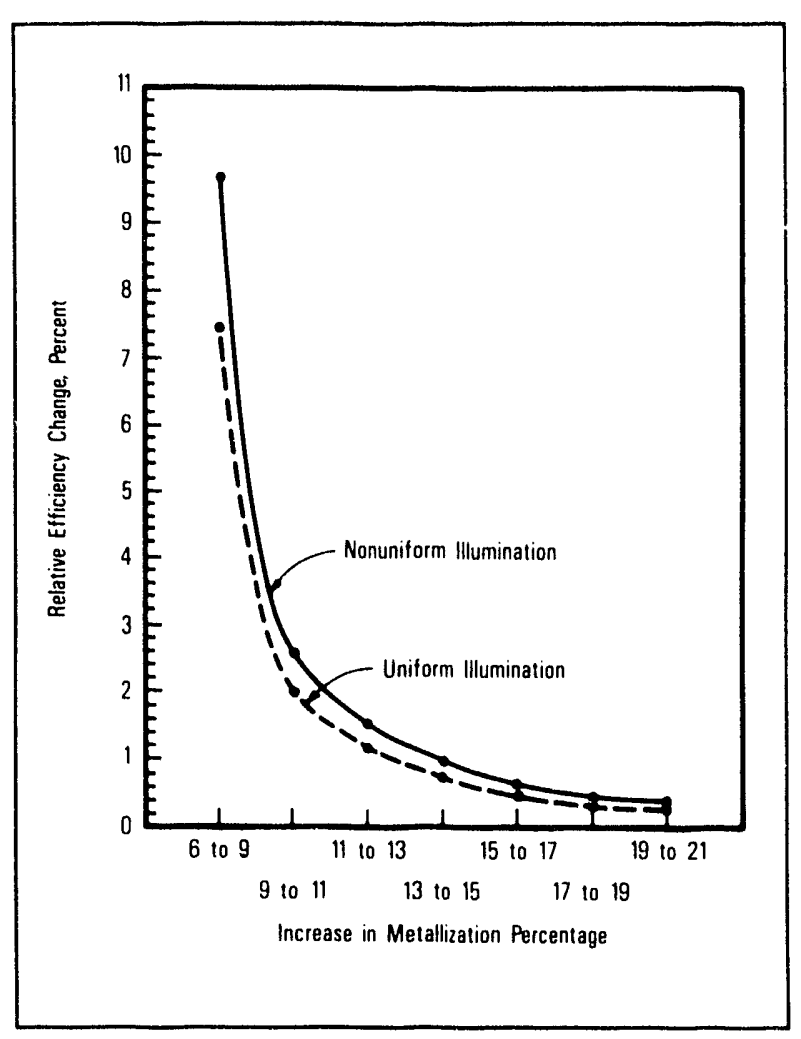

Figure 7

Relative Efficiency Change For Metallization Increases

no previous experience exists in the design or placement of prismatic covers on point focus concentrator cells, 15 percent was selected as the preferred metallization coverage. The slight improvements that this analysis indicates for metallizations above 15 percent may be more than offset by the possible decreases in prismatic cover efficiencies that are more likely with more highly metallized cells.

Finally, an important consideration for performance estimates of modules that use cells with grid lines parallel to the cell edge is the orientation of the offtrack condition to the cell. Figure 8 displays the solarto-electric efficiencies for nonuniformly illuminated cells for three sets of off-track alignments to the grid lines: parallel (higher intensity near grid line - bus bar connection), diagonal (higher intensity at cell corner), and perpendicular (higher intensity on fewer grid lines). This analysis has shown that the lowest output estimates are obtained for a given off-track condition with perpendicular orientation to the grid lines. For a 15 percent 
metallized cell, the relative performance decrease for the 0.5 -degree off-track condition from the parallel alignment is 0.6 percent for the diagonal alignment and 1.3 percent for the perpendicular alignment. Comparison of these performance curves with the grid-line current distributions of Figure 4 indicates that the performance degradation of the diagonal and perpendicular orientations is primarily a result of the uneven division of current between the grid lines.

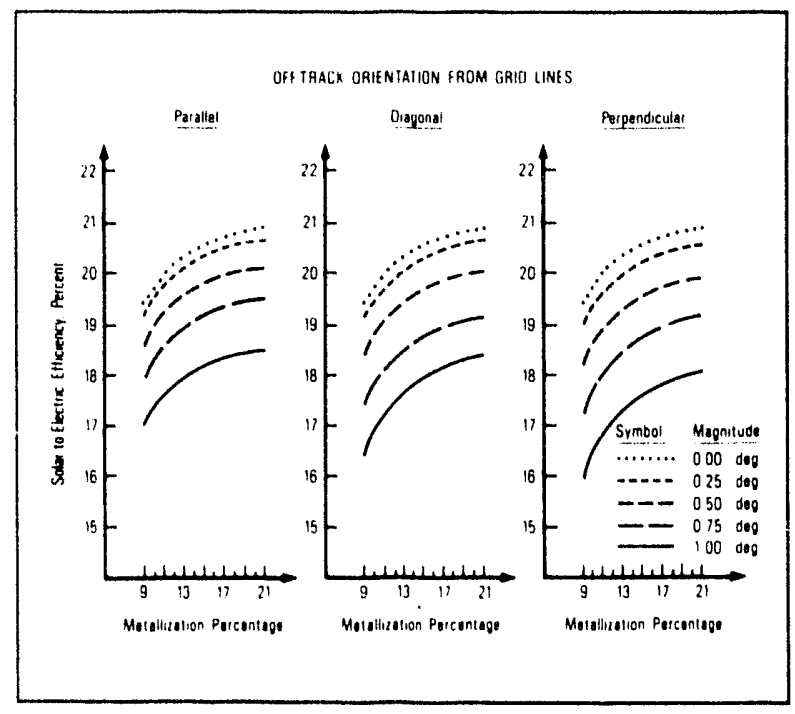

Figure 8

Performance Estimates for

Off-track Alignments

\section{CONCLUSION}

A new model has been developed that estimates the performance of front-gridded cells exposed to the expected illumination conditions of point focus Fresnel concentrator module optics. The model uses standard test data of a reference cell to estimate the performance of similar cells exposed to the nonuniform ilumination conditions of a PV concentrator module. It also is capable of analyzing the impact of a prismatic cover on cell performance.

This model has been applied to the module characteristics of the Sandia PV module studies. This analysis has estimated the impact of nonuniform itlumination on module performance and has provided design insight into the selection of a 15 percent metallized, prismatically covered cell.

\section{REFERENCES}

1. M. A. Green, et al, Silicon Concentrator Solar Cell Research, SAND 88-7032, September 1988.

2. K. A. Kerschen and S. L. Levy, "Determination of Photovoltaic Concentrator Optical Design Specifications Using Performance Modeling," presented at the 19th Photovoltaic Specialist Conference, New Orleans, Louisiana, May 48, 1987.

3. ENTECH, Inc., U.S. Patent No. 4711972, December 8, 1987.

4. S. L. Levy and L. E. Stoddard, High Concentration Photovoltaic Module Design, EPRI AP-4752, August 1986.

5. Pau! A. Basore, "Optimum Crid-Line Patterns for Concentrator Solar Cells Under Nonuniform Illumination," Solar Cells, Volume 14, 1985.

\section{ACKNOWLEDGMENT}

The authors wish to thank Jon Feickert of Black \& Veatch for assistance in model coding, Dave King of Sandia for providing the reference cell performance measurements and modeled cell device characteristics, and Sheldon Levy of Black \& Veatch and Alex Maish of Sandia for helpful review of this work. 


\section{APPENDIX B}

Design, Fabrication, and Performance of Silicon Solar Cell Assemblies for Concentrator Modules

B-1 


\section{ABSTRACI}

The objective of this work is to design, develop, fabricate, and qualify solar cell assemblies for improved terrestrial concentrator modules. The cell assembly includes the concentrator cell, its electrical connections, mechanical mounting, thermal sink, high voltage insulator, prismatic cover, and secondary optical element ( $S O E$ ). The assemblies are designed for operation at a nominal concentration of 200 suns with passive cooling. Fabrication wethods are described, including a novel vacuum soldering process. High voltage isolation testing and $x-r a y$ inspections have identified problet areas in prototype assemblies; design solutions are proposed. Five cell assemblies have undergone qualification testing, and 62 cell assemblies have been produced for incorporation into two prototype modules. Iest results are presented.

\section{INIRODLCIICN}

Photovoltalc concentrator cell assemblies must be designed for minimum cost, high reliability, and high conversion efflciency, to enable concentrator systems to achieve the goal of economical electricity generation [1]. These criteria have resulted in an emphasis in this program on simplicity of design, manufacture, and operation. As an example, the cell assemblies are designed for passive air cooling to simplify module and system fabrication and system operation.

The assembly must provide a means of mounting a cell that satisfies a number of stringent and sometimes conflicting requirements:

- accurate positioning of the cell for alignment to the concentrating optics

- low resistance electrical connections for carrying high current $(10 \mathrm{~A})$ from the cell

- high cell heat rejection rate for efficient $\mathrm{FV}$ conversion

- high voltage isolation of the cell and its connectors from gound for efficient and safe system operation.

This work is part of a team effort by Black \& leatch, Spire Corporation, and Solar kinetics, Inc. to develop an improved concentrator module suitatile for commercial manufacture. Black \& veatch is responsible for optics design and overall project management; Spire is resfonsible for cell assembly design and fabrication; and Solar Kinetics is responsible for housing fabrication and module assembly. Each module comprises 24 cell assemblies. The module $1 \mathrm{~s}$ made of an aluminized steel housing covered by $a \times 6$ parquet of point focus fresnel lenses. A cell assembly is installed beneath each lens on the floor of the housing. I wo prototype modules are being produced for testing at Sandia National Laboratories, Albuquerque, NM, USA.

\section{DESIGN AND FABRICAIICN}

Cell assembly components have been designed, materials selected, and fabrication processes developed. Detailed process specifications were written to provide quality control. Five cell assemblies have been subjected to qualification testing at Sandia, and 62 assemblies have been fabricated for use in prototype modules. Figure 1 is a photograph of a completed cell assembly.

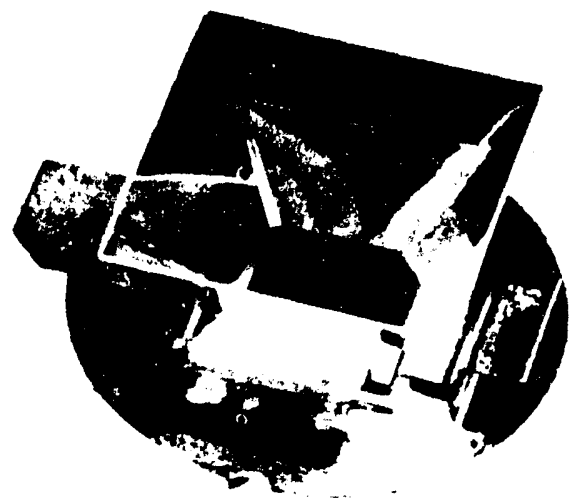

F1gure 1. Concentrator solar cell assembly.

The assembly utilizes microgrooved silicon concentrator cells supplied by Sandia and fabricated at the University of New South wales, Australla (UNSh) [2]. The cells have a conventional bifacial contact arrangement which is less complex and therefore easier to fabricate than cells with both $p$ and $n$ contacts on the back surface. A patented (ENIECh, lnc.) prismatic cover is utilized to reduce losses that occur from the reflection of light from the front contact metallization. The prismatic cover allows the cell to be designed with a much higher metal coverage (15\% of the active area) than is normally used for concentrator cells, thereby decreasing power 
losses due to gridline series resistance. The cells have an $18 \mathrm{~mm} \times 18 \mathrm{~mm}$ die size and a $12.5 \mathrm{~mm}$ $x 12.5 \mathrm{~mm}$ active area designed for operation at 200x concentration.

Figure 2 illustrates the assembly's componerts. The cell is mounted on a copper clad alumina substrate. The substrate comprises two 0.25 mo thick copper sheets directly bonded to a 0.51 mm thick alumina wafer, forming a copper/ alumina/copper stack. The top copper layer provides the electrical connection to the cell's back surface contact, and is extended beyond the alumina to allow for cell interconnection. The alumina provides electrical insulation from ground, while the bottom copper layer allows the substrate to be soldered to the heat spreader.

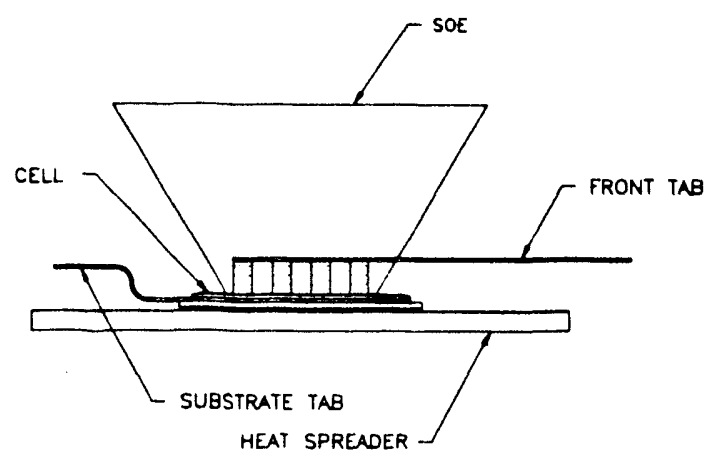

Figure 2. Illustration of concentrator solar cell assembly components.

Connection to the cell front contact is made with a $0.25 \mathrm{~mm}$ thick copper lead frame, or front tab, which has eight leads. Each of the leads is independently soldered to the cell. The eight leads are formed with large radii S-shaped bends to reduce stress on the solder joints and on the cell front contact during diurnal thermal cycling. A similar s-bend is formed in the substrate tab used for the cell back contact.

The front tab is soldered to the cell with alloy $\mathrm{Sn} 62(62.5 \% \mathrm{Sn}, 36.1 \% \mathrm{~Pb}, 1.4 \% \mathrm{Ag})$ solder. The silver component in the solder reduces dissolution of silver from the cell contact into the liquid solder during the soldering step. The same solder alloy is used for mounting the cell onto the copper clad alumina substrate, and for mounting the substrate onto the copper heat spreader. The heat spreader is a 1.59 mm thick copper disk, pretinned by dipping in Sn60 solder $(60 \% \mathrm{Sn}, 40 \%$ $\mathrm{Pb})$ to ensure solderability.

Cne of the failure modes observed for concentrator cell assemblies of this type is the separation of the solder bond that attaches the solar cell to its substrate during thermal cycling [3]. The stress on the solder bond arises from the low thermal coefficient of expansion, $\boldsymbol{\alpha}$, of silicon (2.8E- $\left.-6^{\circ} \mathrm{C}^{-1}\right)$ compared to the $\boldsymbol{\alpha}$ 's of alumina $\left(7.3 \mathrm{E}-6^{\circ} \mathrm{C}^{-1}\right)$ and copper $\left(17 \mathrm{E}-6^{\circ} \mathrm{C}^{-1}\right)$. Work done with Sr-Fb alloy solders by Nightingale, et al., indicates that solder joint strength is maximum when the joint thickness is in the 100 to $150-\mu \mathrm{m}$ range 14]. Thus a 125- $\mu \mathrm{m}$ thick solder preform was selected for joining the cell to the substrate, and for joining the substrate to the heat spreader.
The cell, the front tab, the substrate, and the heat spreader are simultaneously soldered in an automated vacuum laminator. The laminator is a commercial product manufactured by Spire for laminating flat-plate photovoltaic modules using sheet encapsulants. This equipment was chosen because there are simflarities between cell encapsulation and cell solder bonding. Both processes require the void-free bonding of planar objects with solid thick films that melt at elevated temperatures. Special modifications were made to the laminator to allow higher temperature operation for soldering.

A precision, multilevel alignment fixture is used to properly locate the cell assembly components during soldering. Accurate alignment is necessary to ensure proper positioning of the cell with respect to the fresnel lens during module assembly. The alignment fixture is loaded with parts and placed into the laminator's vacuum chamber. The air is evacuated and the parts are heated until the solder melts. A light mechanical pressure ( 0.02 to 0.03 atmosphere) is applied inside the vacuum chamber with a pneumatic diaphragm to ensure that all of the components are in physical contact. The diaphragm allows pressure to be applied without disturbing the vacuum. Fressure and vacuum are maintalned as the components are cooled unt1l the solder freezes. A photograph of a soldered assembly is shown in Figure 3 .

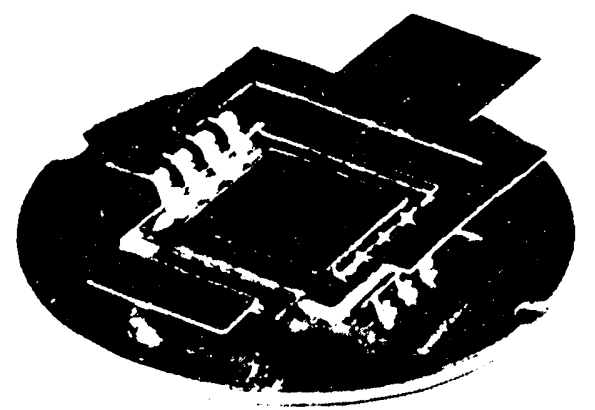

Figure 3. Assembly after vacuum soldering.

Initial experiments were done to see if the vacuum soldering process could be carried out without the use of a chemical flux. The advantage of this approach is that flux residues would not be trapped in the large area joints (between the cell and the substrate, and between the substrate and the heat spreader) where they might cause corrosion or interfere with heat transfer. The solar cell, the front tab, the substrate, and the heat spreader were pretinned by dipping in solder to provide a coating on all solder joint surfaces. The parts were then soldered in the laminator as described above. Visual examinations showed poor wetting of the solder joints between the cell and the front tab. As a result, the process was mod1fled to include the application of a thin layer of low solids content, noncorrosive flux at all solder foint surfaces. This approach resulted in extremely well wetted joints at the front tab. 
Atter soldt: ing, the prismatic cover is adhered to the front surface of the solar cell. The cover is a thin, transparent sheet with tacets that refract light away from the front contact wetallization and onto the cell active area. The prismatic covers were fabricated and attached to the cells by ENIECh, Inc.

The tirial cell assembly step is to install the serundary oftical element (SCE). The SOE, designed ty Biack \& Veatch, is a four-sided aluminuo rellector used to collect stray light that would otherwise fall outside the cell active arta. The sut also provides tolerance of the concentrator module to tracking errors. The $\mathrm{SOE}$ is installec with its exit aperture in contact with the prismatic cover, and secured to the front contact tat with siljcone adhesive. The adhesive is a one-part, thixotropic, noncorrostve, RTV silicone. The same silicone adhesive is used to provide electrical insulation under the cell's back contact tab, where it extends out from the alumina substrate.

\section{TESTIRC}

Cell efficiencles were monitored at Spire during the initial development of the assembly process to detect any changes in cell performance. One-sun efflclency measurements were made at various steps in the process: as-received, after solder dipping, and after soldering into a complete assembly. The data after processing showed varlations of $+2 \%$ or less from the asreceived data. Since these variations are within the accuracy of the measurements, the processes have not caused measurable degradation at one-sun operation.

Cell performance at concentration was measured by Sandia to determine the effects of the prismatic covers. lable 1 compares bare cell data with mounted cell data. The mounted cells have prismatic covers, but the SOE's were not yet installed. Wrille the range in the data (from $6.0 \%$ to $15.6 \%$ increase in efficiency) indicates there is room for improvement in cover mounting techniques, the cells with the highest gains show that the covers can provide near total obscuration of the grid lines, since the grid line coverage is approximately $15 \%$.

lable 1. Cell efflclencles before and after cell mounting.

- Prism cover installed on mounted cello

- SCE's not installed on mounted cells

- Data measured by Sandia flash aldulator at $196 \lambda, 25^{\circ} \mathrm{C}$

\begin{tabular}{|c|c|c|c|}
\hline $\begin{array}{l}\text { Asseably } \\
\text { Number }\end{array}$ & $\begin{array}{c}\text { Bare Cell } \\
\text { Eff } 1 \text { clency } \\
\left(\begin{array}{l}0 \\
i\end{array}\right)\end{array}$ & $\begin{array}{c}\text { Mounted } \\
\text { Eff } 1 \text { clency } \\
(\%)\end{array}$ & $\begin{array}{r}\Delta \eta \\
(\%)\end{array}$ \\
\hline $\begin{array}{l}61 \\
62 \\
63 \\
66 \\
68\end{array}$ & $\begin{array}{l}19.55 \\
20.20 \\
19.50 \\
20.31 \\
20.42\end{array}$ & $\begin{array}{l}21.59 \\
21.81 \\
22.55 \\
22.67 \\
23.27\end{array}$ & $\begin{array}{r}10.4 \\
8.0 \\
15.6 \\
11.6 \\
14.0\end{array}$ \\
\hline \multicolumn{3}{|c|}{$\begin{array}{l}\text { Average change in efficlency: } \\
\text { Standard deviation: }\end{array}$} & $\begin{array}{r}11.9 \\
+\quad 3.0\end{array}$ \\
\hline
\end{tabular}

Front contact pull tests were done at Spire to examine the integrity of the solder foints and the front contact metalilzation. During this test the front tab is sheared to separate the eight Individual leads. Each lead is pulled at a $45^{\circ}$ angle from the surface of the cell, and the maximum pull force required to separate the lead from the cell is recorded by a digltal force gauge. Inttial tests showed low pull strengths (below $0.4 \mathrm{~kg}$ ) due to poor adhesion of the cell $\mathrm{s}^{\prime}$ top surface metal11zation. work done at LNSh indicated that higher pull strengths can be achieved by soldering the tab to the middle of the contact bus, away from the outside edge [5]. The frunt tab s-bend forming tool was modified so the solder joints do not extend to the outer edge of the cell contact. Pull strengths greater than $5 \mathrm{~kg}$ are typlcally obtalned from solder jolnts made with the redesigned tabs.

High voltage isolation tests were also conducted at Spire. Since no system voltage was specifled for these assemblies, it was agreed to test them at Sandia's default criterion of 2,200 volts. Testing of preliminary assemblies showed a wide range of voltage standoff, from 1,600 volts to 3,000 volts (the upper $11 \mathrm{mlt}$ of the test equipment). The voltage standoff is 1imited by leakage current across the gap between the substrate tab and the heat spreader, at the edge of the alumina insulator. Improving the standoff by fllling the gap under the oubstrate tab with silicone RIV was attempted. Testing at Splre and at Sandia found this approach to be unreliable at the 2,200 volt level. A design change is recommended, wherein the substrate tab bends up from the surface of the alumina, rather than extending otraight off the edge.

Flve cell assemblies were fabricated and sent to Sancis for qualification testing. The assemblies underwent environwental tests comprising 250 thermal cycles from $-40^{\circ} \mathrm{C}$ to $+110^{\circ} \mathrm{C}$ and 10 humidity-freeze cycles consisting of 20-hour soaks at $85^{\circ} \mathrm{C}, 85 \%$ relative humidity followed by $-40^{\circ} \mathrm{C}$ freezes. No visible damage was observed after the testing. UItrasonic 1mages of the cell assemblies were taken before and after the environmental tests. No significant differences appeared in these images, indicating that the environmental tests had not caused cracking, delamination, or other damage to the solder bonds. Electrical performance tests at $190 \mathrm{x}$ were also done before and after environmental testing. Small changes in maximum power efficlency, ranging from $-1 \%$ to $+3 \%$, were measured, indicating no performance degradation has occurred. $\lambda$-ray plctures taken prior to environmental testing revealed the presence of volds in the oolder layera between the cell and substrate and between the substrate and heat apreader. Voldo are underirable because they increase the thermal resistance of the assembly, ralsing the cell operating temperature. The volds could be caused by Insufficlent wetting of the pretinned surfaces, or because the mechanical pressure during soldering was insufficlent to press the solder evenly and collapse the volds. Inttial attempto to bolder at higher mechanical pressures were unsuccessful, as the solder from the preforms squeezed out from between the layers. Higher pressures may work if thinner solder layers are used. If insufficlent wetting is the cause of the volds, different methods of flux application or other types of flux should solve the protlem.

Sixty-two cell assemblies have been fabricated for use in two prototype concentrator modules. The cell efficiencies prior to mounting were greater than $20.2 \%$ at $190 x, 25^{\circ} \mathrm{C}$. After soldering these cells into assemblies, the efficlency of one cell decreased to 16.5\%. The cell efficlencies of the remaining 61 assemblies (prior to mounting the prismatic covers and the SOK's, as in Figure 3 ) averaged $21.1 \%$ and ranged from 
$26.4 \%$ to $21.9 \%$ at $150 x, 25^{\circ} \mathrm{C}$. The efficiency of these celis peaks near $150 x$, although $1 t$ is st1ll cluse to peak at $190 x$. At $156 x$, the average mounted cell efficlency of the 61 assemblles (without covers or SCE's) measured $21.3 \%$ and ranged fror $20.6^{\circ}$ to $22.1 \%$ at $25^{\circ} \mathrm{C}$. If the best cell realizes a $15 \%$ galn fror 1 ts prismatic cover, it will achleve $25.4 \%$ efficlency at $150 \mathrm{x}, 25^{\circ} \mathrm{C}$.

\section{CCNCLLSICAS}

Solar cell assemblles have been designed for use in terrestrial concentrator modules. Frocesses have been developed and documented, preliminary assemblies have undergone qualification testing, and prototype assemblies have been fabricated.

Frelininary assemblies have undergone accelerated environmental testing (thermal shock cycling and humldity-freeze cycling). Post-test visual inspections showed no mechanical damage to the assemblies. Lltrasound lmages taken before and after environmental testing showed no delaminations or cracking of the solder bonds. Currentvoltage measurements in a pulsed sun simulator at is GX showed no reductions in cell conversion efficiencles.

$\lambda$-ray pictures have shown the presence of volds in the tin-lead-silver solder which bonds the cell to the substrate and the substrate to the heat spreader. These voids may reduce the heat transfer frod the cell, causing the cell to operate at a higher temperature. Solving the vold problem requires investigation of the soldering process parameters, including solder preform thickness, mechanical pressure, flux quantity, and flux type. High voltage 1solation testing has identifled a current leakage path under the substrate tab. A change in the tab shape to lengthen the path w11l allow the assemblies to be used at higher ayster voltages.

Frolotype cell assemblies have been fabricated for installation into two modules of 24 celle each. The 61 best cell assemblies have an average eff1clency of $21.1 \%$ at $190 \mathrm{x}, 25^{\circ} \mathrm{C}, \mathrm{prlor}$ to mounting of the prismatic cover and the SOE. If the priswatlc covers provide total grid obscuration, the average efflciency of the 61 cells will be $24.3 \%$, and the best cell efficlency will be $25.2 \%$ at 1 GOA, $25^{\circ} \mathrm{C}$. The priso covers and the SOE's w111 be mounted on the cell assemblies, and the assemblies will be installed into the two modules in the summer of 1989 .

\section{ACKNOHLEDGMEN}

This work 1 s being funded by Sandia National Laboratorles, Albuquerque, NM, under contract 56-7211, as part of the United States of America Department of Energy National Photovoltaics Program. Th1s development work 1 s a team effort by Black \& Veatch, Splre Corporation, and Solar Kinetics, Inc. Qualification testing and efficlency weasurements at concentration were done by Sandia; the test results were provided courtesy of C.B. St1llwell.

\section{REFERENCES}

1. U.S. Dept. of Energy, "Five lear Research Plan 1987-1991," DOE/CH10093-7 (1987).

2. J. 2hao, A. Wang, A.W. Blakers, and M.A. Green, "High Efficlency Prismatic Cover silicon Concentrator Solar Cells," Froc. 20th IEEE Photovoltaic Specialists Conf. 529 (1988).

3. C.J. Chiang and E.H. Richards, "Rellability Research and Cell Assembly Design for Photovoltalc Concentrator Modules," Proc. 19th IEEE Photovoltalc Speciallsts Conf. 1222 (1987).

4. H.H. Manko, Solders and Soldering, 2nd ed., McGraw H1ll, New York 94 (1979).

5. C. Chlang, "Design of Cell Mounts for Photovoltaic Concentrator Modules," Proc. 20th IEEE Photovoltalc Specialista Conf. 1327 (1988). 
DISTRIBUTION :

\section{AESI}

Attn: William J. Todorof 1001 w. 17th Street, Unit V

Costa Mesa, CA 92627

Alpha Solarco (2)

Attn: Edward Schmidt Don Carroll

11534 Gondola Drive

Cincinnati, OH 45241

Alternative Sources of Energy

Attn: Larry Stoiaken

$107 \mathrm{~S}$. Central Avenue

Milaca, MN 56353

American optical Corporation

Attn: Clark Grendol

R. F. Woodcock

14 Mechanic Street

Southbridge, MA 01550

Amonix, Inc. (2)

Attn: Vahn Garboushian Sewang Yoon

3545 West Lomita Boulevard

Unit $A$

Torrance, CA 90505

Applied Solar Energy Corp (3)

Attn: Ken Ling

Frank Ho

Peter Iles

15251 E. Don Julian Road

City of Industry, CA 91746

Arizona Public Service Company

Attn: Tom Lepley

P. O. Box 53999

Mail station 3875

Phoenix, AZ 85072-3999

Arizona State University (2)

College of Engineering and Applied Science

Attn: Charles Backus

G. Schwuttke

Tempe, AZ 85287
Astropower Division

Attn: A. Barnett

R. Hall

30 Lovett Avenue

Newark, DE 19711

Austin, City of

Electric Dept.

Attn: John E. Hoffner

P. O. Box 1088

Austin, TX 78767

Bechtel National, Iric.

Attn: Walter J. Stolte

Mail stop 50/15/D17

P. O. Box 3965

San Francisco, CA 94119

Black \& Veatch (11)

Attn: Larry stoddard Kevin Kershen (10)

P. O. Box 8405, Bldg. $F$

Kansas City, MO 64114

Boeing Electronics Company

Attn: Lewis Fraas

P. O. Box 24969, MS 9Z-80

seattle, WA 98124-6269

Electric Power Research Inst. (2)

Attn: Frank Goodman Ed DeMeo

3412 Hillview Avenue

P. O. Box 10412

Palo Alto, CA 94303

ENTECH, InC. (2)

Attn: Walter Hess

Mark O'Neill

P. O. Box 612246

DFW Airport, TX 75261

Fresnel optics, Inc.

Attn: John R. Egger

1300 Mt. Read Blvd.

Rochester, NY 14606

Georgia Institute of Technology (2)

School of Electrical Engineering

Attn: Professor Ajeet Rohatgi Richard King

Atlanta, GA 30331 
High Intensity Photovoltaics, Inc. Attn: Bernard L. Sater

9007 Westlawn Blvd.

Olmsted Falls, OH 44138

Hughes Research Labs (2)
Attn: S. Kamath

3011 Malibu Canyon Road

Malibu, CA 90265

Institute of Advanced

Manufacturing Sciences, Inc.

Attn: Paul R. Warndorf

1111 Edison Drive

Cincinnati, $\mathrm{OH} 45216$

James Associates

Attn: Larry James

7329 Meadow court

Boulder, CO 80301

Jet Propulsion Laboratory

Attn: Ron Ross

R. S. Sugimura

4800 Oak Grove Drive

Pasadena, CA 91109

Kopin corporation

Attn: M. Spitzer

695 Myles Standish Blvd.

Taunton, MA 02780

Luz Engineering Corp.

Attn: David Kearny

924 Westwood Blvd., Suite 1000

Los Angeles, CA 90024

MIT/Lincoln Lab

Attn: George Turner

Box 73

Lexington, MA 02173

Mobil Solar Energy corporation

Attn: Juris Kalejs

4 Suburban Park Drive

Billerica, MA 01821

New Mexico State University (2)

Attn: L. Matthews

G. Mulholland

F. O. Bux 3450

Las Cruces, NM 88003
NYSERDA

Attn: Burton Krakow

Two Rockefellar Plaza

Albany, NY 12223

Oak Ridge National Laboratory (2)

Attn: R. F. Wood

R. D. hestbrook

P. O. Box L:

Oak Ridge, TN 37830

Pacific Cas \& Electric (3)

Attn: Steve Hester Carl Weinberg Christina Jennings

3400 Crow Canyon Road

San Ramon, CA 94583

Pacific Gas \& Electric

Attn: Brian Farmer

Electrical Engineering Dept.

Room F 1126

one California street

San Francisco, CA 94106

Public Service Company

of New Mexico

Attn: R. Frank Burcham

Alvarado Square, MS 0150

Albuquerque, NM 87158

Purdue University

Attn: Richard Schwartz

School of Electrical Engineering

West Lafayette, IN 47907

Science Applications International Corporation

Attn: Roger I. Davenport

10343 Roselle Street, suite G

San Diergo, CA 92121

SERI (3)

Attn: J. Benner

T. Surek

E. Witt

1617 Cole Blvd.

Golden, $C O 80401$ 
SERI Library

1617 Cole Blvd.

Goldr,n, co 80401

Siemens Solar (2)

Attn: Charles Gay

Kim Mitchell

P. O. Box 6032

Camarillo, CA 93010

Solar Engineering Applications Corporation

Attn: D. Curchod

N. Kaminar

2010 Fortune Drive, suite 102

San Jose, CA 95131

Solar Kinetics, Inc. (3)

Attn: Gus Hutchison

Post office Box 540636

Dallas, $\mathrm{TX}$ 75354-0636

Solarex Corporation (2)

Attn: J. Wohlgemuth Mohan Narayanail

630 Solarex Court

Frederick, MD 20701

SOLEC International, Inc.

Attn: Ishaq Shahryar

12533 Chadron Avenue

Hawthorne, CA 90250

Southern California Edison

Attn: Nick Patapoff

2244 Walnut Grove Avenue

Rosemead, CA 91770

Sparta

Attn: Ugur ortabasi

5673 w. Las Positas Blvd.

Suite 205

Pleasonten, CA 94566

SPECO

Attn: Walt Hart

P. O. Box 91

Morrison, CO 80465

Spectrolab

Attn: D. Lillington

12500 Gladstone Avenue

Sylmar, CA 91342
Spire Corporation

Attn: M. J. Nowlan

Patriots Park

Bedford, MA 01730

Springborn Laboratories, Inc.

Attn: Bernard Baun

Enfield, CT 06082

SunPower Corporation

Attn: Richard Swanson

435 Indio Way

Suite 100

Sunnyvale, CA 94086

3M Company

Solar Optical Products

Attn: Paul Jaster, 225-2N-06

3M Center

st. Paul, MN 55144

U. S. Department of Energy (2)

Albuquerque, operations office

Attn: G. P. Tennyson

P. O. Box 5400

N. D. Lackey

Albuquerque, NM 87115

U. S. Department of Energy (5)

Attn: Robert Annan

Morton Prince

James Rannels

Lloyd Herwig

Richard King

1000 Independence Avenue, SW

Washington, DC 20585

University of Arizona

Solar \& Energy Research Facility

Attn: D. E. Osborn

CE BIdg. \#76

Tucson, AZ 85721

University of Chicago

Attn: Joseph O'Gallagher

5640 South Ellis Avenue

Chicago, IL 60637 
University of New Mexico/NMERI

Attn: G. Leigh

Campus Box 25

Albuquerque, NM 87131

VS Corporation

Attn: G. Virshup

611 Hansen Way, MS K-124

Palo Alto, CA 94303

Wattsun

Attn: John Doherty

P. O. Box 751

Albuquerque, NM 87.103

Westinghouse Electric Corporation

Attn: Charles Rose

P. O. Box 10864

Pittsburgh, PA 15236

Wright Patterson AFB

Attn: Jack Geis

AFWAL/POOC

Wright Patterson AFB, $\mathrm{OH}$

$\begin{array}{ll}3141 & \text { S. A. Landenberger (5) } \\ 3145 & \text { Document Processing for } \\ & \text { DOE/OSTI (8) } \\ 3151 & \text { G. C. Claycomb (3) } \\ 6000 & \text { D. L. Hartley } \\ 6200 & \text { B. W. Marshall } \\ 6220 & \text { D. G. Schueler } \\ 6224 & \text { D. E. Hasti } \\ 6224 & \text { D. L. King } \\ 6224 & \text { J. E. Cannon } \\ 6224 & \text { T. D. Hund } \\ 6224 & \text { A. B. Maish } \\ 6224 & \text { M. L. Whipple } \\ 6224 & \text { J. R. Woodworth } \\ 6224 & \text { C. B. Stillwell (5) } \\ 6224 & \text { PV Library (5) } \\ 6223 & \text { G. J. Jones } \\ 8523 & \text { R. C. Christman }\end{array}$



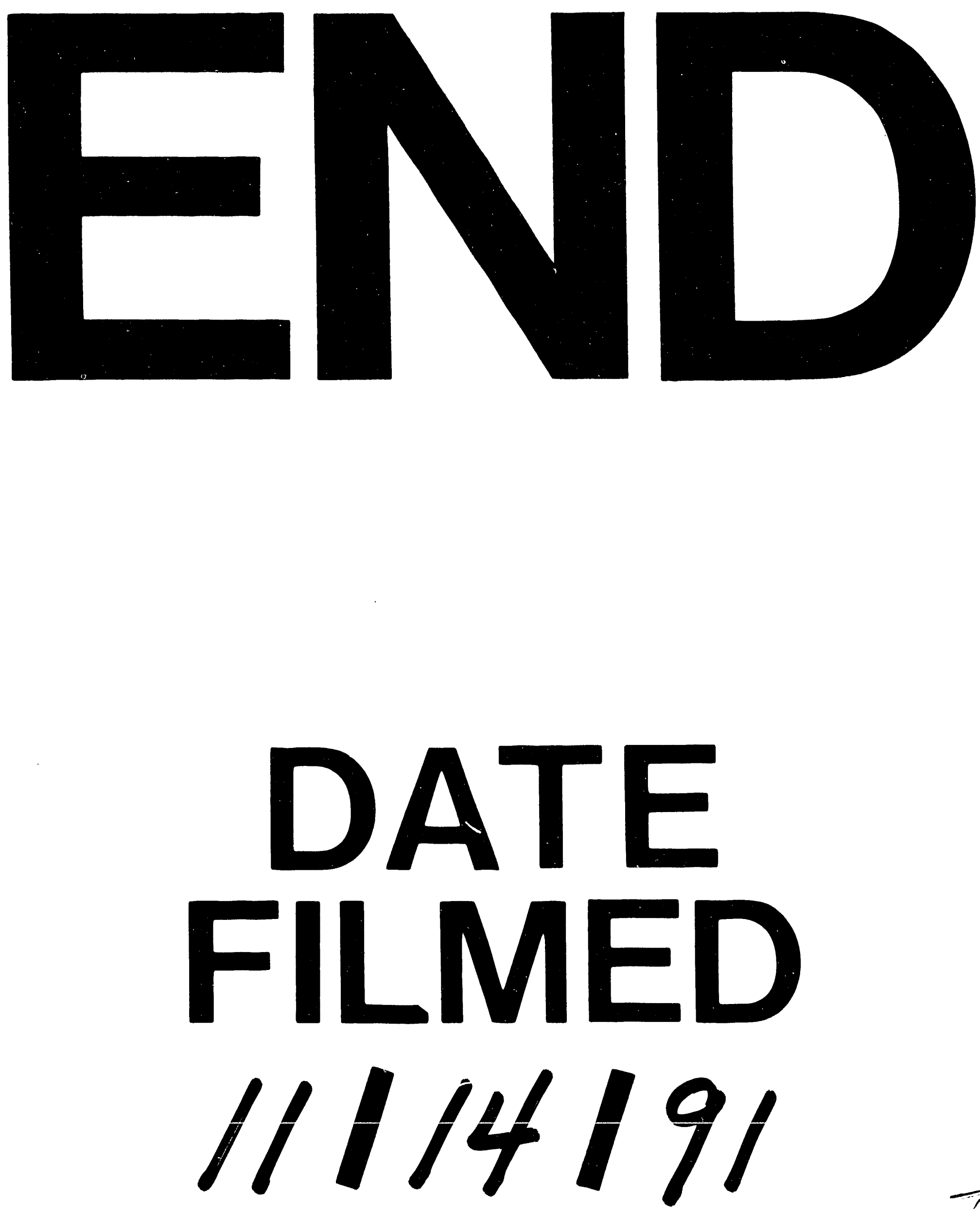
